University of Tennessee Health Science Center

UTHSC Digital Commons

\title{
The Role of Interferon Gamma in the Regulation of IL-18 Binding Protein and the Development of Autoimmune Arthritis in a Genetically Non-Susceptible Mouse Strain
}

Timothy Daniel Kayes

University of Tennessee Health Science Center

Follow this and additional works at: https://dc.uthsc.edu/dissertations

Part of the Amino Acids, Peptides, and Proteins Commons, and the Immune System Diseases Commons

\section{Recommended Citation}

Kayes, Timothy Daniel , "The Role of Interferon Gamma in the Regulation of IL-18 Binding Protein and the Development of Autoimmune Arthritis in a Genetically Non-Susceptible Mouse Strain" (2009). Theses and Dissertations (ETD). Paper 134. http://dx.doi.org/10.21007/etd.cghs.2009.0159. 


\title{
The Role of Interferon Gamma in the Regulation of IL-18 Binding Protein and the Development of Autoimmune Arthritis in a Genetically Non-Susceptible Mouse Strain
}

\begin{abstract}
The etiology of the autoimmune disease rheumatoid arthritis (RA) is unknown, but the role of cytokines, including IFN-g, as effectors of immune cell function has been established by the examination of cytokine production in RA patients and through the use of animal models. C57BL/6 (B6) mice that express MHC class II molecules of the $b$ haplotype $\left(I-A^{b}\right)$ are not typically susceptible to collagen-induced arthritis (CIA), the most widely studied animal model of RA. When the gene encoding IFN-g is removed by genetic deletion, however, susceptibility to $\mathrm{CIA}$ is conferred. In addition, $\mathrm{T}$ cell responses against the immunogen that stimulates $\mathrm{CIA}$, type II collagen (CII), are reduced in the B6 strain when compared to susceptible mouse strains that express differing MHC haplotypes such as the I-A ${ }^{q}$-expressing DBA mouse. These observations led to the development of the following hypothesis. IFN-g functions as a regulator of $T$ cell responses to weak determinants, and $\mathrm{I}-\mathrm{A}^{\mathrm{b}} \mathrm{MHC}$ class II molecules have low affinity for collagen autoantigen determinants. In the IFN-g ${ }^{-/-}$B6 mouse, the absence of IFN-g alters T cell function and cytokine production following immunization with Cll, disrupting normal immune function and allowing the development of CIA.
\end{abstract}

To reveal the pathogenic mechanisms that mediate susceptibility to arthritis in the B6 IFN-g ${ }^{-/-}$mouse we examined several aspects of the immune response that follows immunization with CII. Firstly, alterations in cellular immune responses between wild type and $\mathrm{B} 6 \mathrm{IFN}-\mathrm{g}^{-/-}$mice were examined following immunization with Cll. Secondly, an antigenic determinant present in bovine Cll that stimulates T cell response in mice expressing $1-A^{b}$ was identified. This determinant was identified by the use of direct binding assays between $\mathrm{I}-\mathrm{A}^{\mathrm{b}}$ and $\mathrm{Cll}$ derived peptides as well as by the generation of $\mathrm{T}$ hybridomas generated in $\mathrm{I}-\mathrm{A}^{\mathrm{b}}$-expressing mice that respond to $\mathrm{CII}$. In a second series of experiments, the role of IFN-g in modulating disease progression was examined by the use of microarray analysis to identify genes that are altered between wild type and IFN-g ${ }^{-/-} \mathrm{B} 6$ mice immunized with $\mathrm{CI}$ in CFA emulsion. This allowed the identification of IL-17 and IL-18 Binding Protein (IL-18 BP) as differentially expressed between the two strains. When IL-18 BP was given exogenously to IFN- $\mathrm{g}^{-/-} \mathrm{B} 6$ mice immunized with $\mathrm{Cll}$, the mice were protected from the development of CIA.

These results indicate that a $\mathrm{Cll}$ determinant is present in bovine $\mathrm{Cll}$ and the low immunogenic properties of this determinant may be responsible for the lack of arthritis development in wild type B6 mice. In the absence of IFN-g, there is disregulation of immune function exhibited as decreased expression of IL-18 $\mathrm{BP}$ and increased expression of IL-17. This disregulation allows T cell responses to weakly antigenic CII determinants to progress, thus promoting the development of autoimmune arthritis.

\section{Document Type}

Dissertation

\section{Degree Name}

Doctor of Philosophy (PhD) 


\section{Program}

Interdisciplinary Program

Research Advisor

Edward Rosloniec, Ph.D.

\section{Keywords}

IFN-g, IL-18 BP, CIA, Arthritis, I-Ab, CII, Determinant, B6

\section{Subject Categories}

Amino Acids, Peptides, and Proteins | Chemicals and Drugs | Diseases | Immune System Diseases | Medicine and Health Sciences 


\title{
THE ROLE OF INTERFERON GAMMA IN THE REGULATION OF IL-18 BINDING PROTEIN AND THE DEVELOPMENT OF AUTOIMMUNE ARTHRITIS IN A GENETICALLY NON-SUSCEPTIBLE MOUSE STRAIN
}

\author{
A Dissertation \\ Presented for \\ The Graduate Studies Council \\ The University of Tennessee \\ Health Science Center \\ In Partial Fulfillment \\ Of the Requirements for the Degree \\ Doctor of Philosophy \\ From The University of Tennessee
}

By

Timothy Daniel Kayes

May 2009 
Copyright (C) 2008

by

Timothy Daniel Kayes

All rights reserved 


\section{Dedication}

This work is dedicated to the memory of my mother Christine H. Kayes (19502005). During her dedicated years as a science educator, she sparked interest in science and intellectual pursuit in both myself and in countless others. 


\section{Acknowledgements}

I would like to acknowledge the contribution to my post graduate education made by the members of the Rosloniec and Brand laboratories including Karen Whittington, Laura McCormick, Zaohui Qian, Kary Latham, Nora Moore, and Gillian Bell. I would also like to acknowledge the help of Dr. David Brand for his insight and support during my research. I would also like to thank the members of my graduate committee Elizabeth Fitzpatrick, Terrence Geiger, Tony Marion, and Marko Radic for their guidance. Finally, I would like to thank my mentor Dr. Edward Rosloniec for his support, guidance, and understanding throughout the development of my research. 


\begin{abstract}
The etiology of the autoimmune disease rheumatoid arthritis (RA) is unknown, but the role of cytokines, including IFN- $\gamma$, as effectors of immune cell function has been established by the examination of cytokine production in RA patients and through the use of animal models. C57BL/6 (B6) mice that express MHC class II molecules of the $b$ haplotype $\left(\mathrm{I}-\mathrm{A}^{\mathrm{b}}\right)$ are not typically susceptible to collagen-induced arthritis (CIA), the most widely studied animal model of RA. When the gene encoding IFN- $\gamma$ is removed by genetic deletion, however, susceptibility to CIA is conferred. In addition, T cell responses against the immunogen that stimulates CIA, type II collagen (CII), are reduced in the B6 strain when compared to susceptible mouse strains that express differing $\mathrm{MHC}$ haplotypes such as the I-A ${ }^{\mathrm{q}}$-expressing DBA mouse. These observations led to the development of the following hypothesis. IFN- $\gamma$ functions as a regulator of $\mathrm{T}$ cell responses to weak determinants, and I-A ${ }^{b} \mathrm{MHC}$ class II molecules have low affinity for collagen autoantigen determinants. In the IFN $-\gamma^{-/-} \mathrm{B} 6$ mouse, the absence of IFN- $\gamma$ alters $\mathrm{T}$ cell function and cytokine production following immunization with $\mathrm{CII}$, disrupting normal immune function and allowing the development of CIA.
\end{abstract}

To reveal the pathogenic mechanisms that mediate susceptibility to arthritis in the B6 IFN- $\gamma^{-/-}$mouse we examined several aspects of the immune response that follows immunization with CII. Firstly, alterations in cellular immune responses between wild type and B6 IFN- $\gamma^{-/}$mice were examined following immunization with CII. Secondly, an antigenic determinant present in bovine CII that stimulates $\mathrm{T}$ cell response in mice expressing $\mathrm{I}-\mathrm{A}^{\mathrm{b}}$ was identified. This determinant was identified by the use of direct binding assays between $\mathrm{I}-\mathrm{A}^{\mathrm{b}}$ and CII derived peptides as well as by the generation of T hybridomas generated in $\mathrm{I}-\mathrm{A}^{\mathrm{b}}$-expressing mice that respond to CII. In a second series of experiments, the role of IFN- $\gamma$ in modulating disease progression was examined by the use of microarray analysis to identify genes that are altered between wild type and IFN- $\gamma^{-/-}$B6 mice immunized with CII in CFA emulsion. This allowed the identification of IL-17 and IL-18 Binding Protein (IL-18 BP) as differentially expressed between the two strains. When IL-18 BP was given exogenously to IFN- $\gamma^{-/-} \mathrm{B} 6$ mice immunized with CII, the mice were protected from the development of CIA.

These results indicate that a CII determinant is present in bovine CII and the low immunogenic properties of this determinant may be responsible for the lack of arthritis development in wild type B6 mice. In the absence of IFN- $\gamma$, there is disregulation of immune function exhibited as decreased expression of IL-18 BP and increased expression of IL-17. This disregulation allows T cell responses to weakly antigenic CII determinants to progress, thus promoting the development of autoimmune arthritis. 


\section{Table of Contents}

Chapter 1. Introduction..................................................................................................................1

The Immune System and the Origins of Autoimmunity.................................................

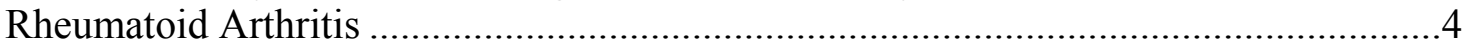

Cytokines in the Pathogenesis of Rheumatoid Arthritis ..............................................5

Collagen-Induced Arthritis, an Animal Model of Rheumatoid Arthritis......................6

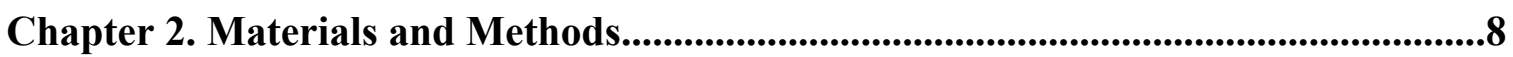

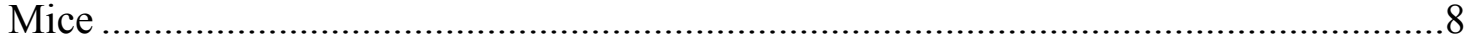

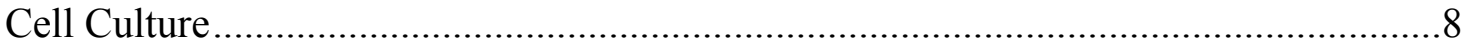

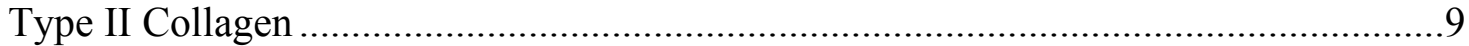

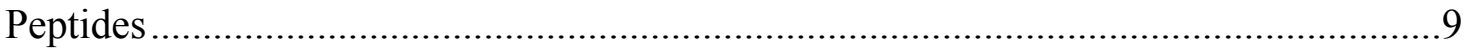

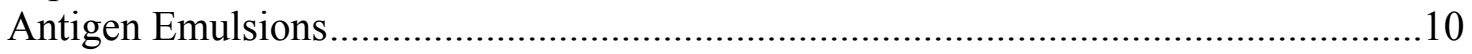

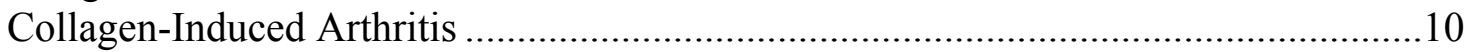

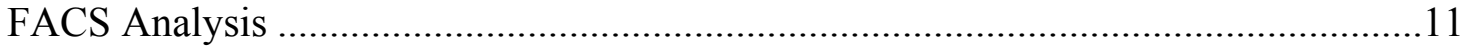

Quantification and Isotyping of Anti-CII Antibodies................................................11

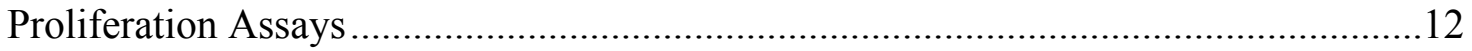

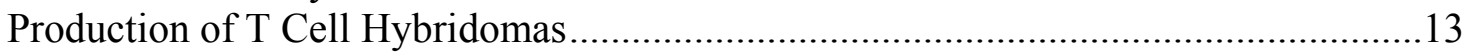

Antigen Presentation to T Cell Hybridomas.................................................................13

Induction of Tolerance in CXB2 Mice with Determinant Peptides................................14

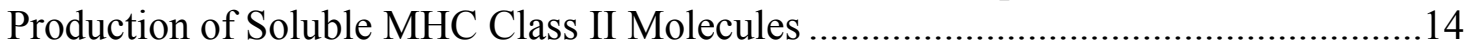

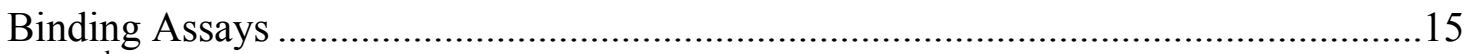

I-A ${ }^{\mathrm{b}}$ Binding of CytC(43-58), $\operatorname{Mog}(35-55)$, and CII(257-274) ……………............15

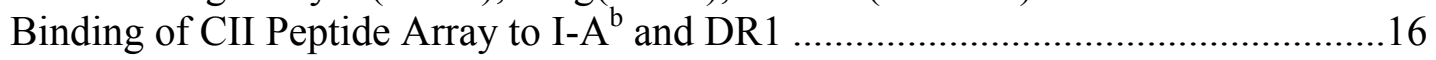

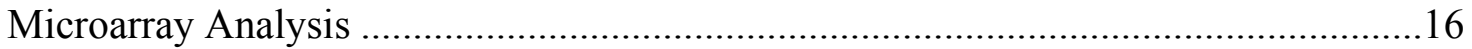

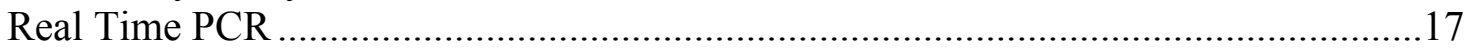

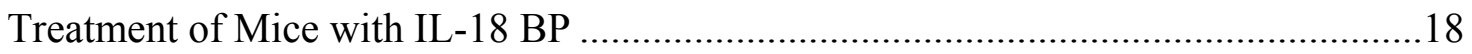

Anti-CD3/CD28 Stimulation Assay ……………..................................................18

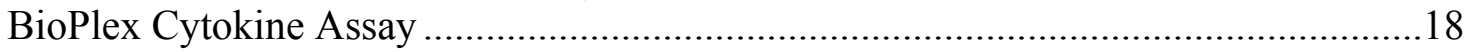

\section{Chapter 3. Modulation of Arthritis Pathogenesis by Variable T Cell Receptor} Complex Interaction with Type II Collagen Determinants .............................................20

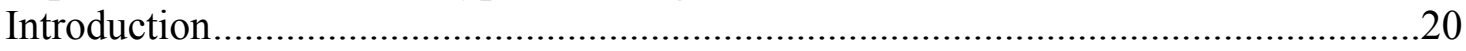

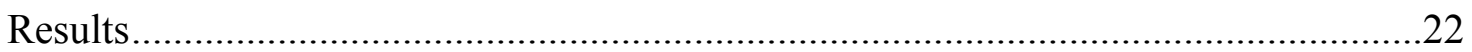

IFN- $\gamma$ Regulates Susceptibility to Autoimmune Arthritis in C57BL/6 Mice ...........22

Regulation of Immune Cell Function by IFN- $\gamma$...................................................2

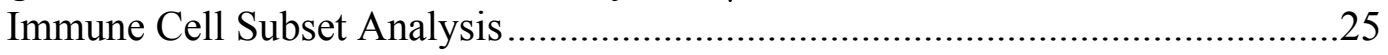

Anti-CII Immunoglobulin Production ..............................................................2

Proliferative Response .................................................................................29

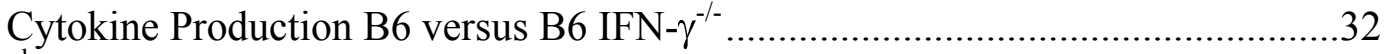

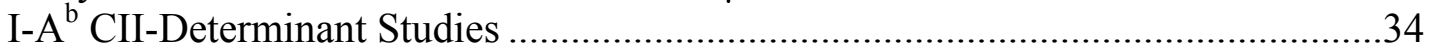

Development of CII-Specific T Hybridomas.......................................................39

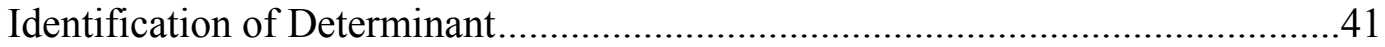


The Core Binding Determinant for the I-A ${ }^{\mathrm{b}}$ T Hybridomas Is CII(517-525) GPRGLPGTP

I-A ${ }^{\mathrm{b}}$-Restricted Cellular Responses to CII Determinant ...........................................47

Proliferative Response ..................................................................................47

Induction of Tolerance by CII Determinant....................................................49

Measurement of Binding Affinity of CII Determinants for I-A ${ }^{\mathrm{b}}$............................52

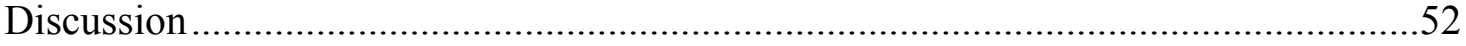

Chapter 4. Interferon $\gamma$ and the Pathogenesis of Inflammatory Arthritis...................58

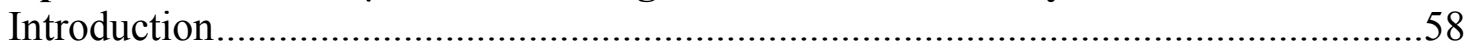

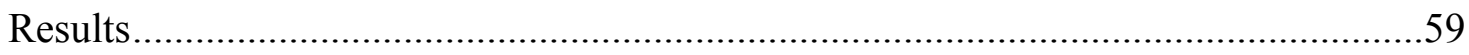

The Role of IFN- $\gamma$ in Regulating Gene Expression .............................................59

Expression Array of Wild Type versus IFN- $\gamma^{-/-}$B6 Mice ....................................59

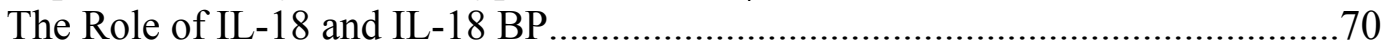

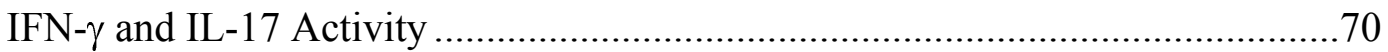

Expression of IL-18 and IL-17 Regulated Genes ............................................ 71

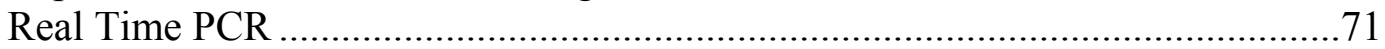

Microfluidics Real Time PCR ....................................................................... 72

Modification of Disease Activity by Exogenous IL-18 Binding Protein ..............75

Alterations in Function Due to Cytokine Regulation by IL-18, IL-17, and IFN- $\gamma$....78

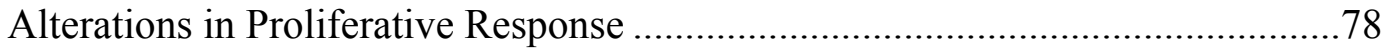

Alterations in Cytokine Production ......................................................... 81

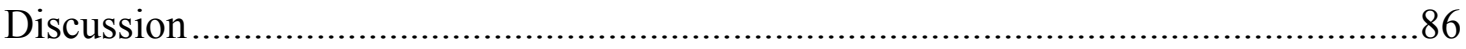

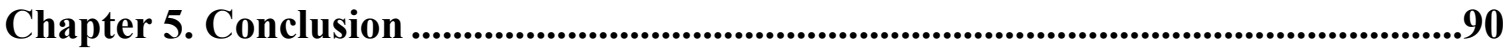

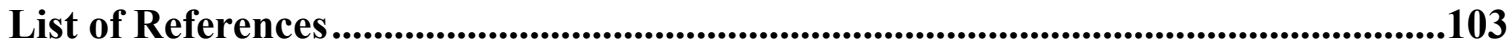

Appendix. Binding of CII Determinant to $\mathrm{I}^{-\mathrm{A}^{\mathrm{b}}}$...............................................118

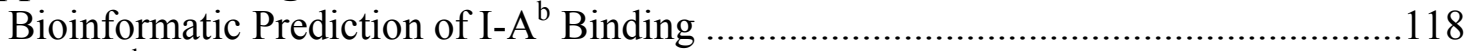

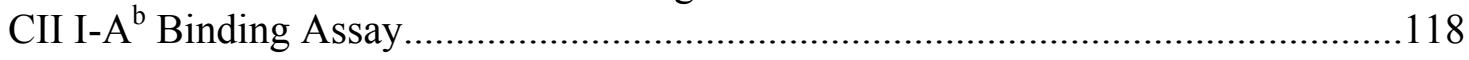

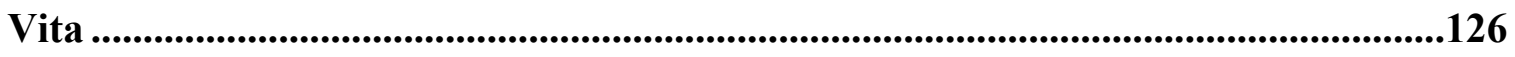




\section{List of Tables}

Table 4.1 The Role of Differentially Expressed Genes between Wild Type and IFN- $\gamma^{-/}$B6 Mice Immunized with CII/CFA in the Pathogenesis of RA and CIA 


\section{List of Figures}

Figure $3.1 \quad$ IFN- $\gamma^{-/-}$Mice Exhibit Increased Susceptibility to CIA ............................23

Figure 3.2 Severity of Arthritis in B6 and B6 IFN- $\gamma^{-/-}$Mice ...................................24

Figure 3.3 Lymphocyte Compartment of CII-Immunized B6 and B6 IFN- $\gamma^{-/}$

Mice

Figure 3.4 Increased Anti-CII Ig Production in B6 IFN- $\gamma^{-/-}$Mice Immunized with

CII Compared to Wild Type ................................................................28

Figure 3.5 Increased Expression of IgG2b in B6 IFN- $\gamma^{-/-}$Mice Immunized with

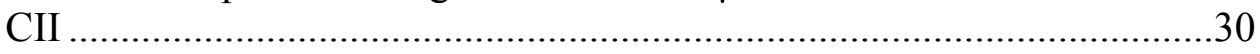

Figure 3.6 Proliferative Response to Type II Collagen in Wild Type and IFN- $\gamma^{-/}$

B6 Mice.....

Figure 3.7 Proliferative Response to CII in Mice Expressing MHC Class II of the

I-A ${ }^{\mathrm{b}}$ Haplotype

Figure 3.8 The Absence of IFN- $\gamma$ Significantly Alters Cytokine Production in Culture Following Stimulation of T Cells with Anti-CD3 and Anti-CD28.

Figure 3.9 Proliferative Response to CII-Library Peptides by T Cells from Mice of Various MHC Class II Background.

Figure 3.10 Proliferative Response to Human Type II Collagen by T Cells from Mice Expressing I-A ${ }^{\mathrm{b}}$

Figure 3.11 IL-2 Production by H2-IA ${ }^{\mathrm{b}}$-Restricted T Cell Hybridomas.....

Figure 3.12 IL-2 Production by I-A ${ }^{\mathrm{b}}$-Restricted T Cell Hybridoma Clones in

Response to Stimulation with CII-Library Peptides

Figure 3.13 The I-A ${ }^{\mathrm{b}}$-Restricted CII Determinant

Figure 3.14 IL-2 Production by CII-Reactive T Cell Hybridomas in Response to

Stimulation with Alanine Substituted CII(512-526)...

Figure 3.15 Stimulation of CII-Specific I-A ${ }^{\mathrm{b}}$-Restricted T Cell Hybridomas by

Titrated Alanine Substituted Determinant Peptides .46

Figure 3.16 Proliferative Response of Lymphocytes from I-A ${ }^{\mathrm{b}}$-Expressing Mice

Stimulated with CII Determinants .. .48 
Figure 3.17 CII-Determinant Sequence Homology .50

Figure 3.18 Proliferation in Response to Stimulation with CII Antigens in

Lymphocytes from I-A ${ }^{\mathrm{b}}$-Expressing Mice Immunized with Native Chicken or Bovine CII

Figure 3.19 Tolerization of CIA-Susceptible CXB2 Mice with CII-Determinant

Peptide.

Figure 4.1 Genes Differentially Expressed between Wild Type and IFN- $\gamma^{-/-}$B6

Mice in Response to Immunization with CII/CFA

Figure 4.2 Intercellular Signaling Molecules Differentially Expressed between Wild Type and IFN- $\gamma^{-/-}$B6 Mice.

Figure 4.3 Markers of Inflammation and Joint Remodeling Genes Differentially Expressed between Wild Type and IFN- $\gamma^{-/-}$B6 Mice

Figure 4.4 Differential Expression of Cytokine Genes between Wild Type and IFN- $\gamma^{-/-}$B6 Mice Immunized with CII/CFA

Figure 4.5 Differential Expression between Wild Type and IFN- $\gamma^{-/}$B6 Mice Immunized with CII/CFA Measured by Immune Panel Real Time PCR Array. .74

Figure 4.6 Administration of IL-18 BP to B6 IFN- $\gamma^{-/-}$Mice Protects against CIA.....76

Figure 4.7 In IFN- $\gamma^{-/-}$B6 Mice, Severity and Limb Involvement of CIA Are Reduced Following Treatment with IL-18 BP.

Figure 4.8 Exogenous Administration of Proinflammatory Cytokines or IL-18 BP Alters the Proliferative Response of Splenocytes from Both Wild Type and IFN- $\gamma^{-/-}$B6 Mice When Stimulated in Culture with Anti-CD3 and Anti-CD28.

Figure 4.9 Modification of Lymphocyte Cytokine Expression by IL-18 BPd in Lymphocyte Cultures Stimulated with Anti-CD3 and Anti-CD28.

Figure 4.10 Modification of Lymphocyte Cytokine Expression by IL-18 in Lymphocyte Cultures Stimulated with Anti-CD3 and Anti-CD28.

Figure 4.11 Modification of Lymphocyte Cytokine Expression by IL-17 in Lymphocyte Cultures Stimulated with Anti-CD3 and Anti-CD28

Figure 4.12 Modification of Lymphocyte Cytokine Expression by IFN- $\gamma$ in Lymphocyte Cultures Stimulated with Anti-CD3 and Anti-CD28 .85

Figure 5.1 Model of Immune Response in Wild Type B6 Mice 
Figure 5.2 Model of Immune Response in IFN- $\gamma^{-/-}$B6 Mice ...................................98

Figure 5.3 Model of $\mathrm{T}_{\mathrm{h}} 2$ Response in IFN- $\gamma^{-/-}$B6 Mice.........................................99

Figure A.1 Prediction of CII Peptide Binding to the MHC Class II Alleles DR1

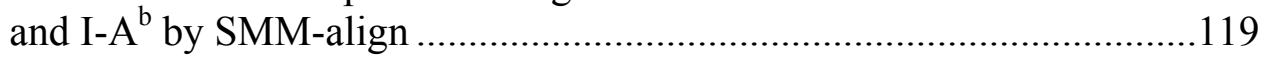

Figure A.2 I-A $\mathrm{A}^{\mathrm{b}}$-Restricted Proliferation in Response to Stimulation with CytC

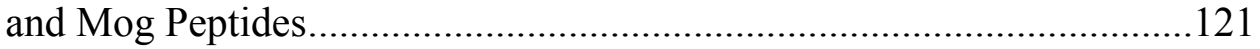

Figure A.3 Binding of Mog, CytC, and CII Peptides to Soluble I-A ${ }^{\mathrm{b}}$......................... 122

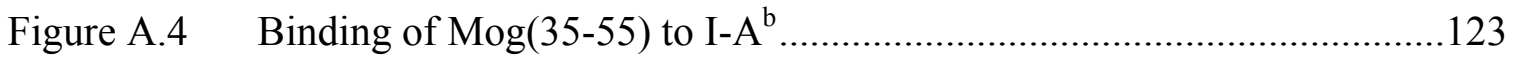

Figure A.5 Binding of CII Determinants to DR1 or I-A ${ }^{\mathrm{b}}$ MHC Class II

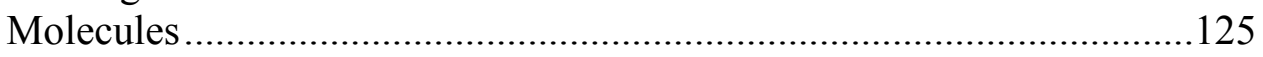




\section{Chapter 1. Introduction}

\section{The Immune System and the Origins of Autoimmunity}

Protection from invading pathogenic microorganisms, and from the development of cancer is critical to homeostasis in vertebrate organisms. In order to combat these potentially deadly threats, a complex adaptive immune system has evolved that is capable of recognizing and neutralizing an enormous variety of foreign invaders. An important function of the adaptive immune system is the distinction of foreign and self, in other words, the distinction of pathogenic organisms from cells and tissue native to a healthy organism. It does this by a mechanism that can distinguish subtle chemical differences between molecules, known as antigens, that are produced by foreign pathogens and native cells produced by the host organism. Once a foreign pathogen is recognized, the immune system responds with an interconnected network of cellular and chemical mediators that conjunctively work to eliminate or neutralize the threat. However, the potency of the immune system is a double-edged sword. The same mechanisms that have evolved to protect against invasion of pathogenic microorganisms can become disregulated, turn against host tissues, and cause disease in a process known as autoimmunity. Autoimmunity occurs when immune cells incorrectly recognize selfantigens (autoantigens) as foreign and mount an immune response against host tissue. The initiating causes of autoimmunity remain elusive to scientific inquiry, but a number of factors are believed to contribute to disease susceptibility and pathogenesis. These can include genetic predisposition, environmental factors such as infectious agents, diet, exercise, and even cigarette smoking (1).

The process by which autoimmunity develops has been an ongoing focus of research since Paul Ehrlich first postulated the concept of horror autotoxicus in the early 1900 's (2). Since that time, a number of advances in genetics and biological methods have allowed the identification of risk factors for the development of autoimmunity. Many mechanisms of autoimmunity have also been discovered, though much work remains to completely understand the pathogenesis of autoimmune diseases, especially the initiating events. It is likely that autoimmunity stems from a combination of both genetic and environmental factors. Probably the most important factor in the predisposition to autoimmune disease is genetic background. The influence of genetics on the development of autoimmunity can be simple in the case of single gene mutations that cause increased risk to specific autoimmune diseases, or complex as in the case of multiple susceptibility alleles that interact with environmental factors to confer increased risk of disease (3). One of the most important genetic factors linked to autoimmune susceptibility is the expression of specific class II major histocompatibility complex (MHC) alleles that are associated at high levels to various autoimmune diseases. For example, susceptibility to the autoimmune disease rheumatoid arthritis is strongly linked to the expression of specific HLA-DR1 and DR4 alleles (4). To understand how these DR alleles mediate this susceptibility, a considerable effort has been made to understand how immune cells recognize and respond to antigen presented by these molecules, and to identify the control mechanisms that regulate these immune responses. 
One of the first steps in an adaptive immune response is the activation of T cells to antigens that have been processed and displayed on the surface of antigen presenting cells. The molecules that mediate this process are the aforementioned MHC molecules and the T cell receptor (TCR). Each TCR contains a variable region that during T cell maturation is altered by genetic recombination. This process produces a multitude of $T$ cell clones that each express a unique TCR with a different specificity for antigen.

Structurally, MHC molecules contain an open groove that binds peptide fragments of proteins generated in endosomic vesicles. This peptide/MHC complex is then transported to the surface of the cell where it is made available to binding by the TCR. If the TCR expressed by a $\mathrm{T}$ cell matches the unique structure of the peptide/MHC complex, it binds and forms a supramolecular structure known as a $\mathrm{T}$ cell receptor complex. The formation of the TCR complex initiates signaling cascades within the T cell that leads to its activation and development as an effector T cell.

There are two predominant types of classical MHC molecules, MHC class I and MHC class II, and each has a distinct role in the presentation of antigen to a $\mathrm{T}$ cell. Class I molecules bind peptide antigens that are derived predominantly from intracellular proteins, such as would be produced by intracellular pathogens like viruses or in cancer cells. MHC class I is expressed on all cells and binds to TCR present on CD8-expressing $\mathrm{T}$ cells known as cytotoxic $\mathrm{T}$ cells $\left(\mathrm{T}_{\mathrm{c}}\right)(5)$. These cells have the ability to either kill infected target cells or to cause the release of substances in the target cell that is harmful to an infectious agent. In contrast, MHC class II binds peptides predominantly derived from proteins produced outside of the antigen presenting cell and presents them to CD4expressing T cells (6). MHC class II, unlike MHC class I, is expressed on only a limited set of cells including those known as professional antigen presenting cells (APC). These cells include macrophages, dendritic cells, and Langerhans cells (7). Also, B cells, in a mechanism related to their immune effector function of antibody production, express MHC class II and present antigens to $\mathrm{CD}^{+}{ }^{+} \mathrm{T}$ cells (8). $\mathrm{CD}^{+} \mathrm{T}$ cells do not act directly on infected target cells like $\mathrm{T}_{\mathrm{c}}$ cells. Rather they serve to promote activation of other immune cells like antibody producing B cells or to stimulate antigen presenting cells to alter their function. They perform this either by direct cell to cell contact or by the production of small intercellular signaling molecules called cytokines. Since $\mathrm{CD}^{+} \mathrm{T}$ cells promote the effector function of other immune cells they are referred to as $\mathrm{T}$ helper cells $\left(\mathrm{T}_{\mathrm{h}}\right)$.

CD4-expressing $\mathrm{T}_{\mathrm{h}}$ cells can be further characterized by their division into subsets based on the types of cytokines they produce and the nature of the immune response that follows their activation. The production of cytokines is crucial to regulation of the immune response and can have major effects on the activation, proliferation, and response of both immune and accessory cells. Subsets of $T_{h}$ cells include $T_{h} 1, T_{h} 2$, and $\mathrm{T}_{\mathrm{h}} 17$ cells. $\mathrm{T}_{\mathrm{h}} 1$ cells are identified by the production of the cytokine IFN- $\gamma$ following antigen stimulation and they promote inflammatory immune responses $(9,10)$. In contrast, $\mathrm{T}_{\mathrm{h}} 2$ cells express IL-4, IL-5, and IL-13 following antigen stimulation and promote humoral immune responses $(9,11) . \mathrm{T}_{\mathrm{h}} 17$ cells are a recently described subclass of $\mathrm{T}_{\mathrm{h}}$ cells that produce IL-17 upon activation $(12,13)$. IL-17 was previously known as a proinflammatory cytokine (14), and the identification of an IL-17 producing cell subset helps to explain some contradictory findings about the role of $\mathrm{T}_{\mathrm{h}} 1$ cells in chronic 
autoimmune and inflammatory disease. For example, administration of exogenous IFN- $\gamma$ can assuage some autoimmune diseases, while its removal can exacerbate it. This phenomenon can be observed in the autoimmune diseases multiple sclerosis (MS) (8), and RA (15) and rodent models of these diseases including experimental autoimmune encephalomyelitis (EAE) (16) and CIA (17). The use of rodent models in the study of RA identified the overexpression of proinflammatory cytokines including TNF- $\alpha$, IL-1 $\beta$, lymphotoxin- $\beta$, and IFN- $\gamma$, whose expression is mediated by $\mathrm{T}_{\mathrm{h}} 1$ cells $(9,18,19)$. Initially, this gave rise to the theory that RA was a $T_{h} 1$ mediated disease. However, there is mounting evidence that $T_{h} 17$ cells play a crucial role in the development of RA as well as many other autoimmune diseases. When genes encoding IFN- $\gamma$, its receptor, or IL-12 are removed, the incidence of disease is exacerbated (17, 20, 21). Since these genes are associated with $\mathrm{T}_{\mathrm{h}} 1$ cell function, the increase in arthritis activity indicated a role for other cells in the pathogenesis of immune arthritis. Several lines of evidence support $\mathrm{T}_{\mathrm{h}} 17$ cells as mediators of autoimmune arthritis. IL-17 expression is increased in the joint synovium of RA patients and stimulates production of IL-6, IL-8, IL-1 $\beta$, and TNF- $\alpha$ (22). In animal models, blockage of IL-17 by genetic deletion or anti-IL-17 antibodies inhibits arthritis development $(23,24)$. One explanation for this observation is that autoimmune disorders previously thought meditated by $\mathrm{T}_{\mathrm{h}} 1$ cells may in fact be dependent on $T_{h} 17$ cell function. For this reason, the identification of $T_{h} 17$ as a proinflammatory subset of $T_{h}$ cells has caused a re-examination of the role of $T_{h} 1$ cells in chronic inflammatory disease (25).

While the TCR/MHC interaction is the mechanism by which $\mathrm{T}$ cells recognize antigens, the mechanisms of self-tolerance regulate the development of self-reactive $\mathrm{T}$ cell responses. Self-tolerance can be thought of as a balance between functional immunocompetence and prevention of autoimmunity. It is the process by which immune cells "learn" what antigens are native to the host and therefore not appropriate targets of immune response. For T cells, there are two mechanisms of self-tolerance, central tolerance and peripheral tolerance. In the process of central tolerance, $T$ cells are positively and negatively selected to produce cells that interact with self-MHC molecules, but not to self-antigen presented by these MHC molecules. This process is largely mediated by the affinity between the MHC, the peptide ligand, and the TCR. During maturation in the thymus $\mathrm{T}$ cells are first positively selected, they are presented with peptides, of poorly defined origin, bound to the MHC molecules of cortical thymic epithelium. The T cells must bind to these MHC/peptide complexes, indicating that they express functional TCR, to be "positively" selected for survival $(26,27)$. Those cells that survive positive selection are next presented with self-antigen/MHC and the costimulatory molecules CD 80 and CD86 by medullary thymic epithelium and dendritic cells, and if they have high binding affinities for self-peptide/MHC complexes, they are deleted by apoptosis. It is at this stage that $\mathrm{T}$ cells with specificity to autoantigens can escape self-tolerance and leave the thymus as mature self-reactive cells (28). One can imagine a scenario where $\mathrm{T}$ cells with intermediate to low affinity for self-peptide/MHC do not have a high enough affinity to be deleted during negative selection and escape to the periphery (29-31). To minimize these self-reactive T cells as a source of autoimmune reactions, mechanisms of peripheral tolerance have evolved. These mechanisms include anergy, deletion, and suppression by regulatory $\mathrm{T}$ cells $\left(\mathrm{T}_{\text {reg }}\right)$ (32). Although peripheral 
tolerance can in part be antigen mediated, these processes are largely dependent on cytokine signaling and costimulation between the APC or $\mathrm{T}_{\text {reg }}$ cells and the self-reactive $\mathrm{T}_{\mathrm{h}}$ cell. Ultimately, the loss of self-tolerance by these self-reactive $\mathrm{T}$ cells is one potential mechanism of autoimmunity. The mechanism by which this loss of tolerance occurs is not entirely understood, but due to the major role of binding affinity in $\mathrm{T}$ cell development and the role of cytokines in the mechanisms of tolerance, it is likely that both the affinity of the TCR for peptide/MHC and cytokine signaling is involved in this process.

\section{Rheumatoid Arthritis}

Rheumatoid arthritis (RA) is a chronic autoimmune disorder that serves as an example of how the development of autoimmunity is dependent both on the activation of $\mathrm{CD}^{+} \mathrm{T}$ cells and by cytokine signaling. RA affects over 2 million people in the United States, and about $1-2 \%$ (33) of the population worldwide. A primary effect of the disease is the destruction of articular cartilage and ankylosis of diarthroidal joints by a progressive proliferative synovitis. The inflammation of RA is not limited to the joint however, and can affect the skin, vasculature, heart, lung, and muscle (34). Destruction of synovial joints is marked by radical changes in joint morphology. These changes include edema, loss of cartilage and bone, and hyperplasia of the synovium. The synovial membrane becomes infiltrated with lymphoid cells, plasma cells, and macrophages, and exhibits increased vascularity. Neutrophils are also present in the normally acellular synovial fluid. Bone resorption by osteoclast activity is increased causing articular erosions and osteoporosis, and allowing the synovium to enter the bone and form subchondral cysts. Ultimately, the joint structure is destroyed by the formation of a pannus. Inflammatory cells, fibroblasts, and granulomatous tissue produce a fibrocellular mass of tissue that gradually degrades the cartilage lining the bone surfaces and bridges the joint space resulting in ankylosis (34).

Though the etiology of RA remains unknown, there are a number of factors that contribute to its development. The incidence of RA is more prevalent in women than in men. The exact figures vary from population to population worldwide, but in women RA occurs 2 to 3 times more often (35-37). A number of other genetic factors are also linked to the development of RA. There is evidence that the risk of RA is increased along familial lines. In one study in the UK, it was found that if an individual in a pair of identical twins develops RA, the chance of the other twin also developing RA is $15 \%$ (38), a nearly 20 fold increase from the $0.8 \%$ (36) risk in the general population. In addition to the familial link to RA susceptibility, the most significant genetic factor that correlates with the advent of RA is human MHC lymphocyte antigen (HLA) genotype. The discovery that expression of HLA-DR4 (39) and HLA-DRB1 (40-42) is linked to RA has an important implication in the pathogenesis of RA. HLA-DR4 and HLA-DRB1 are MHC class II molecules that present peptide antigens to $\mathrm{CD} 4^{+} \mathrm{T}$ cells. Therefore, RA pathogenesis is likely mediated by $\mathrm{T}_{\mathrm{h}}$ subsets of $\mathrm{CD} 4^{+} \mathrm{T}$ cells.

Functional and structural studies of the HLA alleles that are genetically linked to RA enabled the development of the "shared epitope hypothesis" (43). This hypothesis 
provides a potential framework for understanding how RA arises as an autoimmune disease. It is based on the assumption that, initiation of the immune response in RA requires $T$ cell activation via engagement of the $T$ cell receptor with antigen presented by MHC class II molecules. Due to this requirement, alterations in MHC class II structure can influence antigen presentation that ultimately affects how $\mathrm{T}$ cells differentiate and activate in response to antigen. A number of HLA-DR alleles are linked to RA including $* 0101, * 0102, * 0401, * 0404, * 0405, * 0408, * 1001$, and *1402 (44). The structure of MHC class II molecules is such that in the DR $\beta 1$ molecule the point of contact with antigen contains three regions in which the amino acid sequence is hypervariable (polymorphic) among different alleles. This is an evolutionary mechanism for increasing the diversity of peptide determinants that can bind MHC molecules. Among the HLADRB alleles that are linked to RA, the third hypervariable region is highly conserved (43). As a result, the surface of the binding groove in the MHC that carries the antigen is similar in that region. This may affect RA pathogenesis either by limiting the MHC to selectively bind autoantigen determinants, or by influencing the presentation of antigen to potentially self-reactive $\mathrm{T}$ cells.

\section{Cytokines in the Pathogenesis of Rheumatoid Arthritis}

One of the hallmarks of RA is an abundance of cytokine expression. The pathogenesis of RA involves immune processes that are closely regulated by cytokine signaling between immune cells, accessory cells, and the cells of the joint synovium. The pathogenesis of RA requires the development of autoimmunity in which $\mathrm{T}$ and $\mathrm{B}$ cell tolerance is broken, allowing them to respond to self-antigens. Chronic inflammation of the joint synovium that leads to destruction of articular tissue requires maintenance of proinflammatory signals. The onset of clinical disease in RA, coincides with the infiltration of immune cells into the normally hypocellular joint synovium. A broad selection of immune cells including $\mathrm{CD}^{+}$and $\mathrm{CD} 8^{+} \mathrm{T}$ cells, $\mathrm{B}$ and plasma cells, macrophages, mast cells, NK cells, and NKT cells invade the joint synovium and promote articular destruction via the stimulation of tissue modeling cells, including osteoclasts, chondrocytes, and synovial fibroblasts. The pathogenic mechanisms of RA, autoimmunity, chronic inflammation, and joint destruction are all regulated by cytokine signaling (45).

One mechanism by which autoimmunity may arise is when there is an imbalance between proinflammatory and anti-inflammatory cytokines. The cytokine milieu present in the synovium of RA contains proinflammatory IL-1 $\beta$, IL-6, IL-7, IL-12, IL-15, IL-18, IL-23p19, and TGF $\beta$ produced by macrophage cells and synovial fibroblasts (45). These cytokines promote the proliferation and differentiation of IFN- $\gamma$ producing $\mathrm{T}_{\mathrm{h}} 1$ and IL-17 producing $\mathrm{T}_{\mathrm{h}} 17 \mathrm{~T}$ cell subsets. Conversely, there is decreased expression of the antiinflammatory cytokines IL-4 and IL-13 in established RA. However, the expression of these cytokines is biphasic, in very early RA synovial expression of IL-4 and IL-13 is increased (46). This is perhaps a self-regulatory mechanism in which the immune system attempts to neutralize the development of an autoimmune response. Nonetheless, effector T cells are produced in RA, though whether $T_{h} 1$ or $T_{h} 17$ predominate has not been definitively concluded. Similarly, the role of IFN- $\gamma$ remains controversial. IFN- $\gamma$ 
promotes production of complement fixing IgG subclasses (47), causes increased MHC class II expression in APC (48), and induces production of IL-1 $\beta$ in macrophages and cytokine production by synovial fibroblasts. By its support of $T_{h} 1$ differentiation it contributes to the production of the proinflammatory cytokines TNF- $\alpha$ and GM-CSF. $\mathrm{T}_{\mathrm{h}} 17$ derived IL-17 has potent effects on inflammatory mechanisms present in RA. Neutrophil, monocyte, and fibroblast activation and cytokine production are stimulated by IL-17 (49). The proinflammatory properties of IL-17 are amplified when coexpressed with other inflammatory cytokines such as IL- $1 \beta$ and TNF initiating signaling cascades that promote destructive inflammation in the joint synovium (50).

In addition to the production of complement activating autoantibodies, B cells are regulated by and can contribute to the pathogenesis of RA through the production of cytokines in the joint synovium. In culture, exposure of synovial fibroblasts to TNF and IFN- $\gamma$ induced production of B cell activating factor (BAFF) which supports B cell survival and differentiation (51). Activated B cells produce IL-6, IL-10, and lymphotoxin- $\beta$ (LT $\beta$ ) as well as chemokines including CXCL13 and CCL21. The chemokines and LT $\beta$ promote the formation of germinal centers within the synovium $(52,53)$. LT $\beta$ also promotes the production of IL-1, IL-6, GM-CSF, CCL2, CCL5 and matrix metalloproteinases by synovial fibroblasts (54). The formation of germinal centers and the production of inflammatory cytokines by synovial tissues can support $\mathrm{T}$ cell activation and effector function within the joint, demonstrating a role for cytokine regulation in the pathogenesis of RA.

\section{Collagen-Induced Arthritis, an Animal Model of Rheumatoid Arthritis}

As discussed above, both antigen stimulation of $\mathrm{T}$ cells and cytokine signaling are strong candidates as mediators of the autoimmune pathogenesis in RA. Therefore, in order to determine pathogenic mechanisms of RA we sought to identify how the cytokine milieu at the time of antigen exposure affects the activation of $\mathrm{T}$ cells to drive an autoimmune response. In order to do this, a mouse model of RA was used. Immunization with type II collagen (CII) in an emulsion of complete Freund's adjuvant (CFA) results in the development of an autoimmune arthritis in genetically susceptible mouse strains. This model is known as Collagen-Induced Arthritis (CIA) and is the most widely studied model of RA. CIA mirrors RA in many aspects and the use of this model allows insight into the pathogenic mechanisms of RA. As in RA, susceptibility to CIA is strongly linked to MHC class II molecule haplotype. DBA/1 and B10.Q strains (I-A ${ }^{\mathrm{q}}$ ) as well as B10.RIII (I-A $)$ are susceptible to CIA, developing autoimmune disease at a high incidence $(55,56)$. In contrast, strains of mice expressing other MHC class II alleles are resistant to CIA such as the Balb/c (I-A ${ }^{\mathrm{d}}$ ) and C57BL/6 (I-A $\left.\mathrm{A}^{\mathrm{b}}\right)$ strains. These mouse susceptibility markers mirror the genetic susceptibility of RA in humans where the incidence of RA is linked to the expression of certain HLA-DR alleles. In fact, when the human class II molecules HLA-DRB1*0101 or HLA-DRB1*0404, both linked to the development of RA, are expressed in a CIA non-susceptible mouse strain, B10.M (I-A ${ }^{f}$ ), susceptibility to CIA is conferred (57). 
An additional model of RA that is a derivative of CIA is the IFN- $\gamma^{-/ 2}$ C57BL/6 model. C57BL/6 mice express MHC of the I- $\mathrm{A}^{\mathrm{b}}$ haplotype and are normally resistant to CIA, developing arthritis only rarely and exhibiting low severity. However, when the gene encoding the cytokine IFN- $\gamma$ is removed by genetic ablation the strain becomes fully susceptible to CIA and exhibits arthritis at high incidence and severity (17). This model provides a unique opportunity to study the role of the cytokine milieu on autoimmune pathogenesis. In mouse strains susceptible to CIA, the linkage of arthritis susceptibility to specific class II MHC genes indicates a role for $\mathrm{CD}^{+} \mathrm{CII}$-specific $\mathrm{T}_{\mathrm{h}}$ cells. These CIIspecific $T$ cells are identified as predominantly of the $T_{h} 1$ subset by their production of IL- 2 and IFN- $\gamma$. One important consequence of IFN- $\gamma$ production in the pathogenesis of CIA is the IFN- $\gamma$ mediated class switching of Ig to the complement-fixing IgG2a subtype (58-60). In addition, in CIA, inflammation is largely mediated by the cytokines TNF- $\alpha$, IL-1 $\beta$, and IL-6 $(60,61)$. Despite a need for complement-fixing CII-specific antibodies and the production of proinflammatory cytokines driven by a strong $\mathrm{T}_{\mathrm{h}} 1$ response, the absence of IFN- $\gamma$ is able to convert the non-susceptible C57BL/6 strain of mouse to full susceptibility. Explanation of how this conversion occurs is needed and could provide insight into mechanisms of autoimmune pathogenesis. Some of the mechanisms of CIA pathogenesis in the B6 IFN- $\gamma^{-/-}$model may include disregulation of immune regulatory mechanisms dependent on IFN- $\gamma$, increased influence of $T_{h} 17$ or $T_{h} 2$ cell subsets due to reduced $\mathrm{T}_{\mathrm{h}} 1$ cell numbers or effector function, or altered antigen presentation by APC due to IFN- $\gamma$ 's regulatory effects on class II MHC expression.

The chapters that follow relate how the absence of IFN- $\gamma$ results in immune disregulation and promotes the development of autoimmunity. By using CIA in the B6 IFN- $\gamma^{-/}$mouse as a model of RA, experimental systems were designed to determine how the absence of IFN- $\gamma$ affects such immune processes immune cell activation, proliferation, and effector function. Also, since T cell activation is dependent on the interaction of the TCR with antigen presented by MHC, the effects of IFN- $\gamma$ on T cell activation to autoimmune CII determinants was examined. Since an I- $\mathrm{A}^{\mathrm{b}} \mathrm{CII}$ determinant was not previously known, the first step in this process was to identify amino acid sequences present in CII to which auto-reactive $\mathrm{T}$ cells activate to cause an autoimmune response. Finally, an IFN- $\gamma$ mediated regulatory cytokine network was identified that in the absence of IFN- $\gamma$ is disregulated and promotes the development of autoimmunity. 


\section{Chapter 2. Materials and Methods}

\section{Mice}

ME:

The following mice were obtained from The Jackson Laboratory, Bar Harbor,

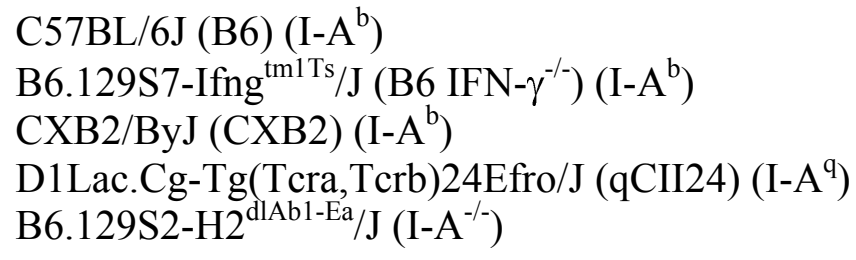

\section{Cell Culture}

HL-1 Media: (Lonza, Walkersville, MD) was supplemented with 50 units/ml penicillin (Invitrogen, Grand Island, NY) $50 \mathrm{mg} / \mathrm{ml}$ streptomycin (Invitrogen, Grand Island, NY), $4 \mu \mathrm{M}$ L-glutamine (Invitrogen, Grand Island, NY), $50 \mu \mathrm{M} 2-$ mercaptoethanol (Sigma, Saint Louis, MO), and 0.1\% electrophoresis grade BSA minimum 96\% (Sigma, Saint Louis, MO) to make complete HL-1 Media.

DMEM: (Lonza, Walkersville, MD) was supplemented with 100 units/ml penicillin (Invitrogen, Grand Island, NY) $100 \mathrm{mg} / \mathrm{ml}$ streptomycin (Invitrogen, Grand Island, NY), 2 mM L-glutamine (Invitrogen, Grand Island, NY), $50 \mu \mathrm{M}$ 2-mercaptoethanol (Sigma, Saint Louis, MO), and 10\% fetal bovine serum (Hyclone, Logan, UT) to make complete DMEM media.

Schneider's Drosophila Medium, Modified: (Cambrex Bio Science, Walkersville, MD) supplemented with 10\% fetal bovine serum (Hyclone, Logan, UT) and 50 units $/ \mathrm{ml}$ penicillin (Invitrogen, Grand Island, NY) $50 \mathrm{mg} / \mathrm{ml}$ streptomycin (Invitrogen, Grand Island, NY).

TNM-FH insect media: (\#554760, BD biosciences, San Diego, CA).

SF-900 II: (\#10902, Gibco, Grand Island, NY) supplemented with 5\% fetal bovine serum (FBS) (Hyclone, Logan, UT), 50 units/ml penicillin (Invitrogen, Grand Island, NY), and $50 \mathrm{mg} / \mathrm{ml}$ streptomycin (Invitrogen, Grand Island, NY) 
Mammalian cell lines were cultured in supplemented DMEM at $37^{\circ} \mathrm{C}$ and $10 \%$ $\mathrm{CO}_{2}$. Ex vivo lymphocyte cell cultures were cultured in supplemented $\mathrm{HL}-1$ media at $37^{\circ}$ $\mathrm{C}$ and $5 \% \mathrm{CO}_{2}$. S2 drosophila cells were cultured in supplemented Schneider's Drosophila Medium, Modified at $25^{\circ} \mathrm{C}$. SF9 cells were cultured in either TNM-FH insect media or SF-900 II supplemented with $5 \% \mathrm{FBS}$ at $27^{\circ} \mathrm{C}$.

\section{Type II Collagen}

The amino acid sequence of type II collagen from chicken, mouse, cow, and human were obtained from the National Centers for Biotechnology Information (NCBI) database and are as follows: chicken CII accession \# NM 204426, bovine CII accession \# NP 001001135, human CII accession \# NM 001844, and mouse CII accession \# NM 031163

Bovine and chicken type II collagen (CII) was prepared locally by the VAMC Collagen Core laboratory. Bovine $\alpha 1$ (II) was prepared from native bovine type II collagen by heat denaturation at $45^{\circ} \mathrm{C}$ and purification of monomeric $\alpha 1$ subunits by separation on a carboxymethylcellulose column (62). Human type II collagen was a kind gift of Dr. Andrew Kang (VAMC, Memphis, TN)

\section{Peptides}

Both biotinylated and unmodified peptides with free end groups were synthesized by Sigma-Genosys (The Woodlands, TX). Biotinylated analogs consist of the peptide plus biotin covalently attached to the $\mathrm{N}$ terminus. Peptide sequences are as follows:

CII(512-526)
CII(512-528)
CytC(43-58)
Mog(35-55)
CII(257-274)

$$
\begin{aligned}
& \text { H-AQGLQGPRGL(Hyp)GT(Hyp)G-OH } \\
& \text { H-AQGLQGPRGL(Hyp)GT(Hyp)GTD-OH } \\
& \text { H-AEGFSYTDANKNKGIT-OH } \\
& \text { H-MEVGWYRSPFSRVVHLYRNGK-OH } \\
& \text { H-E(Hyp)GIAGFKGEQGPKGE(Hyp)G-OH. }
\end{aligned}
$$

The mature form of human CII (GenBank accession \# NM 001844) minus the globular terminal ends found in procollagen, amino acids 1-185 at the amino terminal end and amino acids 1230-1487 at the carboxyl terminus, was used as a template to produce a library of 344 15-mer peptides that progressively overlap by 12 amino acids (Mimotopes, Clayton Victoria, Australia). The sequence in the peptides is numbered according to convention with the first amino acid in the peptide library numbered as -15 , which corresponds to amino acid 186 of the procollagen sequence. Peptides contain a free amino group at the $\mathrm{N}$-terminus and a diketopiperazine group at the $\mathrm{C}$-terminus.

The amino acid sequence of the I- $\mathrm{A}^{\mathrm{b}}$ collagen determinant representing amino acids (512-526) of mature CII was used to produce a substituted library of 15 peptides with each position of the sequence AQGLQGPRGL(Hyp)GT(Hyp)G substituted with 
alanine. Peptides were synthesized with free N- and C-termini (Mimotopes, Clayton Victoria, Australia).

\section{Antigen Emulsions}

Mice were immunized with emulsions of antigen in CFA. To produce CFA, heat killed Mycobacterium tuberculosis (Mtb), strain H37RA, (Difco Laboratories, Detroit, MI) was ground to a fine powder with a mortar and pestle and added to incomplete Freund's adjuvant (IFA) consisting of 15\% Arlacel A in heavy paraffin oil (David Brand, VAMC Memphis, TN) at a concentration of $4 \mathrm{mg} / \mathrm{ml}$. Equal volumes of CFA and antigen solution, $4 \mathrm{mg} / \mathrm{ml} \mathrm{CII} \mathrm{in} 10 \mathrm{mM}$ acetic acid or $2 \mathrm{mg} / \mathrm{ml}$ peptide in PBS, were placed in a $3 \mathrm{ml}$ syringe (BD, Franklin Lakes, NJ) with the end sealed using Dura Seal (Diversified Biotech, Boston, MA) and a plastic cap. Emulsion was created by mixing at high speed with a tissue homogenizer (IKA, Wilmington, NC) on ice for 2-3 min then centrifuging at low speed for $1 \mathrm{~min}$ to remove air bubbles. The quality of the emulsion was then determined by placing a drop of emulsion in a beaker of water. If the emulsion held together for at least $3 \mathrm{~min}$ it was considered stable. The emulsion was then transferred into a $1 \mathrm{ml}$ syringe and capped with a 0.5 inch 26 gauge needle and stored on ice until immunizations were performed. Mice anesthetized with isofluorane were immunized in one of two locations. For experiments requiring the induction of CIA, 100 $\mu l$ of emulsion was injected subdermally at a location $2-3 \mathrm{~cm}$ from the base of the tail. For experiments requiring the later removal of draining lymph nodes mice were immunized subdermally with $50 \mu \mathrm{l}$ emulsion into both rear footpads.

\section{Collagen-Induced Arthritis}

For the induction of CIA, mice aged 8-16 weeks were immunized subdermally in the tail with $100 \mu \mathrm{l}$ of CFA emulsion containing $2 \mathrm{mg} / \mathrm{ml} \mathrm{CII}$ and $2 \mathrm{mg} / \mathrm{ml} \mathrm{Mtb}$. The development of arthritis was monitored visually 2-3 times per week. The severity of arthritis was determined by noting the swelling and joint involvement of each paw using the following scoring system: 0 no erythema and swelling; 1 erythema and swelling confined to mid foot or ankle joint; 2 erythema and moderate swelling extending from the ankle to the metatarsal joints; 3 erythema and severe swelling that encompasses the ankle, foot, and digits; 4 extreme erythema and swelling encompassing all joints of the foot. Mice were monitored until maximal scores were achieved or past 65 days. Data is expressed as the severity and incidence of arthritis exhibited. The nature of the scoring system results in a severity score that ranges from 0 to 16 with 4 points contributed by each paw. 0 represents no arthritis development and 16 represents maximum edema and erythema in all joints of all limbs. To obtain an overall severity score in a particular experimental group the highest severity scores of arthritic mice only were averaged. Incidence is expressed as the percentage of mice in each group that received a severity score of 1 or higher. 


\section{FACS Analysis}

Wild type or IFN- $\gamma^{-/-}$B6 mice were immunized with bovine CII/CFA emulsion and lymphocytes were recovered from the draining popliteal lymph nodes ten days later by mechanical disruption with forceps. The lymphocytes were then washed two times in PBS $0.1 \%$ NaAzide and resuspended at $5 \times 10^{6}$ cells in PBS $0.1 \%$ NaAzide. The cells were then stained with the following fluorescently labeled monoclonal antibodies: antiTCR FITC (\#553171, BD Biosciences, San Diego, CA), anti-CD8a PerCP (\#551162, BD Biosciences, San Diego, CA), anti-CD19 APC (\#550992, BD Biosciences, San Diego, CA), and anti-CD4 Pacific Blue (\#558116, BD Biosciences, San Diego, CA). Staining of cells was performed by adding $0.5 \mu \mathrm{l}$ of monoclonal antibody conjugated to a fluorescent label to $5 \times 10^{5}$ cells in $100 \mu \mathrm{PBS} 0.1 \%$ NaAzide and incubating at $4^{\circ} \mathrm{C}$ for $20 \mathrm{~min}$. The cells were then washed three times with PBS $0.1 \%$ NaAzide to remove unbound antibody and resuspended in $300 \mu 1$ PBS $0.1 \%$ NaAzide. The cells were then analyzed with an LSR II flow cytometer (BD Biosciences, San Diego, CA).

\section{Quantification and Isotyping of Anti-CII Antibodies}

Blood samples were collected from immunized mice via the retro orbital plexus. The blood was allowed to clot by incubation at room temperature for 6 hours and sera were obtained by centrifugation at $300 \mathrm{~g}$ for $10 \mathrm{~min}$. A CII ELISA was performed by coating 96 well vinyl plates (\#2797, Costar, Cambridge, MA) with $100 \mu \mathrm{lof} 5 \mathrm{mg} / \mathrm{ml}$ bovine CII in Jerry Gross buffer $\left(127 \mathrm{mM} \mathrm{Na}_{2} \mathrm{HPO}_{4}, 3.4 \mathrm{mM} \mathrm{KH}_{2} \mathrm{PO}_{4}\right.$, $\mathrm{pH}$ 7.6) overnight at $4^{\circ} \mathrm{C}$. The plates were then washed three times with wash buffer $(154 \mathrm{mM} \mathrm{NaCl}$, $0.05 \%$ Tween-20), and blocked with 2\% BSA in ELISA buffer (PBS, $1 \%$ Tween-20, pH 7.4) for 30 minutes at $4^{\circ} \mathrm{C}$. The plates were then washed three times with wash buffer. Mouse sera was then diluted 1:2000 with ELISA buffer supplemented with 2\% normal goat serum (NGS) (\#32128-5, Pel-Freez, Rogers, AR) and $100 \mu 1$ was two-fold serially diluted over 8 wells in the CII coated plates. Anti-CII antibody standards previously purified from mouse sera by CII conjugated column chromatography were also serially diluted in CII coated plates as a positive control. The plates were then incubated overnight at $4^{\circ} \mathrm{C}$. The plates were washed three times with wash buffer and followed by the addition of a 1:2000 dilution of goat anti-mouse polyvalent immunoglobulins (IgG, IgA, IgM) peroxidase conjugate (\#A 0412, Sigma, Saint Louis, MO) as $2^{\circ}$ antibody in ELISA buffer supplemented with $2 \%$ NGS. The $2^{\circ}$ antibody was incubated for 2 hours at $4^{\circ} \mathrm{C}$ and washed three times with wash buffer. $100 \mu \mathrm{l}$ of HRP substrate was then added. Substrate consists of substrate buffer ( $25 \mathrm{mM}$ citric acid, $50 \mathrm{mM} \mathrm{Na}_{2} \mathrm{HPO}_{4}, 0.018 \%$ $\mathrm{H}_{2} \mathrm{O}_{2}$ ) containing $0.5 \mathrm{mg} / \mathrm{ml}$ o-phenylenediamine dihydrochloride (OPD) (\#P-8287,

Sigma, Saint Louis, MO). The reaction progressed for 30 minutes at which point $50 \mu$ of stopping buffer $\left(2.5 \mathrm{~N} \mathrm{H}_{2} \mathrm{SO}_{4}\right)$ was added. The absorbance at 490-650 $\mathrm{nm}$ was then measured using a Spectramax 340PC spectrophotometer (Molecular Devices, Sunnyvale, CA).

ELISA to determine CII-specific IgG subclass was performed as above with the following differences. To blocked CII coated plates, mouse sera diluted 1:1000 in 
ELISA buffer supplemented with $2 \%$ NGS were added and two-fold serially diluted over 8 wells. Following incubation and wash steps, HRP conjugated $2^{\circ}$ antibodies with specificity for mouse IgG1, IgG2a, IgG2c, and IgG3 from a IgG subclass isotyping kit (\#5300-05, Southern Biotech, Birmingham, AL) were diluted 1:500 in ELISA buffer supplemented with $2 \%$ NGS, and incubated 2 hours at room temp. Following incubation the plates were washed, developed, and absorbance measured by spectrophotometry as above.

\section{Proliferation Assays}

Lymphocytes were isolated from the draining lymph nodes 10 days after immunization by disrupting excised lymph nodes with forceps, and washing two times in HL-1 media. Antigenic stimulation of lymphocytes was performed by culturing the cells in 96 well culture plates (\#92096, TPP, Switzerland) at $5 \times 10^{5}$ cells/well in $300 \mu \mathrm{l}$ complete $\mathrm{HL}-1$ media at $37^{\circ} \mathrm{C}$ and $5 \% \mathrm{CO}_{2}$ with or without antigen stimulation. After three days of stimulation $1 \mu \mathrm{Ci}$ of ${ }^{3} \mathrm{H}$-thymidine (\#NET027A001MC, Perkin Elmer, Boston, MA) was added to each well and allowed to incubate for an additional 18 hours. The cells were then collected onto a glass fiber membrane via aspiration and allowed to dry. The activity of each culture was then measured with a Matrix 96 Direct Beta Counter (Packard, Meriden, CT).

Prior to in vitro stimulation, some lymphocytes were enriched for CD4 expression by magnetic bead cell sorting (MACS). CD4 (L3T4) Microbeads (\#130-049-201, Miltenyi Biotec, Auburn, CA) were used to magnetically label lymphocytes obtained from immunized mice. $10 \mu \mathrm{l}$ of CD4 Microbeads were added to $1 \times 10^{7}$ lymphocytes in $90 \mathrm{ml}$ of autoMACS Rinsing Solution (\#130-091-376) supplemented with 2\% BSA, and incubated at $4^{\circ} \mathrm{C}$ for 15 minutes. The cells were then washed with $2 \mathrm{ml}$ of buffer and peleted by centrifugation at $300 \mathrm{~g}$ for 10 minutes, and resuspended in $500 \mu \mathrm{l}$ of buffer. The labeled cells were then positively selected using the "Possel" program of an autoMACS Separator (Miltenyi Biotec, Auburn, CA). This program operates the autoMACS Separator to retain (positively select) magnetically labeled cells while washing out the unlabeled cells. Following separation, the CD4 enriched lymphocytes were washed two times in complete HL-1 media and stimulated for proliferation as above. Analysis of sorting efficiency was performed by FACS analysis as above using a fluorescently labeled anti-CD4 monoclonal antibody.

Lymphocytes prepared as above from immunized wild type B6, IFN- $\gamma^{-/} \mathrm{B} 6$, CXB2, and B10.M I-A ${ }^{-/}$DR $1 * 0101$ or splenocytes from naïve qCII24 mice were prepared by mincing spleens and treating with GEY'S solution for $5 \mathrm{~min}$ at $4^{\circ} \mathrm{C}$ to lyse red blood cells (RBC). Gey's Solution was prepared in three parts; Part A: $654 \mathrm{mM}$ $\mathrm{NH}_{4} \mathrm{Cl}, 24.7 \mathrm{mM} \mathrm{KCl}, 7.6 \mathrm{mM} \mathrm{Na}_{2} \mathrm{HPO}_{4} \cdot 7 \mathrm{H}_{2} \mathrm{O}, 1.0 \mathrm{mM} \mathrm{KH}_{2} \mathrm{PO}_{4}, 27.7 \mathrm{mM}$ Glucose in $\mathrm{H}_{2} \mathrm{O}$; Part B: $20.6 \mathrm{mM} \mathrm{MgCl} 2 \cdot 6 \mathrm{H}_{2} \mathrm{O}, 5.7 \mathrm{mM} \mathrm{MgSO}_{4} \cdot 7 \mathrm{H}_{2} \mathrm{O}, 30.6 \mathrm{mM} \mathrm{CaCl}{ }_{2} \cdot 2 \mathrm{H}_{2} \mathrm{O}$; Part C: $267.8 \mathrm{mM} \mathrm{NaHCO}_{3}$. Just prior to use, $1.0 \mathrm{ml}$ of Part A, $250 \mu 1 \mathrm{Part} \mathrm{B}$, and $250 \mu 1$ Part $\mathrm{C}$ was added to $3.5 \mathrm{ml}$ of $\mathrm{H}_{2} \mathrm{O}$ and added to the splenocytes in $1 \mathrm{ml} \mathrm{HL}-1$ media. Following incubation the cells were then washed three times with HL-1 media. $5 \times 10^{4}$ 
splenocytes/well were then stimulated for proliferation with $75 \mu \mathrm{g}$ of each peptide in the CII peptide library in $300 \mu \mathrm{l}$ of complete HL-1 media for three days followed by the addition of ${ }^{3} \mathrm{H}$-thymidine as above.

\section{Production of T Cell Hybridomas}

To produce $\mathrm{T}$ cell hybridomas, mice were immunized with $50 \mu \mathrm{l}$ of bovine $\mathrm{CII}$ in CFA emulsion. Ten days post immunization, mice were euthanized and the draining popliteal lymph nodes were removed. Lymph nodes were disrupted with forceps and the released lymphocytes were collected and washed two times in HL-1 media.

Lymphocytes were then cultured at $37^{\circ} \mathrm{C}$ at $5 \% \mathrm{CO}_{2}$ in 96 well culture plates for four days at a concentration of $5 \times 10^{4}$ cells/well in $300 \mu$ of complete HL- 1 medium containing $100 \mu \mathrm{g}$ of the purified $\alpha 1$ (II) chain of bovine CII. Following antigen selective expansion, the lymphocytes in $800 \mu \mathrm{l} \mathrm{HL}-1$ media were added to $300 \mu \mathrm{l}$ Lympholyte-M (\#CL5030, Cedarlane Laboratories, Burlington, NC) for purification by density gradient centrifugation. The cells were washed three times in HL-1 media, and expanded in culture for three days at $5 \times 10^{4}$ cells/well in $300 \mu \mathrm{l}$ complete HL-1 media containing 5 ng/ml IL-2 (\#200-02, PeproTech, Rocky Hill, NJ).

Following IL-2 expansion, T cells were washed in serum free media and mixed with BW5147 cells at a ratio of 2:1. Fusion of cells was induced by the addition of 1.5 $\mathrm{ml}$ PEG 1500 (Roche; Indianapolis, IN) warmed to $37^{\circ} \mathrm{C}$ dropwise over 30 seconds, and followed by the addition of $50 \mathrm{ml}$ warm serum free DMEM. After 30 minutes, the cells were pelleted by centrifugation and the serum free DMEM was replaced with complete DMEM containing 10\% FBS, and the cells were distributed in 96 well plates. Two days later, DMEM supplemented with HAT selection media (Sigma, Saint Louis, MO) was added to fused $\mathrm{T}$ cell/BW5147 hybrid cultures and cultured at $37^{\circ} \mathrm{C}$ in $10 \% \mathrm{CO}_{2}$ until cells reached $50 \%$ confluence. At this point the $\mathrm{T}$ cell hybridomas were tested for responsiveness to antigen stimulation and weaned off of the HAT selection media by the gradual replacement with complete DMEM supplemented with HT (Sigma, Saint Louis, MO) and then complete DMEM over several weeks as the cells were passed.

\section{Antigen Presentation to T Cell Hybridomas}

Antigen was presented to T cell hybridomas using splenocytes from CXB2 mice as APC. To prepare splenocytes, the spleen was removed, placed in $1 \mathrm{ml}$ of HL-1 media, and then disrupted mechanically with forceps. To remove RBC, the cells were incubated for $4 \mathrm{~min}$ at $4^{\circ} \mathrm{C}$ in Gey's solution as above. Following incubation with Gey's solution, the cells were washed three times and resuspended in complete HL-1 media. $100 \mu \mathrm{g}$ $\alpha 1(\mathrm{II}), 100 \mu \mathrm{g}$ bovine CII, $75 \mu \mathrm{g}$ CII-library peptides, or a titration of alanine substituted CII(512-526) peptides ranging from $50 \mu \mathrm{g}$ to $0.188 \mu \mathrm{g}$ were used to stimulate $\mathrm{T}$ cell hybridoma cells. In 96 well culture plates, $4 \times 10^{5}$ splenocytes and $1 \times 10^{5} \mathrm{~T}$ hybridoma cells were added to antigen in $300 \mu$ complete DMEM media, and cultured for 24 hours 
at $37^{\circ} \mathrm{C}$ in $10 \% \mathrm{CO}_{2}$. The supernatants from the cultures were then assayed for IL-2 as follows.

Culture supernatants from stimulated T cell hybridoma cultures were two-fold serially diluted in $80 \mu$ complete DMEM down 8 wells in a 96 well culture plate. In addition, $50 \mathrm{ng}$ IL-2 was also titrated as a positive control. HT-2 cells, which require IL-2 for survival, were then added to the diluted culture supernatants at a concentration of $5 \times 10^{3}$ cells/well and incubated at $37^{\circ} \mathrm{C}$ for 18 hours in $10 \% \mathrm{CO}_{2}$. Survival of HT-2 cells was then assayed by the addition of $10 \mu \mathrm{l}$ of $5 \mathrm{mg} / \mathrm{ml}$ thiazolyl blue tetrazolium bromide (\#M5655, Sigma, Saint Louis, MO) in PBS, which is converted to MTT by living cells, and further incubation at $37^{\circ} \mathrm{C}$ for 3 hours. Supernatants were then removed and MTT was solubilized by the addition of $200 \mu \mathrm{l} 2$-propanol containing $0.02 \mathrm{~N} \mathrm{HCl}$. Once the MTT was dissolved, absorbance at $570 \mathrm{~nm}$ minus $690 \mathrm{~nm}$ was quantitated using a Spectramax spectrophotometer. Wells that exhibited absorbance values twice that of negative control wells were considered positive for HT-2 cell survival and therefore indicated the presence of IL-2 produced by the T cell hybridomas in response to antigen.

\section{Induction of Tolerance in CXB2 Mice with Determinant Peptides}

CXB2 mice were injected in the orbital plexus with $100 \mu \mathrm{l}$ of $1 \mathrm{mg} / \mathrm{ml} \mathrm{CII}(512-$ 528 ) in PBS, or PBS alone. Three days later, the tolerized mice were immunized in the tail with $100 \mu \mathrm{l}$ of $2 \mathrm{mg} / \mathrm{ml}$ bovine CII/CFA emulsion to induce CIA. The mice were then monitored for development of CIA as described above.

\section{Production of Soluble MHC Class II Molecules}

Soluble I-A ${ }^{\mathrm{b}}$ and DR1 were purified from supernatants of S2 drosophila cells transfected with recombinant $\mathrm{I}-\mathrm{A}^{\mathrm{b}}$ or DR1 in which the cytoplasmic and transmembrane portions had been removed by PCR, replaced with a leucine zipper, and cloned into the Drosophila expression vector pRmHA-3. S2 cells were transfected with the cDNA encoding the $\alpha$ and $\beta$ subunits of I-A ${ }^{b}$ or DR 1 at a 10:1 ratio of each to the neomycin resistance vector, $\mathrm{pUChsNeo,} \mathrm{via} \mathrm{calcium} \mathrm{phosphate} \mathrm{precipitation.} \mathrm{Soluble} \mathrm{MHC} \mathrm{class} \mathrm{II}$ production was induced by addition of $1 \% \mathrm{CuSO}_{4}$ and five days later culture supernatants were collected, and modified to contain 1\% octyl b-D-gluco-pyranoside (OcG) (\#O8001, Sigma, Saint Louis, MO) and 0.1\% NaAzide at $\mathrm{pH}$ 8.0.

Soluble MHC class II was purified by passing the supernatant over an affinity column coupled with the DR1-binding monoclonal antibody LB3.1 or I-A $\mathrm{A}^{\mathrm{b}}$-binding monoclonal antibody M5/114.5.2. The column was then washed with PBS containing $0.05 \%$ OcG, $\mathrm{pH} 7.5$, followed by PBS plus $0.5 \mathrm{M} \mathrm{NaCl}$ and $0.05 \% \mathrm{OcG}$, pH 7.5, and then $10 \mathrm{mM}$ TRIS in $0.5 \mathrm{M} \mathrm{NaCl}, \mathrm{pH}$ 7.5. Soluble $\mathrm{MHC}$ was then eluted from the column with $100 \mathrm{mM}$ tris in $0.5 \mathrm{M} \mathrm{NaCl}, \mathrm{pH} 11.2$ and immediately neutralized with acetic acid. Soluble MHC class II molecules recovered were quantitated by OD 280 absorption and concentrated using an Amicon Stirred Cell (Amicon; Beverly, MA). The quality of the 
concentrated soluble class II was monitored by SDS-PAGE containing $12.5 \%$ polyacrylamide.

Soluble I-A ${ }^{\mathrm{b}}$ was also produced in SF9 cells using a baculovirus expression system (\#552846, BD Biosciences, San Diego, CA). A gene encoding soluble I-A ${ }^{\mathrm{b}}$ was cloned into the transfer vector pVL1392 (BD Biosciences; San Diego, CA). This I-A ${ }^{b}$ gene was previously modified by the replacement of the transmembrane and cytoplasmic domains with a leucine zipper. SF9 cells were then co-transfected with I-A ${ }^{b} \alpha$ or I-A $\beta$ in the transfer vector plus BD BaculoGold Bright DNA (\#51-552846, BD Biosciences, San Diego, CA) via calcium phosphate precipitation and cultured in TNM-FH insect medium (\#554760, BD Biosciences, San Diego, CA) at $27^{\circ} \mathrm{C}$. After five days, supernatants were collected and virus titers were determined by plaque assay. To perform the plaque assay, $9 \times 10^{5}$ SF9 cells in $2 \mathrm{ml}$ TMN-FH media were adhered to 12 well plates and inoculated with $20 \mu \mathrm{l}$ of virus containing culture supernatants and incubated for 4 hours. Following incubation, supernatants were removed by aspiration and $2 \mathrm{ml}$ of TMN-FH media containing 1\% plaque assay agarose (\#554766, BD Biosciences, San Diego, CA). Plates were then cultured 4-5 days at $27^{\circ} \mathrm{C}$ after which $200 \mu \mathrm{l}$ of $5 \mathrm{mg} / \mathrm{ml}$ thiazolyl blue tetrazolium bromide was added to the wells and allowed to react for 6 hours. Plaques were then visually counted. Virus titer was repeatedly amplified via infection of fresh SF9 cells with virus laden culture supernatants at a multiplicity of infection (MOI) less than one. When virus titers reached $1 \times 10^{8} / \mathrm{ml}$, SF9 cells cultured in supplemented SF900 II were infected with both $\mathrm{I}_{-} \mathrm{A}^{\mathrm{b}}$ chains at a MOI of five. After five days, virus supernatants were collected and soluble I-A $\mathrm{A}^{\mathrm{b}}$ was purified via column chromatography as in the $\mathrm{S} 2$ derived $\mathrm{I}-\mathrm{A}^{\mathrm{b}}$.

\section{Binding Assays}

\section{I-A ${ }^{b}$ Binding of CytC(43-58), Mog(35-55), and CII(257-274)}

Capture plates were prepared by coating Immulon 2 flat bottom microtiter plates (Dynex Technologies INC. Chantilly, VA) with $100 \mu \mathrm{l}$ of $5 \mu \mathrm{g} / \mathrm{ml} \mathrm{I-A}$-binding monoclonal antibody, M5/114.5.2, in PBS overnight at $4^{\circ} \mathrm{C}$ and then blocked for 1 hour at room temperature with $1 \%$ BSA. Capture plates were then washed three times with $150 \mu \mathrm{PBS}$ containing $0.05 \%$ Tween-20 and buffered with $50 \mu 1$ of $50 \mathrm{mM}$ TRIS containing $1 \% \mathrm{OcG}$ at $\mathrm{pH} 8.0$.

Biotinylated peptides CytC(43-58), Mog(35-55), or CII(257-274) peptides were titrated from $30 \mu \mathrm{M}$ to $0.1 \mathrm{nM}$ in binding buffer (PBS containing $1 \%$ OcG and adjusted to $\mathrm{pH} 6.5$ with $0.1 \mathrm{M}$ potassium phosphate). $100 \mu \mathrm{l}$ of the titrated peptides was added to $50 \mu 1$ of $15 \mathrm{nM}$ soluble I-A $\mathrm{A}^{\mathrm{b}}$ produced by S2 or SF9 insect cells, and incubated overnight at $37^{\circ} \mathrm{C}$ in 96 well round bottom polypropylene plates (\#3365, Corning, Corning, NY). $50 \mu \mathrm{l}$ of the binding reaction was then added to the buffered capture plates for 2 hours at $4^{\circ} \mathrm{C}$. 
Following binding to the capture plate, $\mathrm{I}-\mathrm{A}^{\mathrm{b}}$ peptide complexes were washed three times with PBS containing 0.05\% Tween-20 and the biotin groups on bound peptide were labeled with $100 \mathrm{ng} / \mathrm{ml}$ europium conjugated streptavidin (Perkin Elmer \#1224-360) in $125 \mu \mathrm{m}$ DELPHIA Assay Buffer (Perkin Elmer \#1244-111) by incubation at room temperature for 2 hours. Plates were then washed with $100 \mu$ DELPHIA wash buffer (Perkin Elmer \#1244-114) and $150 \mu$ of DELPHIA Enhancement Solution (Perkin Elmer \#1244-105) was added. Time delayed fluorescence (excitation/emission 315/615 nm) was then quantified using a microplate flurometer (Fluromark, BioRad, Hercules, CA).

\section{Binding of CII Peptide Array to I-A ${ }^{b}$ and DR1}

Capture plates were prepared by adding $100 \mu \mathrm{l} 5 \mu \mathrm{g} / \mathrm{ml} \mathrm{I}^{\mathrm{b}} \mathrm{A}^{\mathrm{b}}$-specific M5/114.5.2 or DR1-specific LB3.1 monoclonal antibody in PBS containing 0.05\% NaAzide to Immulon 2 flat bottom microtiter plates (Dynex Technologies INC., Chantilly, VA) overnight at $4^{\circ} \mathrm{C}$. The plates were them blocked with $250 \mu 11 \%$ BSA in PBS containing $0.05 \%$ NaAzide for 2 hours at room temperature. The plates were then washed three times with wash buffer (150 $\mu$ PBS containing $0.05 \%$ Tween-20), and buffered with 50 $\mu \mathrm{l}$ of $50 \mathrm{mM}$ TRIS $\mathrm{pH} 8.0$ containing $1 \%$ OcG.

Soluble I-A ${ }^{\mathrm{b}}$ or DR1 was prepared at $15 \mathrm{nM}$ and $10 \mathrm{nM}$ respectively in binding buffer (PBS containing 1\% OcG adjusted to $\mathrm{pH} 6.5$ with $0.1 \mathrm{M} \mathrm{KH}_{2} \mathrm{PO}_{4}$ ). I-A $\mathrm{A}^{\mathrm{b}}$ or DR1 was then incubated with $30 \mathrm{nM}$ biotinylated peptides Mog(43-58) or CII(257-274) and 5 $\mu \mathrm{m}$ of each peptide in the CII peptide array overnight at $37^{\circ} \mathrm{C}$ in 96 well polypropylene round bottom plates (Corning, NY). Following incubation, $50 \mu 1$ of the binding reaction was added to the capture plates and incubated at $4^{\circ} \mathrm{C}$ for 2 hours, washed three times with wash buffer, and developed using DELPHIA reagents.

Biotin groups on peptides bound to I-A ${ }^{\mathrm{b}}$ or DR1 were labeled with $100 \mathrm{ng} / \mathrm{ml}$ europium conjugated streptavidin (Perkin Elmer \#1224-360) in $125 \mu \mathrm{m}$ DELPHIA Assay Buffer (Perkin Elmer \#1244-111) by incubation at room temperature for 2 hours. Plates were then washed three times with $100 \mu \mathrm{l}$ DELPHIA wash buffer (Perkin Elmer \#1244114) and $150 \mu \mathrm{l}$ of DELPHIA Enhancement Solution (Perkin Elmer \#1244-105) was added. Time delayed fluorescence (excitation/emission 315/615 nm) was then quantified using a microplate flurometer (Fluromark, BioRad, Hercules, CA).

\section{Microarray Analysis}

Female B6 and B6 IFN- $\gamma^{-/-}$mice between the ages of three and four months were immunized in the footpads of each hind limb with $50 \mu$ l of bovine CII/CFA emulsion. 10 days post immunization, mice were euthanized and the draining popliteal lymph nodes were collected. The lymph nodes were minced with forceps to release lymphocytes and washed in ice cold PBS. An RNeasy kit (\#74124, Qiagen, Valencia, CA) was used to prepare mRNA according to the manufacturer's protocol from the total cells recovered from the nodes. Quantity and purity of the recovered RNA was analyzed by absorbance 
at $260 \mathrm{~nm}$ and the $260 / 280 \mathrm{~nm}$ absorbance ratio with an acceptable range of 1.8 to 2.0. RNA was then concentrated by ethanol/sodium acetate precipitation and dissolved in RNase free water at $2 \mu \mathrm{g} / \mu \mathrm{l}$. Potential degradation of RNA was monitored by analysis of the ratio of 28S/18S rRNA subunits via electrophoresis using an Agilent 2100 Bioanalyser (Agilent, Santa Clara, CA). mRNA was then submitted to the microarray core facility at VAMC Memphis for expression analysis using an Affymetrix GeneChip Mouse Genome 430 2.0 Array on a Affymetrix 7G Plus GeneChip Scanner. The data was then analyzed for statistical significance and cluster analysis via the use of Genespring software produced by Agilent Technologies.

\section{Real Time PCR}

RNA was isolated from lymph node derived lymphocytes recovered from immunized mice using an RNeasy kit (Qiagen, Valencia, CA) according to the manufacturer's protocol. MultiScribe reverse transcriptase (Applied Biosystems, Foster City, CA) was then used to convert $1 \mu \mathrm{g}$ of mRNA to cDNA according to the manufacturer's protocol, and used for real time PCR analysis by the VAMC molecular core facility. Amplitaq Gold (Applied Biosystems), $50 \mathrm{ng}$ of cDNA, and Taqman probes (Applied Biosystems) specific for the transcripts of mouse IL-17A, IL-5, IL-1 $\beta$, IL-6, IL4, GM-CSF, TGF $\beta 1$, IL-18, TNF- $\alpha$, IL-15, IL-10, IL-12 $\alpha$, IL-18 BP, were then used to quantify gene expression using an ABI Prism 7900HT Sequence Detection System (Applied Biosystems) to perform the real time PCR. Ct values were obtained by measuring the cycle times required to reach a threshold value of fluorescence for each probe. These ct values were then normalized to the expression of $\beta$ actin to compare the relative expression of each gene. Data are expressed as the $\Delta \Delta \mathrm{ct}$. This value represents the difference in cycle times required for each reaction to reach the threshold value and is calculated by subtracting the housekeeping $\beta$ actin ct value from the experimental ct value to obtain the $\Delta \mathrm{ct}$, and then subtracting the $\Delta \mathrm{ct}$ value of the IFN- $\gamma^{-/}$real time PCR from the wild type. This value represents the difference in cycle times between the two groups required to reach the threshold fluorescence value.

For microfluidics based real time PCR, RNA was isolated from the lymphocytes recovered from immunized mice using an RNeasy kit (Qiagen, Valencia, CA) according to the manufacturer's protocol. The RNA was converted to cDNA as described above and used for real time PCR analysis by the VAMC molecular core facility using $200 \mathrm{ng}$ cDNA, Amplitaq Gold, a Taqman Gene Signature Array, Mouse Immune Panel (Applied Biosystems) and an ABI Prism 7900HT Sequence Detection System (Applied Biosystems, Foster City, CA). Ct values of each gene in the array were normalized to the expression of the housekeeping gene GAPDH. Data is expressed as the $\Delta \Delta \mathrm{ct}$ value, calculated as above. 


\section{Treatment of Mice with IL-18 BP}

Recombinant IL-18 BPd (\#122-BP, R\&D Systems, Minneapolis, MN) was dissolved in PBS at a concentration of $1 \mathrm{mg} / \mathrm{ml} .10 \mathrm{IFN}-\gamma^{-/-} \mathrm{B} 6$ mice were then injected intraperitoneally with $200 \mu \mathrm{l}$ of IL-18 BPd solution or PBS every 24 hours for 10 days. On the second day of this regimen, the mice were immunized with $100 \mu \mathrm{l}$ of CII/CFA emulsion containing $2 \mathrm{mg} / \mathrm{ml}$ bovine CII and $2 \mathrm{mg} / \mathrm{ml} \mathrm{Mtb}$ subdermally at the base of the tail. Mice were then monitored for the development of CIA.

\section{Anti-CD3/CD28 Stimulation Assay}

Splenocytes from naïve wild type or IFN $-\gamma^{-/-}$B6 mice were cultured in $300 \mu 1$ complete HL-1 media at $1 \times 10^{5}$ cells per well in 96 well plates previously coated with anti-CD3 and anti-CD28 monoclonal antibodies. To prepare antibody coated plates, antiCD3 and anti-CD28 monoclonal antibodies produced from B cell hybridoma clones 1452C11 and HB-12352 (ATCC, Manassas, VA) by the VAMC RDRCC Collagen Core were dissolved in PBS $0.1 \%$ NaAzide at a concentration of $5 \mu \mathrm{g} / \mathrm{ml} .100 \mu \mathrm{l}$ of antibody solution was incubated in 96 well culture plates overnight at $4^{\circ} \mathrm{C}$. Following incubation the plates were washed two times with PBS. Splenocytes were cultured at $1 \times 10^{5}$ cells per well in the antibody coated plates in $300 \mu$ of complete HL-1 media containing $5 \mu \mathrm{g} / \mathrm{ml}$ IL-18 BPd (\#122-BP, R\&D Systems, Minneapolis, MN), 6 ng/ml IFN- $\gamma$ (\#485-MI, R\&D Systems, Minneapolis, MN), 240 ng/ml IL-18 (\#B004-2, R\&D Systems, Minneapolis, MN), 8 ng/ml IL-17 (\# 421-ML, R\&D Systems, Minneapolis, MN), or media only. Cells were cultured for three days at $37^{\circ} \mathrm{C}$ in $5 \% \mathrm{CO}_{2}$ at which point $1 \mu \mathrm{Cu}$ of ${ }^{3} \mathrm{H}$-thymidine was added to each well and incubated for 18 hours at $37^{\circ} \mathrm{C}$ in $5 \% \mathrm{CO}_{2}$. Following incubation the cells were collected onto a glass fiber membrane and activity was read using a Matrix 96 Direct Beta Counter (Packard, Meriden, CT). Some cells were cultured for four days at which point supernatants were collected for cytokine quantification.

\section{BioPlex Cytokine Assay}

Cytokines produced by splenocytes in culture were measured using a 13-plex multiplex bead based cytokine assay kit (BioRad, Hercules, CA) containing development reagents, cytokine standards, and beads conjugated with antibodies specific for IL-1 $\beta$, IL2, IL-4, IL-5, IL-6, IL-13, IL-17, GM-CSF, IFN- $\gamma$, TNF- $\alpha$, IL-15, IL-18, and M-CSF. 50 $\mu \mathrm{l}$ of multiplex beads containing $2 \mu \mathrm{l}$ of conjugated beads and $48 \mu \mathrm{l}$ of BioPlex assay buffer was added to each well of a pre-wetted Multiscreen HTS 96 well filter plate (\#MSBVN1210, Millipore, Bedford, MA). The buffer was removed by vacuum filtration and washed two times with $100 \mu \mathrm{l}$ BioPlex wash buffer. $50 \mu 1$ of the cell culture supernatants was added to the plates in addition to $50 \mu \mathrm{l}$ of the cytokine standards titrated 1:4 in complete HL-1 media over 8 wells. The plate was incubated at room temperature on a plate shaker set to 1,100 RPM (IKA-MTS 4 S2, Staufen, Germany) for 30 minutes. The buffer was removed by vacuum filtration and washed three times with $100 \mu \mathrm{l}$ 
BioPlex wash buffer. $25 \mu \mathrm{l}$ of multiplex detection antibody containing biotin conjugated $2^{\circ}$ antibodies diluted in detection antibody diluent was added, and incubated at room temperature for 30 minutes with agitation at 1,100 rpm. The buffer was removed by vacuum filtration and the plate was washed three times with BioPlex wash buffer. $50 \mu \mathrm{l}$ of streptavidin-PE diluted 1:100 in BioPlex assay buffer was added and incubated for 10 minutes at room temperature while agitated at $1,100 \mathrm{rpm}$ on the plate shaker. The plate was washed three times with BioPlex wash buffer followed by resuspension of the beads in $125 \mu \mathrm{l}$ BioPlex assay buffer. The samples were analyzed using a Luminex 100 BioPlex System (Luminex, Austin, TX). To determine concentration of experimental cytokines in $\mathrm{pg} / \mathrm{ml}$, a standard curve was created using the fluorescence data obtained from the cytokine standards. 


\section{Chapter 3. Modulation of Arthritis Pathogenesis by Variable T Cell Receptor Complex Interaction with Type II Collagen Determinants}

\section{Introduction}

The initial events that trigger the development of autoimmunity remain incompletely understood. IFN- $\gamma$, a proinflammatory cytokine produced by cells of both the innate and acquired immune system, has been implicated in the pathogenesis of a number of inflammatory autoimmune diseases including rheumatoid arthritis, multiple sclerosis, uveitis (63), and type 1 diabetes . However, contrary to a proinflammatory role for IFN- $\gamma$, in animal models of autoimmune diseases targeting IFN- $\gamma$ with neutralizing antibodies or genetic ablation of IFN- $\gamma$ or its receptor, IFN- $\gamma \mathrm{R}$, has been shown to exacerbate disease incidence and severity $(17,20)$.

This paradoxical role of IFN- $\gamma$ as a $\mathrm{T}_{\mathrm{h}} 1$ cytokine has also been observed in a mouse model of rheumatoid arthritis, CIA. In this model, IFN- $\gamma$ regulates susceptibility to arthritis. For example, B6 mice are resistant to CIA. However, when expression of IFN- $\gamma$ or its receptor is removed by genetic ablation, these mice become fully susceptible to CIA $(17,20,64)$. Prior to the discovery that B6 mice lacking IFN- $\gamma$ were susceptible to CIA, a prevailing hypothesis was that among various mouse strains susceptibility to CIA was largely dependent on the expression of MHC class II susceptibility alleles. The hypothesis for MHC-based susceptibility to autoimmune disease was that the susceptible alleles bound and presented the autoantigens that drove the autoimmune $\mathrm{T}$ cell response. In contrast, non-susceptible alleles are incapable of binding these autoantigenic peptides, thus conferring resistance. For example, in the CIA model, mouse strains that express $\mathrm{I}-\mathrm{A}^{\mathrm{q}}$ or I-A $\mathrm{A}^{\mathrm{r}}$ bind $\mathrm{CII}$ determinants with sufficient affinity to stimulate $\mathrm{T}$ cell activation and drive the development of CIA at high incidence. Mice expressing other MHC class II haplotypes, such as I-A ${ }^{b}$ in the B6 mouse strain, either fail to bind or bind CII peptides at a very low affinity and therefore fail to stimulate $\mathrm{T}$ cell activation and thus are resistant to CIA.

Recently, it has become clear that the immunological basis for resistance or susceptibility to autoimmunity is much more complex than the ability of an antigenic peptide to bind to an MHC molecule. In a number of mouse models of autoimmunity, it has been demonstrated that resistant mouse strains can be converted to susceptible by altering the cytokine environment of the mouse during disease initiation. For example, B6 mice genetically deficient for the production of IFN- $\gamma$ are fully susceptible to CIA, whereas wild type B6 mice are resistant (17). These data indicate that both T cell and B cell responses to CII autoantigens develop in B6 mice, thus the "resistant" I-A $\mathrm{b}^{\mathrm{b}}$ molecule binds and presents the CII autoantigen peptides.

One explanation for the altered immune response of B6 IFN- $\gamma^{-/-}$mice is that IFN- $\gamma$ has a regulatory role for $\mathrm{T}$ cell responses, and that this regulation is most apparent for low 
affinity $\mathrm{T}$ cell determinants. In this model, $\mathrm{T}$ cell activation against $\mathrm{CII}$ in $\mathrm{B} 6$ mice is weak and suppressed by IFN- $\gamma$, however, in the absence of IFN- $\gamma$, disregulation of the immune response occurs allowing $\mathrm{T}$ cell activation against weak $\mathrm{CII}$ antigens and autoimmunity develops. Therefore, to explain the differential susceptibility to CIA observed in the B6 IFN- $\gamma^{-/-}$mouse we developed the following hypothesis. If IFN- $\gamma$ functions as a regulator of $\mathrm{T}$ cell responses to weakly immunogenic, low affinity determinants, and $\mathrm{I}-\mathrm{A}^{\mathrm{b}} \mathrm{MHC}$ class II molecules have low affinity for collagen autoantigen determinants, then in the IFN- $\gamma^{-/-}$B6 mouse, the absence of IFN- $\gamma$ alters T cell function and the cytokine response following immunization with CII, disrupting normal immune regulation and allowing the development of CIA.

To address IFN- $\gamma$ 's role in regulating T cell responses to collagen and ultimately the development of autoimmunity a set of specific aims were developed.

1. Identify the alterations in the immune response of B6 IFN- $\gamma^{-/-}$mice in response to immunization with $\mathrm{CII}$, including alterations in the differentiation, proliferation, and cytokine production of CII-specific T cells and accessory cells.

2. Identify the CII determinants to which $\mathrm{I}-\mathrm{A}^{\mathrm{b}}$-expressing mice mount an immune response.

3. Determine the significance of CII determinants in the development of arthritis in the B6 IFN- $\gamma^{-/-}$mouse.

4. Determine the affinity of CII determinants for $\mathrm{I}^{\mathrm{A}} \mathrm{A}^{\mathrm{b}}$.

These aims address both the mechanism of $\mathrm{T}$ cell activation in response to stimulation with CII and how IFN- $\gamma$ potentially mediates susceptibility to autoimmunity. IFN- $\gamma$ has broad regulatory control of immune function. Therefore, its absence has the potential to alter immune functions including cellular differentiation, proliferation of CIIspecific T cells, and cytokine production by immune and accessory cells. Skewed numbers of immune cell populations as a result of disregulation due to the absence of IFN- $\gamma$ could alter the course of the autoimmune response and thus affect pathogenesis. Previous data indicates that IFN- $\gamma$ deficient mice have increased $\mathrm{T}$ cell proliferative response to antigen (65). Increased numbers of CII-reactive $\mathrm{T}$ cells may contribute to arthritis susceptibility. Another aspect of immune cell function that may be altered by the absence of IFN- $\gamma$ is the production of cytokines in response to CII immunization. Cytokines are key mediators of immune response development, and the intercellular communication between T cells, B cells, APC, and accessory cells directs the immune response in terms of cellular differentiation, activation, and function. All of these immune processes can potentially contribute to the pathogenesis of CIA, so understanding how the immune response in the IFN- $\gamma^{-/-}$mouse is altered in response to antigen stimulation broadens our understanding of the immune mechanisms by which autoimmunity develops.

A stipulation of the hypothesis that IFN- $\gamma$ regulates activation of T cells against weak antigens is that CII contains autoantigen determinants to which T cells recognize and respond when disregulation of the immune response is induced by the absence of 
IFN- $\gamma$. The nature of the immune system is such that the potential for the development of autoimmunity is tightly controlled at many levels. For example, mechanisms of selftolerance have evolved that protect the immune system from mounting a response to selfantigens (27). Clonal selection of T cells in the thymus and peripheral mechanisms, such as anergy or $\mathrm{T}_{\text {reg }}$ cell suppression of effector $\mathrm{T}$ cell activation, minimize $\mathrm{T}$ cell activation to self-antigens (32). Both the maturation of $\mathrm{T}$ cells in the thymus and activation of effector T cells in the periphery is largely dependent on the affinity and interaction of the TCR with determinants presented by MHC. There is evidence that subsets of $\mathrm{T}_{\text {reg }}$ cells also exhibit antigen specificity (66-68), indicating that there may be a role for CII determinants in $\mathrm{T}_{\text {reg }}$ cell differentiation. Therefore, to understand how autoantigen determinants present in CII contribute to T cell activation and subsequently autoimmune development, we sought to identify CII determinants in I-A $\mathrm{A}^{\mathrm{b}}$-expressing mice, determine the affinity of those determinants for the components of the TCR complex, and assess the contribution of those determinants to the pathogenesis of CIA.

\section{Results}

\section{IFN- $\gamma$ Regulates Susceptibility to Autoimmune Arthritis in C57BL/6 Mice}

It has been shown previously that mice of different genetic backgrounds exhibit differential susceptibility to CIA $(17,69,70)$. The development of CIA requires an autoimmune $\mathrm{T}$ cell response directed against a processed antigen associated with $\mathrm{MHC}$ on the surface of an antigen presenting cell (71). The structure of a given MHC allele limits the diversity of peptide antigens available to bind and be presented by that MHC molecule. MHC haplotype strongly associates with susceptibility to CIA. I-A ${ }^{\mathrm{q}}(69)$ or $\mathrm{I}-\mathrm{A}^{\mathrm{r}}$-expressing $(70,72)$ mice such as DBA1/J or B.10RIII are fully susceptible to CIA whereas mice expressing other I-A haplotypes, such as I-A ${ }^{b}$ in the C57BL/6 mouse, are resistant to CIA. However, in the B6 background, the deletion of a single gene, IFN- $\gamma$, confers susceptibility to CIA. The wild type B6 mouse is considered non-susceptible to CIA as following immunization with CII these mice develop arthritis only rarely, with less than 10\% incidence (73). In addition, the arthritis exhibited in those mice that do develop disease is of low severity. In contrast, B6 IFN- $\gamma^{-/-}$mice are highly susceptible developing arthritis at a high incidence and severity in comparison to the wild type mice (17). B6 IFN- $\gamma^{-/-}$mice develop arthritis at an 80-100\% incidence within 3-4 weeks following immunization with CII. The first mice develop arthritis two to three weeks after immunization with CII/CFA emulsion, and all affected mice developing arthritis after one month. Multiple limbs of the IFN- $\gamma^{-/-} \mathrm{B} 6$ mice are affected, exhibiting high severity as measured by the extent of inflammation and the number of joints involved. B6 and B6 IFN- $\gamma^{-/-}$mouse strains were immunized with CII for the development of CIA (Fig 3.1, 3.2). Maximum severity scores for each arthritic mouse ranged from 8 to 12 and averaged $9.0 \pm 1.41$ with an average of $2.43 \pm 0.49$ limbs affected. Only $10 \%$ of the B6 wild type group developed arthritis with the affected mouse developing a single arthritic limb on day 52 while greater than $80 \%$ of IFN- $\gamma^{-/-}$mice developed arthritis in 

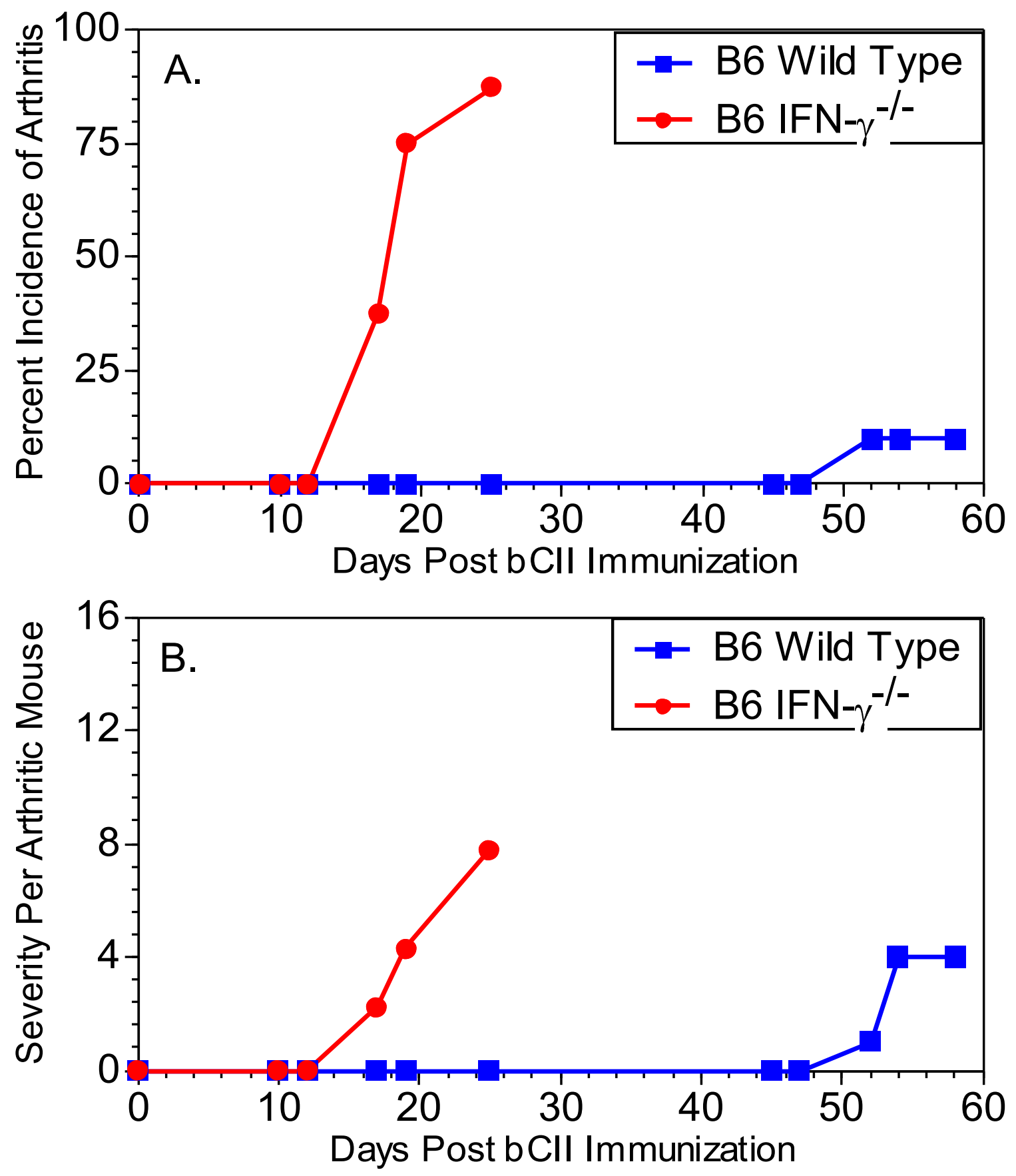

Figure 3.1 IFN- $\gamma^{-/-}$Mice Exhibit Increased Susceptibility to CIA.

B6 IFN- $\gamma^{-/-}$mice are highly susceptible to CIA, and develop arthritis at an earlier time point exhibiting high incidence and severity compared to wild type B6 mice following immunization with CII/CFA emulsion. A. $87.5 \%(\mathrm{~N}=8)$ of $\mathrm{B} 6 \mathrm{IFN}-\gamma^{-/}$developed arthritis between days 14-22 versus $10 \%(\mathrm{~N}=10)$ incidence in $\mathrm{B} 6$ wild type mice on day 52. B. Severity score of arthritis per arthritic mouse. Arthritic B6 IFN- $\gamma^{-/}$mice developed arthritis with a mean severity score of 8 out of a maximum 16 possible, while the B6 wild type mouse developed arthritis with a score of 4 . 


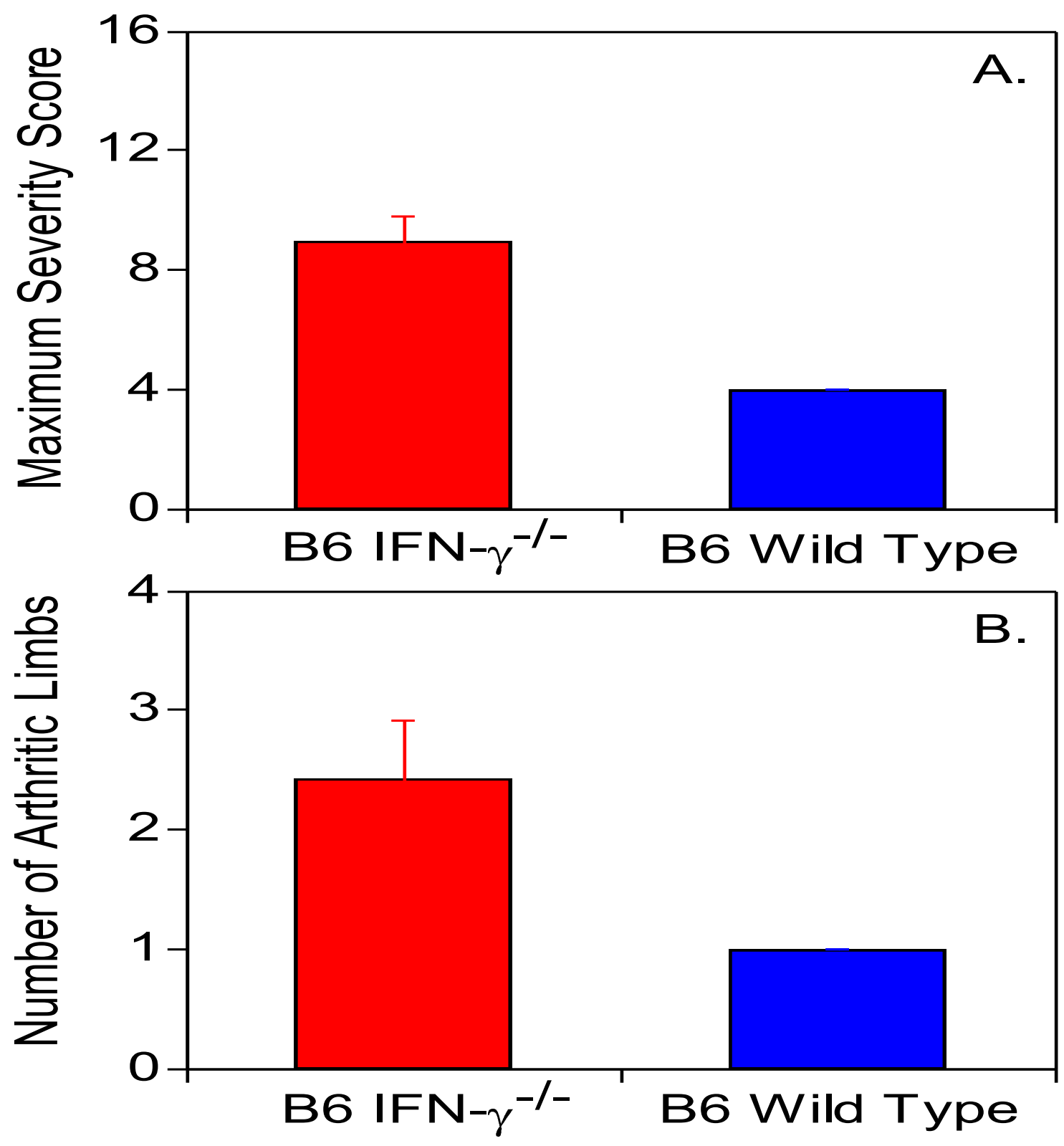

Figure 3.2 Severity of Arthritis in $\mathrm{B6}$ and B6 IFN- $\gamma^{-1-}$ Mice.

B6 IFN- $\gamma^{-1-}$ mice exhibit a severe arthritis with multiple affected limbs when immunized with CII/CFA. Rare arthritis occurrence in B6 wild type is of low severity and limb involvement. A. Average highest severity reached in B6 wild type and $\mathrm{B} 6 \mathrm{IFN}-\gamma^{-/-}$mice that developed arthritis following immunization with CII/CFA. The average maximum severity was determined by averaging the highest severity reached in arthritic mice only. B6 IFN $-\gamma^{-/}$averaged a maximum score of $9.0 \pm 1.41$ among 7 arthritic mice while the lone arthritic B6 wild type mouse achieved a maximum score of 4 . B. Average number of inflamed limbs per arthritic mouse in B6 and B6 IFN- $\gamma^{-/-}$mice. Arthritic B6 IFN- $\gamma^{-/-}$ mice averaged $2.43 \pm 0.49$ arthritic limbs while the arthritic B6 wild type mouse had one arthritic limb. 
multiple affected limbs. Thus, these data imply that IFN- $\gamma$ acts as a regulator of autoimmune response in B6 mice.

\section{Regulation of Immune Cell Function by IFN- $\gamma$}

\section{Immune Cell Subset Analysis}

To determine if the absence of IFN- $\gamma$ was altering the cellular immune responses to $\mathrm{CII}$ in mice expressing I-A $\mathrm{A}^{\mathrm{b}}$, the production of anti-CII immunoglobulins, the proliferative response of $\mathrm{T}$ cells to CII determinants, and their production of cytokines was examined. IFN- $\gamma$ is predominantly a cytokine produced by $T$ cells of the $T_{h} 1$ phenotype, and has regulatory effects on immune cells such as macrophages, B cells, $\mathrm{T}_{\mathrm{h}} 1$, $T_{h} 2$, and $T_{h} 17$ cells $(74,75)$. One major role of IFN- $\gamma$ is the promotion of $T_{h} 1$ differentiation and the inhibition of $\mathrm{T}_{\mathrm{h}} 2$ or $\mathrm{T}_{\mathrm{h}} 17$ cells. As a cell mediated inflammatory disease, the pathogenesis of CIA could be affected by alterations in the numbers of $\mathrm{B}$ cells or $T_{h} 1$ and $T_{h} 2 T$ cells present following immunization with CII. Since the absence of IFN- $\gamma$ in the B6 IFN- $\gamma^{-/-}$mouse may alter the differentiation of T cells into the various $\mathrm{T}$ cell subtypes, we investigated the autoimmune response of $\mathrm{B} 6$ and $\mathrm{B} 6 \mathrm{IFN}-\gamma^{-/-}$mice that were immunized with CII.

Wild type or IFN- $\gamma^{-/-}$B6 mice were immunized with CII/CFA emulsion and lymphocytes were collected from the draining popliteal lymph nodes 10 days later. These lymphocytes were stained with fluorescently labeled antibodies to identify immune cell subpopulations via FACS analysis. The $\alpha / \beta$ TCR was used to identify T cells, CD19 expression to identify B cells, CD4 expression to identify $\mathrm{T}_{\mathrm{h}}$ cells, and CD8a to identify $\mathrm{T}_{\mathrm{c}}$ cells. Similar percentages of $\mathrm{T}$ and $\mathrm{B}$ cells were found to be present in the two mouse strains. In the B6 WT mice, $47.2 \pm 8.2 \%$ of lymphocytes were found to be B cells as indicated by positive CD19 staining compared to $43.9 \pm 14.9 \%$ in the B6 IFN- $\gamma^{-/-}$group $(\mathrm{p}=0.57)$. Similar percentages of T cells were also found between the two strains as indicated by positive staining for $\alpha / \beta$ TCR. $48.8 \pm 8.4 \%$ of lymphocytes were observed to be T cells in the B6 group compared to $53.3 \pm 15.2 \%$ in the B6 IFN- $\gamma^{-/-}$group ( $p=$ 0.55) (Fig 3.3ABE). $T_{h}$ or $T_{c}$ subsets were then measured by examining the percentage of lymphocytes that stained positive for both $\alpha / \beta$ TCR and CD4 or CD8a. The B6 group was found to have a higher percentage of $\mathrm{CD}^{+} \mathrm{T}_{\mathrm{c}}$ cells than the B6 IFN- $\gamma^{-/-}$group $(\mathrm{p}<$ 0.0001 ), while the B6 IFN- $\gamma^{-/-}$group was found to have a higher percentage of $\mathrm{T}_{\mathrm{h}}$ cells ( $\mathrm{p}$ $<0.0002)$. In the B6 group, $53.3 \pm 3.1 \%$ of $\mathrm{T}$ cells were positive for CD8a compared to $42.7 \pm 0.7 \%$ in the B6 IFN $-\gamma^{-/-}$group. Conversely, $54.6 \pm 1.1 \%$ of T cells stained positive for CD4 in the B6 IFN- $\gamma^{-/-}$group compared to $44 \pm 3.7 \%$ in the B6 group (Fig 3.3CDF). As noted earlier, IFN- $\gamma$ has potent regulatory effects on cellular differentiation, however these data indicate that there are only minor alterations in the cellular makeup of the immune response in $\mathrm{B} 6 \mathrm{IFN}-\gamma^{-/-}$mice following immunization with $\mathrm{CII}$. The number of $\mathrm{B}$ cells versus $\mathrm{T}$ cells is unaffected. However, the number of $\mathrm{CD} 4^{+}$or $\mathrm{CD}^{+}$cells is slightly altered in the B6 IFN- $\gamma^{-/-}$mouse with $10 \%$ increase in $\mathrm{CD}^{+}$and a $10 \%$ decrease in $\mathrm{CD}^{+}$cells. These data indicate that the absence of IFN- $\gamma$ does not abrogate $\mathrm{CD} 4^{+} \mathrm{T}$ 

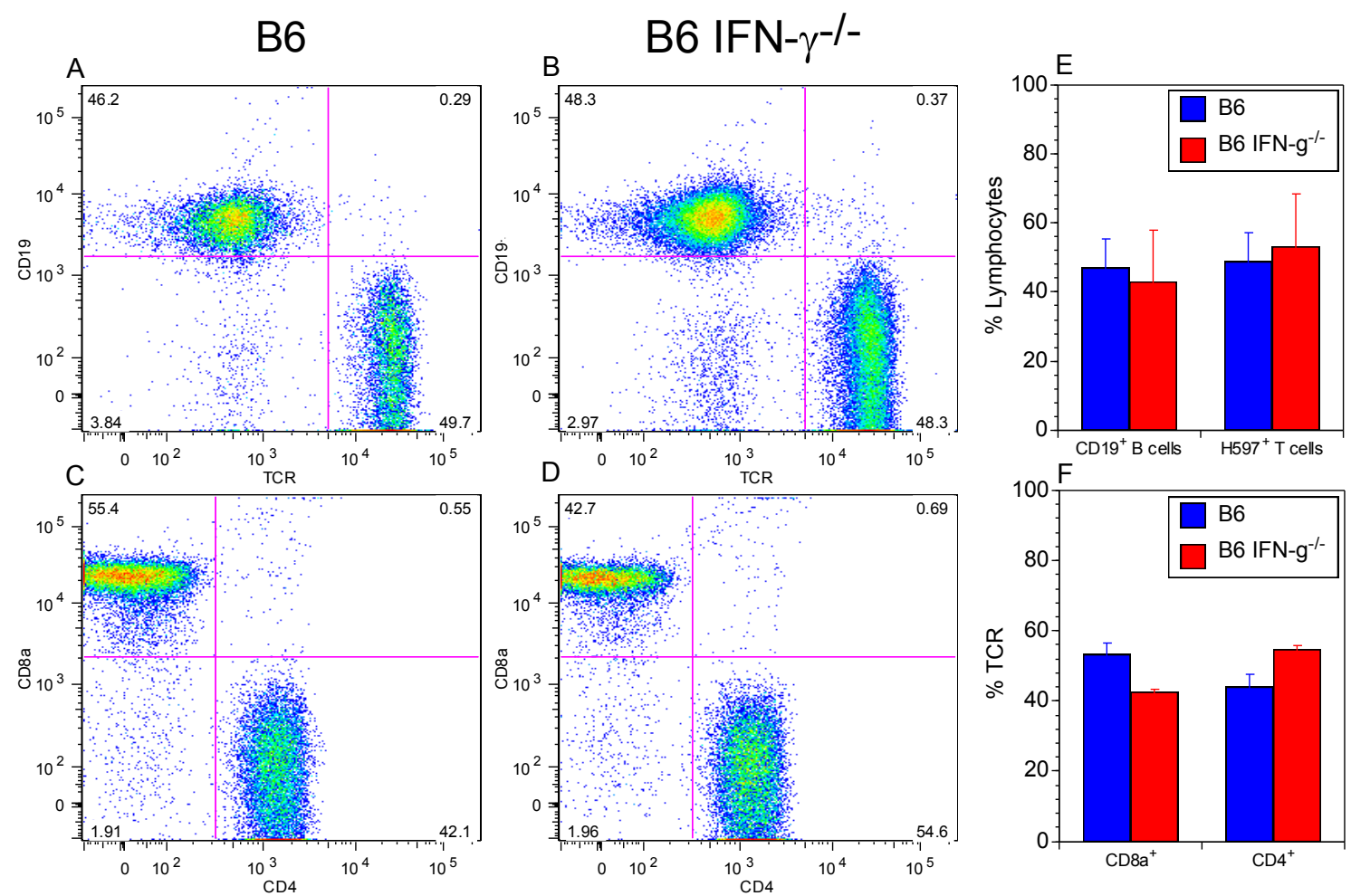

\section{Figure 3.3 Lymphocyte Compartment of CII-Immunized B6 and B6 IFN- $\gamma^{-1-}$ Mice.}

The absence of IFN- $\gamma$ in B6 IFN- $\gamma^{-/}$mice does not alter the percentage of B or T cells in draining lymph nodes following immunization with CII/CFA. However, the percentage of CD8a ${ }^{+} T_{c}$ cells are slightly reduced with a concurrent increase in $\mathrm{CD}^{+} \mathrm{T}_{\mathrm{h}}$ cells. Lymphocytes were recovered from the draining lymph nodes of B6 IFN- $\gamma^{-/ 2}$ or B6 wild type mice immunized with CII/CFA and stained with anti-CD19, anti-TCR, anti-CD4, and anti-CD8a. ABE. The numbers of $B$ and $T$ cells were not significantly different $(p=$ $0.65, \mathrm{p}=0.63)$ between lymphocytes from B6 wild type $(\mathrm{N}=5)$ and B6 IFN- $\gamma^{-/ 2}(\mathrm{~N}=4)$ mice. B6 mice had $47.2 \pm 8.2 \% \mathrm{CD} 19^{+} \mathrm{B}$ cells while B6 IFN $-\gamma^{-/ 2}$ mice had $43 \pm 14.9 \%$ $\mathrm{CD} 19^{+} \mathrm{B}$ cells. B6 mice had $48.8 \pm 8.4 \% \mathrm{TCR}^{+} \mathrm{T}$ cells while B6 IFN- $\gamma^{-/-}$mice had 53.3 $\pm 15.2 \% \mathrm{TCR}^{+} \mathrm{T}$ cells. CDF. When lymphocytes were gated on $\mathrm{TCR}^{+} \mathrm{T}$ cells and examined for expression of $\mathrm{CD} 8 \mathrm{a}^{+} \mathrm{T}_{\mathrm{c}}$ cells or $\mathrm{CD}^{+} \mathrm{T}_{\mathrm{h}}$ cells a significant decrease in $\mathrm{CD} 8 \mathrm{a}^{+} \mathrm{T}_{\mathrm{c}}$ cells $(\mathrm{p}<0.001)$ and increase in $\mathrm{CD} 4^{+} \mathrm{T}_{\mathrm{h}}$ cells $(\mathrm{p}<0.002)$ was observed. B6 mice had $53.3 \pm 3.1 \% \mathrm{CD}^{2} \mathrm{a}^{+} \mathrm{T}_{\mathrm{c}}$ cells while B6 IFN- $\gamma^{-/}$mice had $42.7 \pm 0.7 \% \mathrm{CD} \mathrm{a}^{+} \mathrm{T}_{\mathrm{c}}$ cells. When $\mathrm{T}_{\mathrm{h}}$ cells were examined, B6 mice had $44.0 \pm 3.7 \% \mathrm{CD}^{+} \mathrm{T}_{\mathrm{h}}$ cells while B6 IFN- $\gamma^{-/-}$mice had $54.6 \pm 1.1 \% \mathrm{CD}^{+} \mathrm{T}_{\mathrm{h}}$ cells. 
cell development, rather, the $\mathrm{CD} 4^{+}$complement of $\mathrm{T}$ cells in the $\mathrm{B} 6 \mathrm{IFN}-\gamma^{-/}$cells increases without IFN- $\gamma$. Though $\mathrm{T}_{\mathrm{h}} 1$ differentiation may be inhibited by the absence of IFN- $\gamma, T_{h} 2$ or $T_{h} 17$ differentiation is negatively regulated by IFN- $\gamma$ and the increases in $\mathrm{CD} 4^{+}$cells in the IFN- $\gamma^{-/}$mouse may be in these subsets $(74,76)$. However, these changes are small and may not be biologically significant. In both wild type and IFN- $\gamma^{-/}$ B6 mice, nearly half of the $\mathrm{TCR}^{+} \mathrm{T}$ cell population is $\mathrm{CD}^{+}$while the remaining $\mathrm{TCR}^{+} \mathrm{T}$ cells express $\mathrm{CD}^{+}$. This data indicates that the major mechanisms of immune disregulation in the absence of IFN- $\gamma$ are likely due to alterations in cellular function such as cytokine production, rather than by altered cellular differentiation between $\mathrm{T}$ cells $\mathrm{B}$ cells and the $T_{c}$ or $T_{h}$ subtypes.

\section{Anti-CII Immunoglobulin Production}

Even though the pathogenesis of RA is considered to be primarily $\mathrm{CD} 4^{+} \mathrm{T}$ cell mediated, one of the hallmarks of the disease is the generation of autoantibodies. In RA, Ig directed against determinants in the $\mathrm{Fc}$ region of $\mathrm{IgG}$ is produced and is known as rheumatoid factor (77). Other autoantibodies produced in RA include antibodies directed against citrullinated proteins, CII, and glucose-6-phosphoisomerase $(78,79)$.

Complement activating IgM-IgG immune complexes form and are deposited in the joints and likely contribute to the chronic inflammation that is characteristic of RA. In the CIA model, the generation of autoantibodies with specificity for CII has been implicated as an important mechanism in the pathogenesis of CIA (80-84). CIA can be induced in mice when polyclonal antibodies purified from arthritic mice are passively transferred, or when mice are injected with anti-CII monoclonal antibodies $(80,81,85-88)$. In addition, complement fixing antibodies have been shown to localize to the surface of articular cartilage in a rat model of CIA (89). IFN- $\gamma$ regulates production of antibodies by B cells via several mechanisms. IFN- $\gamma$ acts directly on proliferating B cells to induce Ig class switching to IgG2a and by blocking IL-4 induced class switching to IgE and IgG1 (9092). IFN- $\gamma$ also indirectly regulates antibody production by B cells via its regulation of $\mathrm{T}_{h}$ cell differentiation (93). Given the importance of immunoglobulins in the pathogenesis of CIA and the contribution of IFN- $\gamma$ in promoting of antibody production, serum concentration of anti-CII Ig was examined in B6 and B6 IFN- $\gamma^{-/ /}$mice following immunization with CII/CFA.

Sera were collected from B6 and B6 IFN- $\gamma^{-/-}$mice 36 days following immunization with CII in CFA emulsion, and the quantity of CII-specific Ig present in the serum was measured by ELISA. Quantification of CII-specific antibody was determined using an anti-CII antibody standard previously purified from mouse sera. The concentration of CII-specific Ig was found to be higher in the serum obtained from CII-immunized B6 IFN- $\gamma^{-/-}$mice as compared to the CII-immunized B6 mice $(\mathrm{p}=0.024)$. B6 IFN- $\gamma^{-/ 2}$ serum contained anti-CII Ig at a concentration of $144 \pm 88.9 \mu \mathrm{g} / \mathrm{ml}$ while the B6 serum contained anti-CII Ig at a concentration of $33.3 \pm 14.9 \mu \mathrm{g} / \mathrm{ml}$ (Fig 3.4). IgG subclass potentially mediates joint destruction by two mechanisms, either by complement activation or by activation of monocytes/macrophages via binding to $\mathrm{Fc}$ receptors present on these cells. The different subclasses of IgG have differing ability to effect these two 


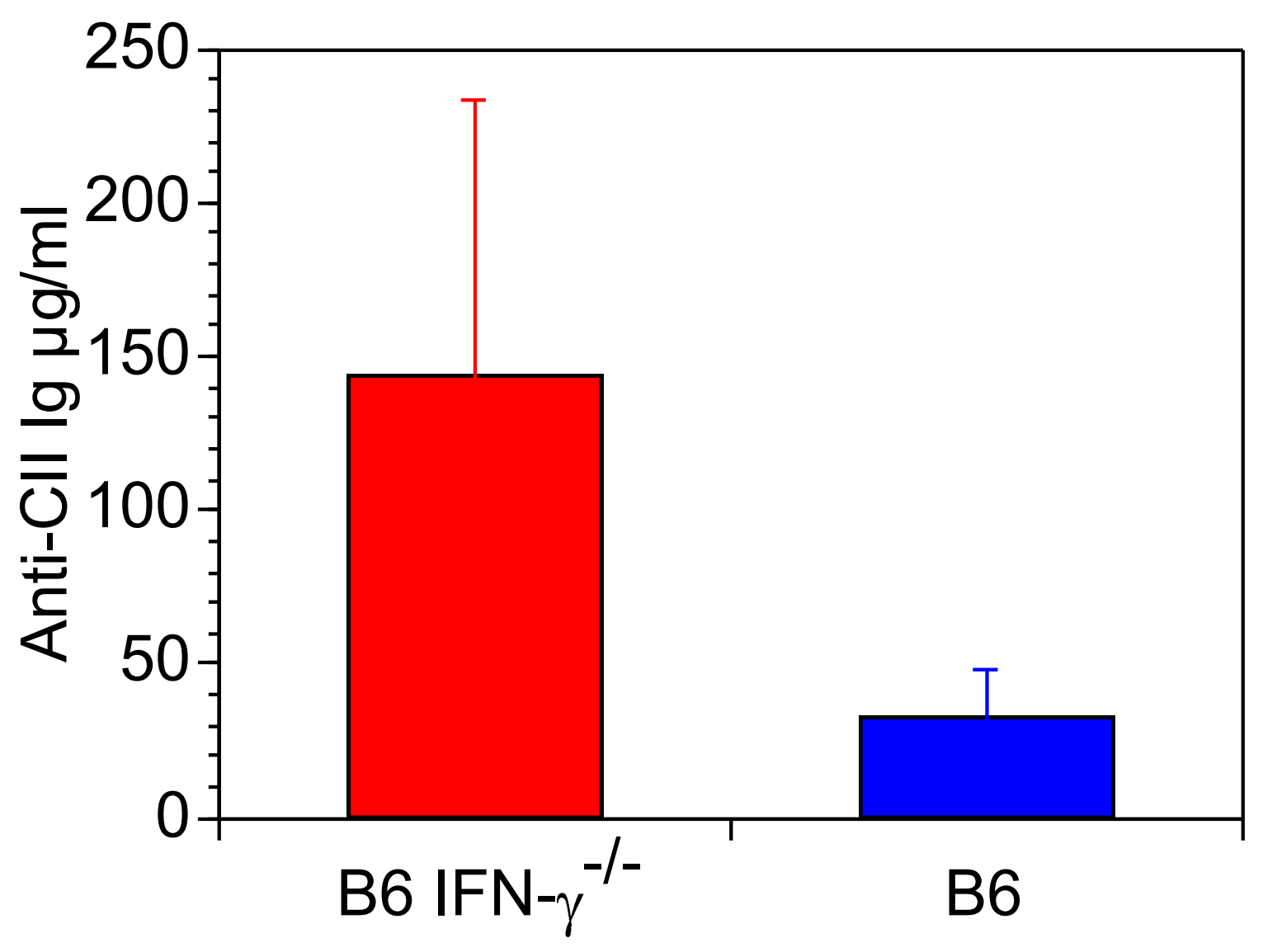

Figure 3.4 Increased Anti-CII Ig Production in B6 IFN- $\gamma^{-/-}$Mice Immunized with CII Compared to Wild Type.

Production of anti-CII Ig is elevated in B6 IFN- $\gamma^{-/}$mice compared to B6 WT mice. B6 or B6 IFN- $\gamma^{-/}$mice were immunized with CII in CFA emulsion, and sera was collected 36 days later. CII-specific Ig previously prepared from mouse sera was used to quantify the concentration of CII-specific Ig present in serum via ELISA. B6 IFN- $\gamma^{-/-}$mice exhibit significantly elevated levels of CII-specific Ig compared to wild type B6 mice ( $\mathrm{p}=$ 0.024). B6 IFN- $\gamma^{-/}$serum contained anti CII Ig at a concentration of $144 \pm 88.9 \mu \mathrm{g} / \mathrm{ml}$ while the B6 serum contained anti-CII Ig at a concentration of $33.3 \pm 14.9 \mu \mathrm{g} / \mathrm{ml}$. 
processes. IgG2a, IgG2b, IgG2c all have complement activating ability while IgG1 and IgG3 do not. The same variation is seen in the ability of the IgG subclasses to bind and activate $\mathrm{Fc}$ receptors. In $\mathrm{I}-\mathrm{A}^{\mathrm{b}}$-expressing mice the gene for $\mathrm{IgG} 2 \mathrm{a}$ is absent, rather, $\mathrm{IgG} 2 \mathrm{c}$ replaces its functional activity $(94,95)$. Since the subclass of IgG expressed may effect the development of arthritis in CIA, the subclasses of IgG present in sera from CIIimmunized wild type B6 and B6 IFN- $\gamma^{-/-}$were measured by ELISA. When the subtypes of $\mathrm{IgG}$ present in $\mathrm{I}-\mathrm{A}^{\mathrm{b}}$-expressing mice, IgG1, IgG2b, IgG2c, and IgG3, were quantified, increased levels of IgG2b were observed in the B6 IFN- $\gamma^{-/}$compared to the B6 wild type (Fig 3.5). The ELISA resulted in an absorbance $3.30 \pm 0.09$ from the IFN- $\gamma^{-/-}$sera compared to the wild type absorbance of $0.23 \pm 0.24(\mathrm{p}<0.001)$. The other subclasses were present at low levels and were not statistically different between groups. Arthritis development in CIA is dependent on both the complement-fixing and Fc $\gamma \mathrm{R}$ binding capability of antibodies. Mice lacking C5, Fc $\gamma$ RI, or Fc $\gamma$ RIII are resistant to CIA (96-98). Despite the absence of IFN- $\gamma$, high levels of complement fixing CII-specific antibodies are produced in B6 IFN- $\gamma^{-/}$mice. CII-specific antibodies of the IgG2b subclass have been shown to be highly arthritogenic in a mechanism dependent on the high affinity Fc $\gamma$ RIII when used to induce arthritis in DBA/1 mice (99). Therefore, the increased production of CII-specific IgG2b as a result of IFN- $\gamma$ deficiency in B6 mice may be a mechanism of increased susceptibility to CIA.

\section{Proliferative Response}

Previous work has indicated that IFN- $\gamma^{-/-}$mice exhibit increased proliferative response to antigen (65). Therefore, in order to determine if the absence of IFN- $\gamma$ causes a disregulated $\mathrm{T}$ cell proliferative response following immunization with $\mathrm{CII}$, the $\mathrm{I}-\mathrm{A}^{\mathrm{b}}$ restricted $\mathrm{T}$ cell response against bovine $\mathrm{CII}$ was examined. 10 days following immunization with CII, lymphocytes were removed from the draining lymph nodes of B6 or B6 IFN- $\gamma^{-/-}$mice and re-stimulated in vitro with bovine CII for four days. The proliferative response of the CII-specific T cells was measured using ${ }^{3} \mathrm{H}$-thymidine incorporation. In both the B6 WT and IFN- $\gamma^{-/-}$no statistically significant increases in $\mathrm{T}$ cell proliferation were observed above the media control (Fig 3.6), although the background level of proliferation appeared to be higher for the IFN- $\gamma^{-/} \mathrm{T}$ cells. This may be indicative of the low antigenicity of CII in the I-A ${ }^{b}$ background, and CII-specific T cells may be produced at levels too low to detect by this assay.

The CXB2 inbred mouse strain is an $\mathrm{I}-\mathrm{A}^{\mathrm{b}}$-expressing strain of mice that is derived from F1 crosses between C57BL/6 mice and the CIA-susceptible BALB/c mouse strains. These mice are significant in that despite expression of $\mathrm{I}-\mathrm{A}^{\mathrm{b}} \mathrm{MHC}$ class II they exhibit an intermediate susceptibility to CIA, an example of how genetic background can affect disease susceptibility. These mice develop a moderate to severe arthritis at around $60 \%$ incidence. Since these I-A ${ }^{b}$-expressing mice develop CIA at an incidence higher than wild type B6 mice it was possible that these mice also would exhibit increased proliferative response against CII, and this would allow the comparison of an CII proliferative response in a CIA-susceptible I- $\mathrm{A}^{\mathrm{b}}$-expressing mouse strain with the response in the IFN- $\gamma^{-/-}$or wild type mice. I-A ${ }^{\mathrm{b}}$-expressing $\mathrm{B} 6$ and $\mathrm{CXB} 2$ mice were 


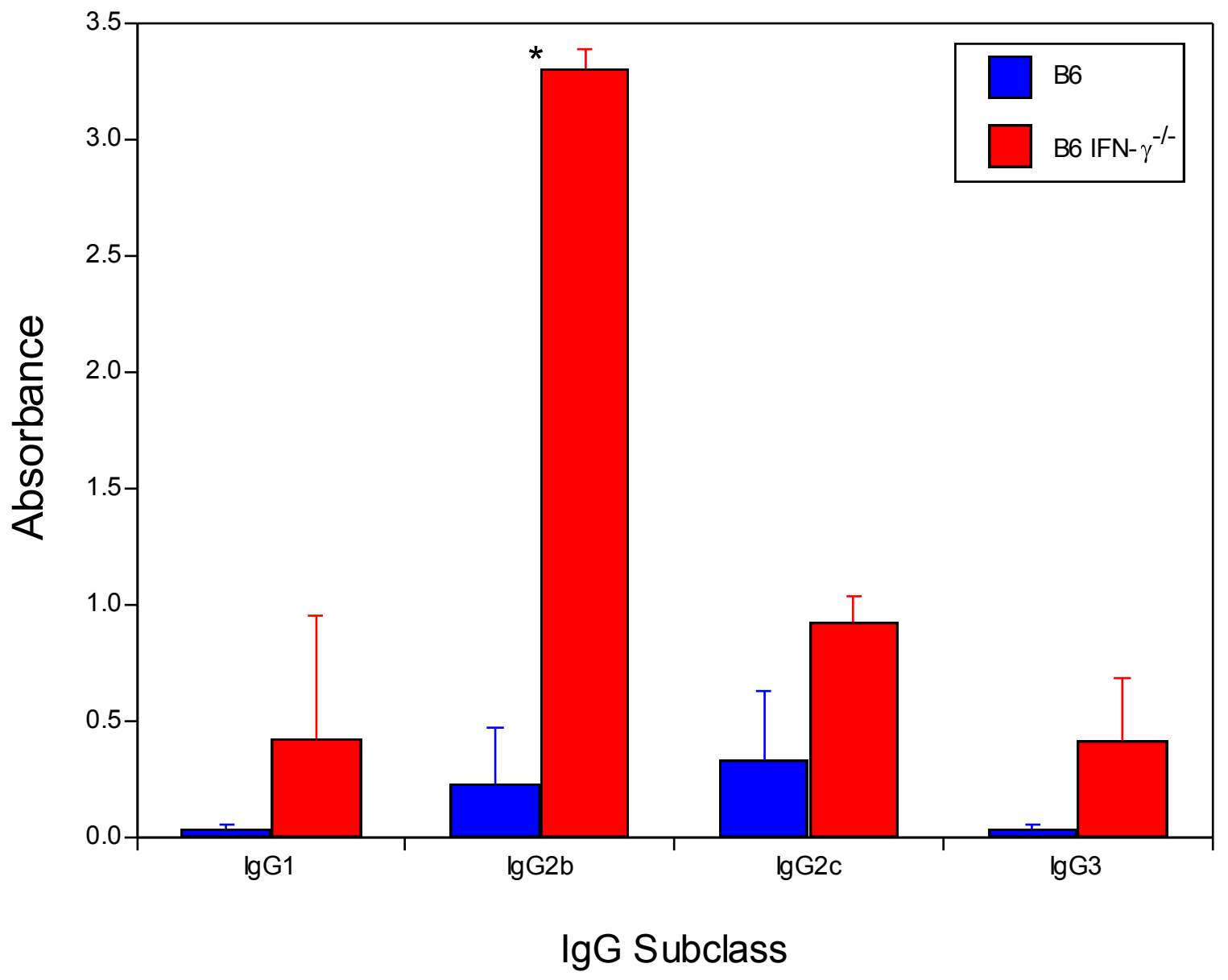

\section{Figure 3.5 Increased Expression of IgG2b in B6 IFN- $\gamma^{-/}$Mice Immunized with} CII.

Expression of IgG subclass was measured in sera collected from wild type and IFN- $\gamma^{-/-}$ B6 mice ten days following immunization with CII/CFA. The relative concentration of each subclass was measured by HRP ELISA and quantified by absorbance at 490-650 $\mathrm{nm}$. In the IFN- $\gamma^{-/ 2} \mathrm{~B} 6$ serum, the concentration of IgG2b was increased compared to the wild type exhibiting an absorbance of $3.30 \pm 0.09$ compared to $0.23 \pm 0.24$ in the wild type $(\mathrm{p}<0.001)$. The other IgG subclasses did not exhibit statistically significant differences in concentration. The background absorbance in serum free wells measured less than 0.01 for all subtypes. 


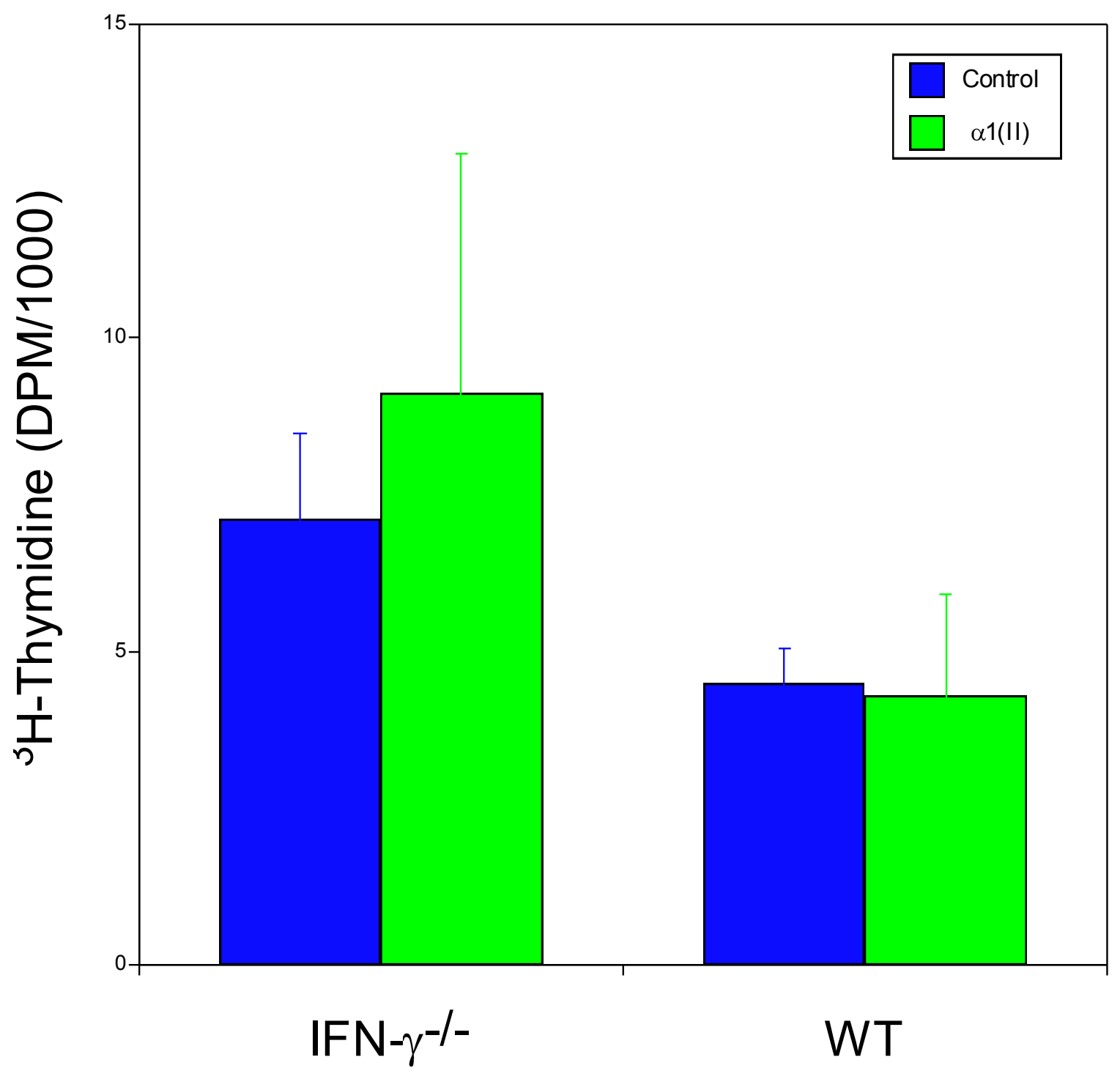

Figure 3.6 Proliferative Response to Type II Collagen in Wild Type and IFN- $\gamma^{-/-}$ B6 Mice.

Bovine CII does not induce proliferative responses in wild type or IFN- $\gamma^{-/ 2} \mathrm{~B} 6$ mice. When stimulated with the $\alpha 1$ (II) chain of CII for proliferation in culture, lymphocytes recovered from the draining lymph nodes 10 days following immunization with native bovine CII/CFA do not proliferate above media control. Proliferation was measured by ${ }^{3} \mathrm{H}$-thymidine incorporation. Lymphocytes from B6 IFN- $\gamma^{-/ 2}$ mice exhibited an activity of $9117 \pm 3816$ DPM when stimulated with $\alpha 1$ (II) compared to $7098 \pm 1367$ DPM when cultured in media only. This is an insignificant difference $(p=0.42)$. Results were similar in lymphocytes recovered from wild type B6 mice. Stimulation with $\alpha 1$ (II) resulted in an activity of $4289 \pm 1613$ DPM, while the media control had an activity of $4478 \pm 557$ DPM $(\mathrm{p}=0.83)$. These results indicate that native bovine collagen is not strongly immunogenic in $\mathrm{I}-\mathrm{A}^{\mathrm{b}}$-expressing mice. 
immunized with native CII in an emulsion of CFA and lymphocytes were recovered from the draining lymph nodes ten days later. These cells were stimulated with CII, the $\alpha 1$ (II) chain of CII, and pepsin, and proliferation was measured by ${ }^{3} \mathrm{H}$-thymidine incorporation. Lymphocytes from the $\mathrm{B} 6$ mouse proliferated in response to $\mathrm{CII}$ and pepsin but not to $\alpha 1$ (II) (Fig 3.7A). In the CXB2 mouse recall proliferative response occurred following stimulation with pepsin, but not against the native CII or $\alpha 1$ (II) (Fig 3.7B). The proliferation data do not indicate that the absence of IFN- $\gamma$ is causing increased in vivo expansion of CII-reactive cells in the IFN- $\gamma^{-/ 2}$ B6 mouse. In all three strains of I-A $\mathrm{A}^{\mathrm{b}}$ expressing mice strong proliferation in response to CII stimulation was not observed. Though CII-reactive T cells are being produced, which can be inferred due to the production of CII-specific IgG, subclasses of which are dependent on $\mathrm{T}$ cell help. Reduced proliferation of T cells in response to stimulation with CII may indicate that CIIreactive $T_{h}$ cells are not being produced at high levels or that activation of these cells is negatively regulated by tolerance mechanisms including anergy or suppression by $\mathrm{T}_{\text {reg }}$ cells. An additional cause of low in vitro $\mathrm{T}$ cell proliferative response may be altered antigen presentation by APC in culture. The absence of strong proliferation in response to CII stimulation may indicate that functional mechanisms such as cytokine production may play a larger role in CIA pathogenesis than proliferative responses to CII. In addition, these results may indicate, as stipulated by the hypothesis that $\mathrm{CII}$ is a weak antigen, that $\mathrm{CII}$ has low intrinsic ability to stimulate I-A $\mathrm{A}^{\mathrm{b}}$-restricted $\mathrm{T}$ cells. Also, a confounding result was also observed. This is the strong proliferative response seen against pepsin. The purification of CII from tissue sources requires the use of pepsin. A result of this is that pepsin contamination is present in the final CII product. In mice expressing I-A $\mathrm{A}^{\mathrm{b}}$, but not other CIA-susceptible strains that express I- $\mathrm{A}^{\mathrm{q}}$ or I- $\mathrm{A}^{\mathrm{r}}$, the slight pepsin contamination is antigenic and results in strong $\mathrm{T}$ cell responses that mask the presence of weaker $\mathrm{T}$ cell responses against CII that may be present. This is evident in the responses seen in the $\mathrm{B} 6$ mice in that when immunized with native CII strong recall proliferative responses are seen against pepsin and not against the $\alpha 1$ (II). The observed proliferative response against native $\mathrm{CII}$ is likely directed against pepsin. During the production of $\alpha 1$ (II), native $\mathrm{CII}$ is heat denatured and protein monomers are separated by column chromatography. This step reduces the levels of pepsin contamination to a concentration below that which $\mathrm{T}$ cells respond. For this reason, in subsequent assays requiring in culture stimulation of lymphocytes with CII, $\alpha 1$ (II) was used.

\section{Cytokine Production B6 versus B6 IFN- $\gamma^{-1-}$}

The expression of proinflammatory cytokines by immune cells in response to stimulation with antigen or bacterial products often has powerful biologic effects owing to both redundant activities among cytokine family members and because of signaling cascades that amplify the effects of small amounts of locally produced cytokines (100). Due to the role of cytokine signaling in the differentiation and function of $\mathrm{T}$ cell subsets early in the developmental stages of an immune response, cytokines likely are key mediators of autoimmune pathogenesis. $T_{h} 1, T_{h} 2$, and $T_{h} 17$ differentiation and function is influenced and mediated by cytokine production (74). Cytokines produced by these cells potentially direct the function of macrophages, monocytes, synovial fibroblasts, and 

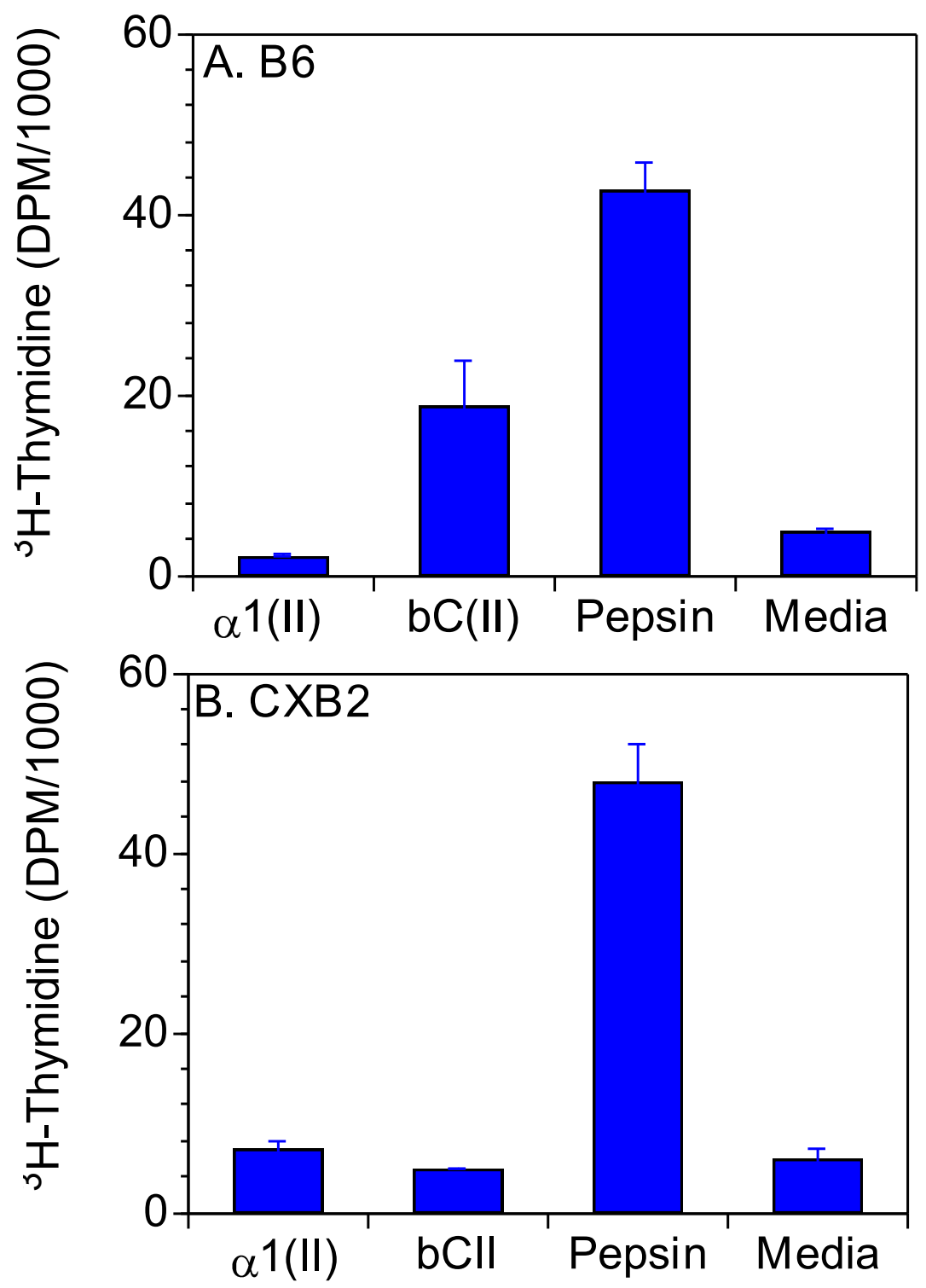

\section{Figure 3.7 Proliferative Response to CII in Mice Expressing MHC Class II of the} I-A $A^{\mathrm{b}}$ Haplotype.

Lymphocytes obtained from CII-immunized B6 or CXB2 mice do not proliferate when stimulated in culture with CII antigens. A. Lymphocytes were obtained from the draining lymph nodes of B6 mice were immunized with bovine CII/CFA. In culture, proliferation was observed in response to stimulation with bovine $\mathrm{CII}$ (bCII), and pepsin, but not to $\alpha 1$ (II). B. Lymphocytes obtained from CXB2 mice proliferated in response to stimulation with pepsin, but not $\alpha 1$ (II) or bCII. The proliferation of the B6 cells in response to bCII and pepsin, but not $\alpha 1$ (II) indicates that low proliferative responses in B6 mice to bCII are due to trace amounts of pepsin present in the CII rather than to CII determinants. The CXB2 mice tended to have a higher threshold of reactivity against pepsin so trace amounts in the bCII prep did not stimulate $\mathrm{T}$ cell proliferation while a higher concentration of pepsin did. 
osteoclasts to disease promoting state (45). The production of IFN- $\gamma$ is a major effector function of $T_{h} 1$ cells, therefore absence of the IFN- $\gamma$ gene clearly alters $T_{h} 1$ immune responses. This may disrupt regulation of the immune response causing aberrant production of other inflammatory cytokines and promoting disease progression. For this reason, the cytokines produced by B6 IFN- $\gamma^{-/-}$lymphocytes were examined. A panel of 13 cytokines was selected based on their association with $\mathrm{T}_{\mathrm{h}}$ subtype or known influence on CIA pathogenesis. Measurement of cytokines produced by lymphocytes from B6 and B6 IFN- $\gamma^{-/-}$mice was performed using a multiplexed bead assay. To measure IFN- $\gamma$ 's influence on the production of cytokines during the activation of T cells, lymphocytes were obtained from the spleens of naïve B6 and B6 IFN- $\gamma^{-/-}$mice and then stimulated in culture for three days with anti-CD3 and anti-CD28 monoclonal antibodies. Following stimulation, the concentration of cytokines present in the supernatant was measured. A number of cytokines expressed by lymphocytes from B6 IFN- $\gamma^{-/-}$T cells following stimulation in culture was significantly altered from wild type $(p<0.05)$ (Fig 3.8). In the IFN- $\gamma^{-/}$derived cells, cytokines produced by all three $T_{h}$ subsets were increased. Levels of the $T_{h} 1$ cytokine, IL-2, were elevated, as were the $T_{h} 2$ cytokines, IL-4, IL-5, and IL-13 and the $T_{h} 17$ cytokine IL-17. In addition, the proinflammatory cytokines IL-1 $\beta$, IL-6, TNF- $\alpha$, M-CSF, and GM-CSF were elevated in the IFN- $\gamma^{-/}$cultures. Two cytokines, IL-15 and IL-18, were not differentially expressed between the two cultures. This cytokine expression profile indicates that in the absence of IFN- $\gamma$ there is a significant change in the expression of proinflammatory cytokines by T cells. IFN- $\gamma$ is known to negatively regulate the function of $T_{h} 2$ and $T_{h} 17$ subsets $(12,13)$. The increases in $T_{h} 2$ and $T_{h} 17$ derived cytokines indicates that in the absence of $T_{h} 1$ produced IFN- $\gamma$ those subsets are more active, and indeed, if these in vitro effects on cytokine production mediated by the absence of IFN- $\gamma$ correlate with in vivo effects, they may represent mechanistic aspects of arthritis pathogenesis in the B6 IFN- $\gamma^{-/-}$CIA model.

\section{I-A ${ }^{\text {b }}$ CII-Determinant Studies}

One of the mechanisms of IFN- $\gamma$ 's regulation of immune response may lie in the regulation of weak $T$ cell stimulation, such as those that may be involved in the generation of autoimmunity (29). In CIA, the antigen that promotes $\mathrm{T}$ cell activation and the subsequent development of arthritis is CII. It is the nature of the immune system that $\mathrm{T}$ cell antigens are presented to T cells by MHC molecules. Evolutionary mechanisms have produced various MHC alleles that by their possession of structurally different antigen binding sites increase the diversity of antigenic determinants presented to $T$ cells for immune surveillance. However, this also means that for a given protein antigen different antigenic determinants may be presented by different $\mathrm{MHC}$ alleles. This means that $\mathrm{MHC}$ alleles such as I-A ${ }^{\mathrm{q}}$ and $\mathrm{I}-\mathrm{A}^{\mathrm{r}}$ present in CIA-susceptible mouse strains likely present distinct CII determinants from those presented by $\mathrm{MHC}$ alleles present in CIA non-susceptible strains such as $\mathrm{I}-\mathrm{A}^{\mathrm{b}}$ in the B6 mouse. Additionally, if the CII determinant presented by $\mathrm{I}-\mathrm{A}^{\mathrm{b}}$ is of low affinity for the MHC or the TCR, it may be weakly stimulatory to $\mathrm{T}$ cell activation, and therefore conferring resistance to CIA in $\mathrm{I}-\mathrm{A}^{\mathrm{b}}$-expressing mice such as in the $\mathrm{B} 6$ strain. IFN- $\gamma$ may regulate $\mathrm{T}$ cell activation to weakly stimulating determinants by creating conditions that inhibit $\mathrm{T}$ cell activation in 

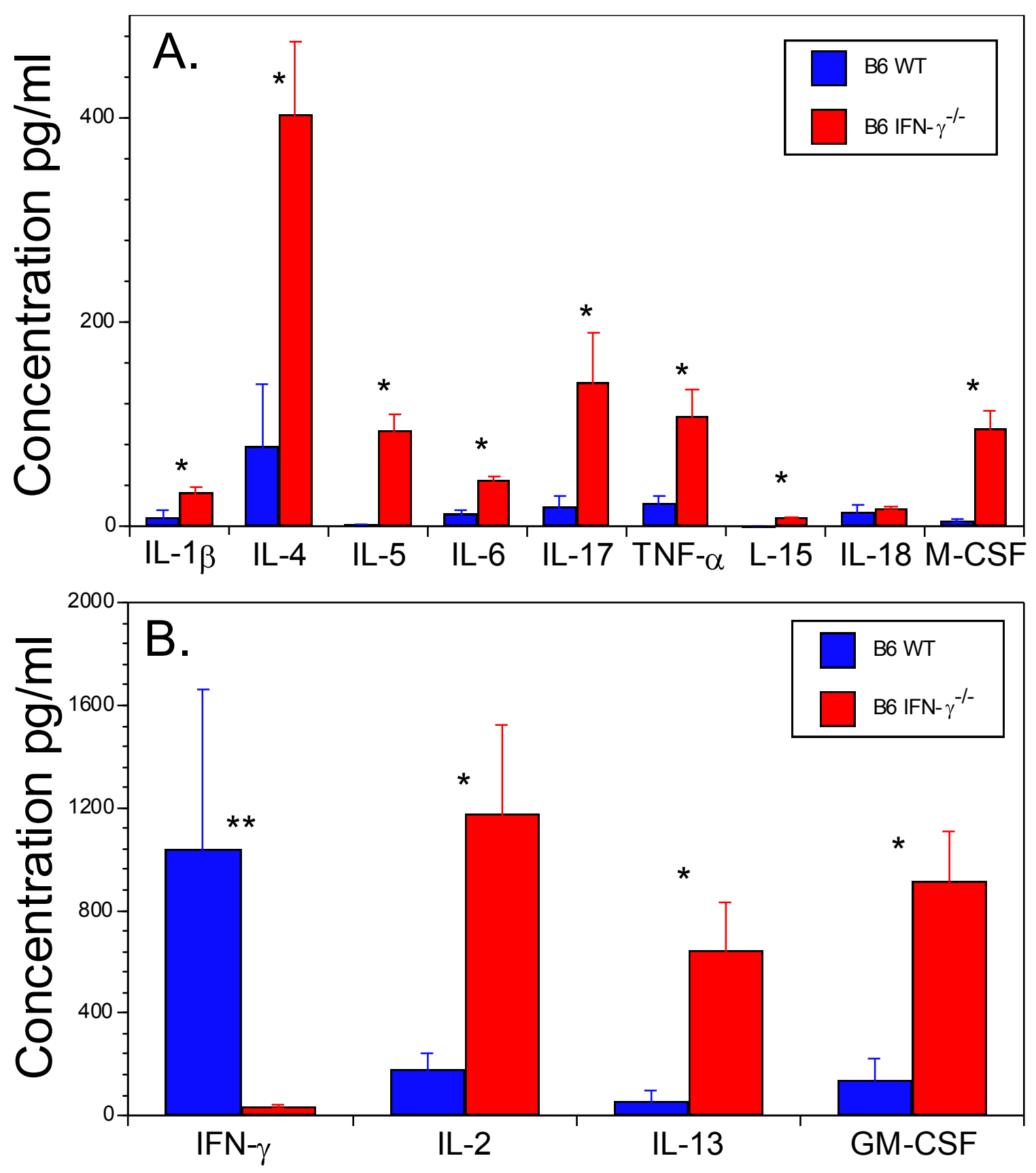

Figure 3.8 The Absence of IFN- $\gamma$ Significantly Alters Cytokine Production in Culture Following Stimulation of T Cells with Anti-CD3 and Anti-CD28.

Splenocytes from naïve wild type or IFN- $\gamma^{-/-}$B6 mice were stimulated in culture with anti-CD3 and anti-CD28 antibody. Cytokine concentration in culture supernatants was then measured by multiplexed bead assay. Cells from IFN- $\gamma^{-/-}$mice produced higher levels of the cytokines IL-1 $\beta$, IL-4, IL-5, IL-6, IL-17, TNF- $\alpha$, IL-15, M-CSF, IL-2, IL13 , and GM-CSF $(* p<0.01, * * p<0.05)$. 
response to weak antigens or, IFN- $\gamma$ 's absence may create conditions that are permissive to $\mathrm{T}$ cell activation. Therefore, to determine if an $\mathrm{I}-\mathrm{A}^{\mathrm{b}}$-restricted CII determinant was weakly antigenic, and to determine if IFN- $\gamma$ 's role in regulating $\mathrm{T}$ cell responses to an I$\mathrm{A}^{\mathrm{b}}$-restricted determinant mediates the pathogenesis of CIA, we sought to identify an I$\mathrm{A}^{\mathrm{b}}$-restricted CII determinant, and investigate its interaction with $\mathrm{MHC}, \mathrm{TCR}$, and its role in stimulating immune responses in $\mathrm{I}-\mathrm{A}^{\mathrm{b}}$-expressing mice.

To identify CII determinants, a set of peptides that duplicated the amino acid sequence of human CII was created. These peptides are 15-mer sequences that progressively overlap by 12 amino acids. This CII peptide library was then used to stimulate proliferation of lymphocytes obtained from I-A ${ }^{b}$-expressing mice immunized with CII. Though stimulation with native CII did not induce proliferative response it was thought that due to the simplified processing by antigen presenting cells and the relatively higher molar concentration of antigen compared to the concentration of antigen that would be present with the use of native CII, unmeasurable T cell proliferative responses against native CII or $\alpha 1$ (II) chain would be amplified by the use of peptide.

Mice expressing I-A ${ }^{b}$ or HLA-DR1 (as a control for proliferation) were immunized with bovine CII/CFA and lymphocytes from the draining lymph nodes were used in a proliferation assay against the CII peptide library. Naïve splenocytes from a TCR transgenic mouse (qCII24) were also used as a positive control. T cells from qCII24 mice express a $\mathrm{T}$ cell receptor that is specific for a previously defined CII determinant. The lymphocytes obtained from DR1 mice strongly proliferated when stimulated in culture with the three peptides 91,92, and 93 which contain the core DR1 binding determinant FKGEQGPKG (101), while lymphocytes from qCII24 mice, which respond to the determinant IAGFKGEQG (102), proliferate in response to the peptides 90, 91, and 92 as expected. The three I- $\mathrm{A}^{\mathrm{b}}$-expressing strains of mice, the B6, B6 IFN- $\gamma^{-/}$, and CXB2, exhibit differential susceptibility to CIA. However, T cells from the three I-A ${ }^{b}$-expressing strains did not proliferate when stimulated with any of the peptides from the CII library (Fig 3.9).

The bovine CII sequence is $98 \%$ homologous with human CII when the leader sequence is removed with only 18 mismatches over 1029 amino acid residues. However, the lack of a detectable proliferative response in lymphocytes derived from the B6, B6 IFN- $\gamma^{-/}$, or CXB2 mice immunized with bovine CII and stimulated in vitro with the human CII derived peptide library raised the possibility that an I-A ${ }^{\mathrm{b}}$-restricted CII determinant lies in an area of non-homologous sequence. To address this issue, B6 or CXB2 mice were immunized with human CII and stimulated in vitro with the CII peptide library. As in mice immunized with bovine CII, increased proliferation to a specific peptide determinant was not observed when human CII was used as the immunogen (Fig 3.10). This indicates that the lack of proliferation observed when the mice were immunized with bovine CII was not due to sequence differences between the bovine and human CII. 


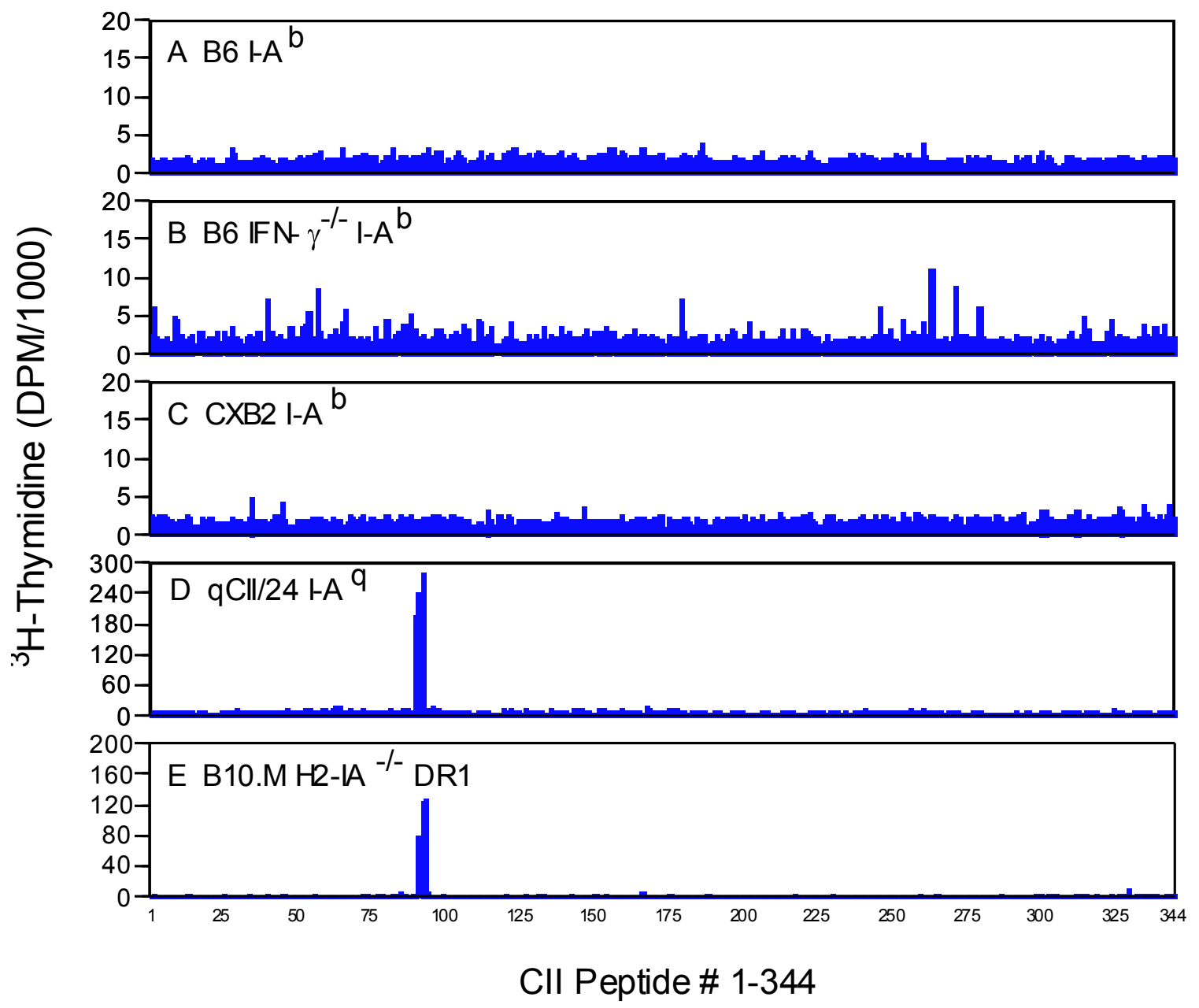

Figure 3.9 Proliferative Response to CII-Library Peptides by T Cells from Mice of Various MHC Class II Background.

ABC. When immunized with bovine CII in CFA emulsion mice expressing MHC of the haplotype $I-A^{b}$ do not exhibit proliferative response when stimulated for proliferation by peptides from the CII peptide library. DE. I-A ${ }^{\mathrm{q}}$ - or DR1-expressing mice immunized with CII in CFA emulsion respond to determinant peptides present in the CII peptide library with large proliferative responses as measured by ${ }^{3} \mathrm{H}$-thymidine incorporation. 


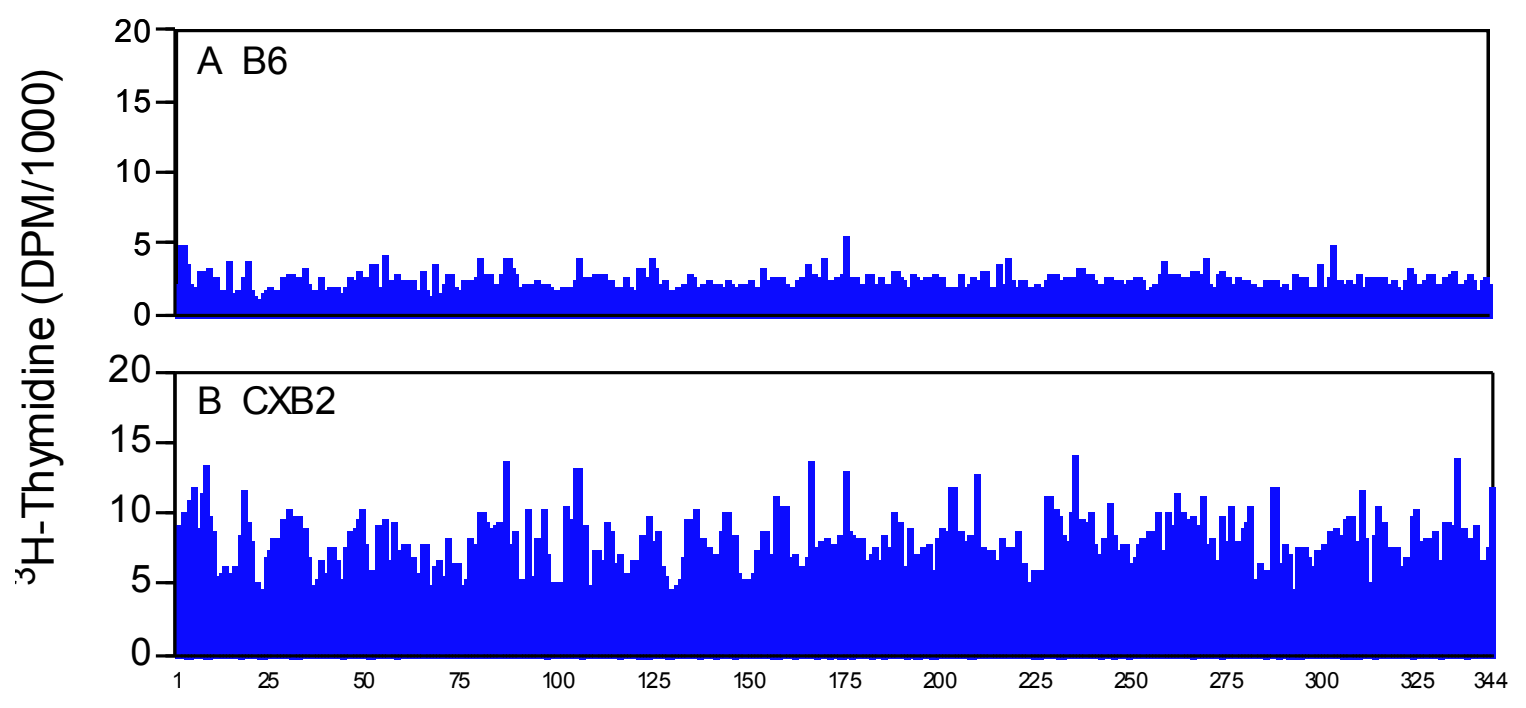

CII Peptide \# 1-344

Figure 3.10 Proliferative Response to Human Type II Collagen by T Cells from Mice Expressing I-A $\mathbf{A}^{\mathbf{b}}$.

Lymphocytes were obtained from the draining lymph nodes of mice 10 days following immunization with human CII/CFA. B6 and CXB2 lymphocytes were stimulated in culture for proliferation with peptides from a CII peptide library. Proliferative response above background was not observed in response to CII peptides in lymphocyte cultures from either mouse strain. 


\section{Development of CII-Specific T Hybridomas}

The absence of proliferative response in both the susceptible and non-susceptible mouse strains expressing I- $\mathrm{A}^{\mathrm{b}}$ prevented identification of an $\mathrm{I}-\mathrm{A}^{\mathrm{b}}$-restricted CII determinant by this method. The difficulty in identification of CII determinants by this method may be an indication of the low immunogenicity of CII, and is consistent with the hypothesis that CII contains low affinity determinants to which $\mathrm{T}$ cell responses are regulated by IFN- $\gamma$. The possibility that CII contains no T cell determinants is not likely due to the fact CIA susceptibility occurs in mice expressing the I- $\mathrm{A}^{\mathrm{b}}$ haplotype, and these mice generate anti-CII antibodies of the IgG class $((69)$ and Fig 3.4, 3.5). Without the presentation of CII derived peptides by $\mathrm{I}-\mathrm{A}^{\mathrm{b}}$-expressing APC to $\mathrm{CD} 4^{+} \mathrm{T}$ cells, it is highly unlikely that CII-specific IgG antibody response would develop.

As a second approach to identifying CII determinants presented by I- $\mathrm{A}^{\mathrm{b}}$, T cell hybridomas were produced from I-A $\mathrm{A}^{\mathrm{b}}$-expressing mice immunized with CII. This method increases the sensitivity of identifying $\mathrm{T}$ cells specific for CII by immortalizing rare $\mathrm{T}$ cells that respond to CII in vivo, and allows large numbers of cells to be screened for antigenic specificity. The minimal in vitro proliferation in response to CII made the production of $\mathrm{T}$ cell hybridomas difficult since only small numbers of proliferating cells were available for fusion. Strategies were developed to optimize the proliferative response to $\mathrm{CII}$ in order to increase the chances for development of T cell hybridoma lines for determinant analysis. Both CIA-susceptible, B6 IFN- $\gamma^{-/-} \mathrm{CXB} 2$, and nonsusceptible, B6, I-A ${ }^{\mathrm{b}}$-expressing strains of mice were immunized with $\mathrm{CII}$ as a source of CII-specific T cells. The pro-proliferative cytokines IL-2 and IL-12 were used in culture or given to mice prior to immunization with CII. $\mathrm{CD}^{+} \mathrm{T}$ cells were sorted by magnetic bead to increase the numbers of CII-specific cells available for recall responses. Finally, highly stimulatory $\mathrm{CD} 11 \mathrm{c}^{+}$activated dendritic cells were purified via magnetic bead from spleens and used as APC to present CII. However, none of these strategies proved successful in producing $\mathrm{T}$ cell hybridomas from $\mathrm{I}-\mathrm{A}^{\mathrm{b}}$-expressing mice that produced IL-2 in response to stimulation with CII.

CXB2, B6, and B6 IFN- $\gamma^{-/}$mice were immunized with bovine CII and lymphocytes were recovered from the draining lymph nodes and re-stimulated for proliferation in vitro with the $\alpha 1$ (II) chain of CII. After three days, the proliferating cells were expanded with IL-2 and fused to $\alpha^{-} / \beta^{-}$BW5147 cells. After selection with G418 a total of 400 clones were produced. The $\mathrm{T}$ cell hybridomas were then screened for CII specificity by stimulation with $\alpha 1$ (II) to induce IL-2 production. Of the $400 \mathrm{~T}$ cell hybridomas produced, a total of ten were found to produce IL-2 in response to stimulation with $\alpha 1$ (II) (Fig 3.11), and all of these came from the CXB2 mice. The production of IL-2 in response to stimulation with $\alpha 1$ (II) indicates that these T cell hybridomas have specificity for CII. This made possible the identification of specific CII determinants by the use of the CII peptide library. 


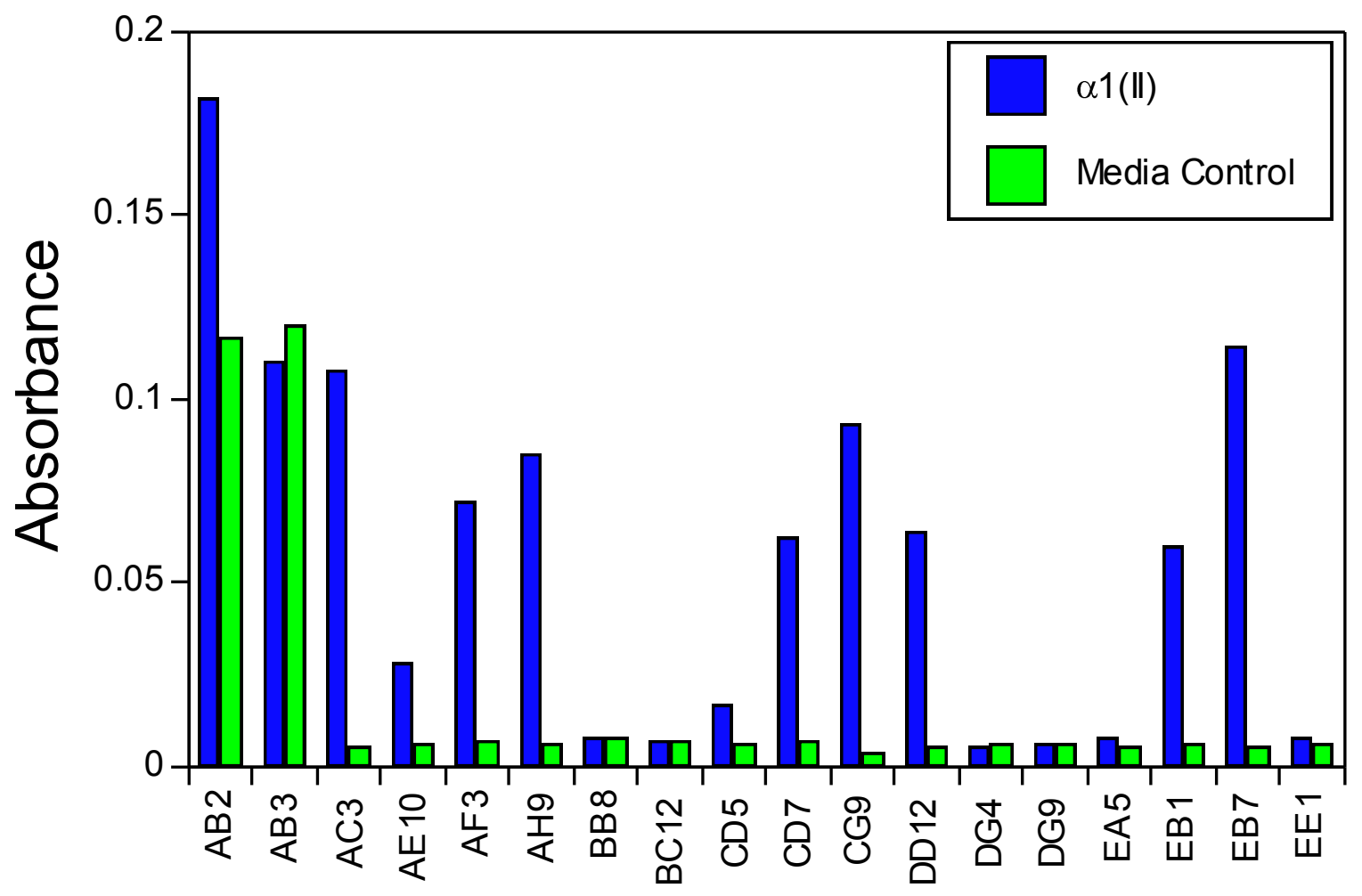

\section{Clone}

Figure 3.11 IL-2 Production by H2-IA ${ }^{\mathbf{b}}$-Restricted T Cell Hybridomas.

Ten $\mathrm{T}$ cell hybridoma clones were produced that possess $\mathrm{T}$ Cell Receptors with specificity for CII determinants. T cell hybridoma cell lines were produced by the fusion of BW5146 cells with T cells obtained from CXB2 mice immunized with native bovine CII. To identify T cell hybridoma cell lines with TCR specificity against CII determinants, IL-2 production by the T cell hybridomas in response to stimulation with $\alpha 1$ (II) was measured by HT-2 cell survival. T cell hybridoma cultures were stimulated with APC plus $\alpha 1$ (II) or media only. After three days, culture supernatants were added to HT- 2 cell cultures, and the survival of HT-2 cells as measured by the production of MTT was assayed by absorbance at 570 minus $690 \mathrm{~nm}$ the following day. Clones AC3, AE10, AF3, AH9, CD5, CD7, CG9, DD12, EB1, and EB7 produced IL-2 in response to stimulation with $\alpha 1$ (II) but not media. This result indicates that these $\mathrm{T}$ cell hybridoma clones possess TCR specific for CII determinants. 


\section{Identification of Determinant}

Production of I-A ${ }^{\mathrm{b}}$-restricted T cell hybridomas specific for CII allowed the use of the CII peptide library to identify CII antigenic determinants. Since the library peptides progressively overlap, the production of IL-2 by the T cell hybridomas stimulated by sequential library peptides also enable identification of the core amino acid sequence of the determinant. The CII-specific T cell hybridomas were subcloned from single cell cultures to produce monoclonal population, and stimulated for IL-2 production with the CII peptide library to identify CII determinants. To do this, the T cell hybridoma clones were mixed together in equal proportions and splenocytes from CXB2 mice were used as APC to present library peptides to the CII responsive T hybridoma cells as shown in Fig 3.12A. IL-2 production by the $T$ cell hybridomas was detected when they were stimulated by peptides 176 and 177, CII(511-526) and CII(514-529), corresponding to the sequences GAQGLQGPRGL(Hyp)GT(Hyp)G and GLQGPRGL(Hyp)GT(Hyp)GTD. These CII peptides were subsequently tested for their ability to stimulate each of the $T$ hybridoma clones (Fig 3.12B). Four of the 10 clones were found to respond to the CII(511-526) and CII(514-529) peptides (Fig 3.12B). The remaining clones were then retested against the CII-library as before, yet none produced IL-2 in response to any of the peptides. The production of IL-2 by the T cell hybridomas in response to peptides covering the CII sequence from amino acid 511-529 indicates that an I-A $\mathrm{A}^{\mathrm{b}}$-restricted CII determinant lies in this region. The $\mathrm{T}$ cell hybridomas that responded to tissue derived $\alpha 1$ (II) but not synthesized peptides may be due to the absence of posttranslational modifications, such as glycosylation, on the synthesized peptides.

\section{The Core Binding Determinant for the I- $A^{b}$ T Hybridomas IS CII(517-525) GPRGLPGTP}

The first domains of the two subunits of the MHC class II molecule form an open ended groove in which peptides bind and are presented to T cells. The nature of this peptide MHC interaction is such that a core nine amino acid sequence binds within the groove with the remaining amino acid residues extending out the open ends of the binding groove. Analysis of the structure of the MHC class II molecules and the peptides that bind to them has led to the conventional identification of 4 to 5 binding pockets referred to as $\mathrm{p} 1, \mathrm{p} 4, \mathrm{p} 6, \mathrm{p} 7$, and $\mathrm{p} 9$. The number of the pocket corresponds to the amino acid residue of the core determinant that fits into the respective pocket. Correspondingly, there are several amino acid residue side chains that are oriented toward the interface with the TCR - residues 2, 3, 5, and 8 . Analysis of different epitopes that can bind the I- $\mathrm{A}^{\mathrm{b}}$ molecule has resulted in the identification of a binding motif for this class II molecule. For the I-A $\mathrm{A}^{\mathrm{b}}$ molecule, large hydrophobic, aromatic, or aliphatic side chains usually fill the $\mathrm{p} 1$ pocket. Pockets $\mathrm{p} 4, \mathrm{p} 6$, and $\mathrm{p} 9$ bind neutral to hydrophobic residues with small side chains preferred. Pockets $\mathrm{p} 4$ and $\mathrm{p} 6$ exclude aromatic and charged side chains. Finally, $\mathrm{I}_{-} \mathrm{A}^{\mathrm{b}}$ can accommodate the lack of side chains in the p1, p4, p6, and p9 pockets due to strong $\mathrm{N}$ terminal and $\mathrm{p} 7$ interactions $(103,104)$.

The response of the T cell hybridomas to only peptides 176 and 177 indicates that the core CII sequence that binds I-A ${ }^{\mathrm{b}}$ is located within the 12 amino acid overlap of these two peptides, corresponding to CII(514-525) (Fig 3.13). However, the size of the 

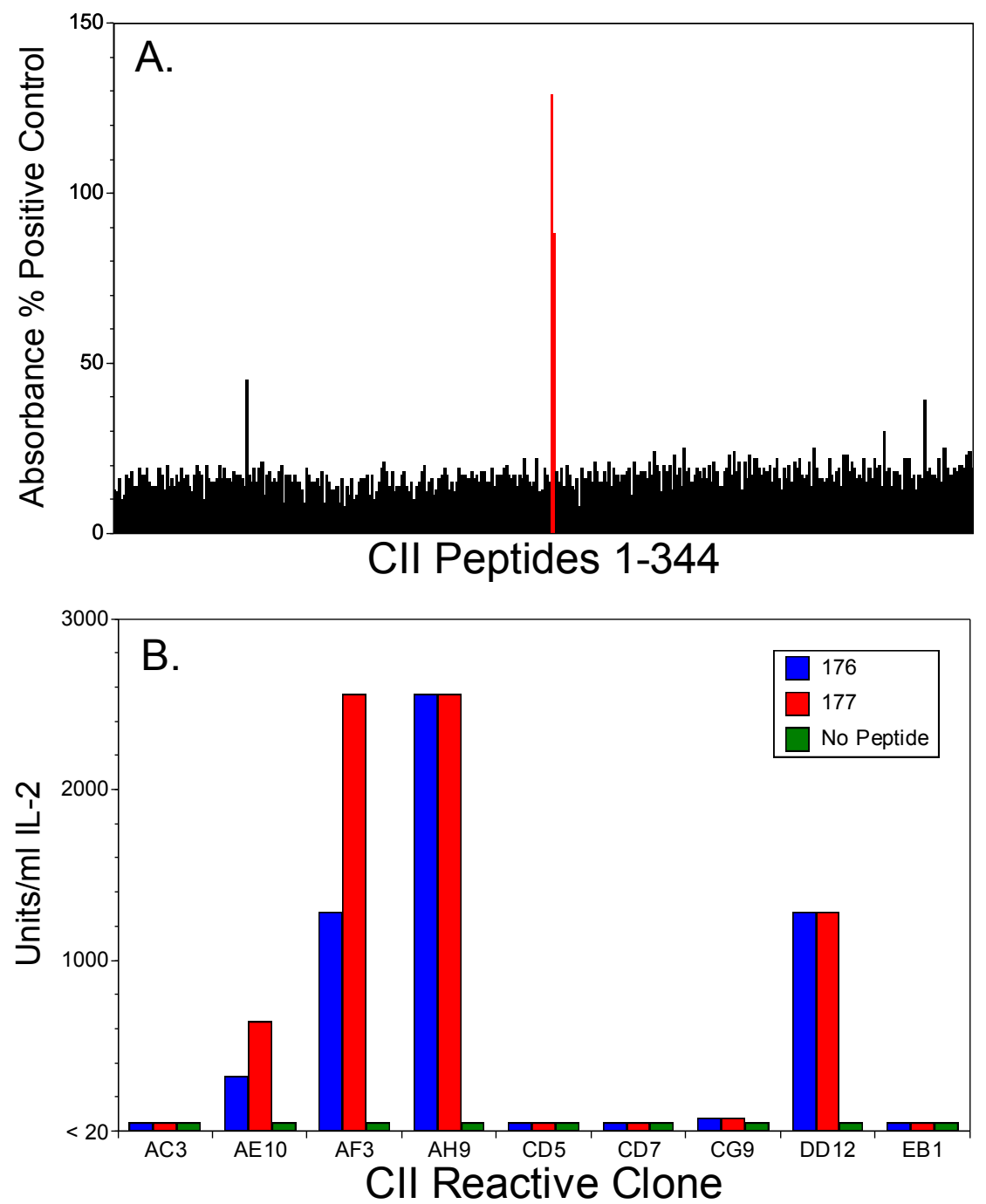

\section{Figure 3.12 IL-2 Production by $\mathbf{I}_{-} \mathrm{A}^{\mathrm{b}}$-Restricted $\mathrm{T}$ Cell Hybridoma Clones in Response to Stimulation with CII-Library Peptides.}

Stimulation of CII-specific T cell hybridomas with an overlapping CII peptide library allowed the identification of an I-A ${ }^{b}$-restricted CII determinant. A. The ten T cell hybridomas that produced IL-2 in response to CII were mixed together and stimulated with a CII peptide library. IL-2 production by the T cell hybridomas was then assayed by HT-2 cell survival as determined by the production of MTT. Data is expressed as the absorbance at 570 minus $690 \mathrm{~nm}$ of experimental wells compared to positive control containing $62 \mathrm{ng} / \mathrm{ml}$ IL-2. Two peptides promoted the production of IL-2 by those cells, peptides 176 and 177 corresponding to the CII sequence from 511-528. B. Each T cell hybrid was then tested individually to the stimulatory peptides. Of the ten T cell hybridoma cell lines, four produced IL-2 in response to the two peptides. Six of the hybrids respond to native CII, but not to peptide. To find units $/ \mathrm{ml}$ of IL- 2 supernatants from $\mathrm{T}$ cell hybridoma cultures were serially diluted in cultures of HT-2 cells. The dilution of T cell hybridoma supernatants that supported HT-2 cell survival is the units/ml of IL-2. 


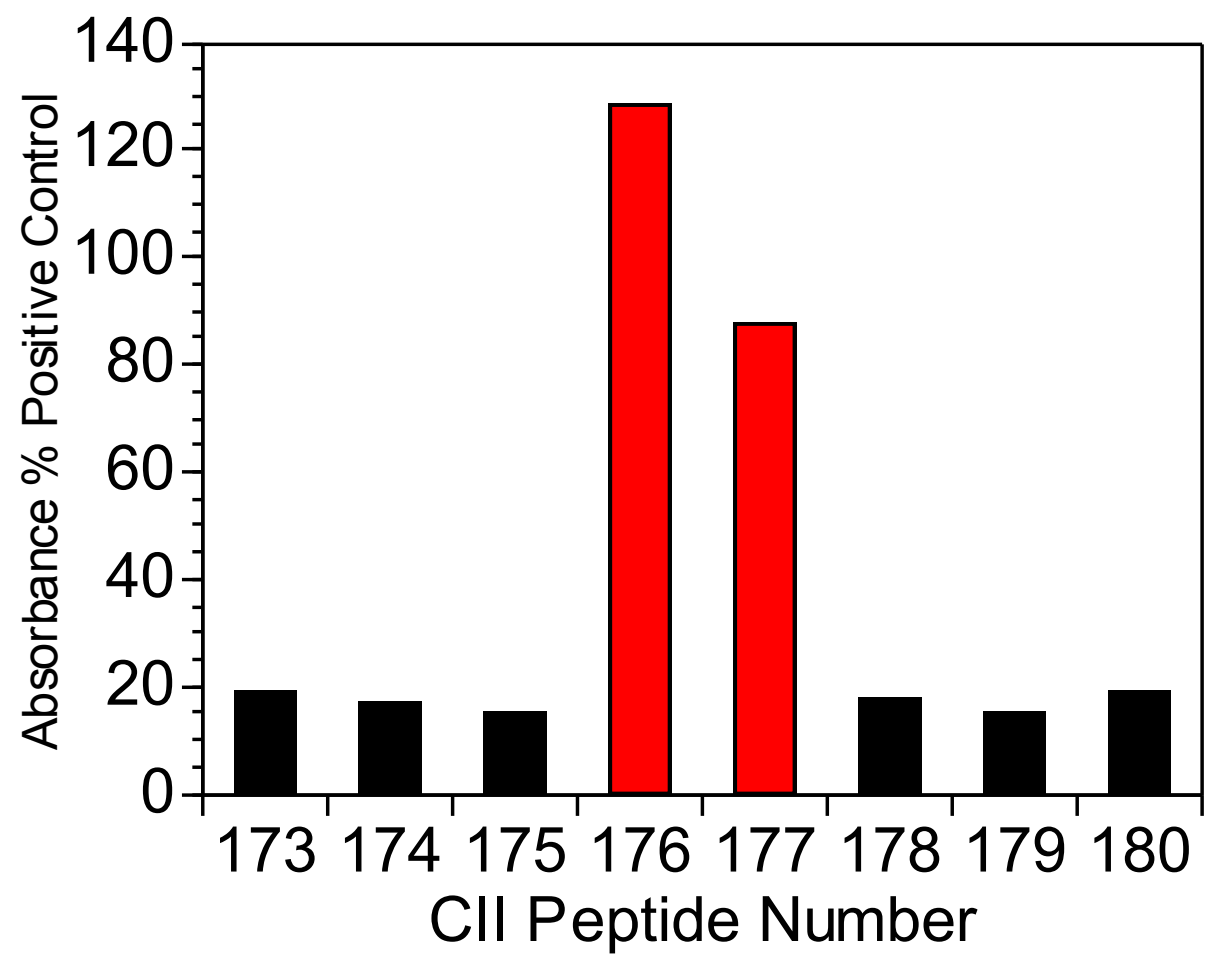

175 GSBGAQGLQGPRGLB

176

177

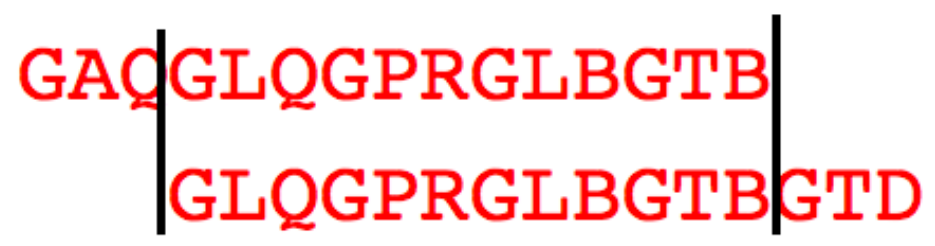

178

GPRGLBGTBGTDGPK

Figure 3.13 The I-A ${ }^{\mathbf{b}}$-Restricted CII Determinant.

Stimulation of T cell hybridomas with the CII-library peptides 176 and 177 induces IL-2 production as measured by HT-2 cell survival, highlighted in red. These peptides correspond to CII(511-528). Due to the overlapping progression of amino acid residues among the library peptides, there is a 12 amino acid stretch that is common to both of the stimulatory peptides 176 and 177, CII(514-525). Since these two peptides stimulate the T cell hybridomas and peptides 175 and 178 do not, it can be inferred that within these 12 amino acid residues a determinant capable of binding $I-A^{b}$ and stimulating the $T$ cell hybridomas is present. The nonstandard amino acid residue hydroxyproline is converted from proline residues by the enzyme prolyl hydroxylase whenever the motif GXP occurs in collagen. In this figure, hydroxyproline is represented with the letter B. 
binding groove within the MHC class II molecule is only large enough to contact directly with a nine amino acid long determinant, which is referred to as the "core". To determine the core residues that bind the MHC class II molecule and to further characterize the interaction of the peptide in the $\mathrm{T}$ cell receptor complex, a set of 15 analog peptides covering the CII sequence present in the two stimulatory peptides was produced with an alanine residue substituted at each position. This set of peptides was then used to stimulate the CII-reactive T cell hybridoma cells. When stimulated with alanine substituted peptides, IL-2 production by the four T cell hybridoma clones was reduced in two distinct clonotypic patterns. In clones AF3 and AE10 T cell hybridoma stimulation as measured by IL-2 production was reduced, starting with the Gln at position 516 and extending to the Thr at position 524 excluding the two Gly at 517 and 523 (Fig 3.14AB). In clones AH9 and DD12 the pattern is similar but extends from the Pro at position 518 to the Thr at position 524 (Fig 3.14CD). This reduction in stimulation indicates that the residues located from 516 to 524 are required for stimulation of the T cell hybridomas and likely represent the core of the determinant that interacts with the binding groove of the I-A $\mathrm{A}^{\mathrm{b}}$ molecule. These data also imply that these $\mathrm{I}-\mathrm{A}^{\mathrm{b}}$-restricted $\mathrm{T}$ cell hybridomas utilize at least two clonally different TCR in their recognition of the CII peptide.

To find the relative contribution of each residue in stimulating the $\mathrm{T}$ cell hybridomas, titration experiments were performed (Fig 3.15). In all four clones, stimulation of the $\mathrm{T}$ cell hybridomas was highly dependent on the 5 residues from 518 to 522, PRGLHyp. When these residues were individually substituted with Ala there was no measurable IL-2 production even at the highest concentration of peptide. These data indicate that these residues are required for formation of the I- $\mathrm{A}^{\mathrm{b}} / \mathrm{peptide} / \mathrm{TCR}$ complex, and these are likely part of the determinant core. The Gln at position 516 and the Thr at position 524 when substituted with Ala resulted in decreased stimulation of the T hybridomas upon titration at a rate that exceeded the control, and therefore indicates that these two residues also play a prominent role in the stimulation of these $\mathrm{T}$ cell hybridomas. Ala substitutions of the remaining residues had little effect on antigen presentation indicating that these amino acid residues are likely not key contact points within the ternary complex. When the sequence of this core determinant of CII(517525), GPRGLHypGTHyp, is compared to the published motif for I- $\mathrm{A}^{\mathrm{b}}$ it is observed that only one frame of the amino acid sequence fits well with the binding pockets located at $\mathrm{p} 1, \mathrm{p} 4, \mathrm{p} 6, \mathrm{p} 7$, and $\mathrm{p} 9$. This frame includes the Gly at positions 517 and 520 filling pockets $\mathrm{p} 1$ and $\mathrm{p} 4$, and the Hyp at positions 522 and 525 filling the $\mathrm{p} 4$ and $\mathrm{p} 9$ pockets. The two Gly have small side chains and one would not expect them to make large contributions to the overall binding of the determinant, although side chains from the I- $\mathrm{A}^{\mathrm{b}}$ molecule may make contact with the backbone of the peptide at these locations, thus helping to stabilize the binding. This may be why the Gln at position 516 is required for stimulation of the $\mathrm{T}$ cell hybridoma clones even though it lies outside of the core determinant. Since MHC class II contains an open ended binding groove amino acids outside of the core region can contribute to binding stability or TCR interaction. In addition the sensitivity of $\mathrm{T}$ hybridoma stimulation to Ala substitution is potentially an indication of low stability of the CII determinants interaction with the I-A $\mathrm{A}^{\mathrm{b}}$ molecule, as individual Ala substitution at six of the nine core residues strongly reduces $\mathrm{T}$ cell hybridoma stimulation. 


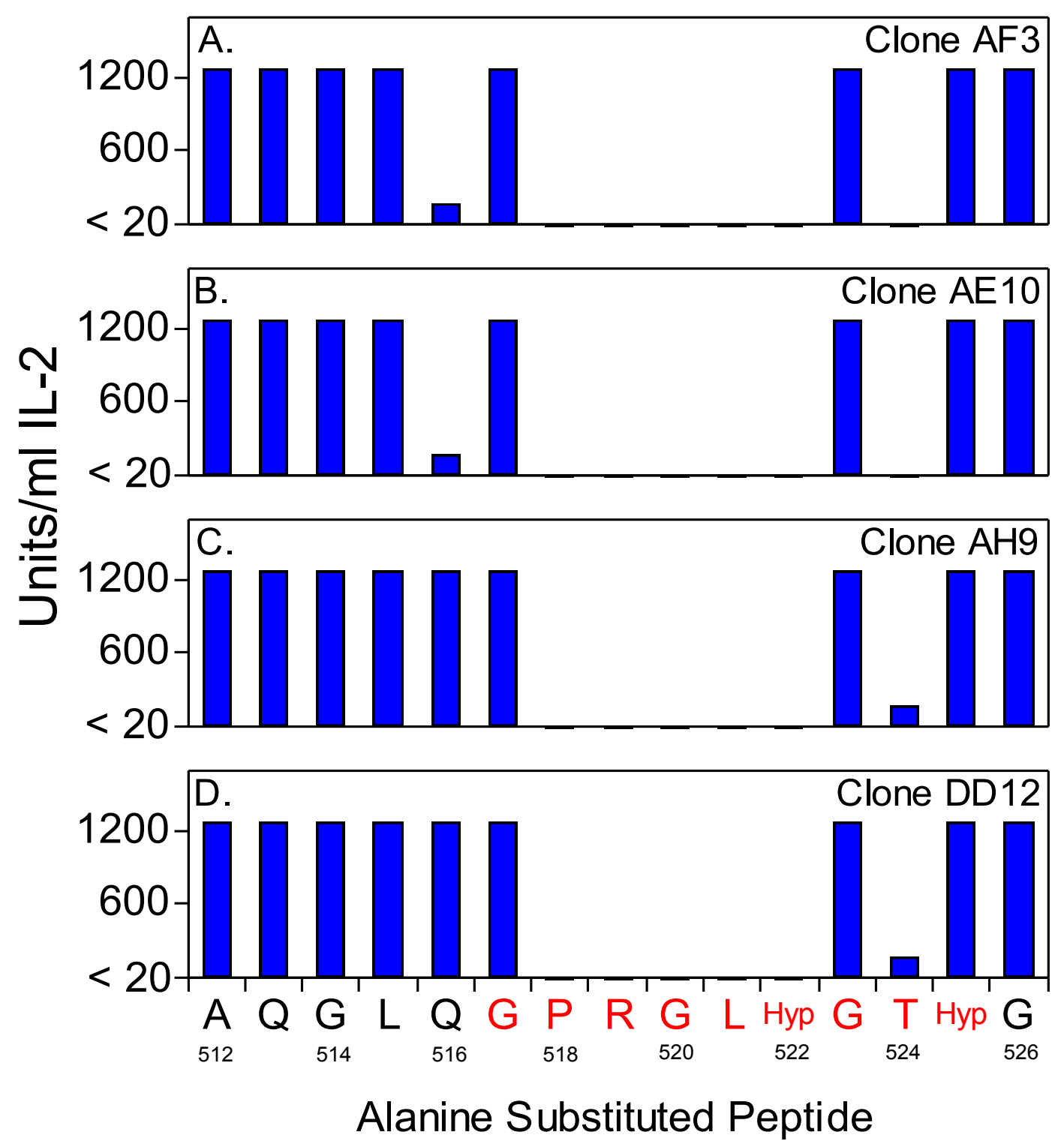

Figure 3.14 IL-2 Production by CII-Reactive T Cell Hybridomas in Response to Stimulation with Alanine Substituted CII(512-526).

CII-reactive clones were stimulated for IL-2 production using alanine substituted peptides covering the CII(512-526) determinant previously shown to stimulate these CII-specific clones. AB. Clones AF3 and AE10 show reduced IL-2 production when stimulated with APC and $50 \mu \mathrm{g}$ peptides with substitutions Q515A, P517A, R518A, G519A, L520A, Hyp521A, and T523A. CD. Clones AH9 and DD12 show reduced IL-2 production when stimulated with APC and $50 \mu \mathrm{g}$ peptides with alanine substituted at P517A, R518A, G519A, L520A, Hyp521A, and T523A. The failure to promote IL-2 production when these residues are substituted with alanine, which has no significant side chain, shows the relative importance of these residues in the TCR complex. The core determinant for these clones and $\mathrm{H} 2-\mathrm{IA}^{\mathrm{b}}$ binding lies in this region, highlighted in red. 


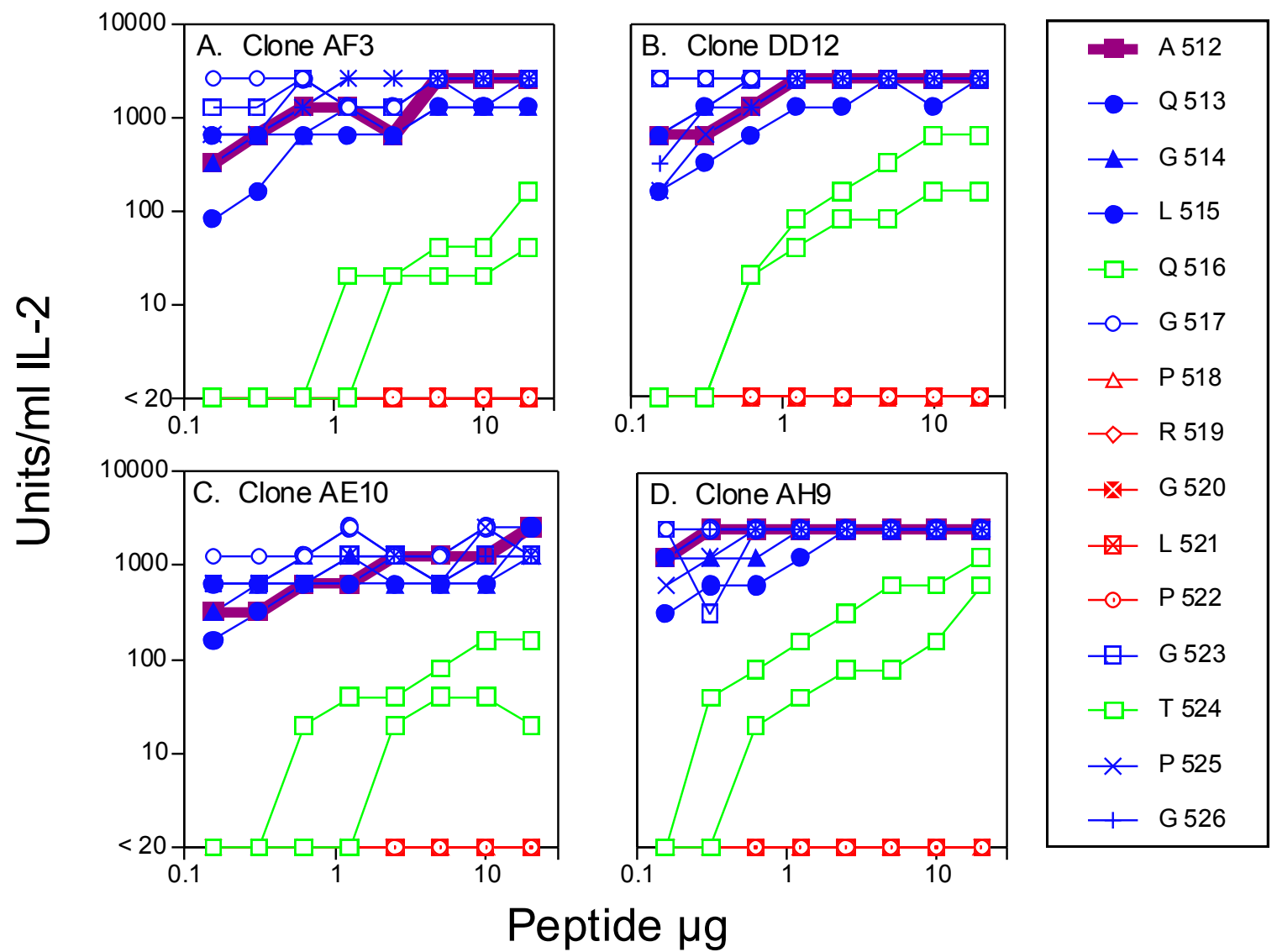

\section{Figure 3.15 Stimulation of CII-Specific I-A $\mathrm{A}^{\mathrm{b}}$-Restricted T Cell Hybridomas by Titrated Alanine Substituted Determinant Peptides.}

Substitution with alanine affects the concentration at which the CII(512-526) determinant is capable of stimulating IL-2 production in the CII-specific T hybridomas. Production of IL-2 by alanine substituted peptides was measured by HT-2 cell survival in wells titrated with the supernatants of co-cultures of CII-specific T cell hybridomas, I- $\mathrm{A}^{\mathrm{b}}$-expressing APC, and alanine substituted peptides of various concentrations. The ability of each peptide to promote IL-2 production by the T cell hybridoma was compared to the native sequence A512. Q513, G514, L515, G517, G523, P525, and G526 (blue) all resulted in titration curves that were similar to the control (purple). P518, R519, G520, L521, and P522 (red) did not stimulate IL-2 production at any measured concentration. Two peptides, Q516 and T524 (green), required higher concentrations than the control to stimulate IL-2 production. This indicates that these two peptides bind the TCR complex at lower affinity than the control bovine CII peptide, indicating that these residues are key contact points within the TCR complex. 


\section{I-A ${ }^{b}$-Restricted Cellular Responses to CII Determinant}

\section{Proliferative Response}

Having identified an $\mathrm{I}-\mathrm{A}^{\mathrm{b}}$-restricted determinant present in CII, the ability of this determinant to stimulate $\mathrm{T}$ cell proliferative responses was examined. This is especially significant given that the previous measurements of proliferative response against nativeCII and $\alpha 1$ (II) failed to exhibit measurable responses. For these experiments, two peptides were synthesized that covered the core binding region of the determinant peptide, CII(512-526) and CII(512-528). These two peptides were chosen based on the core determinant identified by the $\mathrm{T}$ cell hybridomas. Often, peptides that contain only the core determinant exhibit reduced immunogenicity, and in the CII(512-526) peptide, the core CII determinant is only one residue removed from the end of the peptide. Therefore to increase the immunogenicity of the peptide, two residues were added to the $\mathrm{C}$ terminus to make the CII(512-528) peptide. CXB2 mice were immunized with $\mathrm{CII} / \mathrm{CFA}$ and lymphocytes were recovered from the draining lymph nodes ten days later. These lymphocytes were then stimulated for four days and proliferation was measured by ${ }^{3} \mathrm{H}$-thymidine incorporation. Following immunization with CII, neither peptide elicited an in vitro proliferative response by the T cells from the CXB2 mouse (Fig 3.16A). While these data are similar to the lack of proliferative responses we observed in our earlier studies (Fig 3.7), we had hoped that the longer version of this CII peptide would enhance its ability to re-stimulate T cells in vitro. As a second approach to demonstrating the immunogenicity of this peptide, mice were immunized with the peptides and their $\mathrm{T}$ cells were tested for their ability to proliferate in vitro. To increase the concentration of CII-specific T cells in the recall assay, enrichment of $\mathrm{CD} 4{ }^{+}$cells was performed via magnetic bead separation. Cells were obtained from the draining lymph nodes and stimulated in culture with either CII(512-526) or CII(512-528). As shown in Fig 3.16B, proliferation was not stimulated by the shorter CII(512-526) peptide in either mouse, but in the B6 mouse significant proliferation was induced by the longer CII(512-528) peptide (Fig 3.16CD).

The advent of recall proliferation against the longer CII(512-528) peptide in the B6 mouse, and in both the B6 and CXB2 mouse following enrichment of CD4 ${ }^{+} \mathrm{T}$ cells indicates that the determinant sequence identified by the $\mathrm{T}$ cell hybridomas was capable of stimulating $\mathrm{T}$ cell proliferation in vivo. The absence of proliferative responses against native CII may be a consequence of the determinant acting as a weak antigen requiring the use of enrichment steps to detect low in vivo responses of effector $\mathrm{T}$ cells. In addition, the differential response of the CII(512-526) peptide versus the CII(512-528) peptide highlights the contribution of amino acids beyond the core determinant to I- $\mathrm{A}^{\mathrm{b}}$ binding or TCR binding of the I-A $\mathrm{b} /$ peptide complex. In the shorter peptide the sequence extends only one amino acid beyond the core, whereas in the longer peptide there are three amino acids beyond the core determinant. It appears that the addition of these amino acids increased the potency of this peptide, raising $\mathrm{T}$ cell immune response to detectable levels. 

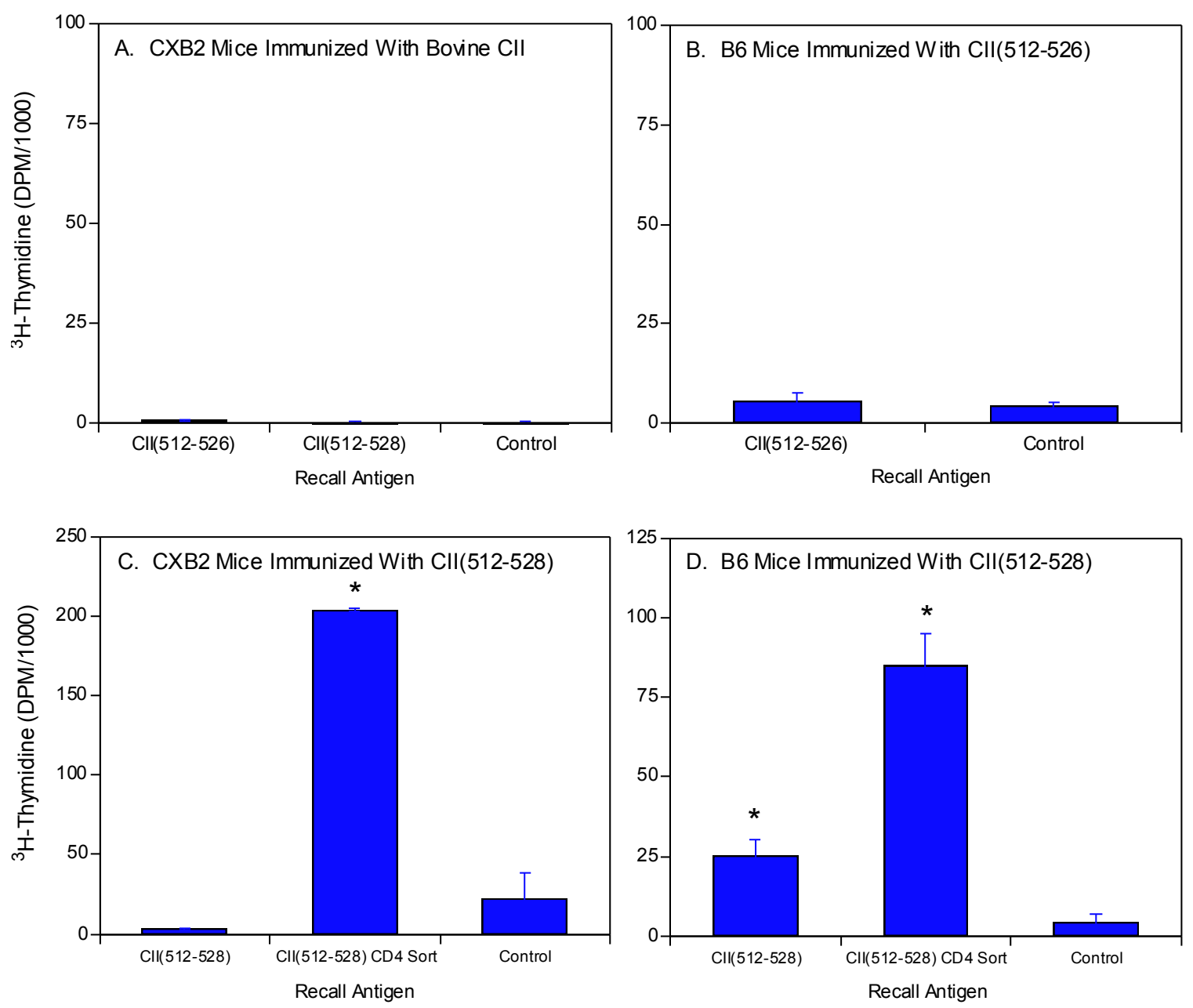

Figure 3.16 Proliferative Response of Lymphocytes from I-A ${ }^{\mathbf{b}}$-Expressing Mice Stimulated with CII Determinants.

When I-A ${ }^{\mathrm{b}}$-expressing mice were immunized with native bovine CII, CII(512-526), or CII(512-528) in CFA emulsion and the draining lymph nodes were recovered ten days later. These cells were then stimulated in culture for proliferation with the CII determinants CII(512-526) and CII(512-528) with or without enrichment of $\mathrm{CD}^{+}$by magnetic bead cell sorting. A. When native CII is used as the immunogen, lymphocytes from CXB2 mice do not proliferate as measured by ${ }^{3} \mathrm{H}$-thymidine incorporation when stimulated with CII(512-526) or CII(512-528). B. When CII(512-526) is used as both the immunogen and the stimulating antigen, lymphocytes from B6 mice do not proliferate. C. When CXB2 mice were immunized with CII(512-528) proliferation in response to stimulation with $\mathrm{CII}(512-528)$ was not observed. However, when these cells were enriched for $\mathrm{CD}^{+}$cells proliferation in response to stimulation with $\mathrm{CII}(512-528)$ was induced. D. When B6 mice were immunized with the longer CII(512-528) determinant stimulation with $\mathrm{CII}(512-528)$ induced proliferation. Proliferation was increased three fold when the lymphocytes were enriched for $\mathrm{CD}^{+}$cells by magnetic bead cell sorting. The control shown represents lymphocytes that were sorted for $\mathrm{CD}^{+}$ cells but not stimulated with $\operatorname{CII}(512-528) .\left({ }^{*} \mathrm{p}<0.01\right)$ 
Recently, chicken derived CII has been identified as arthritogenic in B6 mice when used in place of bovine CII to immunize mice for induction of CIA $(105,106)$. Examination of the CII sequences for mouse, bovine, human, and chicken CII indicated that the bovine sequence differs in two places from the human, mouse, and chicken sequences in the 512-528 peptide. In the bovine sequence, position 512 is serine compared to alanine in the other three species. At position 518 the bovine sequence is an alanine compared to proline in the human, mouse, and chicken sequences (Fig 3.17). Based on our current model, the alanine at position 518 is the $\mathrm{p} 2$ residue of the determinant, a position that likely serves as a TCR interaction site (Fig 3.14). The alanine in the bovine sequence may explain the low proliferative response when native bovine $\mathrm{CII}$ is used as the immunogen for in vitro proliferation assays (Fig 3.6, 3.7, 3.16AB).

To test the immunogenicity of native chicken $\mathrm{CII}$ versus native bovine $\mathrm{CII}$ in $\mathrm{I}-\mathrm{A}^{\mathrm{b}}$-expressing mice, CXB2 mice were immunized with chicken or bovine CII in CFA and proliferative responses against the two synthetic peptides and bovine $\alpha 1$ (II) were measured by ${ }^{3} \mathrm{H}$-thymidine incorporation using cells obtained from the draining lymph nodes of the immunization site. When immunized with chicken CII, recall proliferative responses were observed against both synthetic peptides CII(512-526) and CII(512-528). No proliferation was seen in response to recall with bovine $\alpha 1$ (II). When bovine CII was used as the primary antigen no proliferation was observed upon recall with either CII peptides, CII(512-526) and CII(512-528), or against the bovine $\alpha 1$ (II) (Fig 3.18). These results may explain the differential susceptibility to CIA when CII produced from different sources, chicken or bovine, is used as the immunogen to induce CIA. Bovine $\mathrm{CII}$ contains an alanine at a key binding location, $\mathrm{p} 2$ of the core determinant, and this apparently reduces the immunogenicity of $\mathrm{CII}$ in the $\mathrm{I}-\mathrm{A}^{\mathrm{b}}$ background as evidenced by the reduction in stimulation of the $\mathrm{T}$ cell hybridomas using the alanine analog. In contrast, the chicken $\mathrm{CII}$ at that location contains a proline, which appears to increase the immunogenicity of the I-A $\mathrm{A}^{\mathrm{b}}$-restricted CII determinant (Fig 3.15). This may explain why wild type B6 mice develop CIA when immunized with chicken CII and not with bovine CII. However, in B6 IFN- $\gamma^{-/-}$mice, bovine CII, of low antigenic potential, is capable of inducing CIA due to disregulation of immune function as a result of the absence of IFN- $\gamma$. In contrast, in the wild type mouse chicken derived CII, a stronger antigen than bovine CII, is capable of stimulating a pathogenic immune response in a normal immune background.

\section{Induction of Tolerance by CII Determinant}

In order to demonstrate the significance of the I-A $\mathrm{A}^{\mathrm{b}}$-restricted peptide in driving the development of autoimmunity, we used the 512-528 peptide to induce tolerance in B6 mice and protect them from arthritis. This protection occurs via active suppression or via clonal deletion of CII-reactive $\mathrm{CD} 4^{+} \mathrm{T}$ cells (107-110). If the CII(512-528) determinant is the sequence to which self-reactive $\mathrm{T}$ cells respond during the pathogenesis of CIA then pre-administration of $\mathrm{CII}(512-528)$ to $\mathrm{CXB} 2$ mice should inhibit $\mathrm{T}$ cell responses in these mice and therefore protect from CIA. To induce tolerance, $200 \mu \mathrm{g}$ of CII(512-528) dissolved in PBS or PBS alone was injected into the orbital plexus of CXB2 mice. Three 


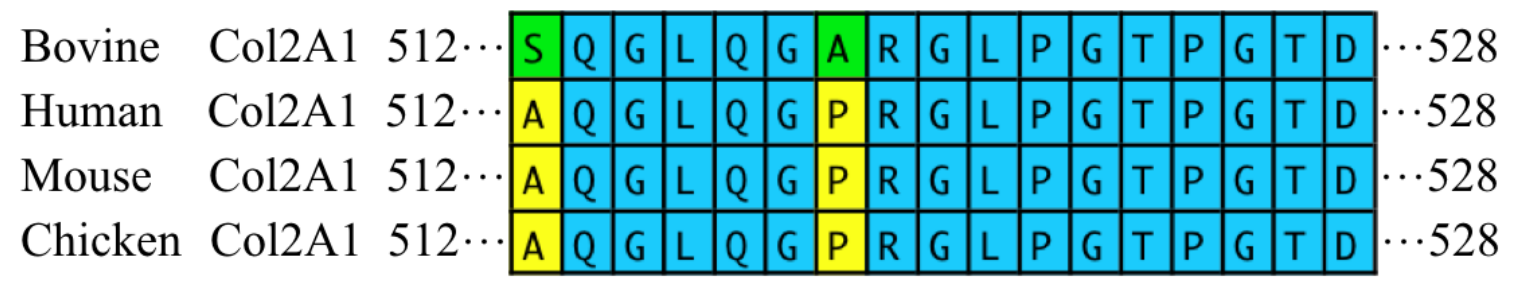

Figure 3.17 CII-Determinant Sequence Homology.

Human, mouse, and chicken CII have identical sequence from amino acid number 512 to 528 in contrast to the bovine sequence which contains two mutations: A512S and P518A. 


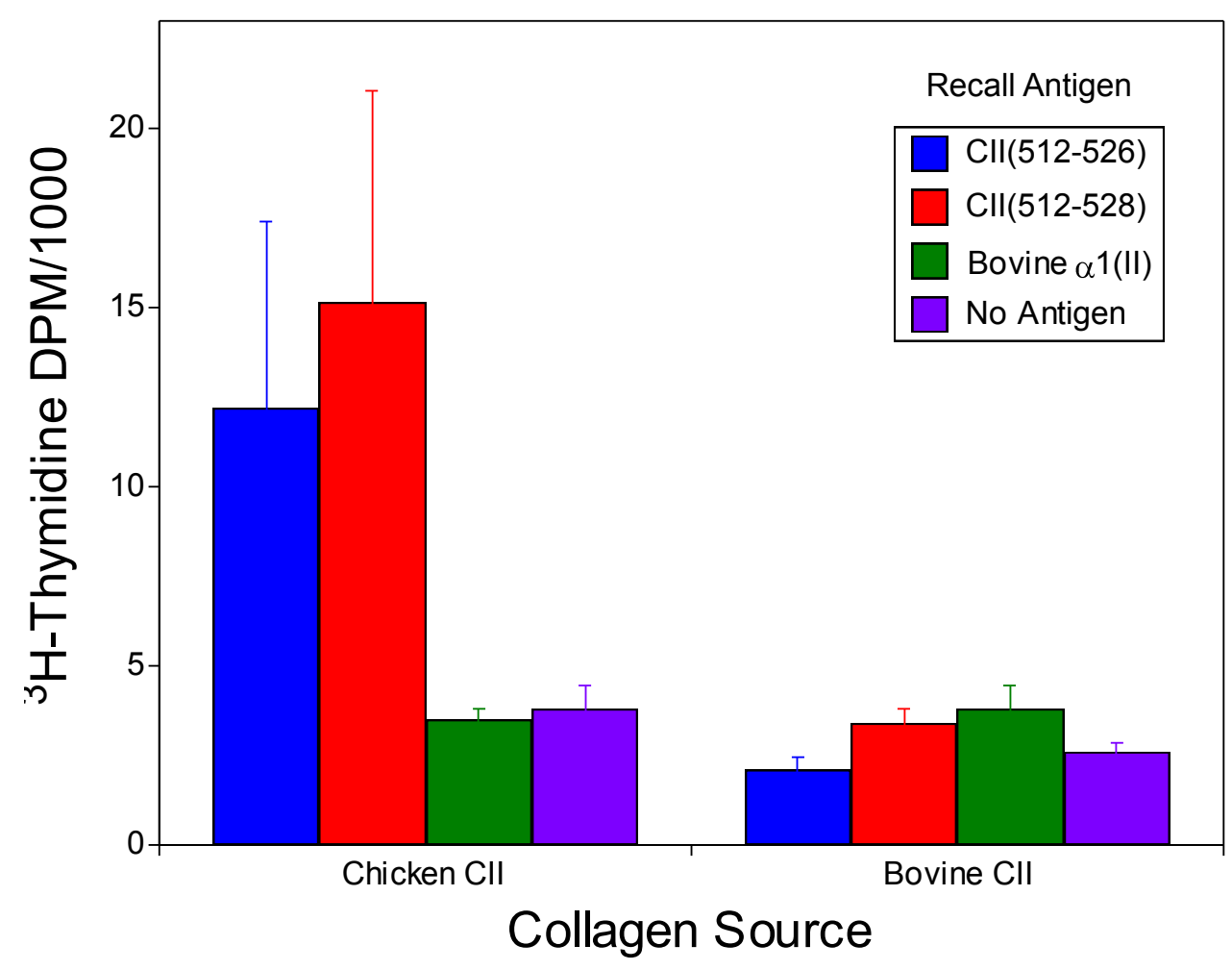

Figure 3.18 Proliferation in Response to Stimulation with CII Antigens in Lymphocytes from $\mathbf{I}-\mathrm{A}^{\mathrm{b}}$-Expressing Mice Immunized with Native Chicken or Bovine CII.

Following immunization with CII lymphocytes obtained from CXB2 mice do not proliferate when stimulated in culture with CII(512-526), CII(512-528), or bovine $\alpha 1$ (II). When the immunizing antigen is chicken derived CII, proliferative responses are observed following stimulation both $\mathrm{CII}(512-526)$ and $\mathrm{CII}(512-528)$ but not bovine $\alpha 1(\mathrm{II})$. 
days later the mice were immunized with CII/CFA emulsion and monitored for development of arthritis. The PBS control group developed arthritis at 50\% incidence and achieved a maximum severity score of 4.3. The mice tolerized with CII(512-528) developed arthritis at $29 \%$ incidence and achieved a maximum severity score of 3.0. In addition, arthritis in these mice developed at a later time point compared to the PBS control mice developing arthritis on days 45 and 38, respectively (Fig 3.19). The inhibitory effect of CII(512-528) on the development of CIA indicates that this CII determinant is an important component in the $\mathrm{T}$ cell autoimmune response that drives CIA pathogenesis in $\mathrm{I}_{-} \mathrm{A}^{\mathrm{b}}$-expressing mice.

\section{Measurement of Binding Affinity of CII Determinants for I-A}

In order to test the hypothesis that IFN- $\gamma$ regulates weak $\mathrm{T}$ cell responses, the affinity of CII determinants for the I-A ${ }^{b}$ molecule was measured. Two experimental systems were used to identify the affinity of CII determinants for I-A ${ }^{\mathrm{b}}$. The first was a bioinformatic approach that used an algorithm based peptides known to bind I-A ${ }^{\mathrm{b}}$ to calculate the binding affinity for $\mathrm{I}-\mathrm{A}^{\mathrm{b}}$ of discrete peptides present in the CII molecule. In the second approach, CII-library peptides and known I- $\mathrm{A}^{\mathrm{b}}$ binding peptides were used to competitively bind a recombinant soluble form of $\mathrm{I}-\mathrm{A}^{\mathrm{b}}$. However, for various reasons these experiments were not entirely successful and yielded inconclusive data about the nature of CII binding to I- $\mathrm{A}^{\mathrm{b}}$. A complete description of this data is located in the Appendix.

\section{Discussion}

Examination of immune function in IFN- $\gamma$ B6 mice did not reveal major defects in the immune function in response to immunization with CII/CFA emulsion. When cell subset analysis was performed, large alterations in $\mathrm{B}$ cell and $\mathrm{T}$ cell numbers were not observed. $\mathrm{T}_{\mathrm{h}}$ and $\mathrm{T}_{\mathrm{c}}$ populations were also similar between CII-immunized wild type and IFN- $\gamma^{-/-}$mice, as there were only minor differences in $\mathrm{CD}^{+}$and $\mathrm{CD} 4^{+} \mathrm{T}$ cell percentages. Despite previous indications that IFN- $\gamma$ deficient mice have increased $\mathrm{T}$ cell proliferative responses (65), increases in $\mathrm{T}$ cell proliferation in response to stimulation with native CII were not observed. This may be due to CII being a low affinity antigen for I-A ${ }^{b}$, thus stimulating a weak $\mathrm{T}$ cell response that is below our method of detection. The major differences in immune function following immunization with CII/CFA in the IFN- $\gamma^{-/-}$ mouse appear to be changes in anti-CII antibody and cytokine production. When serum concentrations of anti-CII antibodies were measured, the levels in IFN- $\gamma^{-/}$B6 mice were increased in comparison to the wild type B6 response. There were also changes in the anti-CII IgG subtype in the IFN- $\gamma^{-/-}$mouse. While IFN- $\gamma$ is known to induce Ig class switching to the IgG2a subclass B6 mice do not express IgG2a, instead, they express IgG2c. When anti-CII Ig subclasses were measured by ELISA there was no significant decrease in anti-CII IgG2c production compared to the wild type B6 mice as might be expected due to the absence of IFN- $\gamma$. However, there was a large increase in the production of anti-CII IgG2b. This subclass of Ig has both complement fixing activity 

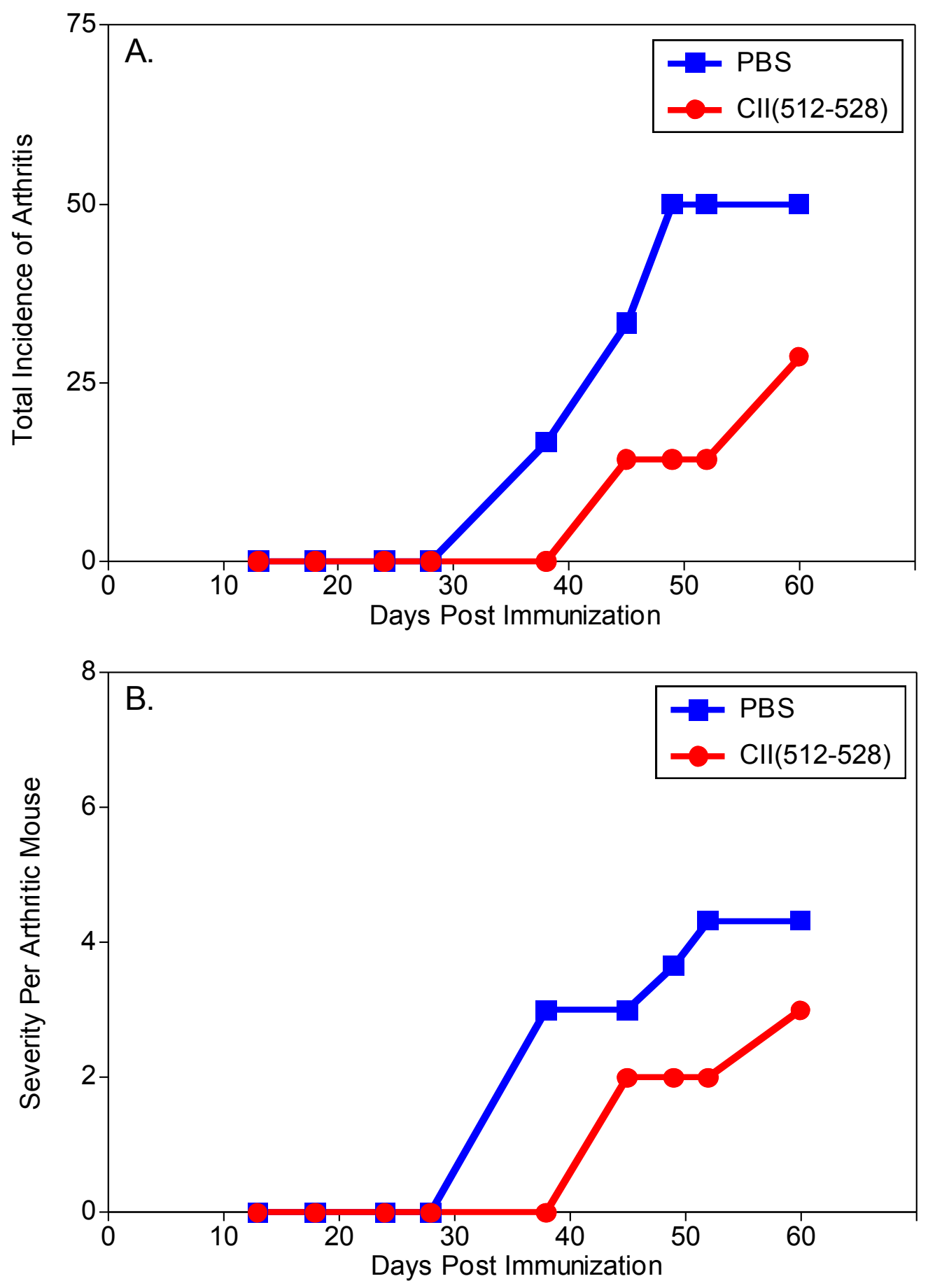

Figure 3.19 Tolerization of CIA-Susceptible CXB2 Mice with CII-Determinant Peptide.

Prior to immunization with bovine $\mathrm{CII}$ in CFA emulsion $\mathrm{CXB} 2$ mice were injected intravenously with CII(512-528) or PBS to induce tolerance. A. Mice tolerized with CII(512-528) develop arthritis at lower instance and on a delayed schedule than control mice injected with PBS. B. Mice tolerized with CII(512-528) develop arthritis at a lower severity than control. 
and binds to the high affinity Fc $\gamma$ RIII, promoting activation of immune cells. In addition anti-CII antibodies of the IgG2b subclass are capable of inducing arthritis when used in antibody induced arthritis models (99).

The major change in immune response of IFN- $\gamma^{-/-}$B6 mice that occurs following immunization with CII/CFA that potentially promotes the development of autoimmunity appears to be disregulated cytokine production. This is consistent with the hypothesis that as a regulatory cytokine, IFN- $\gamma$ directs the nature of the immune response and in its absence disregulation occurs that is permissive to the development of autoimmunity. The cytokine milieu is of paramount importance during the initial stages of an immune response. The cytokines present during this stage can direct the type of T cell immune response that occurs. This is due in part to the self-reinforcing nature of immune responses. For example, $\mathrm{T}$ cells of the $\mathrm{T}_{\mathrm{h}} 1$ phenotype proliferate and produce the proinflammatory cytokines IL-2 and IFN- $\gamma$. These cytokines feed back to both drive expansion of $T_{h} 1$ response and inhibit $T_{h} 2$ response. This is also true of $T_{h} 2$ responses where the production of IL- 4 and IL-10 feed back to reinforce $T_{h} 2$ responses and inhibit $\mathrm{T}_{\mathrm{h}} 1$ responses. Though in some aspects an immune response is self-reinforcing, it is also true that normal immune responses are self-limiting. As the immune response progresses, immune mechanisms such as anergy and the activation of $\mathrm{T}_{\text {reg }}$ cells can come into play to halt the unrestricted development of an immune response. It is in this selflimiting process that the absence of IFN- $\gamma$ may result in the progression of autoimmunity in the IFN- $\gamma^{-/-}$B6 mouse. We propose that the absence of IFN- $\gamma$ has altered the immune response to such an extent that self-limiting mechanisms are impaired and autoimmunity develops. We see an indication that this disregulation occurs when the cytokines produced in response to T cell stimulation in cells from IFN- $\gamma^{-/-} \mathrm{B} 6$ mice were quantitated. In cultures of these cells there is greatly increased production of cytokines associated with all three effector $T$ cell subsets, $T_{h} 1, T_{h} 2$, and $T_{h} 17$. Cytokines such as IL-2, IL-4, IL-5, IL-13, and IL-17, as well as proinflammatory cytokines downstream of these cytokines IL-1 $\beta$, TNF- $\alpha$, M-CSF, and GM-CSF, are all overproduced in comparison to the $\mathrm{T}$ cells from $\mathrm{B} 6$ mice. It is interesting to note that cytokines associated with all three $T_{h}$ subclasses of $T$ cells are upregulated. In the absence of IFN- $\gamma$ one would expect increases in $T_{h} 2$ and $T_{h} 17$ responses, however, the production of IL-2, IL-1 $\beta$, TNF- $\alpha$, M-CSF, and GM-CSF following stimulation of T cells indicates that even $T_{h} 1$ responses are upregulated in the absence of IFN- $\gamma$.

One of the mechanisms of IFN- $\gamma$ 's regulation of immune response may lie in the regulation of weak $\mathrm{T}$ cell responses. In CIA, the antigen that promotes $\mathrm{T}$ cell activation and the subsequent development of arthritis is CII. It is the nature of the immune system that $\mathrm{T}$ cell antigens are presented to $\mathrm{T}$ cells by $\mathrm{MHC}$ molecules. Evolutionary mechanisms have produced various $\mathrm{MHC}$ alleles that by their possession of structurally different antigen binding sites increase the diversity of antigenic determinants presented to $\mathrm{T}$ cells for immune surveillance within a mammalian species. However, this also means that for a given protein antigen different antigenic determinants may be presented by different MHC alleles. This means that MHC alleles such as I- $\mathrm{A}^{\mathrm{q}}$ and $\mathrm{I}-\mathrm{A}^{\mathrm{r}}$ present in CIA-susceptible mouse strains can present physically distinct CII determinants from those presented by MHC alleles present in CIA non-susceptible strains such as I-A ${ }^{\mathrm{b}}$ in the 
B6 mouse. If the CII determinant presented by I-A $\mathrm{A}^{\mathrm{b}}$ is of low affinity for the MHC or the TCR it may be weakly stimulatory to T cell activation, and therefore conferring resistance to CIA in I-A ${ }^{\mathrm{b}}$-expressing mice such as in the B6 strain. One mechanism of IFN- $\gamma$ 's regulation of $\mathrm{T}$ cell activation likely is mediated by the promotion of proinflammatory cytokine expression. Signaling by these cytokines at the time of antigen exposure may potentiate $\mathrm{T}$ cell activation when they are stimulated with weakly immunogenic determinants. Therefore, to determine if an I-A ${ }^{\mathrm{b}}$-restricted CII determinant was weakly antigenic, and to determine if IFN- $\gamma$ 's role in regulating $\mathrm{T}$ cell responses to an $\mathrm{I}-\mathrm{A}^{\mathrm{b}}$-restricted determinant mediates the pathogenesis of CIA, we identified an I-A $\mathrm{A}^{\mathrm{b}}$ restricted CII determinant, and investigated its role in stimulating immune responses in $\mathrm{I}-\mathrm{A}^{\mathrm{b}}$-expressing mice.

Initial assays that measured $\mathrm{T}$ cell responses to bovine $\mathrm{CII}$ indicated that there were minimal $\mathrm{T}$ cell responses to $\mathrm{CII}$ in several strains of $\mathrm{I}-\mathrm{A}^{\mathrm{b}}$-expressing mice that were either susceptible or non-susceptible to CIA. Immunization with bovine CII did not result in measurable $\mathrm{T}$ cell proliferative responses in wild type $\mathrm{B} 6, \mathrm{IFN}-\gamma^{-/-} \mathrm{B} 6$, or CXB2 mice when lymphocytes from these mice were stimulated in culture with either native CII or a peptide library derived from CII sequence. This indicated that I-A $\mathrm{A}^{\mathrm{b}} \mathrm{CII}$ determinants were weakly antigenic as hypothesized. While this supports the concept that I- $\mathrm{A}^{\mathrm{b}}-$ restricted $\mathrm{CII}$ determinants in B6 mice are not conducive to autoimmunity except in the case of disregulation mediated by IFN- $\gamma$, it made difficult the identification of an I-A ${ }^{b}$ restricted CII determinant for detailed analysis. To solve this problem, T cell hybridomas were produced from lymphocytes obtained from I-A $\mathrm{A}^{\mathrm{b}}$-expressing mice previously immunized with CII. This allowed the immortalization and expansion of low frequency I-A $\mathrm{A}^{\mathrm{b}}$-restricted T cells with specificity to CII determinants. Stimulation of these T cell hybridomas with a CII peptide library resulted in one CII determinant identified, located at position 514-525 of the CII molecule (amino acid sequence GLQGPRGLHypGTHyp). Once identified, we further characterized the binding characteristics of the determinant for the components of the TCR complex, and the ability of the determinant to stimulate immune responses in $\mathrm{I}-\mathrm{A}^{\mathrm{b}}$-expressing mice.

The structure of MHC class II molecules is such that there are 4 to 5 binding pockets in an open ended binding groove to which specific amino acids within the antigenic peptide orient. The size of the binding groove dictates that there is a 9 amino acid core sequence within the determinant that closely associates with the MHC to stabilize binding via hydrogen bonding, hydrophobic interactions, ionic binding, and van der walls forces with hydrophobic interactions at the binding pockets usually providing the greatest contribution to overall stability of the MHC/peptide complex. The open ended nature of $\mathrm{MHC}$ class II molecules, however, results in amino acids that extend beyond the core also contributing to MHC/peptide stability. Once bound to the MHC the peptide is made available for binding of the TCR. Binding of the TCR to the MHC/peptide forms the TCR complex which initiates signaling within the T cell that causes its activation. In order to identify the core determinant and to assess the contribution of each amino acid to the formation of the TCR complex, an alanine substituted panel of analog peptides with individual substitutions at each position from CII(512-526) was created and used to stimulate the CII-reactive T cell hybridomas. 
When the T cell stimulatory characteristics of the alanine panel were examined the core determinant was identified as CII(514-528) or GPRGLHypGTHyp. Furthermore, within the core determinant the amino acids from CII(518-522), PRGLHyp, are required for T cell stimulation, while the $\mathrm{Q}$ and $\mathrm{T}$ at positions 516 and 524 also contribute to stability of the TCR/Peptide/MHC complex.

While stimulation of $\mathrm{T}$ hybridoma cells with the CII determinant and the alanine substituted peptide shows the contribution of the amino acids within the determinant to formation of the TCR complex and T cell stimulation, the affinity of the determinant for I-A $A^{b}$ can only be inferred by this method. Therefore to directly measure the affinity of the determinant for $\mathrm{I}-\mathrm{A}^{\mathrm{b}}$ we used both a bioinformatic approach and direct binding assays between the CII determinant and a soluble recombinant form of I- $\mathrm{A}^{\mathrm{b}}$. When binding affinity of CII for I- $\mathrm{A}^{\mathrm{b}}$ was calculated using the MHC class II binding algorithm SMMalign, there were no sequences present in CII that were shown to bind at high affinity, including the CII determinant that was identified by the use of the T cell hybridomas. We next used a binding assay to experimentally measure the binding affinity of CII sequence for I- $\mathrm{A}^{\mathrm{b}}$. To do this, we generated a soluble form of $\mathrm{I}-\mathrm{A}^{\mathrm{b}}$ to be produced in insect cells. However, multiple attempts to produce soluble I- $\mathrm{A}^{\mathrm{b}}$ failed to generate a recombinant form of $\mathrm{I}-\mathrm{A}^{\mathrm{b}}$ that would bind CII peptides in vitro. This prevented the direct measurement of the binding affinity of CII determinants.

Therefore, we sought to measure the ability of the identified CII determinant to stimulate $\mathrm{T}$ cell responses in $\mathrm{I}-\mathrm{A}^{\mathrm{b}}$-expressing mice and to determine its contribution to the pathogenesis of CIA in susceptible strains. CII(512-526) and CII(512-528), CII peptides that correspond to the $\mathrm{I}-\mathrm{A}^{\mathrm{b}} \mathrm{CII}$ determinant and native $\mathrm{CII}$ were used to immunize $\mathrm{B} 6$ and CXB2 mice so the $\mathrm{T}$ cell responses to the determinant could be measured. When the CII peptides were used to stimulate proliferation in lymphocytes recovered from these mice it was found that the shorter CII(512-526) peptide was not strongly immunogenic failing to stimulate proliferation in either mouse strain. However, the longer CII(512-528) peptide, when used at the primary antigen was able to stimulate proliferative response in the B6 cells when stimulated in culture, and in both mice when enrichment of $\mathrm{CD}^{+}$was performed prior to stimulation in culture. These results indicated that the CII determinant identified here is capable of stimulating in vivo $\mathrm{T}$ cell responses in $\mathrm{I}-\mathrm{A}^{\mathrm{b}}$-expressing mice, and these CII-restricted $\mathrm{T}$ cells responses to this $\mathrm{CII}$ determinant may promote the development of autoimmune arthritis. To test this concept, CIA-susceptible CXB2 mice were tolerized with CII(512-528) and immunized with CII to induce CIA. When arthritis developed in these mice, it was observed that prior tolerization with CII(512-528) reduced both the incidence and severity of inflammation indicating that the CII(512-528). Therefore, the CII(512-528) peptide does indeed mediate autoimmune arthritis in the I- $\mathrm{A}^{\mathrm{b}}$ background.

These data indicate that IFN- $\gamma$ regulates immune function in response to immunization with CII. In the absence of IFN- $\gamma$, alterations in immune function occur including increases in the expression of proinflammatory cytokines and production of complement-fixing anti-CII antibodies that promote autoimmune arthritis. A weakly immunogenic I- $\mathrm{A}^{\mathrm{b}}$-restricted determinant present in CII was also identified and characterized. This determinant is capable of stimulating $\mathrm{T}$ cell responses in I-A $\mathrm{A}^{\mathrm{b}}$ 
expressing mice, and is implicated in the pathogenesis of CIA. In IFN- $\gamma^{-/ 2} \mathrm{~B} 6$ mice disregulation of immune function mediated by the absence of IFN- $\gamma$ likely increases $\mathrm{T}$ cell responses to this CII determinant and allows the development of autoimmunity to progress. 


\section{Chapter 4. Interferon $\gamma$ and the Pathogenesis of Inflammatory Arthritis}

\section{Introduction}

IFN- $\gamma$ is a pluripotent mediator of immune function, regulating cytokine production and subsequently the cellular communication of immune and accessory cells responsible for disease progression in autoimmune arthritis. The absence of this cytokine has the potential to fundamentally change the cellular communication that occurs as the immune response initiates and progresses.

We have previously shown that the lack of IFN- $\gamma$ in a CIA non-susceptible strain, B6, converts this strain to one that is highly susceptible. This conversion is likely mediated by alterations in immune function due to the absence of IFN- $\gamma$ signaling, changes including inflammatory cytokine production, autoantibody generation, and increased $\mathrm{T}$ cell activation to weakly antigenic CII determinants. Ultimately, disregulated activation of CII-specific T cells mediated by these processes results in the development of autoimmunity. In light of IFN- $\gamma$ 's emerging role as a master regulator of cellular differentiation and cytokine production, we have developed the following hypothesis. If IFN- $\gamma$ acts as a key regulator of immune function, directing the activation, differentiation, and cytokine production of both immune and accessory cells during the development of an inflammatory response, then removal of IFN- $\gamma$ by genetic ablation, such as in the B6 IFN- $\gamma^{-/-}$mouse, causes disregulation of normal immune regulatory processes, resulting in aberrant cytokine production and immune cell activation. As a result of this disregulation, in the B6 IFN- $\gamma^{-/-}$mouse, the absence of IFN- $\gamma$ allows progression to autoimmunity. Therefore, to investigate how immune function is perturbed in the absence of IFN- $\gamma$, and how that disregulation results in the progression of a pathogenic autoimmune response, we examined how gene expression, cytokine production, cellular response, and disease progression is altered in the absence of IFN- $\gamma$.

The first step in identifying the mechanism by which absence of IFN- $\gamma$ promotes progression to disease was to obtain data that describes the changes in cytokine production and cellular function that occur when immune cells encounter antigen in the absence of IFN- $\gamma$. The CIA-susceptible B6 IFN- $\gamma^{-/-}$mouse model provides an ideal system to compare the cellular responses of a non-pathogenic immune response, as seen in the resistant B6 mouse strain, to one that does progress to autoimmune disease. The CIA model has been widely studied as a model of RA, and has been instrumental in identifying mechanisms of pathogenesis as well as developing new therapeutics. CII dependent immune cell activation, the production and involvement of anti-CII antibodies, and proinflammatory cytokines produced in the joint synovium that mediate pathogenesis have all been characterized to some extent in this model. Since the two mouse strains are congenic and immunization with CII is pathogenic in the IFN- $\gamma^{-/-}$and not the wild type, the immune response in the both strains following CII immunization can be examined in detail and compared to one another. Alterations in the immune response in terms of 
immune cell function and cytokine production of the B6 IFN- $\gamma^{-/-}$mouse from that of the wild type are likely to be mediated either directly or indirectly by the absence of IFN- $\gamma$. If these alterations direct the pathogenic mechanisms of CIA, it is highly probable that those mechanisms are responsible for conferring susceptibility to CIA in the B6 IFN- $\gamma^{-/-}$ mouse.

Cytokines are local mediators of cellular activity, whose numerous effects include cell growth and activation, inflammation, immunity, and differentiation (45). In RA, there is an abundance of cytokines at the site of inflammation, including TNF- $\alpha$, IL- $1 \beta$, IL-6, GM-CSF, IL-8, IL-10, IFN- $\gamma$ IL-2, and TGF $\beta$ (111). Activated immune cells and synoviocytes such as fibroblasts or epithelial cells produce these cytokines. Often cytokines form interconnected regulatory networks where the expression of one cytokine either promotes or inhibits the expression of others by either an autocrine or paracrine mechanism. For example IFN- $\gamma$ promotes its own expression by supporting the differentiation of $\mathrm{T}_{\mathrm{h}} 1$ cells, and inhibits the production of IL-4 or IL-17 by inhibiting the differentiation of $\mathrm{T}_{\mathrm{h}} 2$ or $\mathrm{T}_{\mathrm{h}} 17$ cells. Also, in many cases expression of proinflammatory cytokines is required for disease activity as is shown by knock out mouse models. For example, the proinflammatory cytokines GM-CSF, TNF- $\alpha$, and TGF $\beta$ activate cells that effect joint destruction including monocytes, macrophages, fibroblasts, and osteoclasts within the joint synovium. In the following studies, we examine the relationship between IFN- $\gamma$ and the expression of proinflammatory cytokines in order to identify the mechanism by which CIA susceptibility is conferred in the B6 IFN- $\gamma^{-/}$mouse. Using a combined molecular and cellular approach, our data indicate that IFN- $\gamma$ 's regulation of the expression of IL-18 BP plays a prominent role in this CIA model.

\section{Results}

\section{The Role of IFN- $\gamma$ in Regulating Gene Expression}

\section{Expression Array of Wild Type versus IFN- $\gamma^{-/}$B6 Mice}

The types and quantity of cytokines expressed in the immune system milieu both during and immediately following antigen stimulation can play a significant role in $\mathrm{T}$ cell

and accessory cell differentiation and function. The ultimate outcome of a $\mathrm{T}$ cell immune response in terms of which subtype of $\mathrm{CD}^{+} \mathrm{T}$ cells is activated is tightly controlled by the interplay of signaling in $\mathrm{T}_{\mathrm{h}} 1, \mathrm{~T}_{\mathrm{h}} 2, \mathrm{~T}_{\mathrm{h}} 17$, and $\mathrm{T}$ regulatory cells. IL-12 and IFN- $\gamma$ promote $T_{h} 1$ development while antagonizing $T_{h} 2$ development; the opposite is true for the cytokine IL-4 which antagonizes $T_{h} 1$ cell differentiation and promotes $T_{h} 2$ responses. A similar reciprocal agonist-antagonist arrangement exists between $T_{h} 1$ and $T_{h} 17$ cells. Whereas IFN- $\gamma$ inhibits $T_{h} 17$ function, IL-17 inhibits $T_{h} 1$ function. Since a key effector function of $\mathrm{T}_{\mathrm{h}} 1$ cells is the production of IFN- $\gamma$, in the B6 IFN- $\gamma^{-/-}$mouse, the lack of IFN- $\gamma$ expression must alter $T_{h} 1$ cell function by either preventing the differentiation of 
competent $\mathrm{T}_{\mathrm{h}} 1$ cells, by severely limiting their effector function, or by the lack of feedback inhibition of a pathogenic $\mathrm{T}_{\mathrm{h}} 17$ response.

We propose that reduced $T_{h} 1$ mediated effector function results in a perturbation of the function of immune cells throughout the immune system resulting in a disregulation phenotype. This potential disregulation would explain the differential susceptibility to disease in the B6 IFN- $\gamma^{-/-}$model. In order to determine which genes are regulated by IFN- $\gamma$ in the context of CIA, a gene expression array was performed using mRNA from lymphocytes obtained from the draining lymph nodes of wild type and IFN- $\gamma^{-/-}$B6 mice immunized with bovine CII in an emulsion of CFA. Three female B6 or B6 IFN- $\gamma^{-/-}$age matched between three and four months were immunized with a total of $100 \mu \mathrm{l}$ of $2 \mathrm{mg} / \mathrm{ml} \mathrm{CII} \mathrm{in} \mathrm{CFA} \mathrm{emulsion.} \mathrm{The} \mathrm{draining} \mathrm{lymph} \mathrm{nodes} \mathrm{were} \mathrm{excised} \mathrm{ten}$ days later and the total RNA was recovered from lymphocytes. This RNA was checked for quality with an Agilent Technologies 2100 bioanalyzer to test the quality of the RNA and determine its concentration. Following quality assurance, the mRNA was analyzed by microarray using an Affymetrix GeneChip Mouse Genome 430 2.0 Array.

After the expression chip data were analyzed, one set of data from a B6 IFN- $\gamma^{-/}$ mouse was found to be of poor quality and these data were excluded from subsequent analysis. Among the remaining three wild type chips and the two IFN- $\gamma^{-/}$chips, 1612 genes were shown to be significantly differentially expressed $(\mathrm{p} \leq 0.05)$ among the 45,101, probe sets present on the chip representing 34,000 mouse genes (Fig. 4.1). This list of genes was then analyzed using Ingenuity Pathways Analysis software. This software is a research tool that identifies networks of genes based on known signaling connections. This tool allowed the identification of those genes among the 1612 differentially expressed that are present in signaling networks or those related to immunological function. This analysis revealed 41 signaling networks with 10 or more genes present among the differentially expressed genes. As a final step, genes were then examined manually for differentially expressed immune regulatory genes, especially those associated with rheumatoid arthritis or autoimmunity.

A select group of differentially expressed genes between the wild type and IFN- $\gamma^{-/}$groups were identified as likely to be involved in the pathogenesis of CIA due to their roles as immune signaling molecules, immune effector molecules, and mediators or indicators of inflammation (Fig 4.2, 4.3). The data are represented as fold difference in expression. To obtain these values, the average of the normalized fluorescence for each group was converted to a ratio by dividing the value obtained from the wild type cells by the value obtained from the IFN $-\gamma^{-/-}$derived cells. These values were then converted to the fold difference between the two groups by subtracting the inverse of the WT/IFN- $\gamma^{-/}$ ratio from zero. The result of this calculation is that a gene expressed more highly in the wild type cells will have a positive value while a gene with higher expression in the IFN- $\gamma^{-/}$cells will have a negative value.

Genes encoding immune signaling molecules that include immune modulating cell surface receptors and soluble cell signaling molecules such as cytokines and chemokines were found to be differentially expressed (Fig 4.2A). In the wild type 


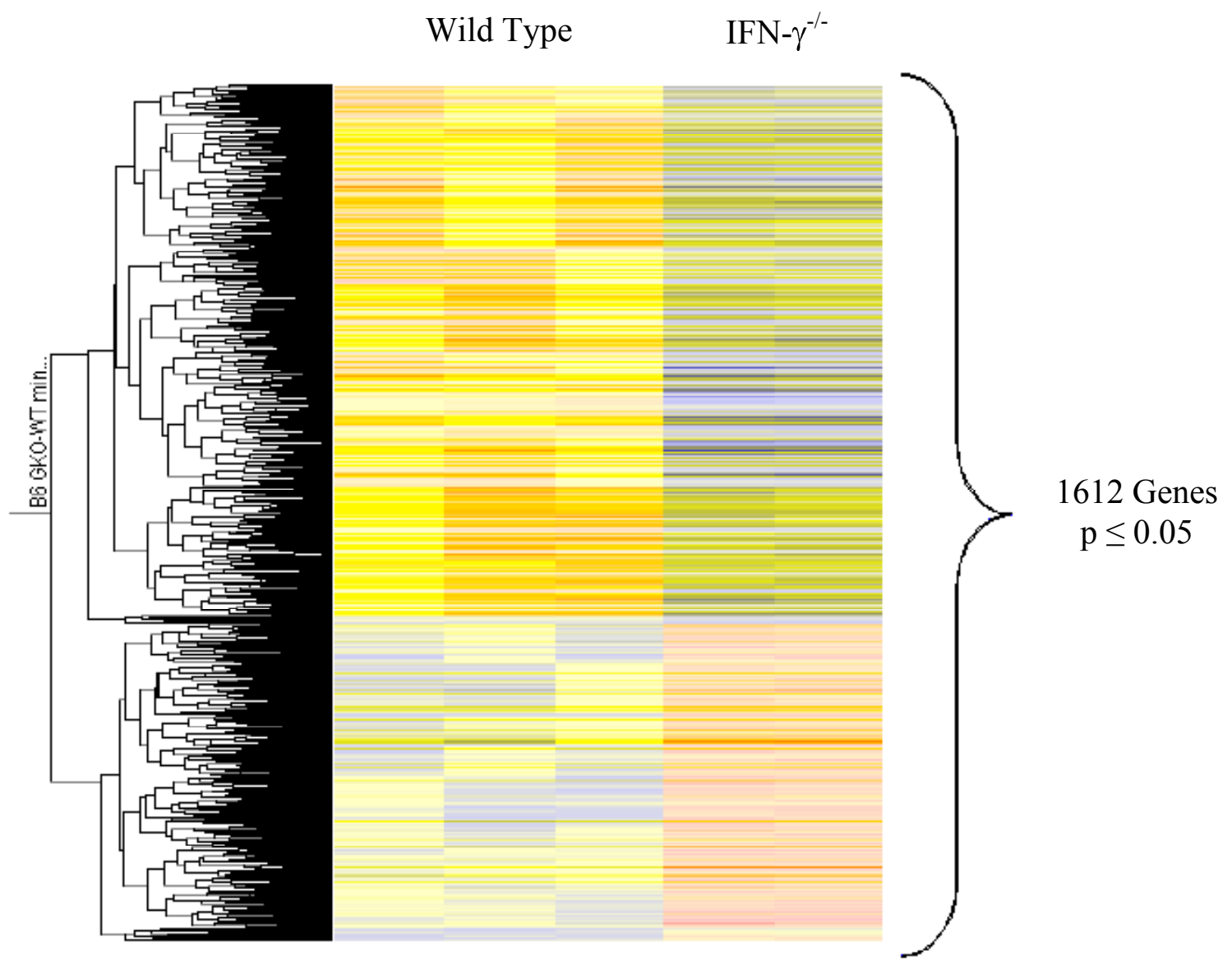

Figure 4.1 Genes Differentially Expressed between Wild Type and IFN- $\gamma^{-/}$B6 Mice in Response to Immunization with CII/CFA.

Wild type and IFN $-\gamma^{-/-}$mice were immunized with CII/CFA. Ten days later, mRNA was isolated from lymphocytes recovered from draining popliteal lymph nodes and examined for gene expression with an Affymetrix GeneChip Mouse Genome 430 2.0 Array. 45,101 probe sets representing 34,000 mouse genes were examined for differential expression. Of these, 1612 genes were observed to be differentially expressed with a significance greater than $p \geq 0.05$. Blue represents higher expression, and red represents lower expression. 

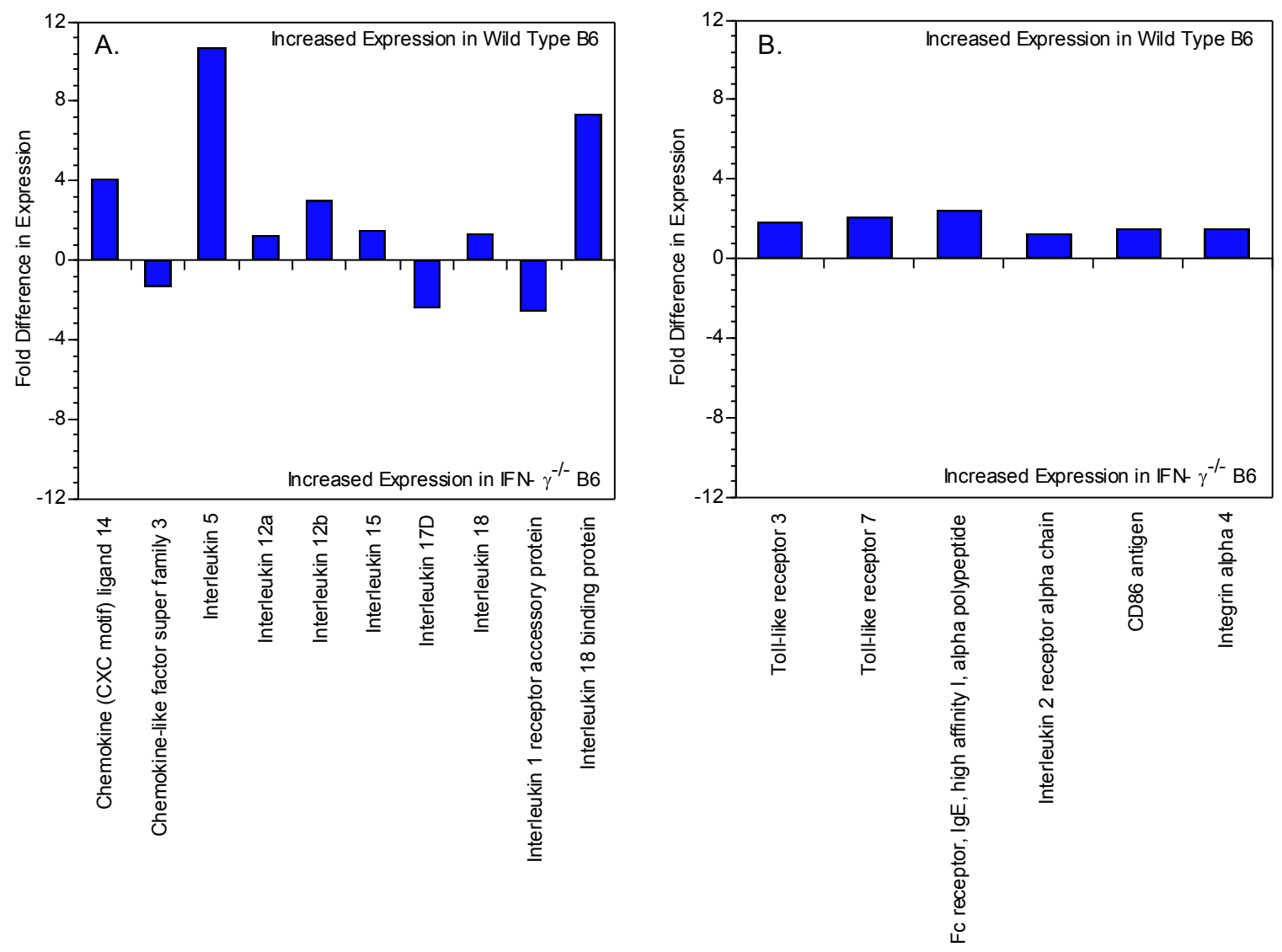

Figure 4.2 Intercellular Signaling Molecules Differentially Expressed between Wild Type and IFN- $\gamma^{-/-}$B6 Mice.

Wild type and IFN- $\gamma^{-/-}$B6 mice were immunized with CII/CFA, and ten days later lymphocytes were recovered from draining lymph nodes. These cells were used to produce mRNA for use in a gene expression array. Selected differentially expressed genes with immunological relevance to arthritis pathogenesis are shown. Data is represented as the fold difference in gene expression between cells from wild type and IFN- $\gamma^{-/}$B6 mice. A. Cytokine and chemokine signaling molecules that are differentially expressed between the two groups. B. Membrane bound receptors and ligands with immunomodulatory effects on immune cell function. For all genes shown, $\mathrm{p} \leq 0.05$. 

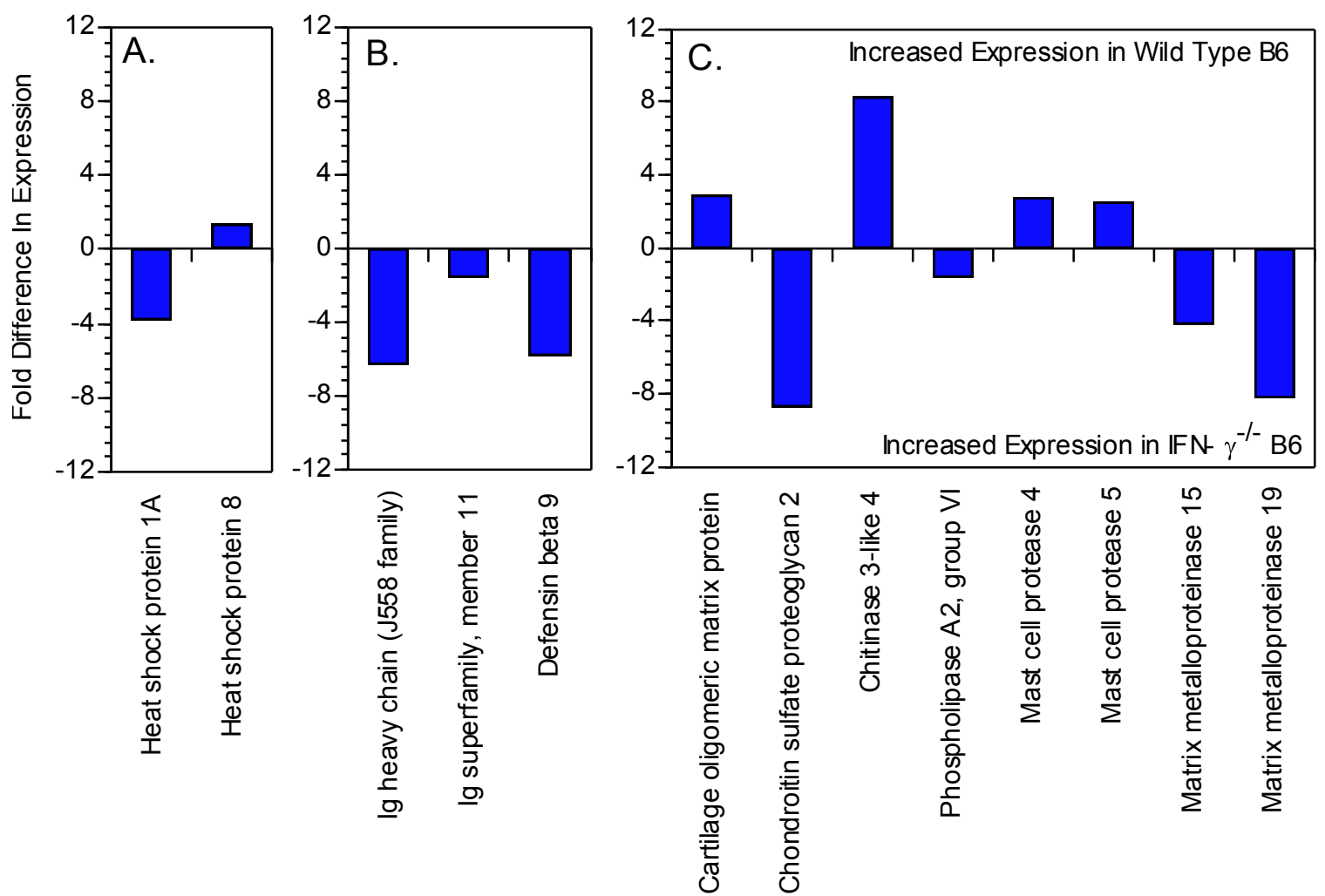

Figure 4.3 Markers of Inflammation and Joint Remodeling Genes Differentially Expressed between Wild Type and IFN- $\gamma^{-/}$B6 Mice.

Wild type and IFN- $\gamma^{-/-}$B6 mice were immunized with CII/CFA, and ten days later lymphocytes were recovered from draining lymph nodes. These cells were used to produce mRNA for use in a gene expression array. Selected differentially expressed genes with immunological relevance to arthritis pathogenesis are shown. Data is represented as the fold difference in gene expression of between cells from wild type and IFN- $\gamma^{-/}$B6 mice. A. Markers of inflammation. B. Immune effector proteins. C. Joint structural and remodeling enzymes. For all genes shown, $\mathrm{p} \leq 0.05$. 
mouse, chemokine (C-X-C motif) ligand 14 (CXCL14), IL-5, IL-12 $\alpha$, IL-12 $\beta$, IL-15, IL-18, and IL-18 binding protein (IL-18 BP) are all up regulated compared to the IFN- $\gamma^{-1-}$ mouse. In the IFN- $\gamma^{-/-}$mouse, the expression of chemokine like factor super family 3 (Cklfsf3), IL-17D, and interleukin 1 receptor accessory protein (IL-1RAP) are upregulated in comparison to expression in the wild type mouse. Cell surface molecules and receptors were also identified as differentially expressed between the two mouse groups (Fig 4.2B). In the wild type mouse, TLR-3, TLR-7, Fc receptor high affinity 1 alpha polypeptide $(\mathrm{Fc \varepsilon R} 1 \alpha)$, interleukin 2 receptor alpha chain (IL-2R $\alpha)$, CD86 antigen, and integrin alpha 4 were all upregulated in comparison to expression in the B6 IFN $-\gamma^{-/-}$ cells.

A third set of genes that were differentially expressed between the two mouse groups include markers of inflammation such as heat shock proteins (Fig. 4.3A), immune effector molecules such as immunoglobulins (Fig 4.3B), or joint structural proteins or remodeling enzymes (Fig $\mathbf{4 . 3 C}$ ). In the wild type mouse, heat shock protein 8, cartilage oligomeric matrix protein, chitinase 3 like 4 , and mast cell protease 4 and 5 are overexpressed compared to the IFN $-\gamma^{-/}$mouse. In the IFN $-\gamma^{-/}$mouse, heat shock protein $1 \mathrm{~A}$, Ig heavy chain, defensin beta 9 , chondroitan sulfate proteoglycan 2, phospholipase A2 group VI, and the matrix metalloproteinases 15 and 19 are overexpressed over the wild type mouse. These genes encode proteins that could affect arthritis pathogenesis at several different levels including 1 . The level of immune cell activation through altered cytokine and regulatory molecule expression. 2. The level of immune effector function via altered Ig expression. 3. The level of joint inflammation by disregulated joint remodeling. Together, these changes could result in the disregulation of the immune response that leads to development of autoimmune arthritis. One important consideration in the analysis of these data is that both groups of mice were immunized with bovine CII in Mtb containing CFA emulsion. So the wild type mouse is undergoing a normal inflammatory response to the CFA, and one would expect to see inflammatory mediators expressed in this mouse. In the wild type mouse, normal regulatory processes limit the progression of the immune response so autoimmunity does not develop. In the IFN- $\gamma^{-1-}$ mouse however, immune regulation is altered allowing the progression to the autoimmune inflammatory disease, CIA.

Many of the genes identified by the expression array have been linked to the development of RA or CIA (Table 4.1). When one examines the genes that are overexpressed in the IFN- $\gamma^{-/}$mouse a pro-arthritogenic pattern emerges. In addition to evidence of joint remodeling by the overexpression of such genes as chondroitan sulfate proteoglycan 2 , and the matrix metalloproteinases 15 , and 19 , two key cytokines with immunomodulatory functions are identified as differentially expressed between the wild type and IFN $-\gamma^{-/ 2}$ mouse. These include increased expression of the proinflammatory cytokine IL-17 and the reduced expression of IL-18 and IL-18 BP in the IFN- $\gamma^{-/-}$mouse. 
Table 4.1 The Role of Differentially Expressed Genes between Wild Type and IFN- $\gamma^{-/-}$B6 Mice Immunized with CII/CFA in the Pathogenesis of RA and CIA.

\begin{tabular}{|c|c|c|}
\hline Gene & Function & Arthritis Pathogenesis \\
\hline Chemokine (C-X-C) Ligand 14 & $\begin{array}{l}\text { Cellular recruitment of } \\
\text { lymphocytes via CCR5 }\end{array}$ & $\begin{array}{l}\text { Expression upregulated in } \\
\text { spontaneous arthritis } \\
\text { models }^{1}\end{array}$ \\
\hline $\begin{array}{l}\text { Chemokine like factor super } \\
\text { family } 3\end{array}$ & $\begin{array}{l}\text { Cellular recruitment of } \\
\text { lymphocytes via CCR5 }\end{array}$ & $\begin{array}{l}\text { Increased gene copy } \\
\text { number increases risk of } \\
\text { RA development }\end{array}$ \\
\hline Interleukin 5 & $\begin{array}{l}\text { B cell growth and } \\
\text { differentiation }^{3}\end{array}$ & $\begin{array}{l}\text { Influences production of } \\
\text { autoantibodies via effects } \\
\text { on B cells }\end{array}$ \\
\hline Interleukin $12 \alpha$ & $\begin{array}{l}\text { Promotes IFN- } \gamma \text { and } \mathrm{T}_{\mathrm{h}} 1 \\
\text { cellular responses }\end{array}$ & $\begin{array}{l}\text { Blockade inhibits severity } \\
\text { of CIA }^{4}\end{array}$ \\
\hline Interleukin $12 \beta$ & $\begin{array}{l}\text { Promotes IFN- } \gamma \text { and } \mathrm{T}_{\mathrm{h}} 1 \\
\text { cellular responses }\end{array}$ & $\begin{array}{l}\text { Blockade inhibits severity } \\
\text { of CIA }^{4}\end{array}$ \\
\hline Interleukin 15 & $\begin{array}{l}\mathrm{T} \text { cell proliferation and } \\
\text { homing, promotes } \\
\text { production of TNF- } \alpha\end{array}$ & $\begin{array}{l}\text { Present in RA synovial } \\
\text { fluid }^{5} \\
\text { Overexpression } \\
\text { exacerbates CIA }\end{array}$ \\
\hline Interleukin $17 \mathrm{D}$ & $\begin{array}{l}\text { Proinflammatory cytokine } \\
\text { promotes expression of } \\
\text { IL-6, IL-8, GM-CSF, IL- } \\
1 \beta, \text { TGF } \beta, \text { TNF- } \alpha \text {, and } \\
\text { PGE }_{2}\end{array}$ & $\begin{array}{l}\text { IL-17 family members } \\
\text { linked to synovial } \\
\text { destruction in } \mathrm{RA}^{7,8}\end{array}$ \\
\hline Interleukin 18 & $\begin{array}{l}\text { Proinflammatory cytokine } \\
\text { induces production of } \\
\text { TNF- } \alpha, \text { GM-CSF, IFN- } \gamma \\
\text { by synovial membrane }\end{array}$ & $\begin{array}{l}\text { Induces expression of } \\
\text { proinflammatory } \\
\text { cytokines in RA } \\
\text { synovium }^{9}\end{array}$ \\
\hline $\begin{array}{l}\text { Interleukin } 1 \text { receptor accessory } \\
\text { protein }\end{array}$ & $\begin{array}{l}\text { Stabilizes binding of IL-1 } \\
\text { to its receptor }\end{array}$ & $\begin{array}{l}\text { Inhibits CIA by } \\
\text { scavenging IL-1 }\end{array}$ \\
\hline Interleukin 18 binding protein & $\begin{array}{l}\text { Binds and inhibits activity } \\
\text { of IL-18 }\end{array}$ & $\begin{array}{l}\text { Binds and inhibits activity } \\
\text { of IL-1 } 18^{11,12}\end{array}$ \\
\hline
\end{tabular}


Table 4.1 (continued).

\begin{tabular}{|c|c|c|}
\hline Gene & Function & Arthritis Pathogenesis \\
\hline TLR 3 & $\begin{array}{l}\text { Pattern recognition } \\
\text { receptor for dsRNA } \\
\text { induces NF- } \mathrm{B} \text { and Type } \\
1 \text { Interferons }\end{array}$ & $\begin{array}{l}\text { Immune signaling and } \\
\text { activation, may promote } \\
\text { expression of } \\
\text { proinflammatory } \\
\text { cytokines in } \mathrm{RA}^{11,13}\end{array}$ \\
\hline TLR 7 & $\begin{array}{l}\text { Pattern recognition } \\
\text { receptor for ssRNA }\end{array}$ & $\begin{array}{l}\text { Immune signaling and } \\
\text { activation, may promote } \\
\text { expression of } \\
\text { proinflammatory } \\
\text { cytokines in } \text { RA }^{13}\end{array}$ \\
\hline $\begin{array}{l}\text { Fc Receptor, IgE high affinity } 1 \text {, } \\
\text { alpha peptide }\end{array}$ & Mast cell activation & $\begin{array}{l}\text { Immune cell activation } \\
\text { and inflammation }\end{array}$ \\
\hline $\begin{array}{l}\text { Fc Receptor, IgE high affinity } 1 \text {, } \\
\text { alpha peptide }\end{array}$ & Mast cell activation & $\begin{array}{l}\text { Immune cell activation } \\
\text { and inflammation }\end{array}$ \\
\hline $\begin{array}{l}\text { Interleukin } 2 \text { receptor alpha } \\
\text { chain }\end{array}$ & $\begin{array}{l}\text { Cellular receptor for IL-2 } \\
\text { T cell growth, } \\
\text { differentiation, survival }\end{array}$ & $\mathrm{T}$ cell function \\
\hline \multirow[t]{2}{*}{ CD86 Antigen } & $\begin{array}{l}\text { CTLA4 ligand, dendritic } \\
\text { cell maturation marker }\end{array}$ & $\begin{array}{l}\text { Upregulated in RA } \\
\text { synovium }^{14}\end{array}$ \\
\hline & & Blockade inhibits CIA ${ }^{15}$ \\
\hline Integrin alpha 4 & $\begin{array}{l}\text { Subunit of VLA-4 } \\
\text { (VCAM-1 Receptor), } \\
\text { cellular localization }\end{array}$ & $\begin{array}{l}\text { VCAM expression in RA } \\
\text { synovium is elevated } \\
\text { compared to normal }^{16}\end{array}$ \\
\hline Heat shock protein $1 \mathrm{~A}$, and 8 & $\begin{array}{l}\text { Indicators of cell stress } \\
\text { and inflammation }\end{array}$ & Marker of inflammation \\
\hline Ig Heavy Chain (J558) & $\begin{array}{l}\text { Immune effector } \\
\text { molecule }\end{array}$ & Autoantibody \\
\hline Defensin beta 9 & $\begin{array}{l}\text { Cytotoxic and } \\
\text { microbiocidal peptide } \\
\text { produced by neutrophils }\end{array}$ & $\begin{array}{l}\text { Defensin beta family } \\
\text { members mediate } \\
\text { articular cartilage } \\
\text { remodeling }\end{array}$ \\
\hline
\end{tabular}


Table 4.1 (continued).

\begin{tabular}{lll}
\hline \multicolumn{1}{c}{ Gene } & \multicolumn{1}{c}{ Function } & \multicolumn{1}{c}{ Arthritis Pathogenesis } \\
\hline $\begin{array}{l}\text { Cartilage oligomeric matrix } \\
\text { protein }\end{array}$ & $\begin{array}{l}\text { Cartilage Structural } \\
\text { protein }\end{array}$ & $\begin{array}{l}\text { Marker of joint } \\
\text { remodeling }\end{array}$ \\
$\begin{array}{l}\text { Chondroitin sulfate } \\
\text { proteoglycan 2 }\end{array}$ & $\begin{array}{l}\text { Cartilage Structural } \\
\text { protein }\end{array}$ & $\begin{array}{l}\text { Marker of joint } \\
\text { remodeling }\end{array}$ \\
Mast Cell Protease 4 & $\begin{array}{l}\text { Chymase produced by } \\
\text { mast cells }\end{array}$ & $\begin{array}{l}\text { Connective tissue } \\
\text { remodeling }\end{array}$ \\
Mast Cell Protease 5 & $\begin{array}{l}\text { Chymase produced by } \\
\text { mast cells }\end{array}$ & $\begin{array}{l}\text { Connective tissue } \\
\text { remodeling }\end{array}$ \\
Matrix 19
\end{tabular}

Sources:

1. Fujikado, N., S. Saijo, and Y. Iwakura. 2006. Identification of arthritis-related gene clusters by microarray analysis of two independent mouse models for rheumatoid arthritis. Arthritis Res Ther 8:R100. (112)

2. McKinney, C., M. E. Merriman, P. T. Chapman, P. J. Gow, A. A. Harrison, J. Highton, P. B. Jones, L. McLean, J. L. O'Donnell, V. Pokorny, M. Spellerberg, L. K. Stamp, J. Willis, S. Steer, and T. R. Merriman. 2008. Evidence for an influence of chemokine ligand 3-like 1 (CCL3L1) gene copy number on susceptibility to rheumatoid arthritis. Ann Rheum Dis 67:409-413. (113)

3. Randall, T. D., F. E. Lund, J. W. Brewer, C. Aldridge, R. Wall, and R. B. Corley. 1993. Interleukin-5 (IL-5) and IL-6 define two molecularly distinct pathways of B-cell differentiation. Mol Cell Biol 13:3929-3936. (114)

4. Malfait, A. M., D. M. Butler, D. H. Presky, R. N. Maini, F. M. Brennan, and M. Feldmann. 1998. Blockade of IL-12 during the induction of collagen-induced arthritis (CIA) markedly attenuates the severity of the arthritis. Clin Exp Immunol 111:377-383. (115)

5. Liew, F. Y., and I. B. McInnes. 2002. Role of interleukin 15 and interleukin 18 in inflammatory response. Ann Rheum Dis 61 Suppl 2:ii100-102. (116) 


\section{Table 4.1 (continued).}

6. Yoshihara, K., H. Yamada, A. Hori, T. Yajima, C. Kubo, and Y. Yoshikai. 2007. IL-15 exacerbates collagen-induced arthritis with an enhanced CD4+ T cell response to produce IL-17. Eur J Immunol 37:2744-2752. (117)

7. Kotake, S., N. Udagawa, N. Takahashi, K. Matsuzaki, K. Itoh, S. Ishiyama, S. Saito, K. Inoue, N. Kamatani, M. T. Gillespie, T. J. Martin, and T. Suda. 1999. IL-17 in synovial fluids from patients with rheumatoid arthritis is a potent stimulator of osteoclastogenesis. J Clin Invest 103:1345-1352. (118)

8. Chabaud, M., P. Garnero, J. M. Dayer, P. A. Guerne, F. Fossiez, and P. Miossec. 2000. Contribution of interleukin 17 to synovium matrix destruction in rheumatoid arthritis. Cytokine 12:1092-1099. (119)

9. Gracie, J. A., R. J. Forsey, W. L. Chan, A. Gilmour, B. P. Leung, M. R. Greer, K. Kennedy, R. Carter, X. Q. Wei, D. Xu, M. Field, A. Foulis, F. Y. Liew, and I. B. McInnes. 1999. A proinflammatory role for IL-18 in rheumatoid arthritis. J Clin Invest 104:1393-1401. (120)

10. Smeets, R. L., L. A. Joosten, O. J. Arntz, M. B. Bennink, N. Takahashi, H. Carlsen, M. U. Martin, W. B. van den Berg, and F. A. van de Loo. 2005. Soluble interleukin-1 receptor accessory protein ameliorates collagen-induced arthritis by a different mode of action from that of interleukin-1 receptor antagonist. Arthritis Rheum 52:2202-2211. (121)

11. Roelofs, M. F., L. A. Joosten, S. Abdollahi-Roodsaz, A. W. van Lieshout, T. Sprong, F. H. van den Hoogen, W. B. van den Berg, and T. R. Radstake. 2005. The expression of toll-like receptors 3 and 7 in rheumatoid arthritis synovium is increased and costimulation of toll-like receptors 3,4 , and $7 / 8$ results in synergistic cytokine production by dendritic cells. Arthritis Rheum 52:2313-2322. (122)

12. Novick, D., S. H. Kim, G. Fantuzzi, L. L. Reznikov, C. A. Dinarello, and M. Rubinstein. 1999. Interleukin-18 binding protein: a novel modulator of the Th1 cytokine response. Immunity 10:127-136. (123)

13. Roelofs, M. F., M. H. Wenink, F. Brentano, S. Abdollahi-Roodsaz, B. OppersWalgreen, P. Barrera, P. L. van Riel, L. A. Joosten, D. Kyburz, W. B. van den Berg, and T. R. Radstake. 2008. Type I interferons might form the link between Toll-like receptor (TLR) 3/7 and TLR4 mediated synovial inflammation in rheumatoid arthritis (RA). Ann Rheum Dis doi:10.1136. (124)

14. Thomas, R., and C. Quinn. 1996. Functional differentiation of dendritic cells in rheumatoid arthritis: role of CD86 in the synovium. J Immunol 156:3074-3086. (125) 


\section{Table 4.1 (continued).}

15. Tellander, A. C., U. Pettersson, A. Runstrom, M. Andersson, and E. Michaelsson. 2001. Interference with CD28, CD80, CD86 or CD152 in collagen-induced arthritis. Limited role of IFN-gamma in anti-B7-mediated suppression of disease. J Autoimmun 17:39-50. (126)

16. Morales-Ducret, J., E. Wayner, M. J. Elices, J. M. Alvaro-Gracia, N. J. Zvaifler, and G. S. Firestein. 1992. Alpha 4/beta 1 integrin (VLA-4) ligands in arthritis. Vascular cell adhesion molecule-1 expression in synovium and on fibroblast-like synoviocytes. J Immunol 149:1424-1431. (127)

17. Varoga, D., T. Pufe, J. Harder, J. M. Schroder, R. Mentlein, U. Meyer-Hoffert, M. B. Goldring, B. Tillmann, J. Hassenpflug, and F. Paulsen. 2005. Human betadefensin 3 mediates tissue remodeling processes in articular cartilage by increasing levels of metalloproteinases and reducing levels of their endogenous inhibitors. Arthritis Rheum 52:1736-1745. (128)

18. Tchougounova, E., G. Pejler, and M. Abrink. 2003. The chymase, mouse mast cell protease 4 , constitutes the major chymotrypsin-like activity in peritoneum and ear tissue. A role for mouse mast cell protease 4 in thrombin regulation and fibronectin turnover. J Exp Med 198:423-431. (129)

19. Nigrovic, P. A., and D. M. Lee. 2005. Mast cells in inflammatory arthritis. Arthritis Res Ther 7:1-11. (130)

20. Murphy, G., V. Knauper, S. Atkinson, G. Butler, W. English, M. Hutton, J. Stracke, and I. Clark. 2002. Matrix metalloproteinases in arthritic disease. Arthritis Res 4 Suppl 3:S39-49. (131) 
There is growing evidence that the interactions of IL-18 and IL-18 BP may play a role in regulating the immune response that leads to the development of RA. IL-18 is a proinflammatory cytokine that is in the IL-1 superfamily. Its expression is widespread, being produced by monocytes, macrophages, articular chondrocytes, synovial fibroblasts, and osteoblasts (132). Once activated by caspase-1 dependent cleavage from its precursor form, it functions to promote the production of proinflammatory cytokines in the joint synovium including IFN- $\gamma$, GM-CSF, IL- $1 \beta$ and TNF- $\alpha$. The production of these cytokines is potentiated by the coexpression of IL-12 and IL-15 $(120,133)$. In RA, IL-18 expression has been detected in the synovial compartment and tissues of patients afflicted with RA $(132,134)$. In CIA-susceptible mouse strains such as DBA1, neutralization of IL-18 by the use of anti-IL-18 monoclonal antibodies, or through the use of IL-18 BP reduces the clinical scores of arthritis severity (135).

IL-18 BP is a soluble glycoprotein produced largely by monocytes that forms part of a feedback regulatory circuit that modulates the activity of IL-18. Two biologically active isoforms of IL-18 BP, IL-18 BPc and IL-18 BPd, are produced in mouse with IL$18 \mathrm{BPd}$ having the most potent activity. In culture, when IL-18 BP is present at an equimolar concentration with IL-18, the IFN- $\gamma$ inducing activity of IL-18 on NKO cells (an NK cell line) stimulated with IL-12 and IL-18 is reduced by 95 percent (136). IL-18 has also been shown to promote the production of IFN- $\gamma$ by $T_{h} 1$ cells (137). Since IL-18 BP inhibits IL-18 signaling, this results in feedback inhibition of IL-18 activity. Increased IL-18 signaling causes increased IFN- $\gamma$ production, which then causes increased IL-18 BP production. IL-18 BP then "feeds back" to reduce IL-18 activity. In the IFN $-\gamma^{-/-}$mouse, there is no production of IFN- $\gamma$. The result of this is reduced production of IL-18 BP and therefore increased levels of free IL-18 available for binding to its receptor. Reduction of IL-18 BP production in the absence of IFN- $\gamma$ was experimentally observed in the gene expression array of wild type B6 versus IFN- $\gamma^{-/-}$ mice. Expression of IL-18 BP is reduced in the IFN- $\gamma^{-/-}$mouse. Its expression is over seven fold lower in the IFN- $\gamma^{-/-}$mouse than in the wild type. Since IL-18 BP expression is induced by IFN- $\gamma$, and IL-18 is known to contribute to or modulate the pathogenesis of RA and CIA, decreased expression of IL-18 BP due the absence of IFN- $\gamma$ in the IFN- $\gamma^{-/-}$ mouse results in increased levels of free IL-18 available for signaling, and thus increasing its activity. Increased activity of IL-18 would increase expression of proinflammatory cytokines such as TNF- $\alpha$ and GM-CSF following immunization with CII, and potentially contributing to CIA susceptibility in the IFN- $\gamma^{-/-}$mouse.

\section{IFN- $\gamma$ and IL-17 Activity}

A strongly proinflammatory family of cytokines has been identified as a critical pathway in the development of chronic autoimmune arthritis. These cytokines include the six IL-17 family members, IL-17 A-F. IL-17A and IL-17F are produced by $\mathrm{T}_{\mathrm{h}} 17$ cells. $\mathrm{T}_{\mathrm{h}} 17$ response is distinguished from proinflammatory $\mathrm{T}_{\mathrm{h}} 1$ response by the absence of production of IFN- $\gamma$, T-bet, or GATA-3. $\mathrm{T}_{\mathrm{h}} 17$ cell differentiation can be induced in 
culture by the addition of the cytokines IL- 6 , and TGF $\beta$ when naïve T cells are stimulated with LPS, and in addition to the production of IL-17, $\mathrm{T}_{\mathrm{h}} 17$ cells also produce the proinflammatory cytokines IL-6, TNF- $\alpha$, and GM-CSF. IL-17 family members exhibit multiple immune regulatory functions via induction of cytokine production in multiple cell types including fibroblasts, endothelial cells, epithelial cells, keratinocytes, and macrophages. These cells produce the cytokines IL-6, IL-8, G-CSF, GM-CSF, IL-1 $\beta$, TGF $\beta$, and TNF- $\alpha$ and the inflammatory mediator $\mathrm{PGE}_{2}$ in response to IL-17 ligation. All of which have been implicated in the pathogenesis of RA. IL-17D was identified as overexpressed in the IFN- $\gamma^{-/-}$B6 mouse by the gene expression array (Fig 4.2A). Interestingly, though IL-17 family members are known to be associated with RA, IL-17D is preferentially expressed in skeletal muscle and nervous tissue and not previously associated with arthritis (138).

\section{Expression of IL-18 and IL-17 Regulated Genes}

Based on their known proinflammatory function, increases in the expression of IL-18 and IL-17 are likely linked to the increased susceptibility of CIA in the IFN- $\gamma^{-/-}$ mouse. To reinforce the expression array data and to further examine the functional changes that occur in the autoimmune response due to the absence of IFN- $\gamma$, the expression of specific immune related genes was measured via real time PCR using two approaches. First, a traditional real time PCR using probes selected on their basis of IL18 and IL-17 signaling or arthritis relevance was used to confirm the expression level of select genes identified from the microarray data. Second, a real time PCR array focused on a panel of immune response genes was used to quantify the expression of 90 genes that effect or regulate immune function. These assays serve a two-fold purpose. They double check the expression data of the expression array, and also measure the expression of cytokines downstream of IL-18 and IL-17 signaling.

\section{Real Time PCR}

Four wild type or IFN- $\gamma^{-/-}$B6 mice were immunized with CII in an emulsion of CFA and ten days later mRNA was isolated from cells from the draining lymph nodes. Taqman real time PCR probes were used to measure the expression of IL-17A, IL-5, IL-1 $\beta$, IL-6, IL-4, GM-CSF, TGF $\beta 1$, IL-18, TNF- $\alpha$, IL-15, IL-10, IL-12 $\alpha$, and IL-18 BP. The difference in expression of the two mouse strains is reported as $\Delta \Delta \mathrm{ct}$ to indicate the relative expression of mRNA between the two groups. To derive this value, the number of cycles (ct) required for fluorescence to reach a predetermined threshold value is normalized to the expression of a "housekeeping" gene that is assumed to be expressed equally in all conditions. The mRNA expression level of structural proteins is often used for this purpose, and the structural protein $\beta$ actin was used in these assays. Subtraction of the housekeeping gene ct value from the ct value of the experimental is known as the $\Delta c t$ and represents a normalized expression value for the experimental gene. The $\Delta \mathrm{ct}$ value from one experimental group is then subtracted from the $\Delta \mathrm{ct}$ of the other group $(\Delta \Delta \mathrm{ct})$. This value can be either positive or negative and represents the difference in 
cycle number between the two groups for a PCR reaction to reach the threshold fluorescence value. Based on the design of the data analysis, a negative $\Delta \Delta \mathrm{ct}$ value indicates higher expression in the IFN- $\gamma^{-/-}$while a positive value indicates higher expression in the wild type. The ct value grows exponentially, doubling with each cycle of the PCR reaction. For this reason, 2 raised to the power of $-\Delta \Delta c t$ is the fold difference in expression between the two groups for a given gene. In this assay, IL-17A, IL-5, IL-1 $\beta$, IL-6, IL-4, and GM-CSF were all expressed higher in the IFN- $\gamma^{-/-}$than in the wild type (Fig 4.4). Conversely, in the wild type, IL-15, IL-10, IL-12 $\alpha$, and IL-18 BP were overexpressed compared to the IFN- $\gamma^{-/}$B6 group. TGF $\beta$, IL-18, and TNF- $\alpha$ were expressed at similar levels in both mouse groups. These data indicate that in the IFN- $\gamma^{-/-}$ there is an increase in proinflammatory cytokines, IL-17, IL-6, and IL-1 $\beta$, were expressed at high levels in the IFN- $\gamma^{-/-}$mice. In addition, IL-18 BP, which negatively regulates the proinflammatory cytokine IL-18, has reduced expression in the IFN- $\gamma^{-/-}$mice. Therefore, the absence of IFN- $\gamma$ potentially mediates CIA susceptibility in IFN- $\gamma^{-/-}$mice by promoting proinflammatory cytokine expression, an effect that may in part be a result of decreased production of IL-18 BP.

\section{Microfluidics Real Time PCR}

A real time PCR array was used to analyze the difference in expression of a focused set of immune response genes in lymphocytes from CII-immunized wild type and IFN- $\gamma^{-/-}$mice. In this assay, a microfluidics plate that measures the expression of 90 immune related genes that include cytokines, chemokines, immune regulators, growth factors, and inflammatory markers was used. This approach expands the analysis of immune response gene expression in a quantitative manner. As in the gene expression array and the previous real time PCR assay, mRNA was purified from lymphocytes obtained from wild type or IFN- $\gamma^{-/-}$B6 mice 10 days following immunization with CII/CFA. This mRNA was then examined for quality and them converted to cDNA for use in the real time PCR assay. While the expression of most of the genes were not statistically different between the two groups of cells, several proinflammatory cytokines were found to be expressed at a significantly higher level in lymphocytes derived from the B6 IFN- $\gamma^{-/-}$mice. IL-15, IL-17A, IL-18, IL-1 $\alpha$, and TGF $\beta$ were all found to be upregulated in the B6 IFN- $\gamma^{-/-}$mice (Fig 4.5). In addition, two genes, CXCR3 and Gzmb, were differentially expressed between wild type and IFN- $\gamma^{-/-} \mathrm{B} 6$ mice with a statistical significance of $\mathrm{p}<0.05$. CXCR3 is a chemokine receptor that binds, interferon inducible T cell- $\alpha$ chemoattractant (CXCL11), interferon-inducible protein 10 (CXCL10), and monokine induced by $\gamma$-interferon (CXCL9) (139). This receptor mediates lymphocyte migration and is preferentially expressed on $\mathrm{T}_{\mathrm{h}} 1$ cells and NK cells $(140,141)$. Gzmb is a serine protease expressed by $\mathrm{T}_{\mathrm{c}}$ cells and $\mathrm{NK}$ cells and is part of their complement of effector proteins that mediate targeted cell death $(142,143)$.

The two real time PCR assays reinforce the concept developed from the gene expression array that in the absence of IFN- $\gamma$ a proinflammatory state is induced. This state appears to be largely mediated by the upregulated expression of proinflammatory cytokines. In the IFN- $\gamma^{--}$mice there is increased production of IL-17, IL-1 $\beta$, IL-6, 


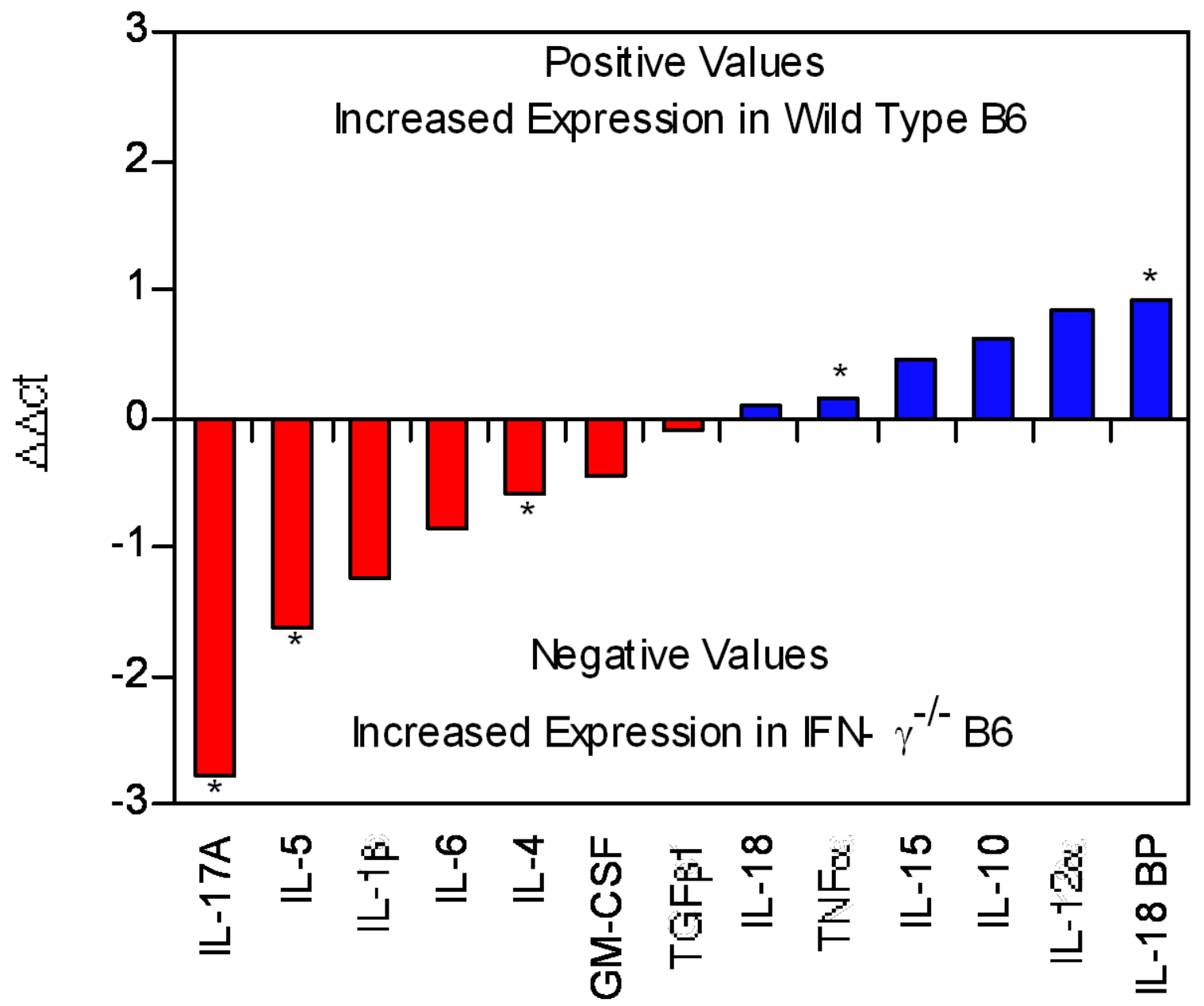

Probe Set

Figure 4.4 Differential Expression of Cytokine Genes between Wild Type and IFN- $\gamma^{-/}$B6 Mice Immunized with CII/CFA.

Wild type or IFN- $\gamma^{-/-}$B6 mice were immunized with CII/CFA emulsion and lymphocytes were recovered from the draining popliteal lymph nodes ten days later. mRNA was isolated from these cells and used to perform Real Time PCR analysis of cytokine gene expression. Data is represented as the $\Delta \Delta \mathrm{ct}$ of IFN $-\gamma^{-/-}$minus wild type, and represents the difference in cycle times between the wild type and IFN $-\gamma^{-/ 2}$ required to reach a threshold value of PCR amplification. Positive values indicate higher gene expression in the wild type cells while negative values indicate higher expression in the IFN- $\gamma^{-/ 2}$ derived cells. In the IFN- $\gamma^{-/}$derived lymphocytes, expression of IL-17A, IL-5, IL-1 $\beta$, IL-6, IL-4, and GM-CSF mRNA was higher than in the wild type cells. TNF- $\alpha$, IL-15, IL-10, IL$12 \alpha$ and IL-18 BP mRNA expression was higher in the wild type B6 cells. $\left({ }^{*} \mathrm{p}<0.05\right)$ 

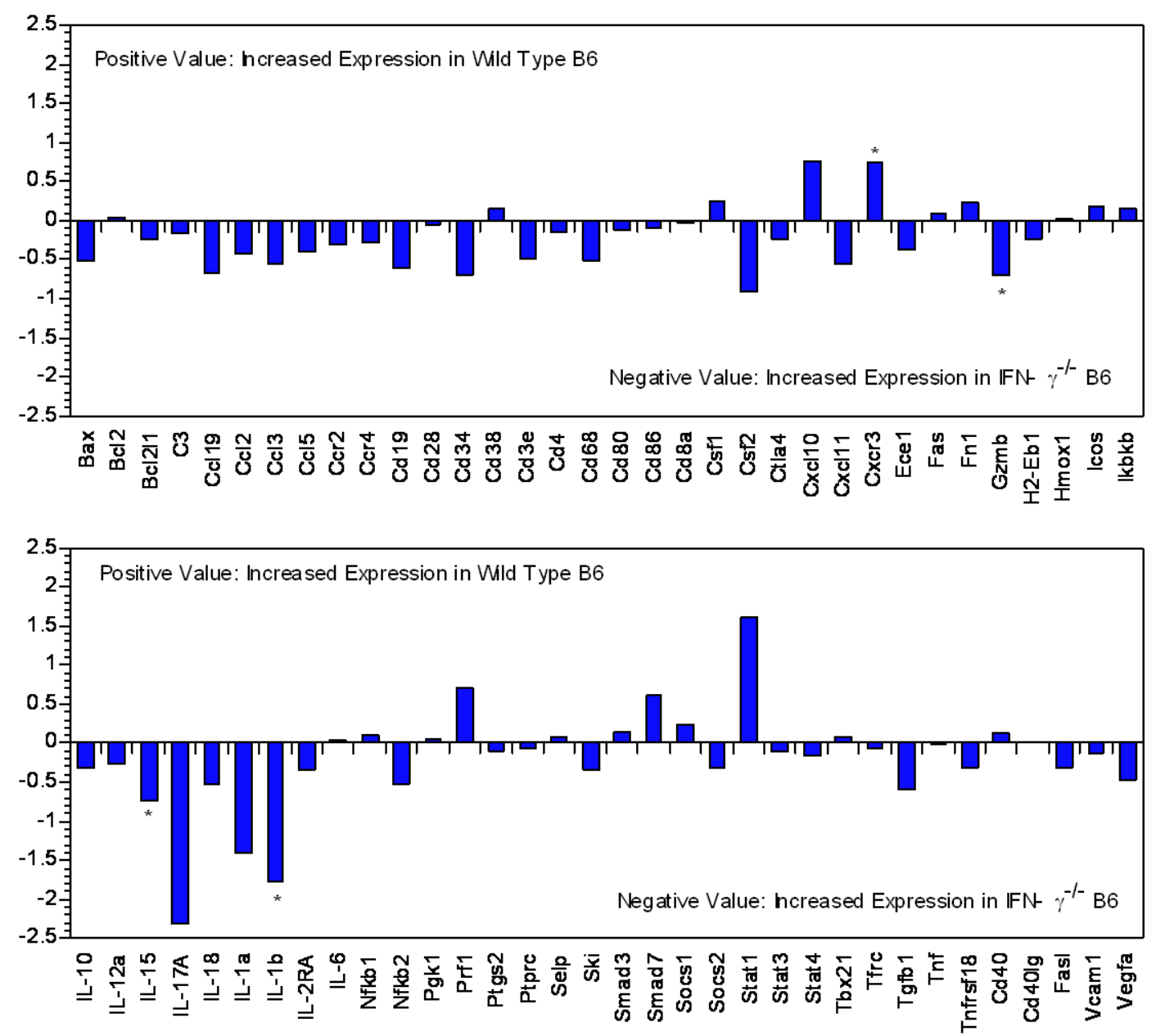

Figure 4.5 Differential Expression between Wild Type and IFN- $\gamma^{-/-}$B6 Mice Immunized with CII/CFA Measured by Immune Panel Real Time PCR Array. mRNA was prepared from lymphocytes recovered from the draining lymph nodes of wild type or IFN- $\gamma^{-/-}$B6 mice 10 days following immunization with CII/CFA. This mRNA was converted to cDNA for use in a microfluidics based real time PCR assay of immune related genes. Most genes were not significantly differentially expressed between the wild type and IFN $-\gamma^{--}$derived cells, but increased expression of several proinflammatory cytokines occurred in IFN- $\gamma^{-/-}$derived cells. These cytokines include: IL-15, IL-17A, IL$1 \alpha$, IL-1 $\beta$, and TGF $\beta$. (*p $\leq 0.05)$ 
GM-CSF, and TGF $\beta$. Each of these cytokines has been linked to arthritis development in CIA, and their upregulation in the absence of IFN- $\gamma$ likely contributes to arthritis susceptibility in the IFN- $\gamma^{-/-}$B6 mice. Of specific interest, the real time PCR data also supports a role for IFN- $\gamma$ 's regulation of IL-18 and IL-18 BP signaling in the pathogenesis of CIA. The gene expression array, and the real time PCR indicated that IL-18 expression was slightly higher in wild type compared to IFN- $\gamma^{-/-}$cells, and these data were supported by the microfluidics real time PCR data but that difference was not statistically significant. Similarly, the production of IL-18 in stimulated wild type and IFN- $\gamma^{-/}$cells in culture was found to be similar when measured by ELISA (Fig 3.8). In contrast, the expression of IL-18 BP was significantly higher in wild type B6 mice (Fig 4.4). In the gene expression array and the real time PCR analysis, the expression of IL-18 BP was found to be significantly upregulated in the wild type cells as compared to the B6 IFN- $\gamma^{-/}$. Thus, one of the roles of IFN- $\gamma$ appears to be regulation of IL-18 BP expression. The net effect in the B6 IFN- $\gamma^{-/-}$model appears to be that in the absence of IFN- $\gamma$, the function of IL-18 is left unregulated due to the absence of IL-18 BP, conferring susceptibility to CIA.

\section{Modification of Disease Activity by Exogenous IL-18 Binding Protein}

The expression data obtained via the real time PCR supports the concept that IL-18 BP is playing a protective role in the development of arthritis in the wild type B6 mouse. In the wild type mouse, expression of IL-18 BP was elevated over that of the IFN- $\gamma^{-/-}$mouse, and several cytokines downstream of IL-18 signaling were seen to be elevated in the IFN- $\gamma^{-/}$mice including IL-1 $\beta$, GM-CSF, and TGF $\beta 1$. If the low expression of IL-18 BP in the IFN- $\gamma^{-/-}$is permissive to the development of CIA and negative regulation of IL-18 in the wild type mediated by IL-18 BP protects from the development of CIA, then exogenous administration of IL-18 BP to the IFN- $\gamma^{-/-}$strain should reduce the incidence or severity of CIA in the IFN- $\gamma^{-/}$.

To test this concept, IFN- $\gamma^{-/-}$B6 mice were injected intraperitoneally with either 1 mg of recombinant murine IL-18 BPd in $200 \mu \mathrm{l}$ PBS or with $200 \mu \mathrm{l}$ PBS every 24 hours for 10 days. On the second day of this regimen, all mice were immunized with CII/CFA to induce CIA. The development of arthritis in each group was monitored and scored for

disease incidence and severity. In the IFN- $\gamma^{-/-}$B6 mice treated with IL-18 BPd, only 13\% of the mice developed arthritis (Fig 4.6A). The development of arthritis in the treatment group was also delayed until day 40 following immunization with CII. In the control mice, treated with PBS, arthritis incidence was significantly higher $(\mathrm{p}<0.01)$, occurring in $63 \%$ of the mice, and developed 22 days earlier (day 18) than in the IL-18 BPd treated mice (Fig 4.6AB). There was also a marked difference in the severity of arthritis observed in the PBS control mice in comparison to the mice treated with IL-18 BPd. In the PBS treated mice the highest severity score observed was 15 out of a possible 16, and for all mice averaged 8.8 out of 16. In the group treated with IL-18 BPd, arthritis severity was significantly lower than in the PBS control group, with the highest severity score reached being 4 out of 16, and the inflammation was short lived (Fig 4.6C, 4.7A). Arthritis severity as judged by the number of arthritic limbs was also significantly lower 

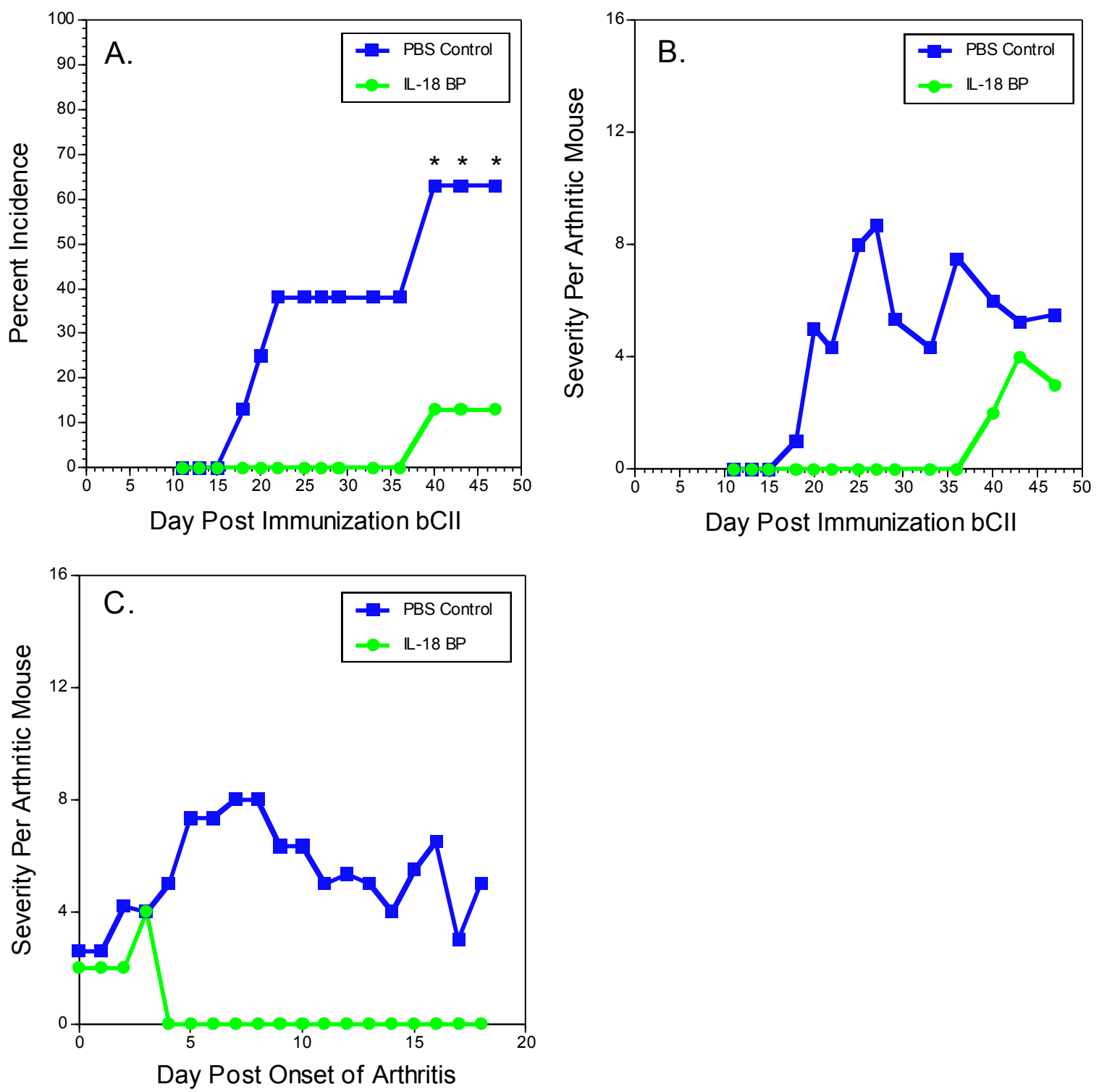

Figure 4.6 Administration of IL-18 BP to B6 IFN- $\gamma^{-/-}$Mice Protects against CIA. B6 IFN- $\gamma^{-/-}$mice were injected intraperitoneally with $200 \mu \mathrm{g}$ of recombinant IL-18 BPd or PBS as a negative control daily for 10 days. On the second day of this regimen the mice were immunized with CII/CFA emulsion in the tail to induce CIA. The mice were then observed for arthritis development and severity. A. Total incidence of arthritis in control PBS $(n=10)$ treated B6 IFN- $\gamma^{-/}(n=9)$ mice is $63 \%$ compared to $13 \%$ in IL-18 $\mathrm{BP}$ treated mice. In the IL-18 BP treated mice, arthritis arises at a delayed time point following immunization with CII/CFA starting on day 40 compared to day 18 in control mice. B. In IL-18 BP treated mice severity per arthritic mouse is approximately half that of the control mice, 8 in IL-18 BP treated mice versus 4 in control mice. C. The dynamics of arthritis were also altered. The PBS control mice exhibited a prolonged active disease period while IL-18 BP treated mice only exhibiting a brief flare of inflammation that quickly subsided over $2-3$ days. $(* p<0.01)$ 


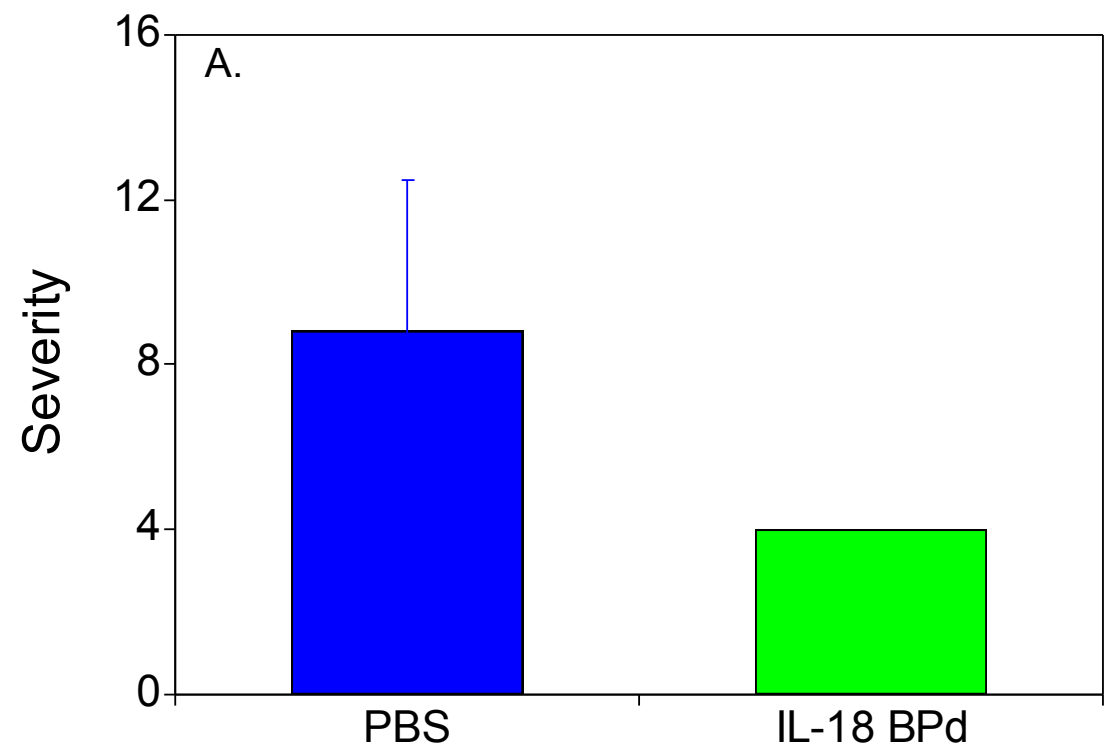

Treatment Group

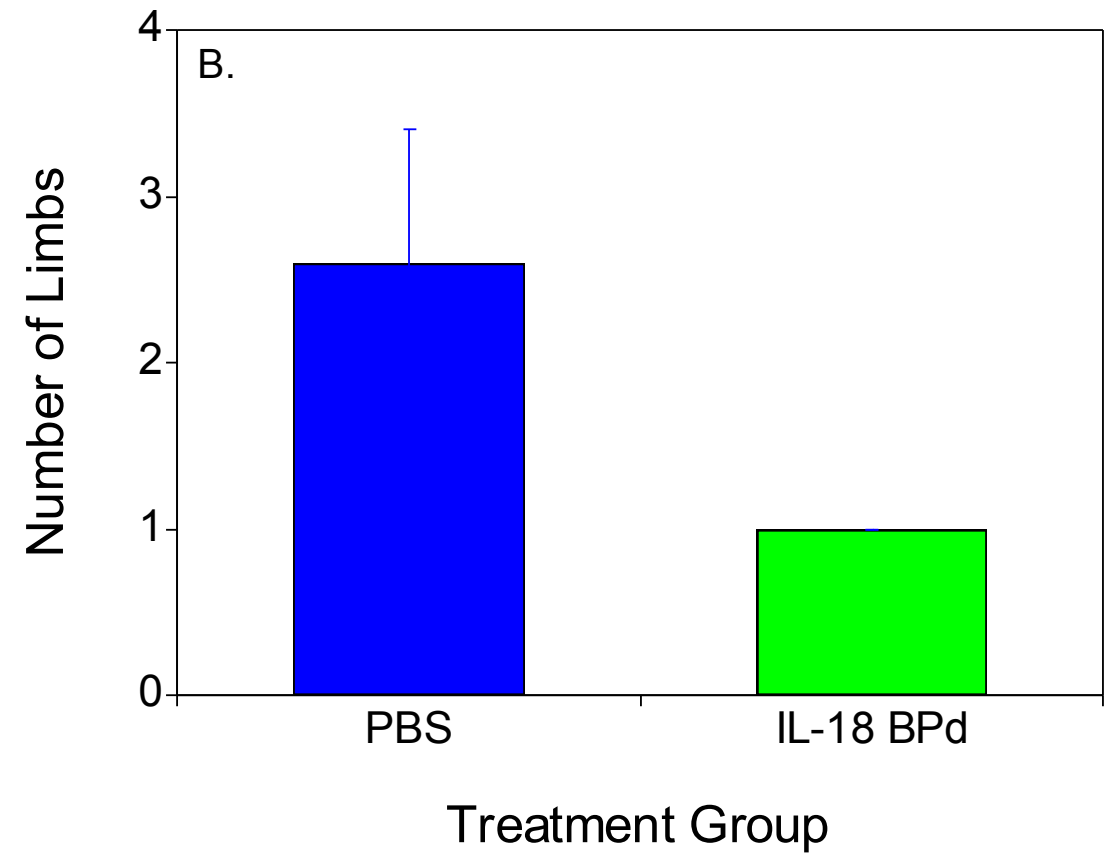

Figure 4.7 In IFN- $\gamma^{-/}$B6 Mice, Severity and Limb Involvement of CIA Are Reduced Following Treatment with IL-18 BP.

10 B6 IFN- $\gamma^{-/}$mice were injected intraperitoneally with $200 \mu \mathrm{g}$ of recombinant IL-18 $\mathrm{BPd}$ or PBS as a negative control daily for 10 days. On the second day of this regimen the mice were immunized with CII/CFA emulsion in the tail to induce CIA. A. The average highest severity was 8.8 out of a maximum 16 in the PBS control mice while in the IL-18 BP treated mice the lone arthritic mouse developed arthritis with a severity of 4. B. The number of limbs affected with arthritis among arthritic mice averaged 2.6 in the PBS group and 1 in the IL-18 BPd treated mice. 
in the IL-18 BPd treated group. The number of limbs in each group that were affected with arthritis averaged 2.6 in the PBS control group and 1.0 in the IL-18 BPd treated group (Fig 4.7B). Thus, treatment with IL-18 BPd protects IFN- $\gamma^{-/-} \mathrm{B} 6$ mice from the development of CIA, delays the onset, and reduces the severity.

To more clearly understand the pro-arthritogenic effects of IL-18 in the development of CIA, wild type B6 mice were treated with exogenous IL-18 and immunized with CII in CFA emulsion. In an experiment similar to the administration of IL-18 BPd, wild type B6 mice were injected intraperitoneally with either $200 \mu \mathrm{g}$ recombinant murine IL-18 in $200 \mu$ PBS or with PBS alone every 24 hours for 10 days. On day two following the first injection with IL-18 or PBS, the mice were immunized with CII/CFA emulsion and monitored for the development of arthritis. When treated with IL-18 or PBS, none of the wild type B6 mice developed arthritis (data not shown). While it is difficult to make a conclusion from these negative results, two likely explanations seem plausible. First, IL-18 alone may not be sufficient to confer susceptibility in the B6 mouse. Other factors upstream of IL-18 upregulation may be required. Second, production of IFN- $\gamma$ is not impaired in the B6 mouse, and the gene expression data indicates that IL-18 BP is produced at high levels compared to the IFN- $\gamma^{-/}$B6 mouse. The negative feedback pathway that regulates IL-18 activity (IL-18 promotes IFN- $\gamma$ production, which in turn promotes IL-18 BP production) may increase levels of IL-18 BP in order to neutralize the extra, exogenously administered IL-18. The self-regulating nature of the normal immune system in the wild type B6 mouse may be capable of mitigating the effects of the extra proinflammatory signal and thus avoids autoimmunity.

\section{Alterations in Function Due to Cytokine Regulation by IL-18, IL-17, and IFN- $\gamma$}

\section{Alterations in Proliferative Response}

The gene expression data and the protection from arthritis by IL-18 BPd, indicates a role for IL-18, IL-18 BP, and IL-17 downstream of IFN- $\gamma$ regulation of CIA pathogenesis. Studies by others have indicated a T cell proliferative defect in IFN- $\gamma^{-/-}$ mice (65). Disregulated proliferation of T cells in the absence of IFN- $\gamma^{-/}$has been implicated as a potential pathogenic mechanism in autoimmune models of CIA and EAE. Baseline proliferation of lymph node cells either in the absence of antigen stimulation or $\mathrm{T}$ cell proliferation following immunization with antigen and stimulation in culture with either CII, $\operatorname{Mog}(35-55)$ or microbial antigens is increased in cells from IFN- $\gamma^{-/-}$B6 compared to wild type cells $(65,144-146)$. Both IL-18 and IL-17 have proinflammatory functions that support the differentiation and expansion of many immune cell types including T cells, NK cell, and monocytes/macrophages, either by acting directly on target cells, or through induction of other proinflammatory cytokines $(120,137,147$, 148). Since the actions of these cytokines are regulated by IFN- $\gamma$, increased proliferation observed in cells from IFN- $\gamma^{-/-}$mice may be due to the activity of IL-18 or IL-17. 
To test this concept, exogenous IL-18, IL-18 BPd, IFN- $\gamma$, and IL-17 was added to cultures of splenocytes from either naive wild type or IFN- $\gamma^{-/}$B6 mice, and proliferation in response to anti-CD3 and anti-CD28 stimulation was measured by ${ }^{3} \mathrm{H}$-thymidine incorporation. In control cultures without exogenous cytokine, the proliferation in response to anti-CD3 and anti-CD28 stimulation was greatly increased in the IFN- $\gamma^{-/-}$ cells compared to the wild type (Fig 4.8A). Proliferation in the IFN- $\gamma^{-/-}$cells was 122,000 \pm 3000 DPM versus $31,000 \pm 5,000$ DPM in the wild type, clearly indicating an enhanced proliferative state in the IFN- $\gamma^{-/-}$cells $(\mathrm{p}<0.05)$. The cells were then stimulated with anti-CD3 and anti-CD28 antibodies in the presence of $5 \mu \mathrm{g} / \mathrm{ml} \mathrm{IL-18} \mathrm{BPd,} 6 \mathrm{ng} / \mathrm{ml} \mathrm{IFN-} \gamma$, $240 \mathrm{ng} / \mathrm{ml} \mathrm{IL-18}$, or $8 \mathrm{ng} / \mathrm{ml} \mathrm{IL-17}$ (Fig 4.8B). To illustrate the differential effect of these cytokines on the proliferative response of cells from wild type or IFN- $\gamma^{-/-}$B6 mice, the proliferation in each culture condition was normalized to the proliferation observed in the control cultures, and is displayed as the percentage of the control. The addition of exogenous cytokines affected the proliferation of wild type cells to a greater extent than the IFN- $\gamma^{-/-}$derived cells. In the wild type, the addition of IL-18 enhanced the proliferative response to $284 \pm 41 \%$ of the control cell response $(\mathrm{p}<0.05)$. In the IFN- $\gamma^{-/-}$ cells, proliferation was $120 \pm 1 \%$ of the control $(\mathrm{p}<0.05)$. When IL-18 BPd was added to the cell cultures, there was a large suppressive effect on proliferation in the wild type cells, but not in the IFN- $\gamma^{-/-}$derived cells. The wild type cells proliferated at only $50 \pm$ $5 \%$ of the control. The wild type cells stimulated with IL-17 did not proliferate more than control cells while in the IFN- $\gamma^{-/-}$derived cells proliferation was slightly higher, 110 $\pm 5 \%$ of the control $(p<0.05)$. The addition of IFN- $\gamma$ significantly suppressed IFN- $\gamma^{-/}$ derived cell proliferation $(\mathrm{p}<0.05)$, but not wild type cells. While statistically significant, the small changes in proliferation observed in the IFN- $\gamma^{-/-}$derived cells when co-cultured with IFN- $\gamma$ or IL-17 may not be biologically significant given the greatly increased proliferative response observed when these cells were stimulated with anti-CD3 and anti-CD28 alone. These data indicate that IL-18 has strong pro-proliferative effects on T cells, with IL-18 strongly supporting proliferation of T cells from wild type B6 mice and to a lesser extent in IFN- $\gamma^{-/}$cells. In wild type cells, this pro-proliferative effect of IL-18 is regulated by IL-18 BP, indicated by the suppression of proliferation when extra exogenous IL-18 BPd is added. In IFN- $\gamma^{-/-}$derived cells, addition of IL-18 BPd is less effective in inhibition of proliferative response to anti-CD3 and anti-CD28 stimulation. This is perhaps due to reduced endogenous IL-18 BP production, or is an indication that proliferation on these cells is supported by the action of other proinflammatory cytokines in addition to IL-18 such as IL-17, TNF- $\alpha$, IL-1 $\beta$, or GM-CSF, all of which have been shown to be increased in IFN- $\gamma^{-/-}$cells following stimulation (Fig. 3.8). Since expression of IL-18 BP is mediated by IFN- $\gamma$, and as indicated here, IL-18 BP regulates T cell proliferative responses in wild type mice, this data reinforces the concept that IFN- $\gamma$ is a regulator of autoimmune development, and one mechanism of this regulation may be by the inhibition of $\mathrm{T}$ cell proliferation. 

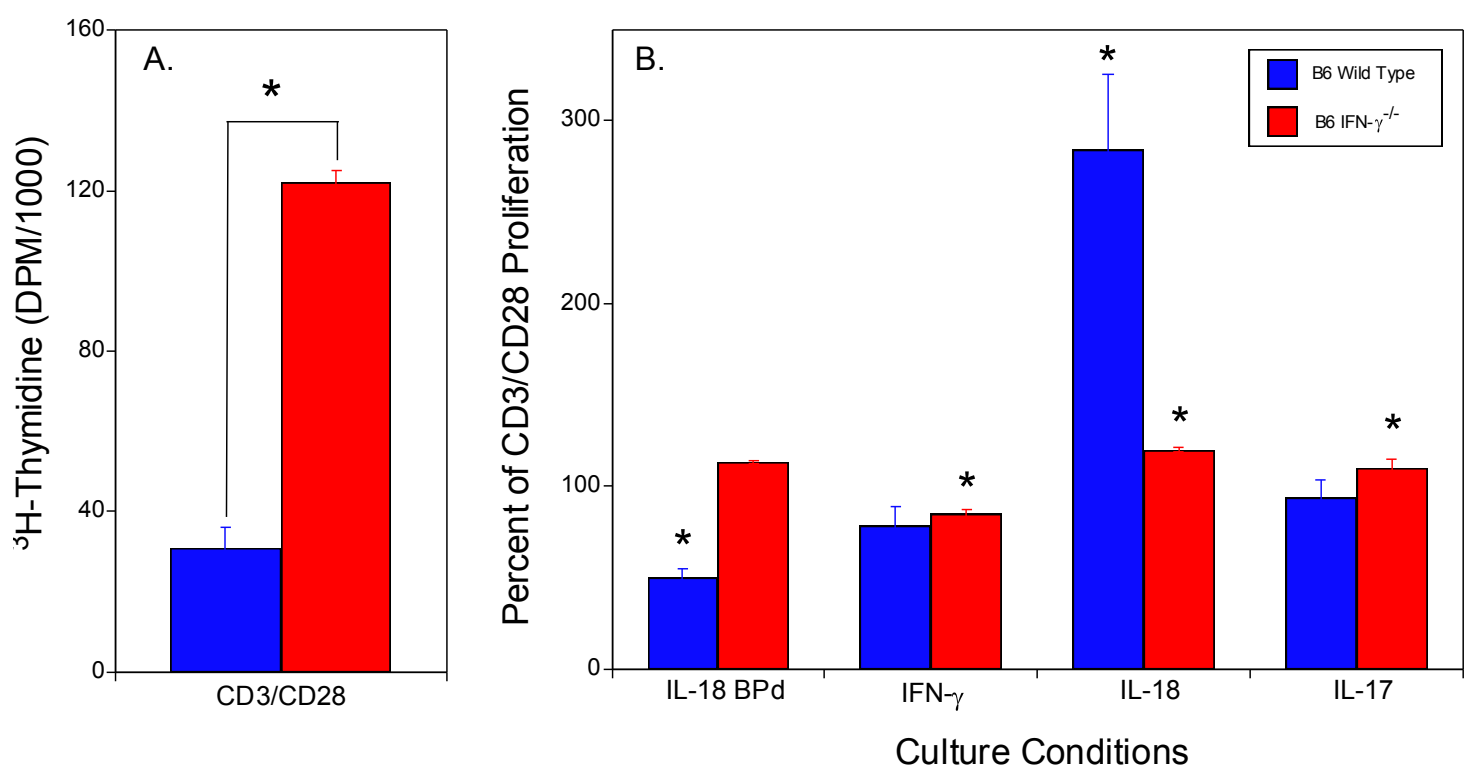

Figure 4.8 Exogenous Administration of Proinflammatory Cytokines or IL-18 BP Alters the Proliferative Response of Splenocytes from Both Wild Type and IFN$\gamma^{-/-}$B6 Mice When Stimulated in Culture with Anti-CD3 and Anti-CD28.

Splenocytes from naïve B6 or B6 IFN- $\gamma^{-/-}$mice were stimulated in culture with anti-CD3 and anti-CD28 monoclonal antibodies in the presence of exogenous IL-18 BPd $(5 \mu \mathrm{g} / \mathrm{ml})$, IFN- $\gamma(6 \mathrm{ng} / \mathrm{ml})$, IL-18 $(240 \mathrm{ng} / \mathrm{ml})$, and IL-17 $(8 \mathrm{ng} / \mathrm{ml})$. Proliferation was measured by ${ }^{3} \mathrm{H}$-thymidine incorporation. A. When stimulated with anti-CD3 and anti-CD28 splenocytes from B6 IFN- $\gamma^{-/-}$mice proliferated to a greater extent than wild type B6 derived cells. B6 IFN $-\gamma^{--}$splenocytes proliferated four fold more than the B6 wild type derived cells. B. In order to measure the effect of exogenously added IL-18 BPd, IFN- $\gamma$, IL-18, and IL-17 on the proliferative response of splenocytes from wild type IFN- $\gamma^{-/-}$B6 mice, proliferation in the presence of each cytokine and IL-18 BPd was normalized to the proliferation observed without exogenous cytokine or IL-18 BPd. This allows comparison of alterations in proliferative response in each culture condition, and comparison of the relative effect on proliferation between the wild type and IFN- $\gamma^{-/} \mathrm{B} 6$ derived splenocytes. In the wild type B6 derived cells addition of IL-18 or IL-18 BP, increased or decreased proliferative response, respectively. In the IFN- $\gamma^{-/}$B 6 derived cells, there were minor alterations in proliferative response when IL-18, IL-18 BP, IFN- $\gamma$, or IL-17 were added. IL-18, and IL-17 significantly promoted increased proliferation in the IFN- $\gamma^{-/}$derived cells while IFN- $\gamma$ significantly reduced proliferative response.

However, these changes are small compared to the high proliferation observed without exogenous addition of cytokines and may not be biologically relevant. $(* p<0.05)$ 


\section{Alterations in Cytokine Production}

One key concept in understanding cytokine regulation of immune function is that cytokines do not operate independently, but in cytokine networks that consist of both stimulatory and inhibitory signals, the balance of which determines the ultimate outcome in terms of cell differentiation, function, and immune response. To better understand how cytokine networks that are permissive to autoimmunity develop in the IFN- $\gamma^{-/-}$mice cytokine production by T cells from wild type and IFN- $\gamma^{-/-}$B6 mice were measured. Splenocytes from naïve wild type or IFN $-\gamma^{-/-}$B6 mice were stimulated in culture for three days with anti-CD3 and anti-CD28 and supernatants were analyzed for cytokine expression using a multiplexed ELISA. Cytokines that were shown to have differential expression between wild type and IFN- $\gamma^{-/-}$B6 mice in the above gene expression and cellular assays were selected based on whether or not their expression is stimulated by IFN- $\gamma$, IL-18, or IL-17, and their relevance to CIA pathogenesis. To assess the role of IFN- $\gamma$, IL-18, and IL-17 on the production of these cytokines in the stimulated splenocytes from wild type and IFN- $\gamma^{-/-}$B6, exogenous recombinant IFN- $\gamma$, IL-18, IL-17 and IL-18 BPd was titrated at concentrations spanning their effective dose in culture. When the concentration of cytokines produced by the stimulated cells was examined it was noted that in the wild type cells there was a dearth of cytokine production following stimulation. Only IFN- $\gamma$ was produced at high levels (Fig 4.9AC). This was in contrast to the production of cytokines in the stimulated IFN- $\gamma^{--}$cells. In these cells there was increased production of IL-2, GM-CSF, IL-13, IL-4, IL-17, IL-5, TNF- $\alpha$, M-CSF, IL-6, and IL-1 $\beta$ with anti-CD3 and anti-CD28 stimulation only (Fig 4.9BD). When exogenous cytokines were added to the cell cultures many modulating effects on cytokine production were noted. The addition of IL-18 BPd had contradictory effects on cytokine production in both wild type and IFN- $\gamma^{-/-}$cells. In the wild type T cells, both IFN- $\gamma$ and IL-17 expression increased with the addition of IL-18 BPd (Fig 4.9AC). In the IFN- $\gamma^{-/}$cell cultures, titration with IL-18 BP promoted increased production of IL-2, GM-CSF, IL-13, IL-4, IL-17, TNF- $\alpha$, IL-5, IL-6, and IL-1 $\beta$ (Fig 4.9BD). IL-18 had potent effects on cytokine production in both wild type and IFN $-\gamma^{-/-}$derived cells. Treatment of wild type derived cells in culture with IL-18 promoted increased production of IFN- $\gamma$, GM-CSF, IL-13, IL-4, IL-2, IL-17, TNF- $\alpha$, IL-6, IL-1 $\beta$, IL-5, and M-CSF (Fig 4.10AC). In the IFN- $\gamma^{-/-}$derived cells, stimulation with IL-18 promoted increased production of IL-13, GM-CSF, IL-17, and IL-5 (Fig 4.10BD). The addition of IL-17 to wild type cell promoted increased TNF- $\alpha$ production (Fig 4.11AC). In the IFN- $\gamma^{-/-}$culture, addition of IL-17 caused increases in the expression of IL-13, IL-4, and TNF- $\alpha$ (Fig 4.11CD). Addition of IFN- $\gamma$ had minimal effects on the wild type cultures causing increased expression of only IL-17 (Fig 4.12AC), but in the IFN- $\gamma^{-/-}$derived cell cultures, there was a dampening effect on cytokine production inhibiting the production of all cytokines measured (Fig 4.12BD). These data illustrate the complex effects of IL-18, IL-17, and IFN- $\gamma$ on the development of cytokine networks. IL-18 has potent effects on the production of proinflammatory cytokines in both the wild type and IFN- $\gamma^{-/-}$cultures which is consistent with a role for IL-18 and IL-18 BP in the regulation of CIA pathogenesis. IL-17 has less of a role in the stimulation of cytokines and seemed to potentiate cytokine production in the IFN- $\gamma^{-/-}$rather than have strong inductive effects. 

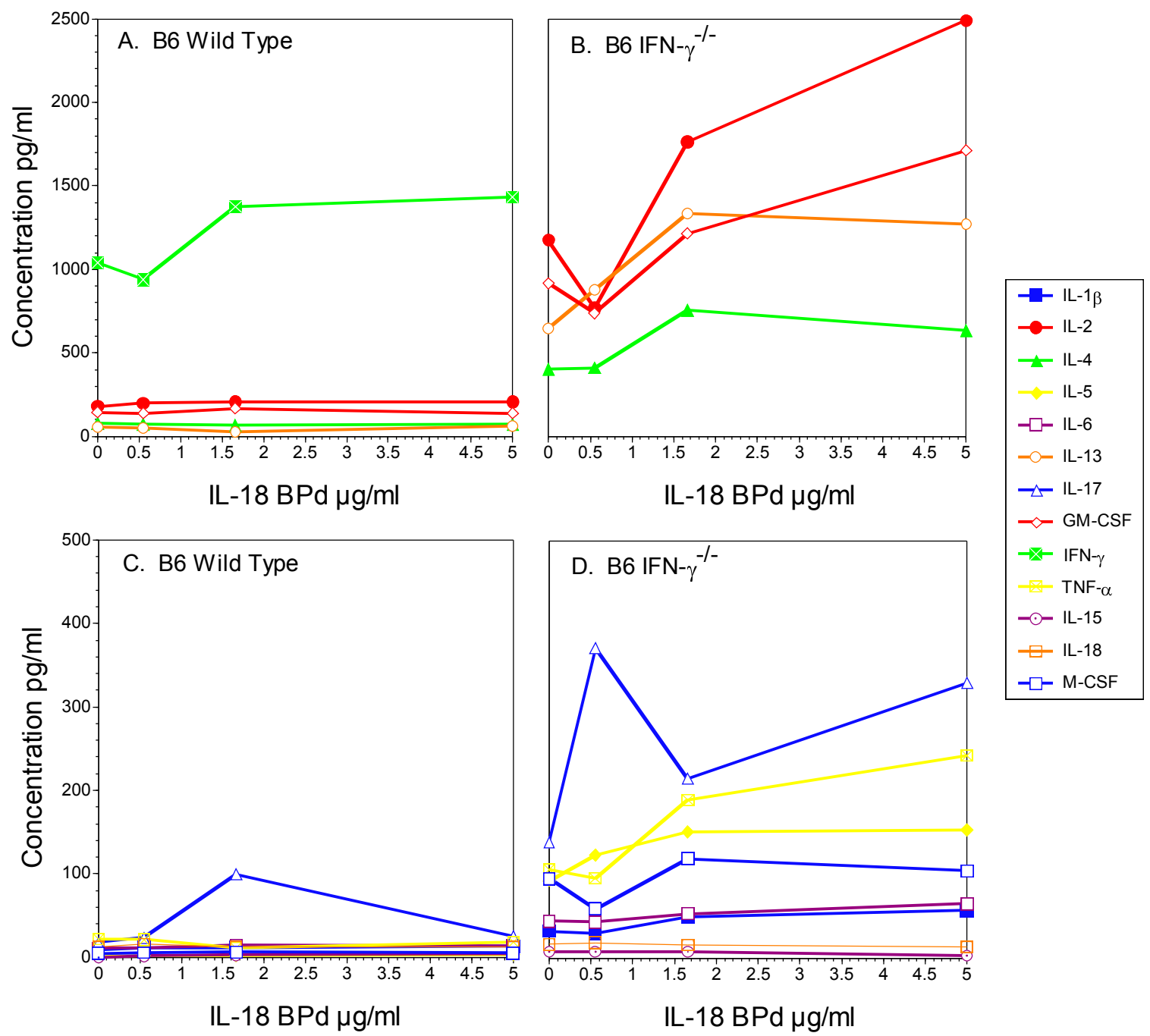

Figure 4.9 Modification of Lymphocyte Cytokine Expression by IL-18 BPd in Lymphocyte Cultures Stimulated with Anti-CD3 and Anti-CD28.

Splenocytes from naïve B6 and B6 IFN- $\gamma^{-/-}$mice were stimulated in culture with antiCD3 and anti-CD28 monoclonal antibodies in the presence of IL-18 BPd titrated over its effective dose. AC. There was decreased production of cytokines in stimulated wild type derived cells compared to IFN $-\gamma^{-/-}$derived cells with only IFN- $\gamma$ produced at high levels in the wild type cells. When stimulated with anti-CD3/CD28 in the presence of IL18 BPd increased production of IFN- $\gamma$ and IL-17 was observed. BD. Conversely, antiCD3/CD28 stimulation of IFN- $\gamma^{-/-}$derived cells resulted in increased production of IL-2, GM-CSF, IL-13, IL-4, IL-17, TNF- $\alpha$, IL-5, M-CSF, IL-6, and IL-1 $\beta$ when compared to the wild type cells. Titration with IL-18 BP promoted increased production of IL-2, GMCSF, IL-13, IL-4, IL-17, TNF- $\alpha$, IL-5, IL-6, and IL-1 $\beta$. 

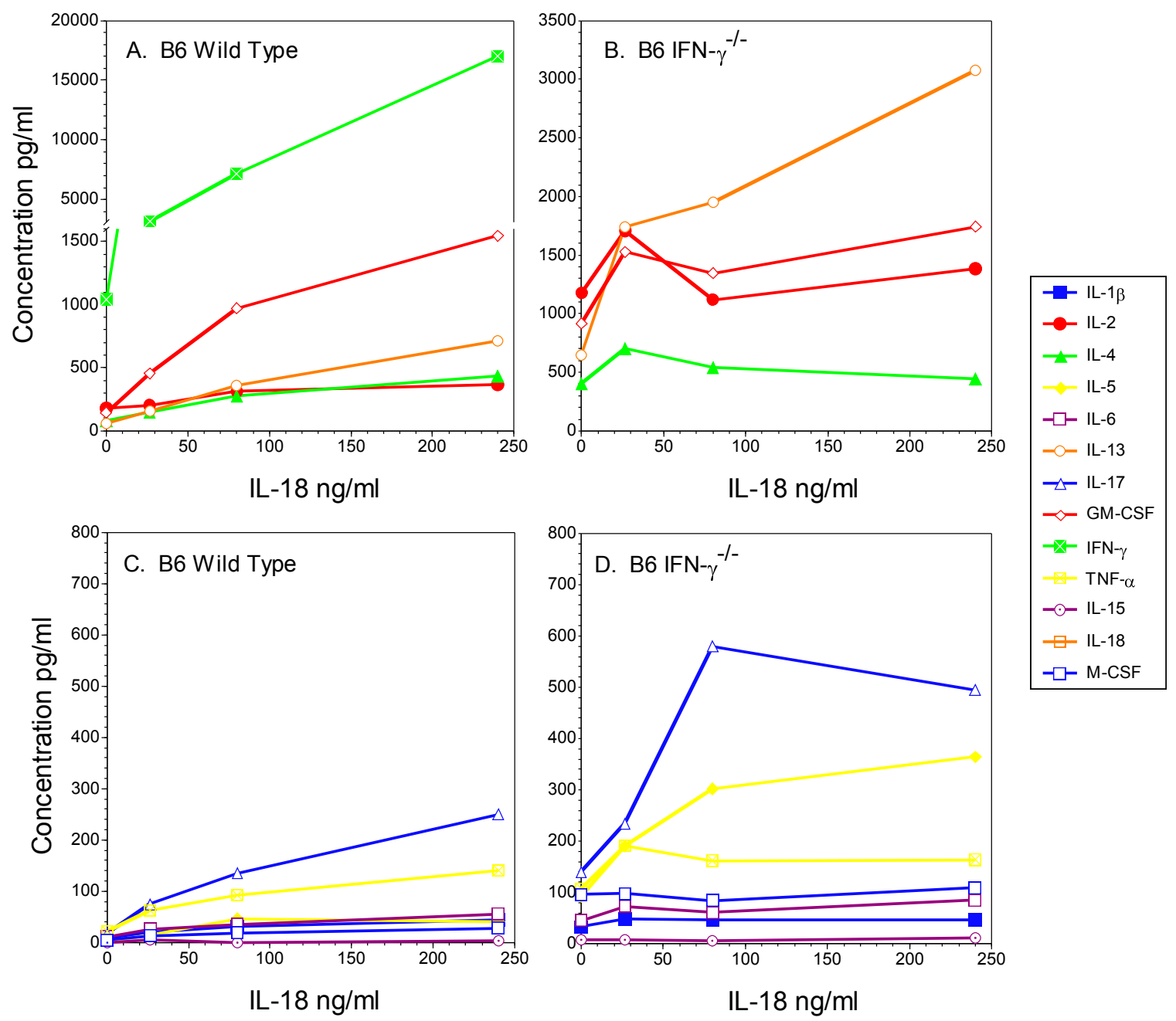

Figure 4.10 Modification of Lymphocyte Cytokine Expression by IL-18 in Lymphocyte Cultures Stimulated with Anti-CD3 and Anti-CD28.

Splenocytes from naïve $\mathrm{B} 6$ and $\mathrm{B} 6 \mathrm{IFN}-\gamma^{-/-}$mice were stimulated in culture with antiCD3 and anti-CD28 monoclonal antibodies in the presence of IL-18 titrated over its effective dose. AC. Treatment of wild type derived cells in culture with IL-18 promoted increased production of IFN- $\gamma$, GM-CSF, IL-13, IL-4, IL-2, IL-17, TNF- $\alpha$, IL-6, IL-1 $\beta$, IL-5, and M-CSF. BD. In the IFN- $\gamma^{-/-}$derived cells, stimulation with IL-18 promoted increased production of IL-13, GM-CSF, IL-17, and IL-5. The expression of IL-4, MCSF, TNF- $\alpha$, IL-6, and IL-1 $\beta$ were unaffected, yet were produced at high levels when compared to the wild type derived cells. 

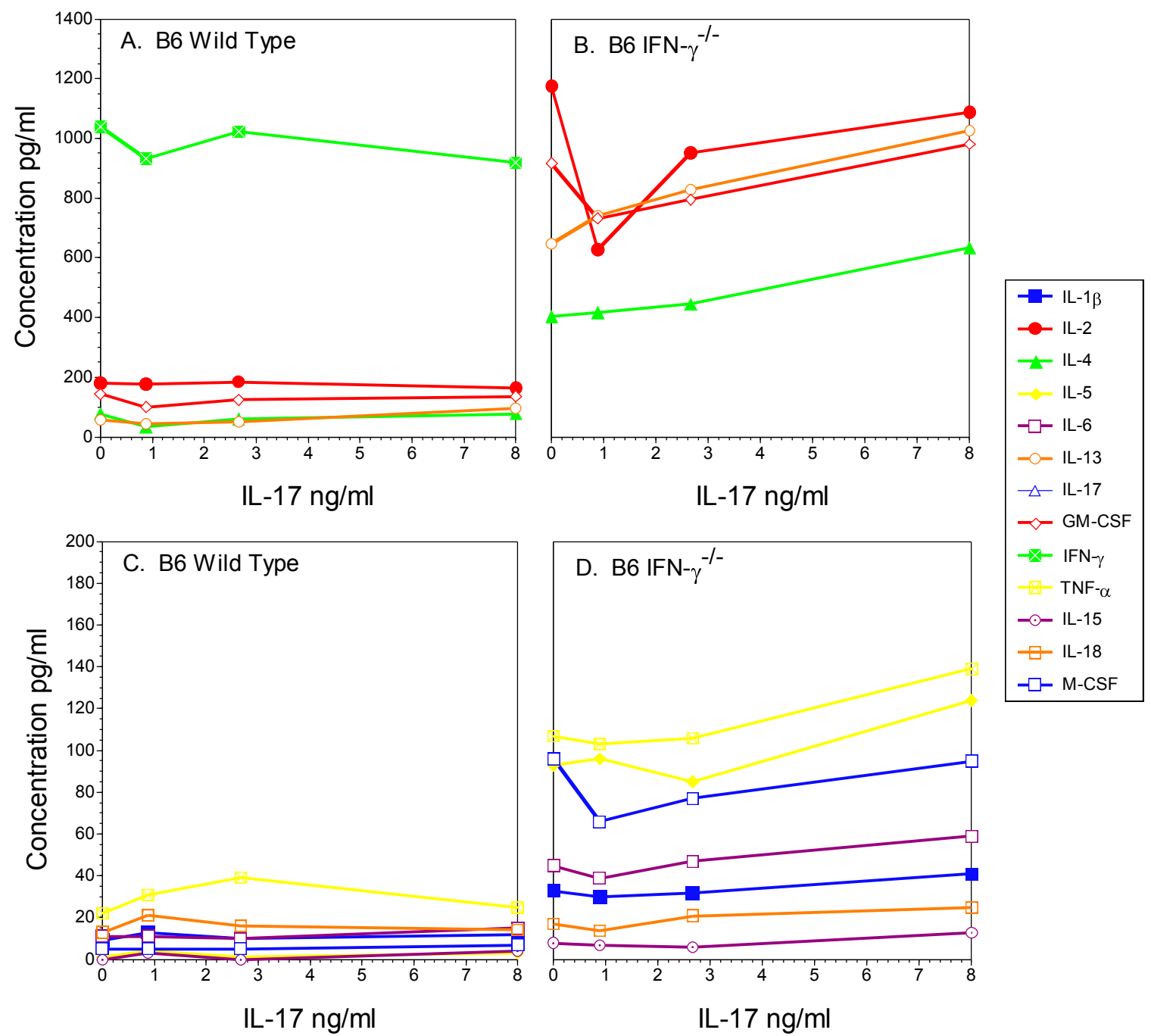

Figure 4.11 Modification of Lymphocyte Cytokine Expression by IL-17 in Lymphocyte Cultures Stimulated with Anti-CD3 and Anti-CD28.

Splenocytes from naïve B6 and B6 IFN- $\gamma^{-/-}$mice were stimulated in culture with antiCD3 and anti-CD28 monoclonal antibodies in the presence of IL-17 titrated over its effective dose. AC. When wild type derived cells were stimulated with anti-CD3/CD28 in the presence of IL-17, only increased production of TNF- $\alpha$ was observed. BD. Addition of IL-17 to IFN- $\gamma$ derived cells promoted increased production of IL-13, IL-4, and TNF- $\alpha$. 

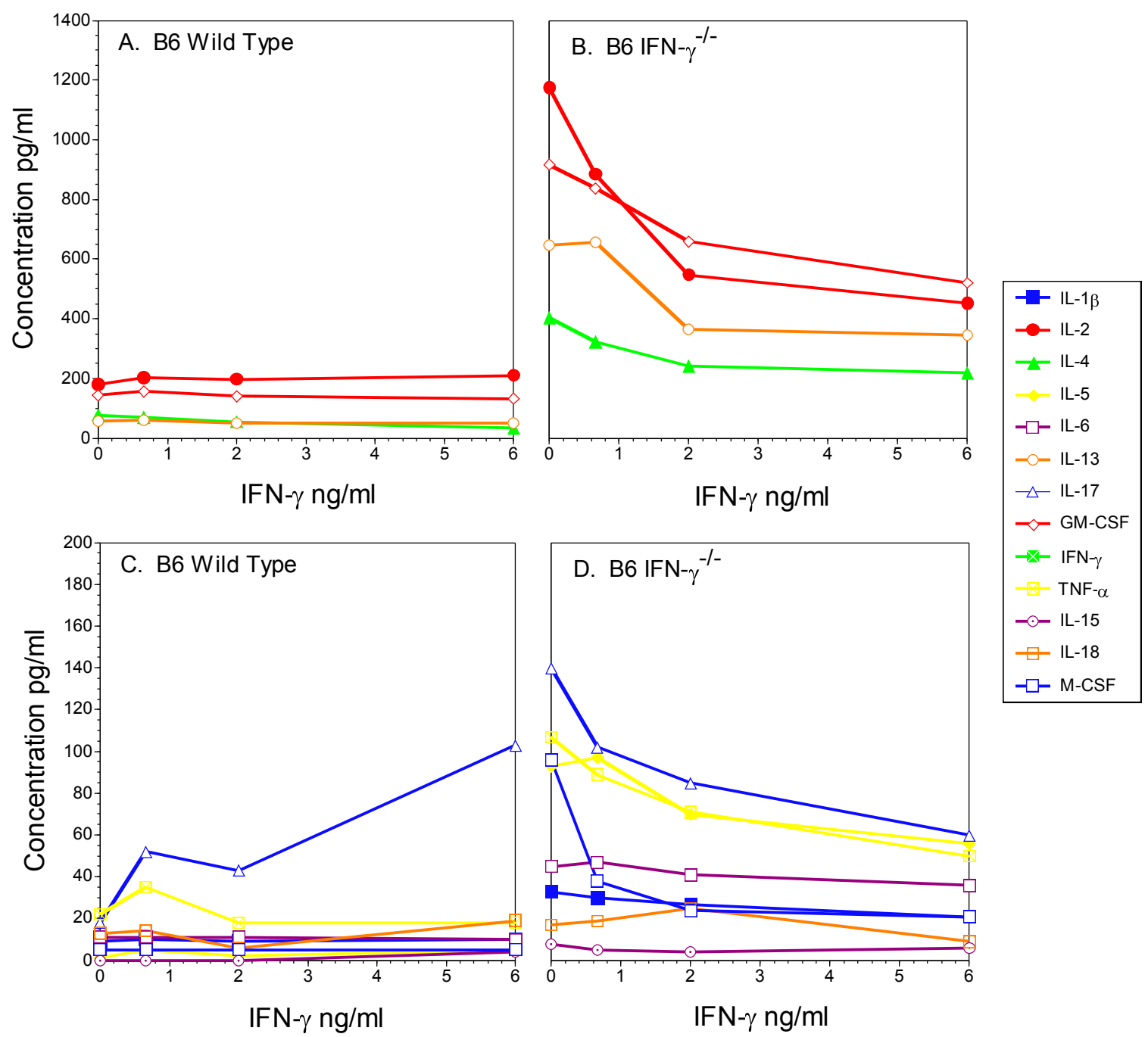

Figure 4.12 Modification of Lymphocyte Cytokine Expression by IFN- $\gamma$ in Lymphocyte Cultures Stimulated with Anti-CD3 and Anti-CD28.

Splenocytes from naïve B6 and B6 IFN- $\gamma^{-/-}$mice were stimulated in culture with antiCD3 and anti-CD28 monoclonal antibodies in the presence of IFN- $\gamma$ titrated over its effective dose. AC. In wild type derived cells, most cytokines were unaffected by the addition of IFN- $\gamma$, however, decreased production of TNF- $\alpha$, and increased production of IL-17 was observed. BD. Addition of IFN- $\gamma$ to stimulated cells derived from IFN- $\gamma^{-/}$ mice had inhibitory effects on cytokine production. Production of all cytokines measured decreased as IFN- $\gamma$ was added to the cultures. 
These data also illustrate the role of IFN- $\gamma$ as a regulatory cytokine. This suppressive effect of IFN- $\gamma$ on the production of proinflammatory cytokines in the IFN- $\gamma^{-/-}$culture indicates that suppression of proinflammatory cytokine production may be one mechanism by which IFN- $\gamma$ protects against the development of CIA in wild type B6 mice.

\section{Discussion}

In these studies we sought to identify a mechanism for alterations in the cytokine milieu mediated by IFN- $\gamma$ that regulate a pathogenic immune response that leads to autoimmunity. To identify this mechanism, alterations in the gene expression and functional markers of immune response between wild type and IFN- $\gamma^{-/-}$B6 mice immunized with CII were investigated in order to identify potential autoimmune mediators that develop as a result of IFN- $\gamma$ deficiency. These studies identified a number of genes whose expression was altered by the absence of IFN- $\gamma$. Among these genes, a specific cytokine signaling pathway, IFN- $\gamma$ 's regulation of IL-18 BP expression, was identified as an important mediator of the pathogenesis of autoimmune arthritis. IL-18 BP expression was reduced in the IFN $-\gamma^{-/-}$mouse and was shown to protect from the development of CIA. In addition, the production of proinflammatory cytokines is increased in the absence of IFN- $\gamma$, resulting in altered $\mathrm{T}$ cell effector function that potentially promotes susceptibility to autoimmune arthritis in IFN- $\gamma^{-/-}$B6 mice.

The expression of genes that are regulated by IFN- $\gamma$, and that contribute to arthritis pathogenesis during the development of CIA, were identified by comparing mRNA expression in lymphocytes obtained from wild type and IFN- $\gamma^{-/}$B6 mice immunized with CII/CFA. The use of a gene expression array identified 1612 genes expressed at statistically significant distinct levels between the two strains of mice. This is nearly $5 \%$ of the 34,000 genes measured, and indicates that IFN- $\gamma$ plays a major role in regulating gene expression during the initial immune response to CII. The gene expression array provided a starting point to uncover the pathogenic mechanisms that lead to autoimmunity in the IFN- $\gamma^{-/-}$B6 mouse. A number of genes that are directly related to immune function were differentially expressed between the wild type and IFN- $\gamma^{-/}$mice, including cytokines and chemokines, immune cell receptors, and tissue remodeling genes that possibly contribute to joint destruction during active inflammation. However, while only IFN- $\gamma^{-/-}$B6 mice are susceptible to CIA, it is important to note that the wild type mouse was also immunized with CII/CFA. Even without the CII component, CFA is strongly immunogenic. The Mtb present in CFA stimulates $T_{h} 1$ responses, while the paraffin oil stimulates innate immune mechanisms (149). The strong IFN- $\gamma$ response to the Mtb in the wild type mouse may explain the increased expression in these mice of several cytokines including IL-5, IL-12, and the immune receptors TLR 3 and TLR 7. However, when one examines the genes that are differentially expressed in the IFN- $\gamma^{-/-}$mouse, a pro-arthritogenic pattern of gene expression emerges, and many of the genes identified by the expression array have been linked to the development of RA or CIA. In the IFN- $\gamma^{-/-}$mice, these differentially expressed genes include increased expression of the cell trafficking molecule Clfsf3 whose expression has been linked to 
increased risk of RA (113). In addition, evidence of increased joint remodeling in IFN- $\gamma^{-/ 2}$ mice is observed in the overexpression of genes including chondroitan sulfate proteoglycan 2 , and the matrix metalloproteinases 15 , and 19. Additionally, two cytokines with immunomodulatory functions are identified as differentially expressed between the wild type and IFN- $\gamma^{-/}$mouse. These include increased expression of the proinflammatory cytokine IL-17 and the reduced expression of IL-18 BP in the IFN- $\gamma^{-1-}$ mouse.

The expression of both IL-18 and IL-17 has been linked to the development of autoimmunity in both human and rodent models $(22,120,150)$. Based on their known proinflammatory function, increases in the expression of IL-18 and IL-17 are likely linked to the increased susceptibility of CIA in the IFN- $\gamma^{-/-}$mouse. Therefore, to further examine the functional changes that occur in the autoimmune response due to the absence of IFN- $\gamma$, the expression of specific immune related genes was quantitated using real time PCR. These data indicated that in the absence of IFN- $\gamma$ there is upregulated expression of the proinflammatory cytokines IL-17, IL-1 $\beta$, IL-6, GM-CSF, and TGF $\beta$. Each of these cytokines had been linked to arthritis development in CIA, and their upregulation is consistent with the concept that the absence of IFN- $\gamma$, a proinflammatory phenotype is created that mediates arthritis susceptibility in the IFN- $\gamma^{-/} \mathrm{B} 6$ mice. The real time PCR data also supports a role for IFN- $\gamma$ regulation of IL-18 and IL-18 BP signaling in the pathogenesis of CIA, as the expression of IL-18 BP was significantly higher in wild type B6 mice that are resistant to CIA. IL-18 BP forms part of a feedback regulatory circuit that modulates the activity of IL-18 (151). Increased IL-18 signaling causes increased IFN- $\gamma$ production, which then promotes increased IL-18 BP production. IL-18 BP then binds to IL-18 and prevents its signaling through the IL-18 receptor. IFN- $\gamma$ regulation of IL-18 BP makes sense as a regulator of autoimmune pathogenesis in CIA. Since in the IFN- $\gamma^{-/}$mouse there is no production of IFN- $\gamma$, the result of this is reduced production of IL-18 BP and therefore increased levels of free IL-18 available for binding to its receptor. IL-18 BP expression is induced by IFN- $\gamma$, and IL-18 is known to contribute to or modulate the pathogenesis of RA and CIA, decreased expression of IL-18 BP due to the absence of IFN- $\gamma$ in the IFN- $\gamma^{-/}$mouse results in increased levels of free IL-18 available for signaling, thus increasing its activity and promoting the development of autoimmunity in IFN- $\gamma^{-/}$B6 mice. In order to test this concept that IFN- $\gamma$ 's regulation of IL-18 BP mediates arthritis pathogenesis, the development of CIA was monitored in wild type or IFN- $\gamma^{-1-}$ B6 mice immunized with CII and treated with exogenous IL-18 BP. When treated with exogenous IL-18 BP, IFN- $\gamma^{-/} \mathrm{B} 6$ mice were protected from the development of CIA with reduction in both the incidence and severity of arthritis. These results confirm that IL-18 BP plays a significant role in promoting the development of CIA in IFN- $\gamma^{-/-}$B6 mice.

Having identified IL-18 BP and implicating the expression of proinflammatory cytokines including IL-17 as mediators of autoimmune arthritis in the IFN- $\gamma^{-/}$mouse, we next sought to identify functional mechanisms by which IL-18/IL-18 BP and IL-17 alter immune response to promote autoimmunity. To do this, we examined the functional responses of stimulated $\mathrm{T}$ cells from wild type and $\mathrm{IFN}-\gamma^{-/ 2} \mathrm{~B} 6$ mice in terms of altered 
proliferative and cytokine production of T cells when stimulated with anti-CD3 and antiCD28 in culture and supplied with exogenous IL-17, IL-18, IFN- $\gamma$, and IL-18 BP. Proliferation of $\mathrm{T}$ cells in response to stimulation with anti-CD3/CD28 was significantly increased in the IFN- $\gamma^{-/-}$cells when compared to the wild type and is consistent with published data that the absence of IFN- $\gamma$ expression induces a pro-proliferative state. The most significant alteration in proliferation occurred when IL-18 or IL-18 BP was added to the cultures of wild type cells. In these cultures addition of IL-18 significantly increased proliferation in response to CD3/CD28 stimulation while the addition of IL-18 BP inhibited proliferation in response to $\mathrm{CD} 3 / \mathrm{CD} 28$ stimulation of wild type cells. In IFN- $\gamma^{-/}$cells, proliferative responses to $\mathrm{CD} 3 / \mathrm{CD} 28$ stimulation were also altered when exogenous cytokine was added. When IFN- $\gamma$ was added to the cultures, proliferative responses were slightly inhibited, while IL-17 or IL-18 slightly enhanced the proliferative response. However, though statistically significant, these small alterations may not be biologically significant given the magnitude of proliferation observed in IFN- $\gamma^{-/-}$cells in response to $\mathrm{CD} 3 / \mathrm{CD} 28$ stimulation. The alterations observed in the wild type cells when co-cultured with IL-18 or IL-18 BP and the high proliferative response observed in the IFN- $\gamma^{-/}$cells supports a role for proliferative defects mediated by IFN- $\gamma$ and IL-18 as a potential mechanism of arthritis susceptibility in IFN- $\gamma^{-/-}$B6 mice. We propose that in the IFN- $\gamma^{-/-}$B6 mice, proliferation of T cells is disregulated, while in the wild type mice proliferation is controlled, in part by the negative regulation of IL-18 signaling mediated by IL-18 BP. Evidence of this regulation is the increased or reduced proliferation observed when IL-18 or IL-18 BP, respectively, is added to T cell cultures. In the IFN $-\gamma^{-/-}$B6 there is reduced production of IL-18 BP that allows increased signaling of IL-18 resulting in increased $\mathrm{T}$ cell proliferative responses.

One aspect of our hypothesis that IFN- $\gamma$ regulates autoimmune susceptibility is that in the absence of IFN- $\gamma$, global alterations occur in the immune system milieu that cause a pro-inflammatory phenotype mediated by cytokine signaling that regulates susceptibility to autoimmunity. The previous studies described here have indicated that proinflammatory cytokines are expressed at high levels in IFN- $\gamma^{-/-}$mice and that IL-17 and IL-18 have particular importance in the regulation of autoimmunity. However, to understand autoimmune pathogenesis it is important to consider that cytokines do not operate independently of one another. Instead, immune and accessory cells produce networks of cytokines that provide both stimulatory and inhibitory signals to immune cells. The balance of these signals ultimately directs the final outcome of an immune response. In order to identify how the absence of IFN- $\gamma$ regulates these networks and to characterize the role of IL-17 and IL-18 in this regulation, cytokine production by lymphocytes from wild type or IFN- $\gamma^{-/} \mathrm{B} 6$ mice was measured in culture supernatants following stimulation in culture with anti-CD3 and anti-CD28 antibodies. When cytokine levels were measured in these cultures it was observed that the IFN- $\gamma^{-/-}$derived cells produced an abundance of cytokines when compared to the wild type derived cells including those associated with both an inflammatory $T_{h} 1$ or $T_{h} 17$ response and those associated with a $T_{h} 2$ response. This is consistent with our earlier observations that cytokine production is upregulated in the IFN $-\gamma^{-/-} \mathrm{B} 6$ mice following immunization with CII/CFA. The most significant regulatory mechanism identified by this assay is the 
influence of IL-18 on cytokine expression when added to wild type cell cultures stimulated with anti-CD3/CD28 and the influence of exogenous IFN- $\gamma$ when titrated in cultures of IFN- $\gamma^{-/}$derived cells. IL-18 induces production of cytokines in the wild type derived cells in a pattern that closely resembles the expression pattern of cytokines produced by IFN $-\gamma^{-/-}$derived cells, either with or without exogenous cytokine administration. In addition, when IFN- $\gamma$ is titrated in cultures of stimulated IFN- $\gamma^{-/}$cells there is a inhibition of cytokine production. This result supports the concept that in the IFN- $\gamma^{-/-}$the development of a pro-arthritogenic cytokine network is mediated by increased IL-18 signaling likely due to decreased production of IL-18 BP in the absence of IFN- $\gamma$. Surprisingly, the addition of IL-17 did not seem to greatly alter cytokine production. IL-17 induced only minor increases in cytokine production in IFN- $\gamma^{-/}$ derived cells, and had little or no effect on wild type derived T cells.

These studies have identified mechanisms by which IFN- $\gamma$ mediates arthritis susceptibility. Consistent with our hypothesis that IFN- $\gamma$ acts as a regulator of immune function, alterations in immune function were identified as a result of IFN- $\gamma$ deficiency that likely mediate susceptibility to autoimmunity and CIA in IFN- $\gamma^{-/-}$B6 mice. Among these changes, alterations in cytokine production, proliferative response, and gene expression were observed. A key pathway of IFN- $\gamma$ 's regulation of autoimmune susceptibility was identified as IFN- $\gamma$ 's regulation of IL-18 signaling via its influence on the production of IL-18 BP. This pathway was shown to directly regulate CIA susceptibility as exogenous IL-18 BP protected against the development of CIA when administered to IFN- $\gamma^{-/ 2}$ mice at the time of antigen exposure. These observations about the nature of immune function during an autoimmune response increases our understanding of the regulatory processes that protect from autoimmune development and may potentially serve as models in the design of therapeutic treatments for autoimmune disease. 


\section{Chapter 5. Conclusion}

In the autoimmune disease, RA, the initial events of the autoimmune response are poorly defined. However, several aspects of RA pathogenesis have been identified. For example, $\mathrm{CD}^{+} \mathrm{T}_{\mathrm{h}}$ cells have been implicated in RA pathogenesis due to linkage of HLADR to increased susceptibility to RA (152). Proinflammatory cytokines have also been implicated in driving the pathogenic immune response in RA. The expression of T cell derived cytokines including IL-2, IFN- $\gamma$, and IL-17, has been observed in the synovial fluid of arthritic joints during RA $(21,22,153,154)$. These T cell derived cytokines promote the production, in the RA joint synovium, of a number of inflammatory macrophage and fibroblast derived cytokines including IL-1, IL-6, IL-15, IL-18, TNF- $\alpha$, and GM-CSF. Though inflammatory cytokine-producing $\mathrm{CD}^{+} \mathrm{T}_{\mathrm{h}}$ cells, stimulated by autoantigens presented by MHC class II molecules have been implicated in the pathogenesis of RA, the exact mechanisms by which autoantigen stimulation and cytokine signaling interact to activate $\mathrm{T}$ cells and cause autoimmunity remains elusive, and many questions remain about how $\mathrm{T}_{\mathrm{h}}$ derived cytokines promote autoimmunity. For this reason, the use of mouse models in the study of RA has the potential to provide needed insight into the mechanisms of autoimmune development that lead to autoimmune disease. CIA is a mouse model of RA that mimics the human disease in many aspects. The histopathology of CIA resembles RA with similar cartilage and bone erosions and cellular infiltrate into the joint synovium (155). In addition, the pathogenesis of CIA appears to be similar to RA. As in RA, CIA susceptibility among mouse strains is strongly linked to MHC class II haplotype, implicating $\mathrm{CD}^{+} \mathrm{T}_{\mathrm{h}}$ cells in the pathogenesis of CIA (69). Finally, the expression of proinflammatory cytokines is similar in RA and CIA. The T cell derived cytokines IL-2, IFN- $\gamma$, and IL-17 as well as downstream proinflammatory cytokines IL-1, IL-6, IL-15, IL-18, TNF- $\alpha$, and GM-CSF are all produced in the joint synovium during CIA $(21,156,157)$. For these reasons, the mouse model of CIA provides an ideal system in which to examine autoimmune mechanisms that may provide insight to the pathogenesis of the human autoimmune disease RA.

In mice, susceptibility to CIA is strongly linked to expression of the MHC class II alleles I-A ${ }^{\mathrm{q}}$ and $\mathrm{I}-\mathrm{A}^{\mathrm{r}}(55,56,69)$. Mice that express other MHC class II alleles such as I$\mathrm{A}^{\mathrm{b}}$ in the B6 mouse are non-susceptible to CIA. Consistent with previous theory of MHC based susceptibility to autoimmunity we hypothesized that CII, the inducing antigen for CIA, contains determinants that bind I- $\mathrm{A}^{\mathrm{b}}$ only with low affinity and reduces the immunogenicity of CII in I-A ${ }^{\mathrm{b}}$-expressing mice, and therefore confers resistance to $\mathrm{I}-\mathrm{A}^{\mathrm{b}}$ expressing mice such as the B6 strain. Recently, a CIA model was described in which the removal of the gene expressing the cytokine IFN- $\gamma$ results in the conversion of CIA non-susceptible B6 mice to full CIA susceptibility (17). The discovery that susceptibility to autoimmunity was solely mediated by the absence of the $T_{h} 1$ produced proinflammatory cytokine, IFN- $\gamma$, was paradoxical to conventional dogma that autoimmune pathogenesis was mediated by $\mathrm{CD}^{+} \mathrm{T}_{\mathrm{h}} 1 \mathrm{~T}$ cells, and has caused a reexamination of the role of these cells and the role of cytokines in autoimmune development. In light of the discovery that IFN- $\gamma$ mediates autoimmune susceptibility, that CII likely contains weakly antigenic I-A ${ }^{b}$ determinants, and that the cytokine milieu 
is of paramount importance in autoimmune development, we hypothesized that in the IFN- $\gamma^{-/-}$B6 mouse, the absence of IFN- $\gamma$ alters immune function in terms of $\mathrm{T}$ cell activation, proliferation, and cytokine production. We propose that as a result of these alterations in immune function, a disregulated proinflammatory phenotype develops in which a pro-autoimmune cytokine milieu is created that supports the activation of CIIspecific T cells by weakly antigenic CII determinants and allows the progression to autoimmunity. Therefore, in order to test this hypothesis, we examined functional alterations that occur in IFN- $\gamma^{-/-}$B6 mice following immunization with CII and sought to characterize $\mathrm{I}-\mathrm{A}^{\mathrm{b}}$-restricted determinants present in CII that support $\mathrm{T}$ cell activation and the progression to autoimmunity.

Since we believed that CII contains I-A ${ }^{\mathrm{b}}$-restricted determinants of low immunogenic potential, and that the $\mathrm{T}$ cell response to these determinants was mediated by IFN- $\gamma$, we examined the immunogenicity of CII in both CIA-susceptible and nonsusceptible mouse strains that express I-A $A^{b}$ To do this, we immunized wild type B6 mice, which are non-susceptible to CIA, and IFN- $\gamma^{-/-}$B6 or CXB2 mice, which are susceptible to CIA, with CII and examined the proliferative responses of T cells from these mice when stimulated with CII or a library of peptides derived from CII sequence in culture. When proliferative responses to CII were examined in these three strains of mice it was found that there were minimal $\mathrm{T}$ cell responses to CII. This indicated that I-A ${ }^{b}$ CII determinants were weakly antigenic as hypothesized. However, other explanations of the weak proliferative response observed in these cells following stimulation are possible. For example, regulatory $\mathrm{T}$ cells may be present that inhibit proliferation in response to stimulation with CII. Also, the absence of IFN- $\gamma$ may reduce proliferative response in vitro by altering the expression of costimulatory molecules on the surface of APC. IFN- $\gamma$ is known to promote the activation of macrophages and dendritic cells (158), and promotes the expression of both MHC class II and costimulatory molecules including CD80/CD86 (159). If T cell costimulation is altered in the absence of IFN- $\gamma$, weak proliferative responses may be observed in response to antigen presented by APC that have not been activated. Several experiments are possible to test this possibility. One method to test this possibility would be to use a control antigen other than CII such as Mog or CytC that is known induce proliferation of I-A ${ }^{\mathrm{b}}$ restricted T cells $(160,161)$. In vitro proliferation of $\mathrm{I}-\mathrm{A}^{\mathrm{b}}$-restricted $\mathrm{T}$ cells obtained from immunized IFN- $\gamma^{-/-}$B6 mice would rule out ineffectual antigen presentation by APC as a mechanism of reduced proliferative response in the IFN- $\gamma^{-/-}$background.

While there appeared to be minimal $\mathrm{T}$ cell proliferative response to $\mathrm{CII}$ determinants in $\mathrm{I}-\mathrm{A}^{\mathrm{b}}$-expressing mice, we believed that CII-reactive $\mathrm{T}$ cells were being produced. Evidence for this was that anti-CII IgG subclasses are produced in these mice following immunization with CII (69). Since the switch from IgM to IgG production by B cells is driven by T cells, this evidence of CII-specific IgG strongly indicated a CIIspecific $\mathrm{T}$ cell response was occurring in vivo. We sought to identify these $\mathrm{T}$ cells and the CII determinants they recognize by producing $\mathrm{I}-\mathrm{A}^{\mathrm{b}}$-restricted $\mathrm{T}$ cell hybridomas from wild type B6, IFN- $\gamma^{-/}$B6, and CXB2 mice immunized with CII. Hybridoma generation allowed the low frequency CII-specific $\mathrm{T}$ cells to be immortalized and expanded for subsequent determinant analysis. While various attempts were made to produce these $T$ 
cell hybridomas in wild type and IFN- $\gamma^{-/}$B6 mice, the production of these cells proved successful in only the CXB2 mouse strain. Stimulation of these CII-specific T cell hybridomas with a CII peptide library allowed the identification of an immunodominant I-A ${ }^{b}$-restricted CII determinant, located at position 514-525 of the CII sequence.

Structurally, MHC class II molecules contain an open ended binding grove in which nine amino acids can bind closely. The peptide determinant interacts closely with the MHC class II molecule in this region through interactions with the carbon backbone of the peptide and via a series of hydrophobic pockets within the MHC molecule referred to as p1, p4, p6, p7, and p9. Also, due to the open ended nature of the binding groove, amino acids of the peptide that extend beyond the nine amino acid core can contribute to binding stability (162). In order to experimentally define the core determinant, and to assess the contribution of each amino acid within the CII determinant to the formation of the ternary complex, the $\mathrm{T}$ cell hybridomas were stimulated with a panel of alanine substituted analog peptides with individual substitutions at each position from CII(512526). Analysis of $T$ cell hybridoma stimulation by these analog peptides allowed the identification of the core determinant as CII(517-525). Interestingly, it was found that substitution with alanine at five of the positions within the nine amino acid core completely abrogated $\mathrm{T}$ cell stimulation. This is unusual in that similar studies, in which alanine substituted analog peptides were used to stimulate CII-specific T cell hybridomas restricted to other MHC class II haplotypes, including DR1 and I- $\mathrm{A}^{\mathrm{q}}$, the substitutions were well tolerated and tended to reduce rather than completely inhibit $\mathrm{T}$ cell stimulation by the analog peptide $(101,163)$. This may be an indication that the stability of the I-A CII determinant within the peptide/MHC /TCR complex is low and therefore highly sensitive to slight changes in affinity mediated by the alanine substitutions. As an additional approach to determine the immunogenic properties of the I-A ${ }^{\mathrm{b}}$-restricted CII determinant, we used a bioinformatic method, the MHC binding algorithm SMM-align, to calculate the affinity of CII for I-A ${ }^{b} \mathrm{MHC}$. These calculations indicated that there were no sequences present in CII that bind $\mathrm{I}_{-} \mathrm{A}^{\mathrm{b}}$ with high affinity, including the CII(512528) determinant identified by the $T$ cell hybridomas.

Characterization of CII and CII(512-528) indicates that CII determinants weakly bind $\mathrm{I}-\mathrm{A}^{\mathrm{b}}$. Evidence for this include the low proliferative responses of $\mathrm{T}$ cells following stimulation with CII, the weak stimulatory characteristics of alanine substituted analog determinant peptides, the identification of the core binding residues of CII(517-525), and the observation that amino acid differences among CII from different species (mouse, chicken, and bovine) may cause the altered immunogenicity of CII from the different species. Reduced TCR affinity for peptide determinants reduces the activation of T cells for those determinants. A low affinity determinant engages fewer T cell receptors and would cause reduced signaling, thus resulting in reduced $T$ cell activation (164). In a mouse model of MS, EAE, there is evidence that IFN- $\gamma$ may regulate T cell responses to weak antigens (165). In one study by Brian Evavold, a low affinity variant of the encephalogenic peptide $\operatorname{Mog}(35-55)$ was used to induce EAE. The use of this peptide variant in wild type B6 mice results in attenuated disease severity and reduced $\mathrm{CD} 4{ }^{+} \mathrm{T}$ cell proliferative responses. However, when IFN- $\gamma^{-/-}$or IFN- $\gamma \mathrm{R}^{-/-}$mice are immunized with the variant peptide, both increased encephalogenicity and $\mathrm{CD}^{+}{ }^{\mathrm{T}}$ cell proliferative responses are increased in a manner independent of IL-17 (165). The increased immune 
response to the low affinity Mog determinant observed in the EAE model bears a striking resemblance to the responses observed in the CIA model to the determinant identified here, and may be a mechanism of IFN- $\gamma$ regulation of disease susceptibility in the IFN- $\gamma^{-/-}$ CIA model. CII derived from chicken or bovine sources differs in one amino acid in the $\mathrm{CII}(517-525)$ core region, P518A. This mutation between the two species may explain why chicken derived CII is arthritogenic in the B6 mouse while the bovine derived CII is not. The bovine derived CII determinant is likely of lower affinity than the chicken derived determinant. Additional studies are needed to define how the weak CII determinant present in bovine CII affects T cell response in the IFN- $\gamma^{-/-}$B6 mice. Measurement of $\mathrm{T}$ cell proliferation in wild type and IFN- $\gamma^{-/-} \mathrm{B} 6$ mice in response to stimulation with both chicken and bovine determinants would identify if IFN- $\gamma$ is regulating $\mathrm{T}$ cell responses to this low affinity determinant and potentially mediating CIA susceptibility by this mechanism. In the CIA model, immunization with peptide does not induce arthritis. This is likely due to the absence of CII-specific antibodies that are produced only when native collagen is used as the immunogen. An experiment that would be useful in characterizing low affinity determinants in the pathogenesis of CIA would be to co-immunize wild type or IFN- $\gamma^{-/-}$B6 mice with both native bovine CII and peptide determinants derived from either chicken or bovine sequence. Enhanced CIA in wild type mice when co-immunized with higher affinity CII determinants would indicate that variation in affinity of CII determinants mediates arthritis susceptibility. In the IFN- $\gamma^{-/-}$B6 mice enhanced CIA with higher affinity determinants as opposed to low affinity determinants would indicate that determinant affinity mediates arthritis susceptibility in these mice.

Having identified a low affinity I-A ${ }^{\mathrm{b}}$-restricted CII determinant in vitro, we next sought to confirm its relevance to CIA pathogenesis in vivo. To do this we measured the proliferative response of $\mathrm{T}$ cells from $\mathrm{I}-\mathrm{A}^{\mathrm{b}}$-expressing mice immunized with $\mathrm{CII}(512$ 528), and examined the ability of the CII (512-528) peptide to induce tolerance when given to CXB2 mice prior to immunization with CII to induce CIA. When T cells from $\mathrm{B} 6$ or CXB2 mice were stimulated with $\mathrm{CII}(512-528)$ a proliferative response was observed. Also, tolerizing CXB2 mice with CII(512-528) prior to immunization with CII reduced both the incidence and severity of the resulting arthritis. These studies confirmed that the CII(512-528) determinant was capable of stimulating a $\mathrm{T}$ cell proliferative response in vivo, and its suppression of CIA indicated that this determinant is responsible for mediating autoimmune development in I-A ${ }^{\mathrm{b}}$-expressing mice.

The data described above are consistent with our hypothesis that CII contains at least one low affinity determinant that mediates autoimmune development, and that in $\mathrm{I}-\mathrm{A}^{\mathrm{b}}$-expressing mice $\mathrm{T}$ cells specific for this determinant are produced. The activation of these $\mathrm{T}$ cells in response to this low affinity determinant may be a point at which IFN- $\gamma$ regulates the development of autoimmunity in B6 mice. By its influence on immune cell differentiation, activation, and cytokine production, IFN- $\gamma$ serves as master regulator of immune function. In IFN- $\gamma^{-/-} \mathrm{B} 6$ mice, it is likely that alterations in these immune processes mediated by the absence of IFN- $\gamma$ in IFN- $\gamma^{-/-}$B6 mice allows activation of T cells to weak CII antigens and promotes autoimmune development. Therefore, in order to determine the mechanism by which the absence of IFN- $\gamma$ promotes autoimmunity we 
examined the alterations in the cytokine milieu that occur in IFN- $\gamma^{-/-}$B6 mice, and examined changes in the immune cell functions of proliferation, differentiation, autoantibody production, and cytokine production that occur following $\mathrm{T}$ cell stimulation in the IFN- $\gamma^{-/-}$B6 mouse.

Major alterations in immune function in response to CII immunization that occur in IFN $-\gamma^{-/-}$B6 mice appear to be primarily in cytokine and autoantibody production, and in $\mathrm{T}$ cell proliferative responses when $\mathrm{T}$ cells are stimulated nonspecifically. When $\mathrm{B}$ cells, $\mathrm{T}$ cells, and the $\mathrm{T}$ cell subtypes that develop following immunization with CII were examined by flow cytometry, no significant differences in cell differentiation were observed. However, when cytokine production was measured by ELISA, increases in $\mathrm{T}_{\mathrm{h}} 1, \mathrm{~T}_{\mathrm{h}} 17$, and $\mathrm{T}_{\mathrm{c}}$ associated cytokines were observed in cultures of IFN- $\gamma^{-/-}$derived $\mathrm{T}$ cells compared to wild type derived cells following stimulation with anti-CD3 and antiCD28 antibodies. Similarly, levels of anti-CII antibodies, especially the complement fixing IgG subtype IgG2b, were also increased in IFN- $\gamma^{-/-}$B6 mice when compared to wild type mice following immunization with CII. Also, while CII-specific T cell proliferative responses were too weak to detect differences between wild type and IFN- $\gamma^{-1-}$ B6 mice, when T cells from these mice were stimulated nonspecifically with antiCD3 and anti-CD28 monoclonal antibodies, increased proliferation in IFN- $\gamma^{-/}$derived cells was observed in comparison to the wild type cells. While all of these changes potentially contribute to increased susceptibility to CIA in the IFN- $\gamma^{-/-}$B6 mouse it is likely that the immune mechanisms of proliferation, and autoantibody production are downstream effects of altered cytokine production in the IFN- $\gamma^{-/-}$B6 mouse. Immune cell differentiation is mediated by the cytokine milieu, for example $\mathrm{T}_{\mathrm{h}} 1$ cell differentiation is promoted by IFN- $\gamma$ and inhibited by IL-4 and IL-10, $\mathrm{T}_{\mathrm{h}} 17$ differentiation is promoted by IL-6 and TGF $\beta$ (166), while $\mathrm{T}_{\mathrm{h}} 2$ differentiation is promoted by IL-4 and IL-10 and inhibited by IFN- $\gamma$. Similarly, antibody production by B cells is influenced by cytokine signaling, IL-5 promotes B cell growth (114) and differentiation while IFN- $\gamma$ promotes Ig class switching to IgG2a and IL-4 promotes Ig class switching to IgE and IgG1 (90-92).

In order to determine how the absence of IFN- $\gamma$ effects global changes in the cytokine milieu, and to determine how these changes potentially alter immune function to produce a disregulation phenotype that results in increased susceptibility to CIA in IFN- $\gamma^{-/-}$B6 mice, gene expression analysis by microarray was performed using mRNA from lymphocytes obtained from wild type and IFN- $\gamma^{-/-}$B6 mice immunized with CII. This analysis identified a number of genes that were differentially expressed between wild type and IFN- $\gamma^{-/-}$B6 mice including immune signaling molecules, immune effector molecules, and mediators or indicators of inflammation. While several genes were identified as upregulated in the IFN $-\gamma^{-/-}$mice that may be effectors of the destructive inflammation that is characteristic of autoimmune arthritis, two genes were identified that are likely mediators of autoimmune susceptibility. These genes were the proinflammatory cytokine IL-17, identified as upregulated in the IFN- $\gamma^{-/-}$mouse, and the negative regulator of IL-18, IL-18 BP, identified as downregulated in the IFN- $\gamma^{-/-}$mouse. IL-17 is a strongly proinflammatory cytokine that is produced by $\mathrm{T}_{\mathrm{h}} 17$ cells that also produce the proinflammatory cytokines, IL-6, TNF- $\alpha$, and GM-CSF. IL-17 further 
promotes inflammation by stimulating the production of IL-6, IL-8, G-CSF, GM-CSF, IL-1 $\beta$, TGF $\beta$, and TNF- $\alpha$ by fibroblasts, endothelial cells, epithelial cells, keratinocytes, and macrophages (167). Its influence on RA pathogenesis has been identified by its expression in RA synovium, and by knock out mouse models in which the absence of IL17 reduces the development of CIA $(45,150)$. IL-18 is also a proinflammatory cytokine that has been linked to autoimmune pathogenesis in RA. IL-18 is expressed in the RA synovium, and functions to promote the expression of proinflammatory cytokines including IFN- $\gamma$, GM-CSF, IL-1 $\beta$, and TNF- $\alpha$ by synoviocytes (120). Furthermore, removal of IL-18 by knock out models or by the use of anti-IL-18 antibodies reduces the severity of CIA (132). IL-18 BP is a negative regulator of IL-18 and is produced by macrophages and endothelial cells stimulated by IFN- $\gamma$ (123). As a negative regulator of the proinflammatory cytokine IL-18 whose expression is promoted by IFN- $\gamma$, IL-18 BP likely plays a large role in the susceptibility to CIA in IFN- $\gamma^{-/-}$mice. Further evidence of IL-18 BP's role in mediating arthritis susceptibility is the increased expression of cytokines including IL-1 $\beta$, GM-CSF, and TGF $\beta 1$ that are downstream of IL-18 signaling in IFN- $\gamma^{-/-}$B6 mice. In IFN- $\gamma^{-/-}$B6 mice immunized with CII, expression of these genes is observed to be upregulated compared to wild type B6 mice as measured by real time PCR. In addition, when the levels of these cytokines are measured by ELISA in the supernatants of $T$ cells stimulated in culture with anti-CD3/CD28 antibodies, the concentration of these cytokines is increased in the IFN- $\gamma^{-/-}$cells as compared to the wild type. These data provide compelling evidence that a major mechanism of IFN- $\gamma$ regulation of CIA susceptibility is the promotion of IL-18 BP expression. In this model, IFN- $\gamma$ mediated expression of IL-18 BP by wild type mice is high, and protection from autoimmunity is conferred. In IFN- $\gamma^{-/} \mathrm{B} 6$ mice, the absence of IFN- $\gamma$ reduces expression of IL-18 BP and allows increased signaling by IL-18, and the proinflammatory function of IL-18 likely promotes the susceptibility to autoimmunity in IFN- $\gamma^{-/-} \mathrm{B} 6$ mice. To test this model of IL-18 BP regulation of autoimmunity, IFN- $\gamma^{-/-}$B6 mice were treated with exogenous IL-18 BP concurrently with CII immunization to induce CIA. This treatment protected CIA-susceptible mice from the development of disease, delayed onset, and reduced the severity of arthritis. These data confirm that IFN- $\gamma$ mediated IL-18 BP expression regulates autoimmune development in these mice.

Having confirmed IL-18 BP's role in mediating autoimmune susceptibility in an in vivo model, we further characterized the mechanism by which IL-18/IL-18 BP signaling mediates immune development by examining the effects of IL-18 and IL-18 BP on the proliferation and cytokine production of T cells from wild type and IFN- $\gamma^{-/-} \mathrm{B} 6$ mice stimulated with anti-CD3 and anti-CD28 antibodies. When added to stimulated T cell cultures, IL-18 promoted T cell proliferation, while addition of IL-18 BP inhibited the proliferation of wild type $T$ cells. These data indicate that in wild type mice, one mechanism of autoimmune regulation may be through reduced IL-18 dependent T cell proliferation mediated by high levels of endogenous IL-18 BP. Furthermore, when cytokine production was examined in stimulated $\mathrm{T}$ cell cultures, it was observed that wild type cells had reduced cytokine production compared to stimulated IFN- $\gamma^{-/-} \mathrm{T}$ cells. When IL-18 was added to these cultures, the wild type cells produced cytokines in a pattern that closely resembled the cytokine production of stimulated IFN- $\gamma^{--}$T cells. 
Additionally, when stimulated IFN- $\gamma^{-/-} \mathrm{T}$ cells were supplied with exogenous IFN- $\gamma$ there was a reduction in cytokine production. These data indicate that there is a regulatory loop between IL-18 and IFN- $\gamma$ that serves to mediate the production of cytokines by $\mathrm{T}$ cells following antigenic stimulation.

Concepts of immune function identified in these studies has allowed the development of a model to that illustrates how IFN- $\gamma$ regulates immune function, and how in IFN- $\gamma^{-/ 2}$ mice, autoimmunity occurs. In this model, $\mathrm{T}$ cell interaction with a low affinity CII determinant in an immune milieu that consists of abnormal cytokine signaling mediated by the absence of IFN- $\gamma$ allows activation of CII-specific T cells. The absence of IFN- $\gamma$ both causes a reduction in the expression of IL-18 BP and alters the function of $\mathrm{T}_{\mathrm{h}} 1$ cells. The reduced production of IL-18 BP increases IL-18 signaling and increases the influence of this proinflammatory cytokine on the function of both effector $\mathrm{T}$ cells and cells within the joint synovium that mediate the chronic inflammation and erosive joint destruction that is characteristic of autoimmune arthritis.

Fig 5.1 illustrates the function of T cells in wild type B6 mice following immunization with CII/CFA. In this model, immunization with CII/CFA stimulates an adaptive immune response that is primarily of the $T_{h} 1$ phenotype. Differentiation of $T_{h} 1$ cells is promoted by the presence of Mtb in the CII/CFA emulsion that promotes the production of IL-12, and therefore drives differentiation of $T$ cells towards the $T_{h} 1$ phenotype (149). These cells produce $T_{h} 1$ associated cytokines, especially IFN- $\gamma$, that promote a cell mediated immune response. However, several mechanisms exist in B6 mice that limit the progression of this response to autoimmunity. These include negative regulation by $\mathrm{T}_{\text {reg }}$ cells and feedback inhibition of $\mathrm{T}_{\mathrm{h}} 1$ effector function mediated by cytokine signaling. In addition, B6 mice express MHC of the I-A $\mathrm{A}^{\mathrm{b}}$ haplotype. Since CII is weakly immunogenic in this MHC background, possibly due to the low affinity of CII determinants for $\mathrm{I}-\mathrm{A}^{\mathrm{b}} \mathrm{MHC}$, the expansion of $\mathrm{T}_{\mathrm{h}} 1 \mathrm{~T}$ cells is not particularly robust, and is particularly sensitive to negative regulation. The negative regulation that protects wild type B6 mice from the development of autoimmunity is mediated in part by the expression of IL-18 BP. IL-18 BP expression by macrophages and epithelial cells is induced by IFN- $\gamma$ produced by the developing $\mathrm{T}_{\mathrm{h}} 1$ cells. The IL-18 BP binds to IL-18 extracellularly and prevents it from binding to IL-18 receptors present on $T_{h}$ cells, and therefore abrogates the proinflammatory effects of IL-18 (151). Since the $T_{h}$ cell response to CII determinants presented by $\mathrm{I}-\mathrm{A}^{\mathrm{b}} \mathrm{MHC}$ is not strong, the reduction of the proinflammatory signal mediated by IL-18 is sufficient to limit $\mathrm{T}$ cell response to $\mathrm{CII}$ in wild type B6 mice.

In IFN- $\gamma^{-/-} \mathrm{B} 6$ mice, the absence of IFN- $\gamma$ alters the immune milieu both prior to and following immunization with CII/CFA, and results in a pro-autoimmune phenotype. As shown in Fig 5.2 and Fig 5.3, the absence of IFN- $\gamma$ disrupts immune regulatory mechanisms resulting in altered cytokine production, $\mathrm{T}_{\mathrm{h}}$ cell differentiation, and disease progression. In IFN- $\gamma^{-/-} \mathrm{B} 6$ mice immunization with $\mathrm{CII} / \mathrm{CFA}$ stimulates an adaptive immune response to CII resulting in the generation of $T_{h} 1, T_{h} 17$, and $T_{h} 2$ subsets of CIIspecific $\mathrm{T}$ cells. However, since IFN- $\gamma$ cannot be produced in these mice, $\mathrm{T}_{\mathrm{h}} 1$ effector function is limited. The malfunctioning effector response of $\mathrm{T}_{\mathrm{h}} 1$ cells both disrupts 


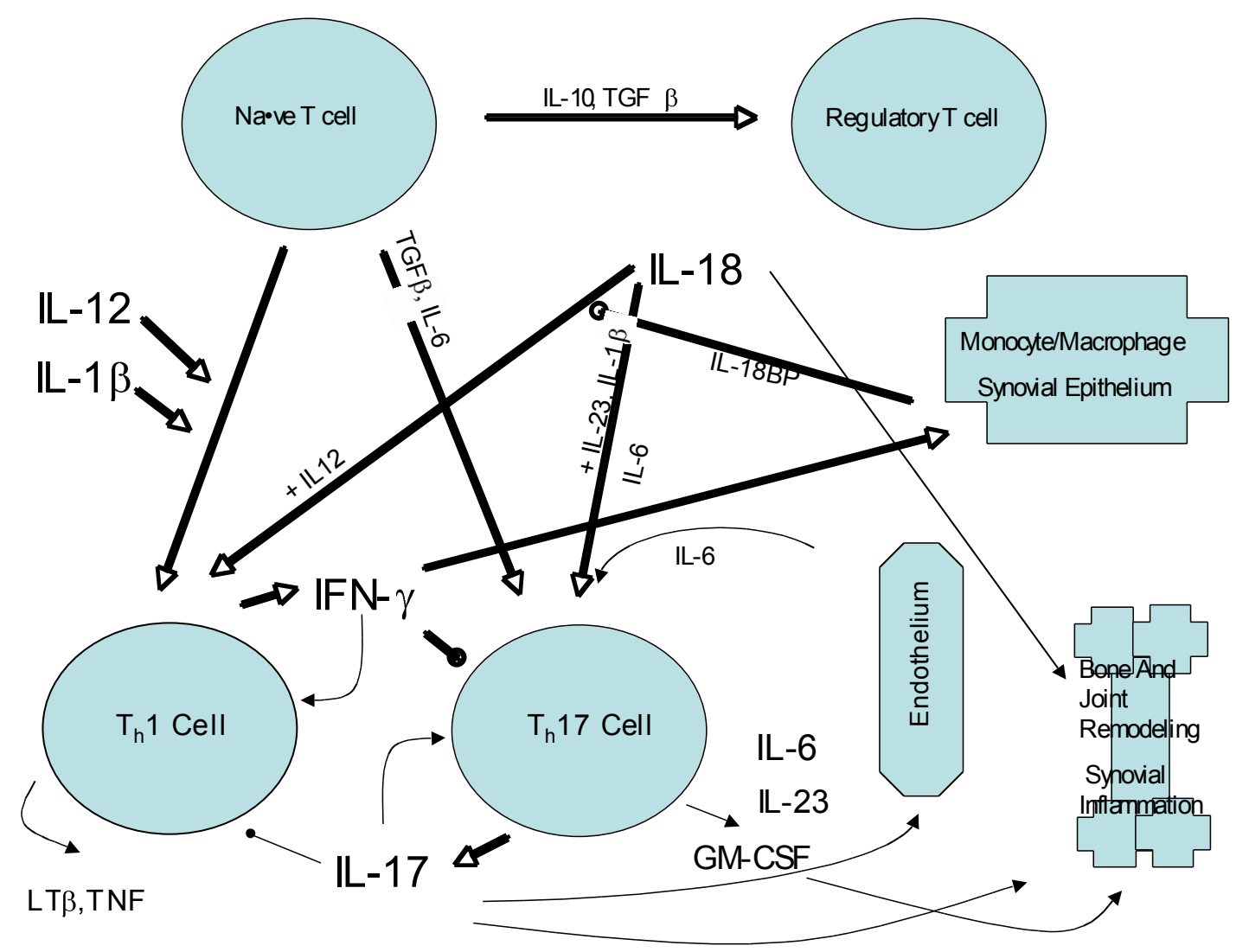

Figure 5.1 Model of Immune Response in Wild Type B6 Mice.

In wild type B6 mice, regulation of immune response prevents uncontrolled progression to autoimmunity. Each $T_{h}$ cell subtype is regulated by both autocrine and paracrine mechanisms. Cytokines produced by an effector $T_{h}$ subtype can inhibit the function of development of other $T_{h}$ responses. In addition, an uncontrolled continuously expanding immune response is inhibited by feedback inhibition. For example, $\mathrm{T}_{\mathrm{h}} 1$ type $\mathrm{T}$ cell response is self-limited by IFN- $\gamma$. IFN- $\gamma$ promotes IL-18 BP expression by monocytes, macrophages, and synovial epithelium. This in turn reduces IL-18 signaling leading to reduced expression of IFN- $\gamma$ and $\mathrm{T}_{h} 1$ cell function. In a regulated immune response, these mechanisms prevent the progression to autoimmunity. 


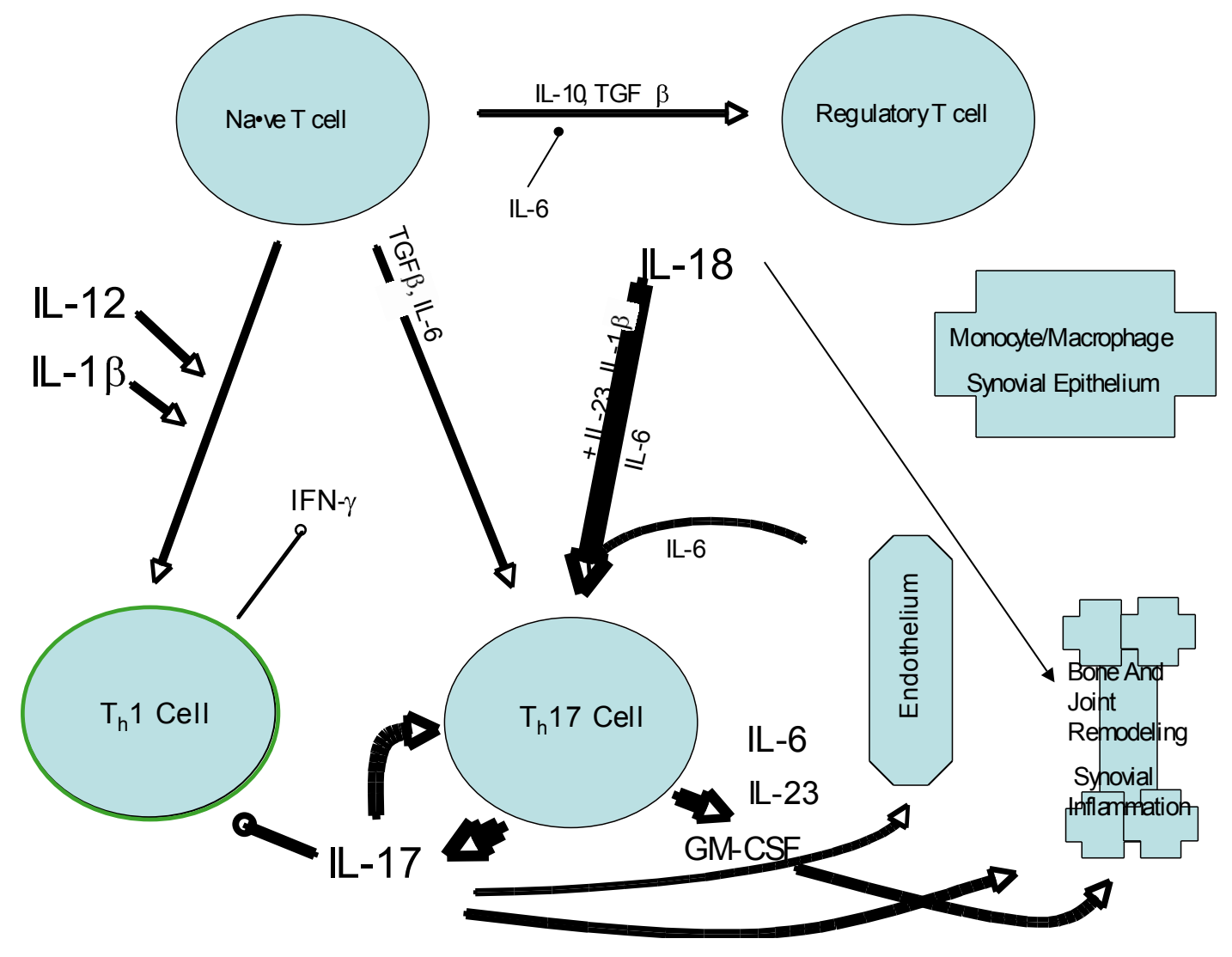

Figure 5.2 Model of Immune Response in IFN- $\gamma^{-/-}$B6 Mice.

In IFN- $\gamma^{-/-}$B6 mice, autoimmune arthritis develops as a result of dysfunctional immune regulation. The absence of IFN- $\gamma$ causes abnormal $\mathrm{T}_{\mathrm{h}} 1$ cell response, highlighted in green. Without IFN- $\gamma$, regulatory mechanisms that would normally inhibit the progression of an immune response to a low affinity $\mathrm{T}$ cell determinant fail to activate, particularly the production of IL-18 BP. As a result, abnormal $\mathrm{T}_{\mathrm{h}}$ cell differentiation and function occurs. $T_{h} 1$ cell response is reduced while $T_{h} 17$ and $T_{h} 2$ responses increase, leading to production of cytokines that promote inflammation and the activation of synoviocytes that mediate the erosion of cartilage and bone. 


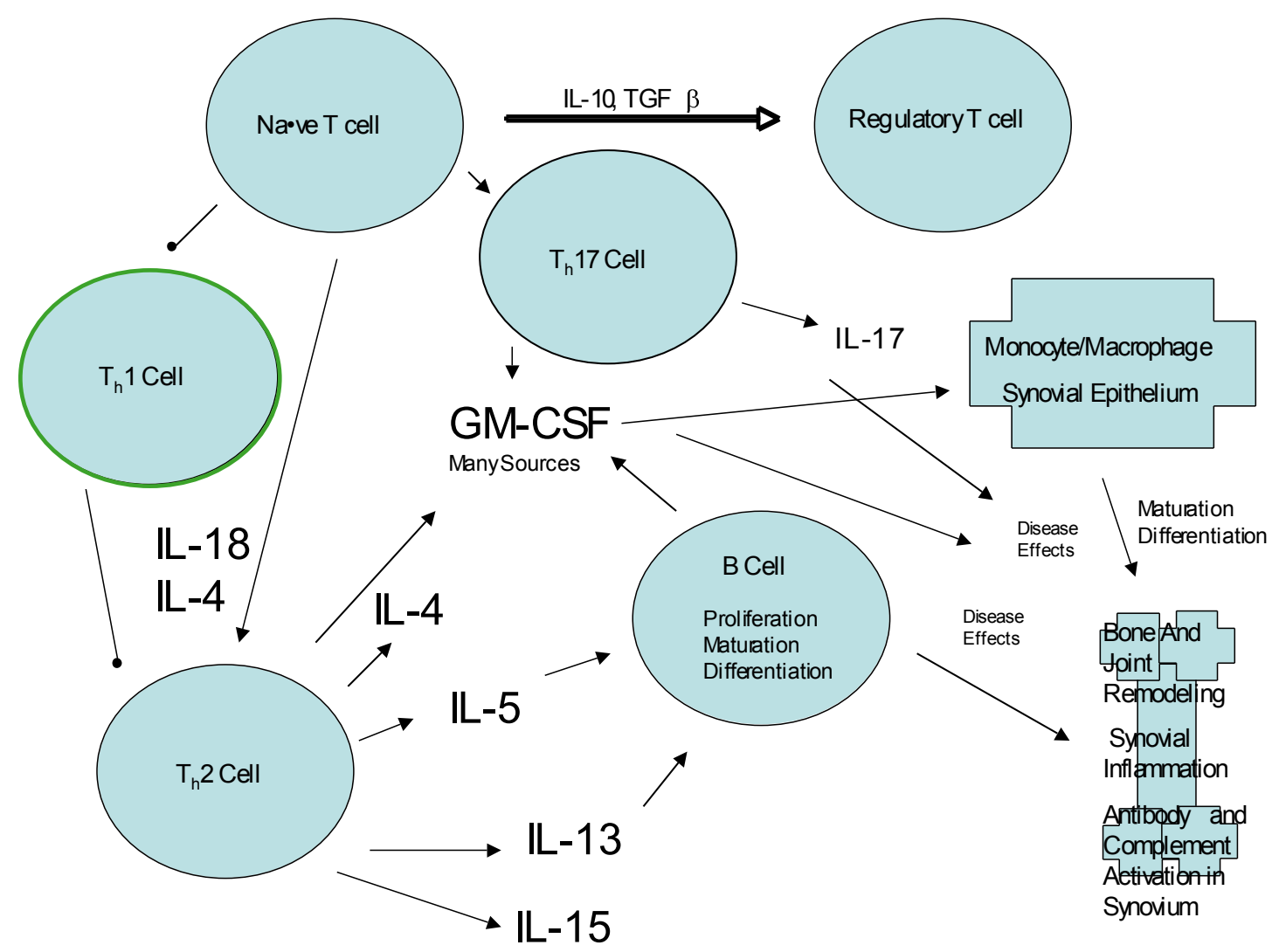

Figure 5.3 Model of $\mathbf{T}_{\mathrm{h}} \mathbf{2}$ Response in IFN $-\gamma^{-/ 2} \mathrm{B6}$ Mice.

$\mathrm{T}_{h} 2$ response is increased in the absence of IFN- $\gamma$. The lack of negative regulation of $\mathrm{T}_{h} 2$ cell differentiation mediated by IFN- $\gamma$ leads to the activation and disregulated function of $\mathrm{T}_{h} 2$ cells. $B$ cell stimulation of $B$ cells by $T_{h} 2$ cells, and the production of $T_{h} 2$ associated cytokines promotes the production of CII-specific antibodies by B cells and promotes disease immune complex mediated complement activation, and FcR mediated activation of macrophages and lymphocytes. Production of $\mathrm{T}_{\mathrm{h}} 2$ cytokines contributes to the disregulation of $T_{h} 1$ and $T_{h} 17$ responses that promote autoimmunity. 
regulatory mechanisms that would limit autoimmune progression and promotes the expansion and effector function of disease promoting $T_{h} 17$ and $T_{h} 2$ subsets $(21,76)$. The absence of IFN- $\gamma$ production by $\mathrm{T}_{\mathrm{h}} 1$ cells fails to stimulate the production of IL-18 BP by macrophages and synovial epithelium. The effect of reduced production of IL-18 BP is increased $\mathrm{T}$ cell stimulation by the proinflammatory cytokine IL-18. In contrast to wild type B6 mice, in IFN- $\gamma^{-/-}$B6 mice I-A ${ }^{b}$-restricted CII-specific T cells encounter low affinity $\mathrm{CII}$ determinants in the presence of increased proinflammatory signaling mediated by IL-18 and activate. In addition, the absence of IFN- $\gamma$ alters how the CIIspecific $T$ cells differentiate. IFN- $\gamma$ inhibits the differentiation of both $T_{h} 17$ and $T_{h} 2 T$ cell subtypes $(21,76,168)$. Therefore as CII-specific T cells activate and differentiate, the $T_{h} 17$ and $T_{h} 2$ cells begin to dominate the immune response due to disregulated proliferation of these $\mathrm{T}$ cell subtypes. This has direct effects on the mechanisms of arthritis pathogenesis. Coinciding with the expansion of these cells is the production of cytokines including IL-17 and GM-CSF. Along with IL-18, these cytokines act directly on synoviocytes to promote inflammation in the joint and initiate cartilage and bone erosion $(45,132,150,157,169)$. Disregulated $\mathrm{T}_{\mathrm{h}} 2$ cell function also promotes arthritis pathogenesis in IFN- $\gamma^{-/-}$B 6 mice. Since IFN- $\gamma$ inhibits $\mathrm{T}_{\mathrm{h}} 2$ cell differentiation and expansion, in the absence of IFN- $\gamma$ the activity of these cells is increased. Following activation, CII-specific $\mathrm{T}_{\mathrm{h}} 2$ cells produce high levels of IL-4, IL-5, and IL-13, which promotes $\mathrm{B}$ cell maturation, differentiation, and proliferation and allows $\mathrm{T}_{\mathrm{h}} 2$ dependant CII-specific antibody production by activated B cells (170). These alterations in the immune milieu, disregulated cytokine production, disregulated immune cell differentiation, and disregulated feedback inhibition of immune response, all deriving from the absence of IFN- $\gamma$ in IFN- $\gamma^{-/-}$B6 mice, allow progression autoimmunity and directly promote arthritis pathogenesis.

The identification of an I-A $\mathrm{A}^{\mathrm{b}}$-restricted CII determinant that stimulates $\mathrm{T}$ cells has the potential to greatly expand our understanding of the pathogenic mechanisms of autoimmune arthritis. In other mouse strains that are susceptible to CIA, the identification of a CII determinant restricted to the MHC haplotypes expressed in these mice such as I-A ${ }^{\mathrm{q}}$ in the DBA/1, and DR1 in humanized B10 mice, allowed the development of MHC class II tetramer based assays to identify CII-specific T cells in these mice that are generated in response to immunization with CII and to study their pathogenic function. This allows subtle changes in immune response to autoantigen to be examined in exquisite detail (171). This ability expands the capability to investigate the mechanisms of autoimmune pathogenesis and also provides a tool to directly measure the efficacy of autoimmune therapy by measuring alterations in $\mathrm{T}$ cell immune response that may occur from treatment with therapeutic agents. For example, using flow cytometric methods, CII-specific T cells identified with CII tetramer can be examined for activation and cell subset markers. In addition, cell sorting technology allows the isolation of CIIspecific $\mathrm{T}$ cells for further in vitro study or adoptive transfer. The identification of an I- $\mathrm{A}^{\mathrm{b}}$-restricted CII determinant provides the ability to generate CII I- $\mathrm{A}^{\mathrm{b}}$ tetramers, and this would greatly expand our ability to investigate the mechanisms of pathogenesis in this altered-cytokine model of autoimmune arthritis. 
One limitation of previous studies of the autoimmune mechanisms of CIA is the relatively small number of knock out mice available in the genetic backgrounds that are susceptible to CIA such as the DBA/1 strain. Therefore, in order to study how specific genes mediate autoimmune pathogenesis many months of breeding and backcrossing are required to generate knock out mice on these backgrounds. The identification of an I-A $\mathrm{A}^{\mathrm{b}}$ restricted CII determinant has the potential to facilitate the study of specific genes in the pathogenesis of autoimmune arthritis. As one of the most widely studied mouse strains, numerous knock out B6 models have been developed including those with inflammatory cytokines like IL-17, IL-12, IL-1 $\beta$, and other immune modulating genes. The use of these B6 knock out strains to analyze immune cell function in response to the CII autoantigen identified here using either CII I-A ${ }^{b}$ tetramer or the use of more traditional methods such as measurement of proliferation and cytokine production has the potential to identify the detailed regulatory pathways by which these genes mediate autoimmunity.

Though the identification of an I-A ${ }^{\mathrm{b}}$-restricted CII determinant has the potential to provide insight into the generation of a pathogenic $\mathrm{T}$ cell response during autoimmune development, further avenues of investigation remain to fully characterize autoantigen specific $\mathrm{T}$ cell responses in the CIA model. One immunodominant I-A ${ }^{b}$ determinant present in CII has been definitively identified here, yet it is likely that other epitopes are present in CII that are capable of binding to I- $\mathrm{A}^{\mathrm{b}} \mathrm{MHC}$ molecules and stimulating $\mathrm{T}$ cells. Some evidence of this possibility can be inferred from the binding of CII determinants to DR1 and the predicted binding of 29 low affinity CII determinants to I-A ${ }^{b}$. Recent unpublished observations have indicated that T cells specific for "minor" CII determinants other than the immunodominant CII(257-274) epitope are generated in DR1-expressing mice and can be stimulated in vivo following CII immunization. For I-A $\mathrm{A}^{\mathrm{b}}$, other low affinity CII determinants are likely to be present as indicated by the 29 predicted low affinity sequences. These low affinity determinants may prove to be important regulators of autoimmunity, potentially mediating the generation or function of $\mathrm{T}_{\text {reg }}$ cells that inhibit the development of effector $\mathrm{T}$ cells against stronger $\mathrm{CII}$ antigens, or by promoting anergy of CII-reactive $\mathrm{T}$ cells when these low affinity CII determinants are presented by APC in the absence of costimulatory signaling.

The identification of IL-18 BP as a mediator of autoimmune susceptibility has provided insight into the pathogenic mechanisms of autoimmune arthritis. Yet for several reasons, it is likely that this pathway alone does not comprise all of IFN- $\gamma$ 's regulation of autoimmune susceptibility. While the gene expression array allowed the identification of IL-18 BP as differentially expressed between wild type and IFN- $\gamma^{-/}$ mice, there remain 1611 other genes that were identified as differentially expressed between the two mice. Many of these genes are of unknown function, and therefore may prove to be important immune mediators of as yet unknown immune regulatory pathways. Furthermore, the gene expression array data represents the gene expression of all the cells obtained from the lymph nodes, and includes mRNA from T cells, B cells, macrophages, dendritic cells, and all other cells present at the time that the mRNA was isolated from the lymph node cells. For this study, this cell diversity was useful since IL$18 \mathrm{BP}$ is produced largely by macrophages, and may not have been identified in a more restricted cell population analysis. However, microarray analysis based on discrete cell 
types from IFN- $\gamma^{-/-}$mice has the potential to expand our knowledge of how IFN- $\gamma$ mediates immune response of individual cell types. One potential experiment that would be extremely useful in discerning autoimmune $\mathrm{T}$ cell responses would be gene expression analysis of CII-specific T cells. If CII I-A ${ }^{b}$ tetramer were to be generated using the CII epitope defined here, these cells could be sorted by flow cytometry. mRNA could then be isolated from discrete CII-specific T cell populations for examination of their gene expression. Not only would this be useful for examination of IFN- $\gamma$ mediated immune regulation, but also any of the other knock out models that exist in the B6 background. When one considers the various T cell markers that could be used as sorting criteria, and the vast number of knock out models available, these approaches could be combined to generate a large amount of new data regarding autoimmune pathogenesis. 


\section{List of References}

1. Stavropoulos-Kalinoglou, A., G. S. Metsios, V. F. Panoulas, K. M. Douglas, A. M. Nevill, A. Z. Jamurtas, M. Kita, Y. Koutedakis, and G. D. Kitas. 2008. Cigarette smoking associates with body weight and muscle mass of patients with rheumatoid arthritis: a cross-sectional, observational study. Arthritis Res Ther 10:R59.

2. Silverstein, A. M. 2001. Autoimmunity versus horror autotoxicus: the struggle for recognition. Nat Immunol 2:279-281.

3. Rioux, J. D., and A. K. Abbas. 2005. Paths to understanding the genetic basis of autoimmune disease. Nature 435:584-589.

4. Barnetche, T., A. Constantin, A. Cantagrel, A. Cambon-Thomsen, and P. A. Gourraud. 2008. New classification of HLA-DRB1 alleles in rheumatoid arthritis susceptibility: a combined analysis of worldwide samples. Arthritis Res Ther 10:R26.

5. Jensen, P. E. 2007. Recent advances in antigen processing and presentation. Nat Immunol 8:1041-1048.

6. Bryant, P., and H. Ploegh. 2004. Class II MHC peptide loading by the professionals. Curr Opin Immunol 16:96-102.

7. Vyas, J. M., A. G. Van der Veen, and H. L. Ploegh. 2008. The known unknowns of antigen processing and presentation. Nat Rev Immunol 8:607-618.

8. Lanzavecchia, A. 1985. Antigen-specific interaction between T and B cells. Nature 314:537-539.

9. Mosmann, T. R., H. Cherwinski, M. W. Bond, M. A. Giedlin, and R. L. Coffman. 1986. Two types of murine helper T cell clone. I. Definition according to profiles of lymphokine activities and secreted proteins. J Immunol 136:2348-2357.

10. Mosmann, T. R., and R. L. Coffman. 1989. TH1 and TH2 cells: different patterns of lymphokine secretion lead to different functional properties. Annu Rev Immunol 7:145-173.

11. Coffman, R. L., and J. Carty. 1986. A T cell activity that enhances polyclonal IgE production and its inhibition by interferon-gamma. J Immunol 136:949-954.

12. Harrington, L. E., R. D. Hatton, P. R. Mangan, H. Turner, T. L. Murphy, K. M. Murphy, and C. T. Weaver. 2005. Interleukin 17-producing CD4+ effector T cells develop via a lineage distinct from the T helper type 1 and 2 lineages. Nat Immunol 6:1123-1132. 
13. Park, H., Z. Li, X. O. Yang, S. H. Chang, R. Nurieva, Y. H. Wang, Y. Wang, L. Hood, Z. Zhu, Q. Tian, and C. Dong. 2005. A distinct lineage of CD4 T cells regulates tissue inflammation by producing interleukin 17. Nat Immunol 6:11331141.

14. Kolls, J. K., and A. Linden. 2004. Interleukin-17 family members and inflammation. Immunity 21:467-476.

15. Machold, K. P., K. Neumann, and J. S. Smolen. 1992. Recombinant human interferon gamma in the treatment of rheumatoid arthritis: double blind placebo controlled study. Ann Rheum Dis 51:1039-1043.

16. Billiau, A., H. Heremans, F. Vandekerckhove, R. Dijkmans, H. Sobis, E. Meulepas, and H. Carton. 1988. Enhancement of experimental allergic encephalomyelitis in mice by antibodies against IFN-gamma. J Immunol 140:1506-1510.

17. Guedez, Y. B., K. B. Whittington, J. L. Clayton, L. A. Joosten, F. A. van de Loo, W. B. van den Berg, and E. F. Rosloniec. 2001. Genetic ablation of interferongamma up-regulates interleukin-1beta expression and enables the elicitation of collagen-induced arthritis in a nonsusceptible mouse strain. Arthritis Rheum 44:2413-2424.

18. Abbas, A. K., K. M. Murphy, and A. Sher. 1996. Functional diversity of helper T lymphocytes. Nature 383:787-793.

19. Mosmann, T. R., and S. Sad. 1996. The expanding universe of T-cell subsets: Th1, Th2 and more. Immunol Today 17:138-146.

20. Vermeire, K., H. Heremans, M. Vandeputte, S. Huang, A. Billiau, and P. Matthys. 1997. Accelerated collagen-induced arthritis in IFN-gamma receptor-deficient mice. J Immunol 158:5507-5513.

21. Murphy, C. A., C. L. Langrish, Y. Chen, W. Blumenschein, T. McClanahan, R. A. Kastelein, J. D. Sedgwick, and D. J. Cua. 2003. Divergent pro- and antiinflammatory roles for IL-23 and IL-12 in joint autoimmune inflammation. $J$ Exp Med 198:1951-1957.

22. Chabaud, M., J. M. Durand, N. Buchs, F. Fossiez, G. Page, L. Frappart, and P. Miossec. 1999. Human interleukin-17: A T cell-derived proinflammatory cytokine produced by the rheumatoid synovium. Arthritis Rheum 42:963-970.

23. Lubberts, E., M. I. Koenders, B. Oppers-Walgreen, L. van den Bersselaar, C. J. Coenen-de Roo, L. A. Joosten, and W. B. van den Berg. 2004. Treatment with a neutralizing anti-murine interleukin-17 antibody after the onset of collageninduced arthritis reduces joint inflammation, cartilage destruction, and bone erosion. Arthritis Rheum 50:650-659. 
24. Nakae, S., A. Nambu, K. Sudo, and Y. Iwakura. 2003. Suppression of immune induction of collagen-induced arthritis in IL-17-deficient mice. J Immunol 171:6173-6177.

25. McGeachy, M. J., and D. J. Cua. 2008. Th17 cell differentiation: the long and winding road. Immunity 28:445-453.

26. Berg, L. J., A. M. Pullen, B. Fazekas de St Groth, D. Mathis, C. Benoist, and M. M. Davis. 1989. Antigen/MHC-specific T cells are preferentially exported from the thymus in the presence of their MHC ligand. Cell 58:1035-1046.

27. Huseby, E. S., J. White, F. Crawford, T. Vass, D. Becker, C. Pinilla, P. Marrack, and J. W. Kappler. 2005. How the T cell repertoire becomes peptide and MHC specific. Cell 122:247-260.

28. Bouneaud, C., P. Kourilsky, and P. Bousso. 2000. Impact of negative selection on the $\mathrm{T}$ cell repertoire reactive to a self-peptide: a large fraction of $\mathrm{T}$ cell clones escapes clonal deletion. Immunity 13:829-840.

29. Liu, G. Y., P. J. Fairchild, R. M. Smith, J. R. Prowle, D. Kioussis, and D. C. Wraith. 1995. Low avidity recognition of self-antigen by $\mathrm{T}$ cells permits escape from central tolerance. Immunity 3:407-415.

30. Lohmann, T., R. D. Leslie, and M. Londei. 1996. T cell clones to epitopes of glutamic acid decarboxylase 65 raised from normal subjects and patients with insulin-dependent diabetes. J Autoimmun 9:385-389.

31. Semana, G., R. Gausling, R. A. Jackson, and D. A. Hafler. 1999. T cell autoreactivity to proinsulin epitopes in diabetic patients and healthy subjects. $J$ Autoimmun 12:259-267.

32. Walker, L. S., and A. K. Abbas. 2002. The enemy within: keeping self-reactive T cells at bay in the periphery. Nat Rev Immunol 2:11-19.

33. Lee, D. M., and M. E. Weinblatt. 2001. Rheumatoid arthritis. Lancet 358:903911.

34. Cotran, R. S., V. Kumar, T. Collins, and S. L. Robbins. 1999. Robbins pathologic basis of disease. Saunders, Philadelphia. 1248-1251.

35. Gabriel, S. E., C. S. Crowson, and W. M. O'Fallon. 1999. The epidemiology of rheumatoid arthritis in Rochester, Minnesota, 1955-1985. Arthritis Rheum 42:415-420.

36. Symmons, D., G. Turner, R. Webb, P. Asten, E. Barrett, M. Lunt, D. Scott, and A. Silman. 2002. The prevalence of rheumatoid arthritis in the United Kingdom: new estimates for a new century. Rheumatology (Oxford) 41:793-800. 
37. Symmons, D. P. 2002. Epidemiology of rheumatoid arthritis: determinants of onset, persistence and outcome. Best Pract Res Clin Rheumatol 16:707-722.

38. Silman, A. J., A. J. MacGregor, W. Thomson, S. Holligan, D. Carthy, A. Farhan, and W. E. Ollier. 1993. Twin concordance rates for rheumatoid arthritis: results from a nationwide study. Br J Rheumatol 32:903-907.

39. Statsny. 1978. Association of the B-cell autoantigen DrW4 with rheumatoid arthritis. New England Journal of Medicine 298:869-871.

40. Schiff, B., Y. Mizrachi, S. Orgad, M. Yaron, and E. Gazit. 1982. Association of HLA-Aw31 and HLA-DR1 with adult rheumatoid arthritis. Ann Rheum Dis 41:403-404.

41. Woodrow, J. C., F. E. Nichol, and G. Zaphiropoulos. 1981. DR antigens and rheumatoid arthritis: a study of two populations. Br Med J (Clin Res Ed) 283:1287-1288.

42. Legrand, L., G. M. Lathrop, A. Marcelli-Barge, A. Dryll, T. Bardin, N. Debeyre, J. C. Poirier, M. Schmid, A. Ryckewaert, and J. Dausset. 1984. HLA-DR genotype risks in seropositive rheumatoid arthritis. Am J Hum Genet 36:690-699.

43. Gregersen, P. K., J. Silver, and R. J. Winchester. 1987. The shared epitope hypothesis. An approach to understanding the molecular genetics of susceptibility to rheumatoid arthritis. Arthritis Rheum 30:1205-1213.

44. Wordsworth, B. P., J. S. Lanchbury, L. I. Sakkas, K. I. Welsh, G. S. Panayi, and J. I. Bell. 1989. HLA-DR4 subtype frequencies in rheumatoid arthritis indicate that DRB1 is the major susceptibility locus within the HLA class II region. Proc Natl Acad Sci U S A 86:10049-10053.

45. McInnes, I. B., and G. Schett. 2007. Cytokines in the pathogenesis of rheumatoid arthritis. Nat Rev Immunol 7:429-442.

46. Raza, K., F. Falciani, S. J. Curnow, E. J. Ross, C. Y. Lee, A. N. Akbar, J. M. Lord, C. Gordon, C. D. Buckley, and M. Salmon. 2005. Early rheumatoid arthritis is characterized by a distinct and transient synovial fluid cytokine profile of T cell and stromal cell origin. Arthritis Res Ther 7:R784-795.

47. Snapper, C. M., and W. E. Paul. 1987. Interferon-gamma and B cell stimulatory factor-1 reciprocally regulate Ig isotype production. Science 236:944-947.

48. Akbar, S. M., K. Inaba, and M. Onji. 1996. Upregulation of MHC class II antigen on dendritic cells from hepatitis B virus transgenic mice by interferon-gamma: abrogation of immune response defect to a T-cell-dependent antigen. Immunology 87:519-527. 
49. Weaver, C. T., R. D. Hatton, P. R. Mangan, and L. E. Harrington. 2007. IL-17 family cytokines and the expanding diversity of effector T cell lineages. Annu Rev Immunol 25:821-852.

50. Miossec, P. 2003. Interleukin-17 in rheumatoid arthritis: if T cells were to contribute to inflammation and destruction through synergy. Arthritis Rheum 48:594-601.

51. Seyler, T. M., Y. W. Park, S. Takemura, R. J. Bram, P. J. Kurtin, J. J. Goronzy, and C. M. Weyand. 2005. BLyS and APRIL in rheumatoid arthritis. J Clin Invest 115:3083-3092.

52. Weyand, C. M., and J. J. Goronzy. 2003. Ectopic germinal center formation in rheumatoid synovitis. Ann N Y Acad Sci 987:140-149.

53. Takemura, S., A. Braun, C. Crowson, P. J. Kurtin, R. H. Cofield, W. M. O'Fallon, J. J. Goronzy, and C. M. Weyand. 2001. Lymphoid neogenesis in rheumatoid synovitis. J Immunol 167:1072-1080.

54. Braun, A., S. Takemura, A. N. Vallejo, J. J. Goronzy, and C. M. Weyand. 2004. Lymphotoxin beta-mediated stimulation of synoviocytes in rheumatoid arthritis. Arthritis Rheum 50:2140-2150.

55. Wooley, P. H., H. S. Luthra, M. M. Griffiths, J. M. Stuart, A. Huse, and C. S. David. 1985. Type II collagen-induced arthritis in mice. IV. Variations in immunogenetic regulation provide evidence for multiple arthritogenic epitopes on the collagen molecule. J Immunol 135:2443-2451.

56. Brunsberg, U., K. Gustafsson, L. Jansson, E. Michaelsson, L. Ahrlund-Richter, S. Pettersson, R. Mattsson, and R. Holmdahl. 1994. Expression of a transgenic class II Ab gene confers susceptibility to collagen-induced arthritis. Eur J Immunol 24:1698-1702.

57. Rosloniec, E. F., D. D. Brand, L. K. Myers, K. B. Whittington, M. Gumanovskaya, D. M. Zaller, A. Woods, D. M. Altmann, J. M. Stuart, and A. H. Kang. 1997. An HLA-DR1 transgene confers susceptibility to collagen-induced arthritis elicited with human type II collagen. $J$ Exp Med 185:1113-1122.

58. Doncarli, A., L. M. Stasiuk, C. Fournier, and O. Abehsira-Amar. 1997. Conversion in vivo from an early dominant Th0/Th1 response to a Th2 phenotype during the development of collagen-induced arthritis. Eur J Immunol 27:14511458.

59. Mauri, C., R. O. Williams, M. Walmsley, and M. Feldmann. 1996. Relationship between Th1/Th2 cytokine patterns and the arthritogenic response in collageninduced arthritis. Eur J Immunol 26:1511-1518. 
60. Stasiuk, L. M., O. Abehsira-Amar, and C. Fournier. 1996. Collagen-induced arthritis in DBA/1 mice: cytokine gene activation following immunization with type II collagen. Cell Immunol 173:269-275.

61. Marinova-Mutafchieva, L., R. O. Williams, L. J. Mason, C. Mauri, M. Feldmann, and R. N. Maini. 1997. Dynamics of proinflammatory cytokine expression in the joints of mice with collagen-induced arthritis (CIA). Clin Exp Immunol 107:507512.

62. Rosloniec, E. F., M. Cremer, A. Kang, and L. K. Myers. 2001. Collagen-induced arthritis. Curr Protoc Immunol Chapter 15:Unit 1515.

63. Lacomba, M. S., C. M. Martin, R. R. Chamond, J. M. Galera, M. Omar, and E. C. Estevez. 2000. Aqueous and serum interferon gamma, interleukin (IL) 2, IL-4, and IL-10 in patients with uveitis. Arch Ophthalmol 118:768-772.

64. Manoury-Schwartz, B., G. Chiocchia, N. Bessis, O. Abehsira-Amar, F. Batteux, S. Muller, S. Huang, M. C. Boissier, and C. Fournier. 1997. High susceptibility to collagen-induced arthritis in mice lacking IFN-gamma receptors. J Immunol 158:5501-5506.

65. Chu, C. Q., S. Wittmer, and D. K. Dalton. 2000. Failure to suppress the expansion of the activated CD4 T cell population in interferon gamma-deficient mice leads to exacerbation of experimental autoimmune encephalomyelitis. $J$ Exp Med 192:123-128.

66. Kronenberg, M., and A. Rudensky. 2005. Regulation of immunity by self-reactive T cells. Nature 435:598-604.

67. Tarbell, K. V., S. Yamazaki, K. Olson, P. Toy, and R. M. Steinman. 2004. CD25+ CD4+ T cells, expanded with dendritic cells presenting a single autoantigenic peptide, suppress autoimmune diabetes. J Exp Med 199:1467-1477.

68. Walker, L. S., A. Chodos, M. Eggena, H. Dooms, and A. K. Abbas. 2003. Antigen-dependent proliferation of CD4+ CD25+ regulatory T cells in vivo. $J$ Exp Med 198:249-258.

69. Wooley, P. H., H. S. Luthra, J. M. Stuart, and C. S. David. 1981. Type II collagen-induced arthritis in mice. I. Major histocompatibility complex (I region) linkage and antibody correlates. J Exp Med 154:688-700.

70. Wooley, P. H., and J. M. Chapedelaine. 1987. Immunogenetics of collageninduced arthritis. Crit Rev Immunol 8:1-22.

71. Haqqi, T. M., G. D. Anderson, S. Banerjee, and C. S. David. 1992. Restricted heterogeneity in $\mathrm{T}$-cell antigen receptor $\mathrm{V}$ beta gene usage in the lymph nodes and arthritic joints of mice. Proc Natl Acad Sci U S A 89:1253-1255. 
72. Leslie, C. A., W. A. Gonnerman, M. D. Ullman, K. C. Hayes, C. Franzblau, and E. S. Cathcart. 1985. Dietary fish oil modulates macrophage fatty acids and decreases arthritis susceptibility in mice. $J$ Exp Med 162:1336-1349.

73. Myers, L. K., E. F. Rosloniec, M. A. Cremer, and A. H. Kang. 1997. Collageninduced arthritis, an animal model of autoimmunity. Life Sci 61:1861-1878.

74. Nakae, S., Y. Iwakura, H. Suto, and S. J. Galli. 2007. Phenotypic differences between Th1 and Th17 cells and negative regulation of Th1 cell differentiation by IL-17. J Leukoc Biol 81:1258-1268.

75. Boehm, U., T. Klamp, M. Groot, and J. C. Howard. 1997. Cellular responses to interferon-gamma. Annu Rev Immunol 15:749-795.

76. Reiner, S. L. 2001. Helper T cell differentiation, inside and out. Curr Opin Immunol 13:351-355.

77. Dorner, T., K. Egerer, E. Feist, and G. R. Burmester. 2004. Rheumatoid factor revisited. Curr Opin Rheumatol 16:246-253.

78. Reparon-Schuijt, C. C., W. J. van Esch, C. van Kooten, G. A. Schellekens, B. A. de Jong, W. J. van Venrooij, F. C. Breedveld, and C. L. Verweij. 2001. Secretion of anti-citrulline-containing peptide antibody by B lymphocytes in rheumatoid arthritis. Arthritis Rheum 44:41-47.

79. Rowley, M. J., K. S. Nandakumar, and R. Holmdahl. 2008. The role of collagen antibodies in mediating arthritis. Mod Rheumatol 18:429-441.

80. Terato, K., K. A. Hasty, R. A. Reife, M. A. Cremer, A. H. Kang, and J. M. Stuart. 1992. Induction of arthritis with monoclonal antibodies to collagen. J Immunol 148:2103-2108.

81. Stuart, J. M., and F. J. Dixon. 1983. Serum transfer of collagen-induced arthritis in mice. $J$ Exp Med 158:378-392.

82. Terato, K., D. S. Harper, M. M. Griffiths, D. L. Hasty, X. J. Ye, M. A. Cremer, and J. M. Seyer. 1995. Collagen-induced arthritis in mice: synergistic effect of E. coli lipopolysaccharide bypasses epitope specificity in the induction of arthritis with monoclonal antibodies to type II collagen. Autoimmunity 22:137-147.

83. Svensson, L., J. Jirholt, R. Holmdahl, and L. Jansson. 1998. B cell-deficient mice do not develop type II collagen-induced arthritis (CIA). Clin Exp Immunol 111:521-526.

84. Nandakumar, K. S., L. Svensson, and R. Holmdahl. 2003. Collagen type IIspecific monoclonal antibody-induced arthritis in mice: description of the disease and the influence of age, sex, and genes. Am J Pathol 163:1827-1837. 
85. Holmdahl, R., L. Jansson, A. Larsson, and R. Jonsson. 1990. Arthritis in DBA/1 mice induced with passively transferred type II collagen immune serum. Immunohistopathology and serum levels of anti-type II collagen auto-antibodies. Scand J Immunol 31:147-157.

86. Watson, W. C., P. S. Brown, J. A. Pitcock, and A. S. Townes. 1987. Passive transfer studies with type II collagen antibody in B10.D2/old and new line and C57Bl/6 normal and beige (Chediak-Higashi) strains: evidence of important roles for C5 and multiple inflammatory cell types in the development of erosive arthritis. Arthritis Rheum 30:460-465.

87. Wooley, P. H., H. S. Luthra, C. J. Krco, J. M. Stuart, and C. S. David. 1984. Type II collagen-induced arthritis in mice. II. Passive transfer and suppression by intravenous injection of anti-type II collagen antibody or free native type II collagen. Arthritis Rheum 27:1010-1017.

88. Wooley, P. H., H. S. Luthra, S. K. Singh, A. R. Huse, J. M. Stuart, and C. S. David. 1984. Passive transfer of arthritis to mice by injection of human anti-type II collagen antibody. Mayo Clin Proc 59:737-743.

89. Stuart, J. M., K. Tomoda, T. J. Yoo, A. S. Townes, and A. H. Kang. 1983. Serum transfer of collagen-induced arthritis. II. Identification and localization of autoantibody to type II collagen in donor and recipient rats. Arthritis Rheum 26:1237-1244.

90. Snapper, C. M., C. Peschel, and W. E. Paul. 1988. IFN-gamma stimulates IgG2a secretion by murine B cells stimulated with bacterial lipopolysaccharide. $J$ Immunol 140:2121-2127.

91. Armitage, R. J., W. C. Fanslow, L. Strockbine, T. A. Sato, K. N. Clifford, B. M. Macduff, D. M. Anderson, S. D. Gimpel, T. Davis-Smith, C. R. Maliszewski, and et al. 1992. Molecular and biological characterization of a murine ligand for CD40. Nature 357:80-82.

92. Renshaw, B. R., W. C. Fanslow, 3rd, R. J. Armitage, K. A. Campbell, D. Liggitt, B. Wright, B. L. Davison, and C. R. Maliszewski. 1994. Humoral immune responses in CD40 ligand-deficient mice. J Exp Med 180:1889-1900.

93. Smith, K. M., L. Pottage, E. R. Thomas, A. J. Leishman, T. N. Doig, D. Xu, F. Y. Liew, and P. Garside. 2000. Th1 and Th2 CD4+ T cells provide help for B cell clonal expansion and antibody synthesis in a similar manner in vivo. J Immunol 165:3136-3144.

94. Martin, R. M., J. L. Brady, and A. M. Lew. 1998. The need for IgG2c specific antiserum when isotyping antibodies from C57BL/6 and NOD mice. J Immunol Methods 212:187-192. 
95. Jouvin-Marche, E., M. G. Morgado, C. Leguern, D. Voegtle, F. Bonhomme, and P. A. Cazenave. 1989. The mouse Igh-1a and Igh- $1 \mathrm{~b} \mathrm{H}$ chain constant regions are derived from two distinct isotypic genes. Immunogenetics 29:92-97.

96. Johansson, A. C., M. Sundler, P. Kjellen, M. Johannesson, A. Cook, A. K. Lindqvist, B. Nakken, A. I. Bolstad, R. Jonsson, M. Alarcon-Riquelme, and R. Holmdahl. 2001. Genetic control of collagen-induced arthritis in a cross with NOD and C57BL/10 mice is dependent on gene regions encoding complement factor 5 and FcgammaRIIb and is not associated with loci controlling diabetes. Eur J Immunol 31:1847-1856.

97. Kleinau, S., P. Martinsson, and B. Heyman. 2000. Induction and suppression of collagen-induced arthritis is dependent on distinct fcgamma receptors. $J$ Exp Med 191:1611-1616.

98. Wang, Y., S. A. Rollins, J. A. Madri, and L. A. Matis. 1995. Anti-C5 monoclonal antibody therapy prevents collagen-induced arthritis and ameliorates established disease. Proc Natl Acad Sci U S A 92:8955-8959.

99. Nandakumar, K. S., M. Andren, P. Martinsson, E. Bajtner, S. Hellstrom, R. Holmdahl, and S. Kleinau. 2003. Induction of arthritis by single monoclonal IgG anti-collagen type II antibodies and enhancement of arthritis in mice lacking inhibitory FcgammaRIIB. Eur J Immunol 33:2269-2277.

100. Feldmann, M., and S. R. Maini. 2008. Role of cytokines in rheumatoid arthritis: an education in pathophysiology and therapeutics. Immunol Rev 223:7-19.

101. Rosloniec, E. F., K. B. Whittington, D. M. Zaller, and A. H. Kang. 2002. HLADR1 (DRB1*0101) and DR4 (DRB1*0401) use the same anchor residues for binding an immunodominant peptide derived from human type II collagen. $J$ Immunol 168:253-259.

102. Brand, D. D., K. B. Whittington, and E. F. Rosloniec. 2001. I-Aq and I-Ap bind and present similar antigenic peptides despite differing in their ability to mediate susceptibility to autoimmune arthritis. Autoimmunity 34:133-145.

103. Rudensky, A., P. Preston-Hurlburt, B. K. al-Ramadi, J. Rothbard, and C. A. Janeway, Jr. 1992. Truncation variants of peptides isolated from MHC class II molecules suggest sequence motifs. Nature 359:429-431.

104. Liu, X., S. Dai, F. Crawford, R. Fruge, P. Marrack, and J. Kappler. 2002. Alternate interactions define the binding of peptides to the MHC molecule IA(b). Proc Natl Acad Sci U S A 99:8820-8825.

105. Inglis, J. J., G. Criado, M. Medghalchi, M. Andrews, A. Sandison, M. Feldmann, and R. O. Williams. 2007. Collagen-induced arthritis in C57BL/6 mice is associated with a robust and sustained T-cell response to type II collagen. Arthritis Res Ther 9:R113. 
106. Inglis, J. J., E. Simelyte, F. E. McCann, G. Criado, and R. O. Williams. 2008. Protocol for the induction of arthritis in C57BL/6 mice. Nat Protoc 3:612-618.

107. Faria, A. M., and H. L. Weiner. 2005. Oral tolerance. Immunol Rev 206:232-259.

108. Chu, C. Q., and M. Londei. 1999. Differential activities of immunogenic collagen type II peptides in the induction of nasal tolerance to collagen-induced arthritis. $J$ Autoimmun 12:35-42.

109. Marth, T., W. Strober, and B. L. Kelsall. 1996. High dose oral tolerance in ovalbumin TCR-transgenic mice: systemic neutralization of IL-12 augments TGF-beta secretion and T cell apoptosis. J Immunol 157:2348-2357.

110. Marth, T., M. Zeitz, B. R. Ludviksson, W. Strober, and B. L. Kelsall. 1999. Extinction of IL-12 signaling promotes Fas-mediated apoptosis of antigenspecific T cells. J Immunol 162:7233-7240.

111. Feldmann, M., F. M. Brennan, and R. N. Maini. 1996. Role of cytokines in rheumatoid arthritis. Annu Rev Immunol 14:397-440.

112. Fujikado, N., S. Saijo, and Y. Iwakura. 2006. Identification of arthritis-related gene clusters by microarray analysis of two independent mouse models for rheumatoid arthritis. Arthritis Res Ther 8:R100.

113. McKinney, C., M. E. Merriman, P. T. Chapman, P. J. Gow, A. A. Harrison, J. Highton, P. B. Jones, L. McLean, J. L. O'Donnell, V. Pokorny, M. Spellerberg, L. K. Stamp, J. Willis, S. Steer, and T. R. Merriman. 2008. Evidence for an influence of chemokine ligand 3-like 1 (CCL3L1) gene copy number on susceptibility to rheumatoid arthritis. Ann Rheum Dis 67:409-413.

114. Randall, T. D., F. E. Lund, J. W. Brewer, C. Aldridge, R. Wall, and R. B. Corley. 1993. Interleukin-5 (IL-5) and IL-6 define two molecularly distinct pathways of B-cell differentiation. Mol Cell Biol 13:3929-3936.

115. Malfait, A. M., D. M. Butler, D. H. Presky, R. N. Maini, F. M. Brennan, and M. Feldmann. 1998. Blockade of IL-12 during the induction of collagen-induced arthritis (CIA) markedly attenuates the severity of the arthritis. Clin Exp Immunol 111:377-383.

116. Liew, F. Y., and I. B. McInnes. 2002. Role of interleukin 15 and interleukin 18 in inflammatory response. Ann Rheum Dis 61 Suppl 2:ii100-102.

117. Yoshihara, K., H. Yamada, A. Hori, T. Yajima, C. Kubo, and Y. Yoshikai. 2007. IL-15 exacerbates collagen-induced arthritis with an enhanced CD4+ T cell response to produce IL-17. Eur J Immunol 37:2744-2752.

118. Kotake, S., N. Udagawa, N. Takahashi, K. Matsuzaki, K. Itoh, S. Ishiyama, S. Saito, K. Inoue, N. Kamatani, M. T. Gillespie, T. J. Martin, and T. Suda. 1999. 
IL-17 in synovial fluids from patients with rheumatoid arthritis is a potent stimulator of osteoclastogenesis. J Clin Invest 103:1345-1352.

119. Chabaud, M., P. Garnero, J. M. Dayer, P. A. Guerne, F. Fossiez, and P. Miossec. 2000. Contribution of interleukin 17 to synovium matrix destruction in rheumatoid arthritis. Cytokine 12:1092-1099.

120. Gracie, J. A., R. J. Forsey, W. L. Chan, A. Gilmour, B. P. Leung, M. R. Greer, K. Kennedy, R. Carter, X. Q. Wei, D. Xu, M. Field, A. Foulis, F. Y. Liew, and I. B. McInnes. 1999. A proinflammatory role for IL-18 in rheumatoid arthritis. J Clin Invest 104:1393-1401.

121. Smeets, R. L., L. A. Joosten, O. J. Arntz, M. B. Bennink, N. Takahashi, H. Carlsen, M. U. Martin, W. B. van den Berg, and F. A. van de Loo. 2005. Soluble interleukin-1 receptor accessory protein ameliorates collagen-induced arthritis by a different mode of action from that of interleukin-1 receptor antagonist. Arthritis Rheum 52:2202-2211.

122. Roelofs, M. F., L. A. Joosten, S. Abdollahi-Roodsaz, A. W. van Lieshout, T. Sprong, F. H. van den Hoogen, W. B. van den Berg, and T. R. Radstake. 2005. The expression of toll-like receptors 3 and 7 in rheumatoid arthritis synovium is increased and costimulation of toll-like receptors 3,4 , and $7 / 8$ results in synergistic cytokine production by dendritic cells. Arthritis Rheum 52:2313-2322.

123. Novick, D., S. H. Kim, G. Fantuzzi, L. L. Reznikov, C. A. Dinarello, and M. Rubinstein. 1999. Interleukin-18 binding protein: a novel modulator of the Th1 cytokine response. Immunity 10:127-136.

124. Roelofs, M. F., M. H. Wenink, F. Brentano, S. Abdollahi-Roodsaz, B. OppersWalgreen, P. Barrera, P. L. van Riel, L. A. Joosten, D. Kyburz, W. B. van den Berg, and T. R. Radstake. 2008. Type I interferons might form the link between Toll-like receptor (TLR) 3/7 and TLR4 mediated synovial inflammation in rheumatoid arthritis (RA). Ann Rheum Dis doi:10.1136.

125. Thomas, R., and C. Quinn. 1996. Functional differentiation of dendritic cells in rheumatoid arthritis: role of CD86 in the synovium. J Immunol 156:3074-3086.

126. Tellander, A. C., U. Pettersson, A. Runstrom, M. Andersson, and E. Michaelsson. 2001. Interference with CD28, CD80, CD86 or CD152 in collagen-induced arthritis. Limited role of IFN-gamma in anti-B7-mediated suppression of disease. J Autoimmun 17:39-50.

127. Morales-Ducret, J., E. Wayner, M. J. Elices, J. M. Alvaro-Gracia, N. J. Zvaifler, and G. S. Firestein. 1992. Alpha 4/beta 1 integrin (VLA-4) ligands in arthritis. Vascular cell adhesion molecule-1 expression in synovium and on fibroblast-like synoviocytes. J Immunol 149:1424-1431. 
128. Varoga, D., T. Pufe, J. Harder, J. M. Schroder, R. Mentlein, U. Meyer-Hoffert, M. B. Goldring, B. Tillmann, J. Hassenpflug, and F. Paulsen. 2005. Human betadefensin 3 mediates tissue remodeling processes in articular cartilage by increasing levels of metalloproteinases and reducing levels of their endogenous inhibitors. Arthritis Rheum 52:1736-1745.

129. Tchougounova, E., G. Pejler, and M. Abrink. 2003. The chymase, mouse mast cell protease 4 , constitutes the major chymotrypsin-like activity in peritoneum and ear tissue. A role for mouse mast cell protease 4 in thrombin regulation and fibronectin turnover. J Exp Med 198:423-431.

130. Nigrovic, P. A., and D. M. Lee. 2005. Mast cells in inflammatory arthritis. Arthritis Res Ther 7:1-11.

131. Murphy, G., V. Knauper, S. Atkinson, G. Butler, W. English, M. Hutton, J. Stracke, and I. Clark. 2002. Matrix metalloproteinases in arthritic disease. Arthritis Res 4 Suppl 3:S39-49.

132. Liew, F. Y., X. Q. Wei, and I. B. McInnes. 2003. Role of interleukin 18 in rheumatoid arthritis. Ann Rheum Dis 62 Suppl 2:ii48-50.

133. Banda, N. K., A. Vondracek, D. Kraus, C. A. Dinarello, S. H. Kim, A. Bendele, G. Senaldi, and W. P. Arend. 2003. Mechanisms of inhibition of collagen-induced arthritis by murine IL-18 binding protein. J Immunol 170:2100-2105.

134. Moller, B., J. Paulukat, M. Nold, M. Behrens, N. Kukoc-Zivojnov, J. P. Kaltwasser, J. Pfeilschifter, and H. Muhl. 2003. Interferon-gamma induces expression of interleukin-18 binding protein in fibroblast-like synoviocytes. Rheumatology (Oxford) 42:442-445.

135. Plater-Zyberk, C., L. A. Joosten, M. M. Helsen, P. Sattonnet-Roche, C. Siegfried, S. Alouani, F. A. van De Loo, P. Graber, S. Aloni, R. Cirillo, E. Lubberts, C. A. Dinarello, W. B. van Den Berg, and Y. Chvatchko. 2001. Therapeutic effect of neutralizing endogenous IL-18 activity in the collagen-induced model of arthritis. J Clin Invest 108:1825-1832.

136. Kim, S. H., M. Eisenstein, L. Reznikov, G. Fantuzzi, D. Novick, M. Rubinstein, and C. A. Dinarello. 2000. Structural requirements of six naturally occurring isoforms of the IL-18 binding protein to inhibit IL-18. Proc Natl Acad Sci U S A 97:1190-1195.

137. Gracie, J. A., S. E. Robertson, and I. B. McInnes. 2003. Interleukin-18. J Leukoc Biol 73:213-224.

138. Starnes, T., H. E. Broxmeyer, M. J. Robertson, and R. Hromas. 2002. Cutting edge: IL-17D, a novel member of the IL-17 family, stimulates cytokine production and inhibits hemopoiesis. J Immunol 169:642-646. 
139. Moser, B., and P. Loetscher. 2001. Lymphocyte traffic control by chemokines. Nat Immunol 2:123-128.

140. Qin, S., J. B. Rottman, P. Myers, N. Kassam, M. Weinblatt, M. Loetscher, A. E. Koch, B. Moser, and C. R. Mackay. 1998. The chemokine receptors CXCR3 and CCR5 mark subsets of T cells associated with certain inflammatory reactions. $J$ Clin Invest 101:746-754.

141. Loetscher, M., B. Gerber, P. Loetscher, S. A. Jones, L. Piali, I. Clark-Lewis, M. Baggiolini, and B. Moser. 1996. Chemokine receptor specific for IP10 and mig: structure, function, and expression in activated T-lymphocytes. $J$ Exp Med 184:963-969.

142. Trapani, J. A. 1995. Target cell apoptosis induced by cytotoxic $\mathrm{T}$ cells and natural killer cells involves synergy between the pore-forming protein, perforin, and the serine protease, granzyme B. Aust N Z J Med 25:793-799.

143. Smyth, M. J., and J. A. Trapani. 1995. Granzymes: exogenous proteinases that induce target cell apoptosis. Immunol Today 16:202-206.

144. Chu, C. Q., Z. Song, L. Mayton, B. Wu, and P. H. Wooley. 2003. IFNgamma deficient C57BL/6 (H-2b) mice develop collagen induced arthritis with predominant usage of T cell receptor Vbeta6 and Vbeta8 in arthritic joints. Ann Rheum Dis 62:983-990.

145. Dalton, D. K., S. Pitts-Meek, S. Keshav, I. S. Figari, A. Bradley, and T. A. Stewart. 1993. Multiple defects of immune cell function in mice with disrupted interferon-gamma genes. Science 259:1739-1742.

146. Krenger, W., G. Falzarano, J. Delmonte, Jr., K. M. Snyder, J. C. Byon, and J. L. Ferrara. 1996. Interferon-gamma suppresses T-cell proliferation to mitogen via the nitric oxide pathway during experimental acute graft-versus-host disease. Blood 88:1113-1121.

147. Afzali, B., G. Lombardi, R. I. Lechler, and G. M. Lord. 2007. The role of T helper 17 (Th17) and regulatory T cells (Treg) in human organ transplantation and autoimmune disease. Clin Exp Immunol 148:32-46.

148. Ghilardi, N., and W. Ouyang. 2007. Targeting the development and effector functions of TH17 cells. Semin Immunol 19:383-393.

149. Billiau, A., and P. Matthys. 2001. Modes of action of Freund's adjuvants in experimental models of autoimmune diseases. J Leukoc Biol 70:849-860.

150. Lubberts, E., M. I. Koenders, and W. B. van den Berg. 2005. The role of T-cell interleukin-17 in conducting destructive arthritis: lessons from animal models. Arthritis Res Ther 7:29-37. 
151. Paulukat, J., M. Bosmann, M. Nold, S. Garkisch, H. Kampfer, S. Frank, J. Raedle, S. Zeuzem, J. Pfeilschifter, and H. Muhl. 2001. Expression and release of IL-18 binding protein in response to IFN-gamma. J Immunol 167:7038-7043.

152. Nepom, G. T., P. Byers, C. Seyfried, L. A. Healey, K. R. Wilske, D. Stage, and B. S. Nepom. 1989. HLA genes associated with rheumatoid arthritis. Identification of susceptibility alleles using specific oligonucleotide probes. Arthritis Rheum $32: 15-21$.

153. Steiner, G., M. Tohidast-Akrad, G. Witzmann, M. Vesely, A. Studnicka-Benke, A. Gal, M. Kunaver, P. Zenz, and J. S. Smolen. 1999. Cytokine production by synovial T cells in rheumatoid arthritis. Rheumatology (Oxford) 38:202-213.

154. Ziolkowska, M., A. Koc, G. Luszczykiewicz, K. Ksiezopolska-Pietrzak, E. Klimczak, H. Chwalinska-Sadowska, and W. Maslinski. 2000. High levels of IL17 in rheumatoid arthritis patients: IL-15 triggers in vitro IL-17 production via cyclosporin A-sensitive mechanism. J Immunol 164:2832-2838.

155. Trentham, D. E., A. S. Townes, and A. H. Kang. 1977. Autoimmunity to type II collagen an experimental model of arthritis. J Exp Med 146:857-868.

156. Mussener, A., M. J. Litton, E. Lindroos, and L. Klareskog. 1997. Cytokine production in synovial tissue of mice with collagen-induced arthritis (CIA). Clin Exp Immunol 107:485-493.

157. Campbell, I. K., A. Bendele, D. A. Smith, and J. A. Hamilton. 1997. Granulocytemacrophage colony stimulating factor exacerbates collagen induced arthritis in mice. Ann Rheum Dis 56:364-368.

158. Koga, T., M. Mitsuyama, T. Handa, Y. Watanabe, and K. Nomoto. 1987. Gamma interferon-mediated increase in the number of Ia-bearing macrophages during infection with Listeria monocytogenes. Infect Immun 55:2300-2303.

159. Ezekowitz, R. A., J. Austyn, P. D. Stahl, and S. Gordon. 1981. Surface properties of bacillus Calmette-Guerin-activated mouse macrophages. Reduced expression of mannose-specific endocytosis, Fc receptors, and antigen F4/80 accompanies induction of Ia. $J$ Exp Med 154:60-76.

160. Bettelli, E., M. P. Das, E. D. Howard, H. L. Weiner, R. A. Sobel, and V. K. Kuchroo. 1998. IL-10 is critical in the regulation of autoimmune encephalomyelitis as demonstrated by studies of IL-10- and IL-4-deficient and transgenic mice. J Immunol 161:3299-3306.

161. Ogasawara, K., W. L. Maloy, B. Beverly, and R. H. Schwartz. 1989. Functional analysis of the antigenic structure of a minor $\mathrm{T}$ cell determinant from pigeon cytochrome C. Evidence against an alpha-helical conformation. J Immunol 142:1448-1456. 
162. Arnold, P. Y., N. L. La Gruta, T. Miller, K. M. Vignali, P. S. Adams, D. L. Woodland, and D. A. Vignali. 2002. The majority of immunogenic epitopes generate CD4+ T cells that are dependent on MHC class II-bound peptideflanking residues. $J$ Immunol 169:739-749.

163. Rosloniec, E. F., K. B. Whittington, D. D. Brand, L. K. Myers, and J. M. Stuart. 1996. Identification of MHC class II and TCR binding residues in the type II collagen immunodominant determinant mediating collagen-induced arthritis. Cell Immunol 172:21-28.

164. McNeil, L. K., and B. D. Evavold. 2003. TCR reserve: a novel principle of CD4 T cell activation by weak ligands. J Immunol 170:1224-1230.

165. Sabatino, J. J., Jr., J. Shires, J. D. Altman, M. L. Ford, and B. D. Evavold. 2008. Loss of IFN-gamma enables the expansion of autoreactive CD4+ T cells to induce experimental autoimmune encephalomyelitis by a nonencephalitogenic myelin variant antigen. J Immunol 180:4451-4457.

166. Dong, C. 2008. TH17 cells in development: an updated view of their molecular identity and genetic programming. Nat Rev Immunol 8:337-348.

167. Hwang, S. Y., J. Y. Kim, K. W. Kim, M. K. Park, Y. Moon, W. U. Kim, and H. Y. Kim. 2004. IL-17 induces production of IL-6 and IL-8 in rheumatoid arthritis synovial fibroblasts via NF-kappaB- and PI3-kinase/Akt-dependent pathways. Arthritis Res Ther 6:R120-128.

168. Tanaka, K., K. Ichiyama, M. Hashimoto, H. Yoshida, T. Takimoto, G. Takaesu, T. Torisu, T. Hanada, H. Yasukawa, S. Fukuyama, H. Inoue, Y. Nakanishi, T. Kobayashi, and A. Yoshimura. 2008. Loss of suppressor of cytokine signaling 1 in helper T cells leads to defective Th17 differentiation by enhancing antagonistic effects of IFN-gamma on STAT3 and Smads. J Immunol 180:3746-3756.

169. Sato, K. 2008. Th17 cells and rheumatoid arthritis--from the standpoint of osteoclast differentiation. Allergol Int 57:109-114.

170. Hajoui, O., H. Zheng, J. Guay, S. Letuve, L. M. Fawaz, and B. D. Mazer. 2007. Regulation of IL-13 receptor alpha 1 expression and signaling on human tonsillar B-lymphocyte subsets. J Allergy Clin Immunol 120:1425-1432.

171. Latham, K. A., K. B. Whittington, R. Zhou, Z. Qian, and E. F. Rosloniec. 2005. Ex vivo characterization of the autoimmune $T$ cell response in the HLA-DR1 mouse model of collagen-induced arthritis reveals long-term activation of type II collagen-specific cells and their presence in arthritic joints. J Immunol 174:39783985.

172. Nielsen, M., C. Lundegaard, and O. Lund. 2007. Prediction of MHC class II binding affinity using SMM-align, a novel stabilization matrix alignment method. BMC Bioinformatics 8:238. 


\section{Appendix. Binding of CII Determinant to I-A ${ }^{b}$}

In order to test the hypothesis that IFN- $\gamma$ regulates weak $\mathrm{T}$ cell responses, the affinity of CII determinants for the I-A ${ }^{b}$ molecule was measured. If the affinity for CII determinants for $\mathrm{I}-\mathrm{A}^{\mathrm{b}}$ is low, then the ability of this peptide to stimulate a $\mathrm{T}$ cell response would be reduced. In order to determine the strength of CII determinants in binding to I-A ${ }^{b}$, two methods were employed. The first method was a bioinformatic approach that used an algorithm to predict the binding strength of potential determinants for $I-A^{b}$ based on the sequence of known I-A $\mathrm{A}^{\mathrm{b}}$ binding determinants. The second method was a biochemical competition binding assay.

\section{Bioinformatic Prediction of $\mathbf{I}-\mathrm{A}^{\mathrm{b}}$ Binding}

A bioinformatic examination of the CII sequence was performed using the binding prediction algorithm SMM-align (172). The binding affinity of CII for both I-A $\mathrm{A}^{\mathrm{b}}$ and DR1 was calculated. DR1 serves as a control since CII determinants were known for this molecule and could be compared to the calculated results. This method uses the sequence of the determinants of various MHC class II molecules with known binding affinity to calculate a weight matrix for each amino acid residue in a nonamer peptide that corresponds to the binding groove of a MHC class II molecule. It does this by using an algorithm that seeks to match calculated values of peptide determinants to known affinity values. This calculation results in a binding affinity prediction for peptides in terms of the $\mathrm{IC}_{50}$ required to bind a given MHC class II molecule. In a competitive binding assay, the $\mathrm{IC}_{50}$ is the concentration of unlabeled peptide required to inhibit $50 \%$ of the binding of labeled peptide. Therefore, lower $\mathrm{IC}_{50}$ values indicate higher binding affinities (172). When the MHC class II algorithm was used to predict the binding properties of the CII sequence from amino acid number -15 to 1060 against DR1 the data indicated 294 weak binding sequences with an $\mathrm{IC}_{50}$ lower than $500 \mathrm{nM}$ and 51 strong binders with an $\mathrm{IC}_{50}$ lower than $50 \mathrm{nM}$. Binding affinity of CII for DR1 was experimentally derived by competition assay of CII-library peptides with a labeled peptide of a known DR1 determinant, CII(257-274). The experimental values match well with the computed affinity of DR1 with regions of high binding matching the predicted areas of elevated binding affinity in CII (Fig A.1AB). When the prediction algorithm was used to calculate affinity values for the binding of CII to I-A ${ }^{b}$ only 29 low affinity peptides were identified with calculated affinities between 50 and $500 \mathrm{nM}$ (Fig A.1C). No high affinity peptides $\left(\mathrm{IC}_{50}<50 \mathrm{nM}\right)$ were identified. This result indicates that overall, the CII sequence likely has low affinity for I-A ${ }^{b}$ with no discrete sequences within CII that have a predicted high affinity for I-A ${ }^{b}$. The CII determinant identified by the $\mathrm{T}$ cell hybridomas, CII(512-528), was one of the predicted low affinity peptides.

\section{I-A ${ }^{\text {b }}$ Binding Assay}

A requirement for the identification and subsequent measurement of binding affinity of $\mathrm{I}-\mathrm{A}^{\mathrm{b}}$-restricted CII determinants was the generation of soluble MHC Class II of 

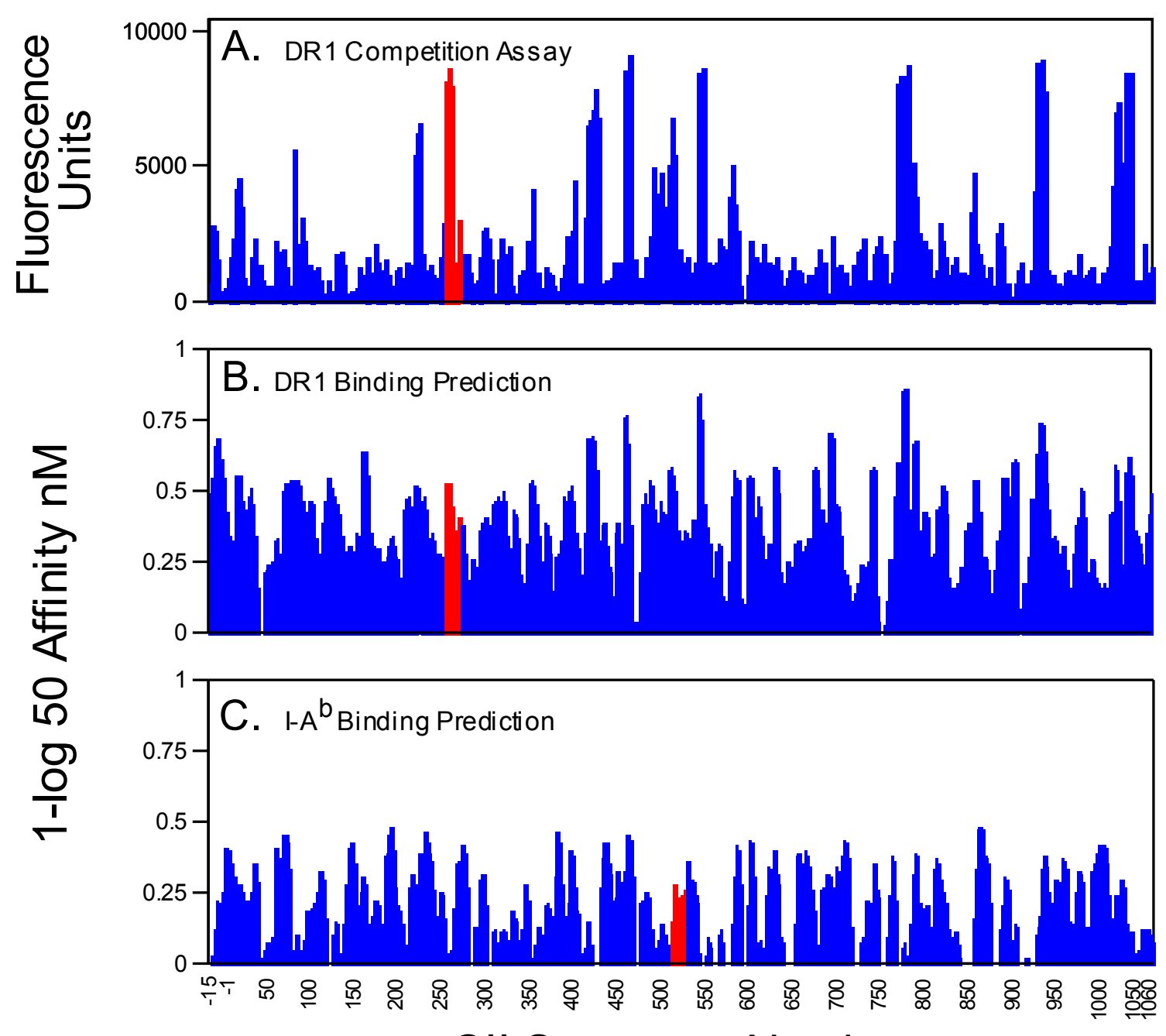

\section{Cll Sequence Number}

Figure A.1 Prediction of CII Peptide Binding to the MHC Class II Alleles DR1 and $I-A^{b}$ by SMM-align.

AB. When the scoring algorithm SMC-align is used to predict the binding affinity of DR1 CII determinants, the predicted regions of high binding correlate well with the experimental measurements of binding affinity. Affinity values in $\mathrm{nM}$ are $\log$ transformed using the equation $1-\log _{50 \mathrm{k}}\left(\mathrm{IC}_{50} \mathrm{nM}\right)$. Affinity values higher than 50,000 were assigned a transformed value of 0 , higher values indicate stronger binding. B. In the predicted CII determinants of DR1 many regions show high affinity for DR1 binding. C. In contrast to the DR 1 , the prediction of CII binding to I-A ${ }^{b}$ is lower throughout the CII sequence with no regions exhibiting high binding affinity above $50 \mathrm{nM}$. Highlighted in red is a known determinant for HLA-DR1 present in the peptide library AB and the putative CII determinant identified in this study $\mathbf{C}$. 
the $b$ haplotype. Two strategies were employed to produce a soluble form of $I-A^{b}$ in insect cell lines. mRNA was recovered from the splenocytes of I-A $\mathrm{A}^{\mathrm{b}}$-expressing $\mathrm{B} 6$ mice and used to produce cDNA encoding the alpha and beta subunits of MHC class II in which the transmembrane region was replaced with a leucine zipper by PCR. These constructs were then cloned into drosophila or baculovirus expression vectors and transfected into S2 cells or to infect SF9 cells, respectively.

An additional requirement for binding affinity measurements is a labeled peptide known to bind $\mathrm{I}-\mathrm{A}^{\mathrm{b}}$. In a competition binding assay, this peptide is used as the indicator to compete with unlabeled test peptides for binding to I-A ${ }^{\mathrm{b}}$. To produce this indicator, two peptides, known to bind I-A ${ }^{b}, \operatorname{Mog}(35-55)(160)$ and CytC(43-58) $(104,161)$ were synthesized with biotin groups added to the amino termini. As an empirical test of the ability of these two peptides to bind I-A ${ }^{b}$, B6 mice were immunized with $\operatorname{Mog}(35-55)$ or CytC(43-58) in an emulsion of CFA. Lymphocytes were recovered from draining lymph nodes ten days later, and re-stimulated in vitro with the biotinylated analogs of the two peptides. Lymphocytes recovered from immunized mice proliferated in vitro as measured by ${ }^{3} \mathrm{H}$-thymidine incorporation when stimulated with $\operatorname{Mog}(35-55)$ or $\mathrm{CytC}(43-$ 58 ) indicating that the peptides were functional and could bind I-A $\mathrm{A}^{\mathrm{b}}$ both in vivo and in vitro (Fig A.2).

To assess the function of the biotinylated indicator peptides and the function of the recombinant soluble $\mathrm{I}-\mathrm{A}^{\mathrm{b}}$, the ability of the two indicator peptides to bind the soluble $\mathrm{I}-\mathrm{A}^{\mathrm{b}}$ was measured using a binding assay. The two indicator peptides, and biotinylated $\mathrm{CII}(257-274)$ as a negative control, were incubated with soluble I-A $\mathrm{A}^{\mathrm{b}}$ and the degree of binding for each peptide over a range of concentrations was subsequently measured. Peptide I-A $\mathrm{A}^{\mathrm{b}}$ complexes were allowed to form in solution and I-A $\mathrm{A}^{\mathrm{b}}$ was captured by antibodies adhered to microtiter wells, and the levels of bound indicator peptide were detected using europium labeled streptavidin. An increase in fluorescence indicates the presence of biotinylated peptide bound to $I-A^{b}$. Binding of the $\operatorname{Mog}(35-55)$ peptide to S2 derived I-A ${ }^{\mathrm{b}}$ occurred at a concentration greater than $0.1 \mu \mathrm{M}$ (Fig A.3). No significant binding was observed in either preparation of soluble $\mathrm{I}-\mathrm{A}^{\mathrm{b}}$ for the $\mathrm{CytC}(43-58)$ or the CII(257-274) negative control peptide. These results indicated that $\mathrm{Mog}(35-55)$ peptide bound to the S2 produced I-A $\mathrm{A}^{\mathrm{b}}$. However, the $\operatorname{Mog}(35-55)$ peptide was observed to have low solubility in the buffers required for the binding assay, forming a precipitate at high concentrations. To examine whether or not this insolubility caused technical problems with the binding assay resulting in non-specific binding, a titration of $\operatorname{Mog}(35-55)$ peptide was performed using both the $\mathrm{S} 2$ and SF9 derived I-A ${ }^{\mathrm{b}}$ and a mock binding assay without I-A $\mathrm{A}^{\mathrm{b}}$ added (Fig A.4). In each test condition, fluorescence was observed when the $\operatorname{Mog}(35-55)$ peptide was at a concentration above $1 \mu \mathrm{M}$. This indicates that at high concentrations the $\operatorname{Mog}(35-55)$ peptide binds non-specifically.

To directly measure the relative affinity of the CII peptide in comparison with other known binders of I-A $\mathrm{A}^{\mathrm{b}}$, the CII peptide library was used in a binding competition assay with the soluble I- $\mathrm{A}^{\mathrm{b}}$ produced above as well as a soluble DR1 molecule produced previously as a positive control for the assay. In the binding assay, the library peptides were used at a concentration of $5 \mu \mathrm{M}$ to compete for binding to I-A $\mathrm{A}^{\mathrm{b}}$ with $10 \mathrm{nM}$ of biotin labeled $\operatorname{Mog}(35-55)$. The $\operatorname{Mog}(35-55)$ peptide was used in this assay as it was the only 


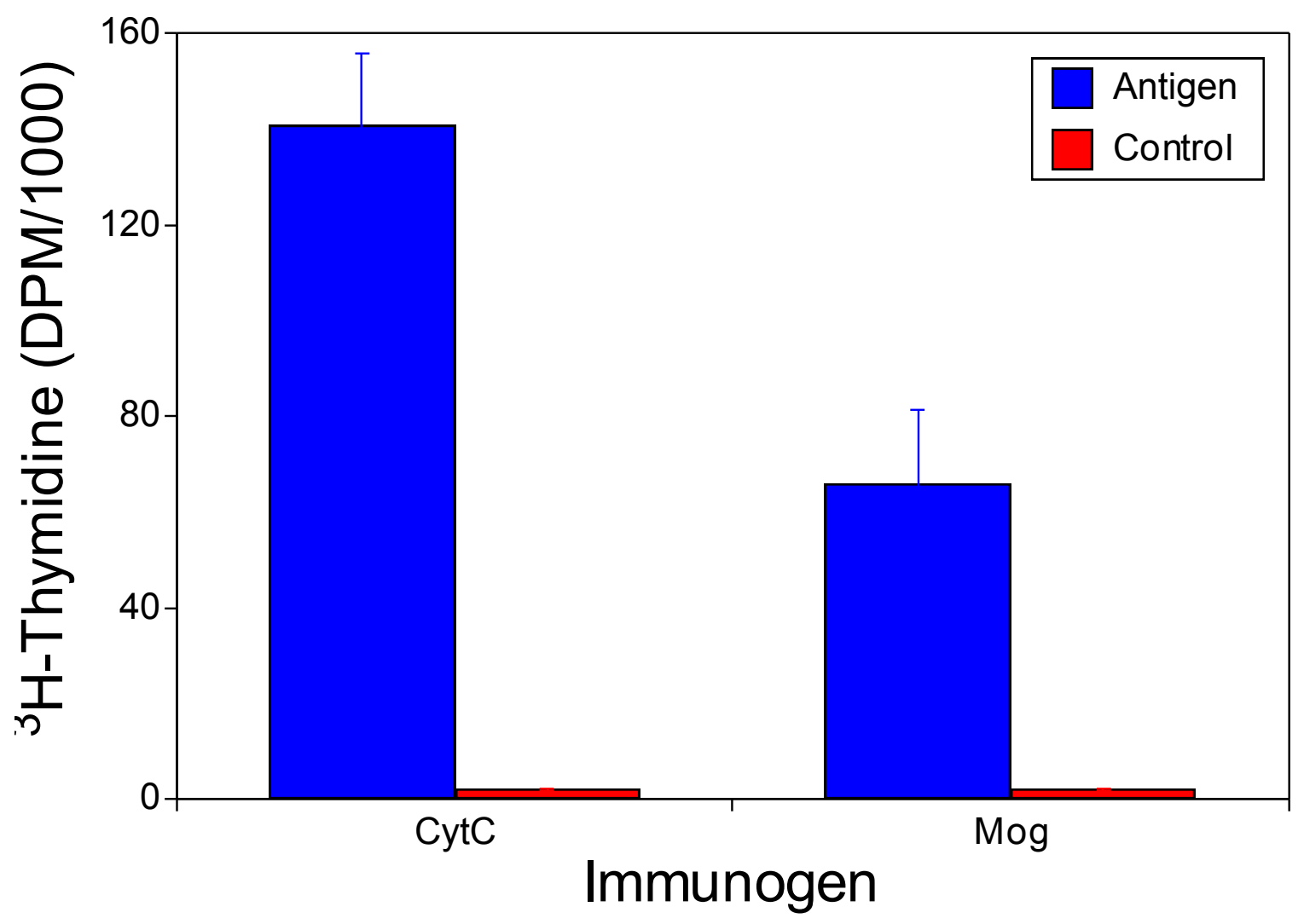

Figure A.2 I-A $\mathrm{A}^{\mathrm{b}}$-Restricted Proliferation in Response to Stimulation with CytC and Mog Peptides.

As an empirical test of $\operatorname{Mog}(35-55)$ and $\operatorname{CytC}(43-58)$ ability to bind I-A $\mathrm{A}^{\mathrm{b}}$, the peptides were used in CFA emulsion to immunize CXB2 mice. When lymphocytes obtained from the draining nodes of the immunized mice were stimulated with their respective peptides, robust proliferation of $\mathrm{T}$ cells over media control was observed $(\mathrm{p}<0.001)$. This result indicated that these peptides were indeed capable of binding $\mathrm{I}-\mathrm{A}^{\mathrm{b}}$ and were strong inducers of $\mathrm{T}$ cell proliferation. 


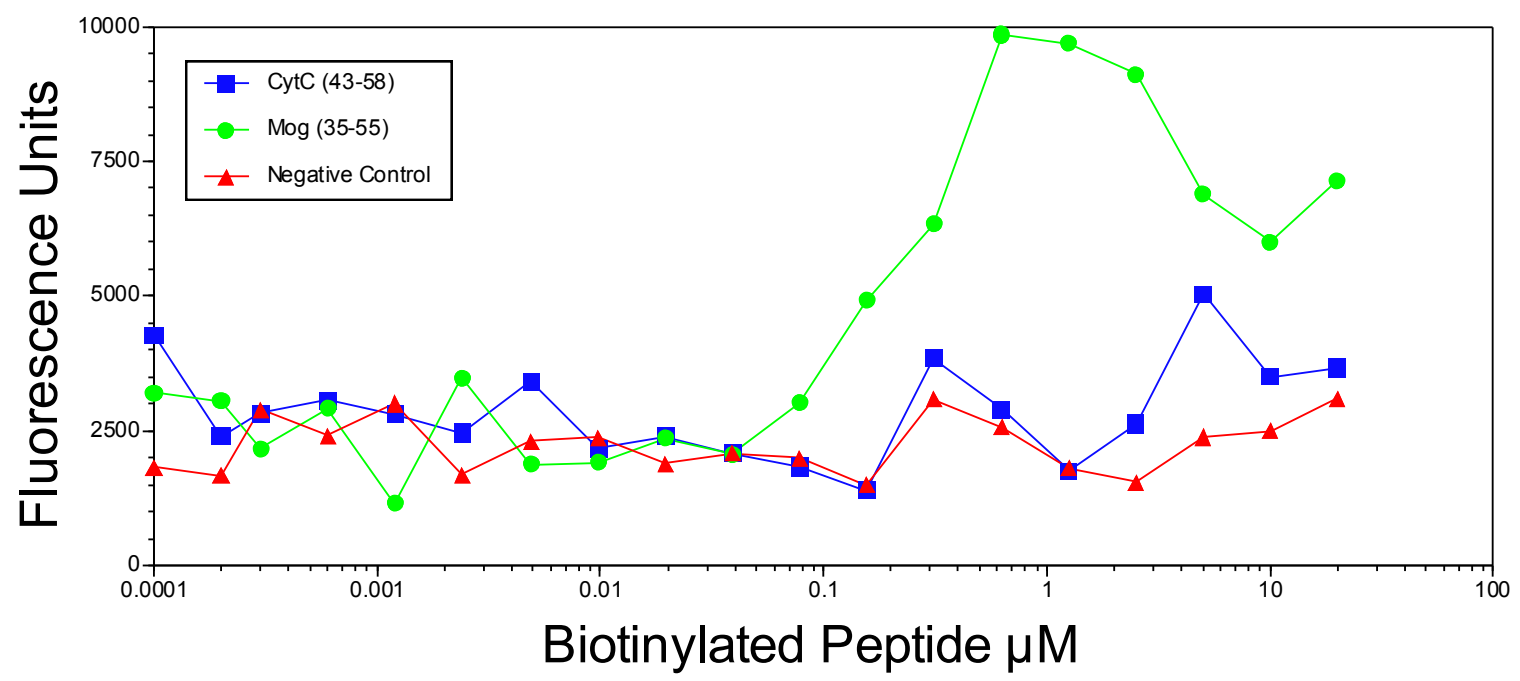

Figure A.3 Binding of Mog, CytC, and CII Peptides to Soluble I-A $\mathbf{A}^{\mathrm{b}}$. Direct binding of known I-A $\mathrm{A}^{\mathrm{b}}$ determinants to recombinant soluble I-A $\mathrm{A}^{\mathrm{b}}$ produced in $\mathrm{S} 2$ cells was measured by fluorescence assay. Two biotinylated peptides known to bind $\mathrm{I}_{-} \mathrm{A}^{\mathrm{b}}, \operatorname{Mog}(35-55)$ and $\mathrm{CytC}(43-58)$, and a biotinylated negative control peptide, CII(257274) were titrated with soluble $I-A^{b}$. Binding was observed for the $\operatorname{Mog}(35-55)$ but not for CytC(43-58) or the negative control CII(257-274) peptides. 


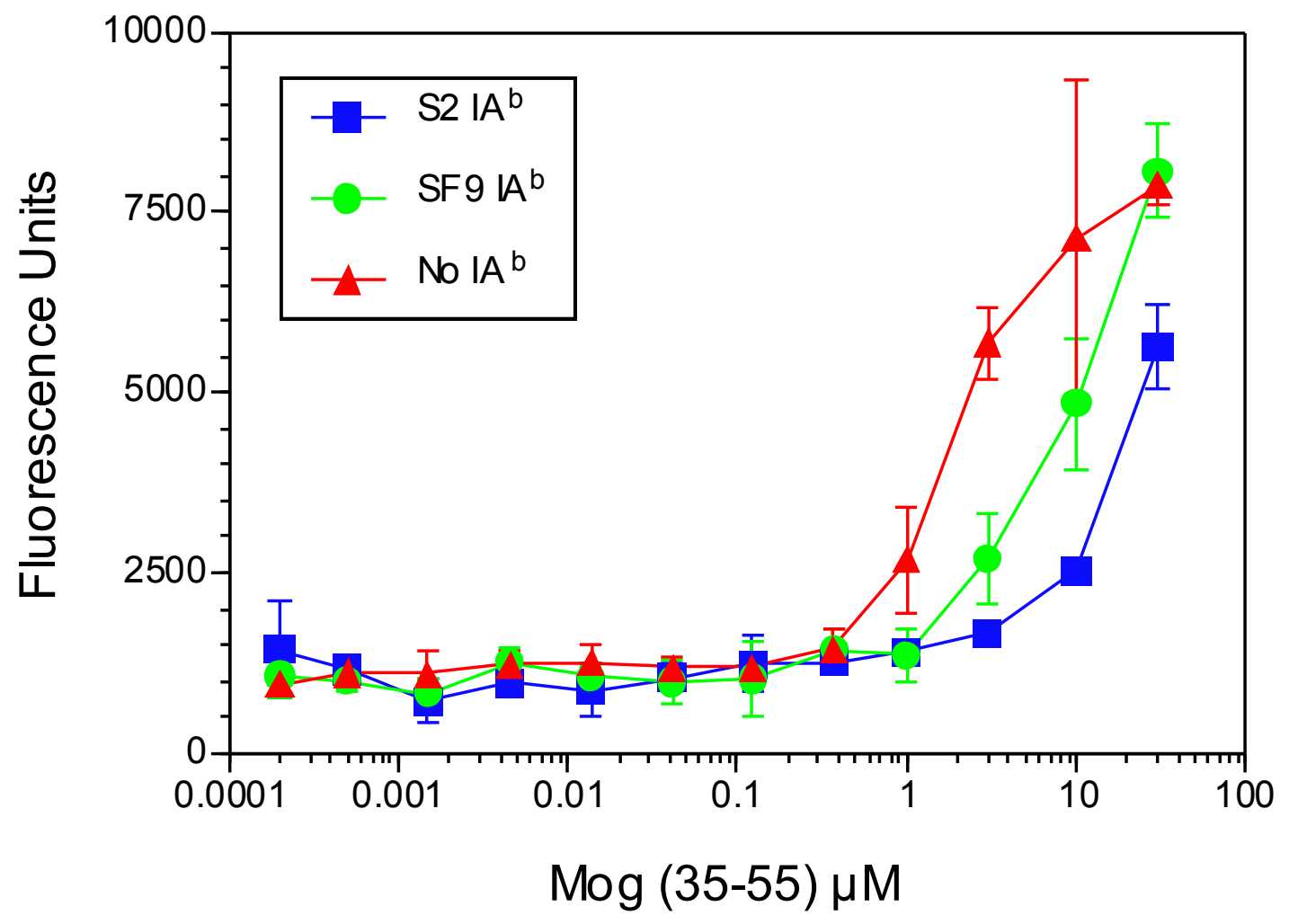

Figure A.4 Binding of $\operatorname{Mog}(35-55)$ to $I-A^{b}$.

When Mog(35-55) was titrated for binding to either S2 or SF9 derived I-A ${ }^{b}$ or in a negative control assay containing no MHC class II molecule increases in fluorescence were observed in all three test conditions when the $\operatorname{Mog}(35-55)$ peptide was at a concentration above $1 \mu \mathrm{M}$. 
peptide that was observed to bind I- $\mathrm{A}^{\mathrm{b}}$. At this concentration, we hoped to avoid the nonspecific binding of the $\operatorname{Mog}(35-55)$ peptide observed at the higher concentrations while still being able to detect competition with the CII peptides by increasing the gain of the flurometer. Increased gain, amplifies the ability of the flurometer to measure low levels of fluorescence yet has the drawback of causing increased background. In the DR1 binding assay the CII peptide library was used at $5 \mu \mathrm{M}$ to compete for binding to DR1 with $30 \mathrm{nM}$ biotin labeled CII(257-274). Biotin labeled peptide bound to the MHC class II molecules was detected using europium streptavidin and the resulting fluorescence was measured. Data is expressed as the measured fluorescence subtracted from 10,000, the maximum value possible, in order to facilitate data interpretation. Due to the mathematical conversion, high values indicate that the CII peptide competed successfully with the labeled peptide. When bound to DR1, the CII library successfully competes for binding with the indicator peptide in 12 regions (Fig A.5A). In the assay competing CIIlibrary peptides with $\operatorname{Mog}(35-55)$ for $\mathrm{I}-\mathrm{A}^{\mathrm{b}}$ binding, no binding above background was observed (Fig A.5B). Proliferation in response to stimulation with the $\mathrm{CytC}(43-58)$ and $\operatorname{Mog}(35-55)$ peptides indicate that these peptides are functional antigens when presented to $\mathrm{T}$ cells by $\mathrm{I}-\mathrm{A}^{\mathrm{b}}$-expressing APC. In addition, the assay is technically sound as indicated by the ability to detect binding of peptides to the DR1 molecule. However, competition with CII peptides was not detectable. These data indicate that the recombinant $\mathrm{I}-\mathrm{A}^{\mathrm{b}}$ is not performing well in these binding assays as $\operatorname{Mog}(35-55)$ apparently binds at low concentration but there is no indication that CII(512-528) competes. 


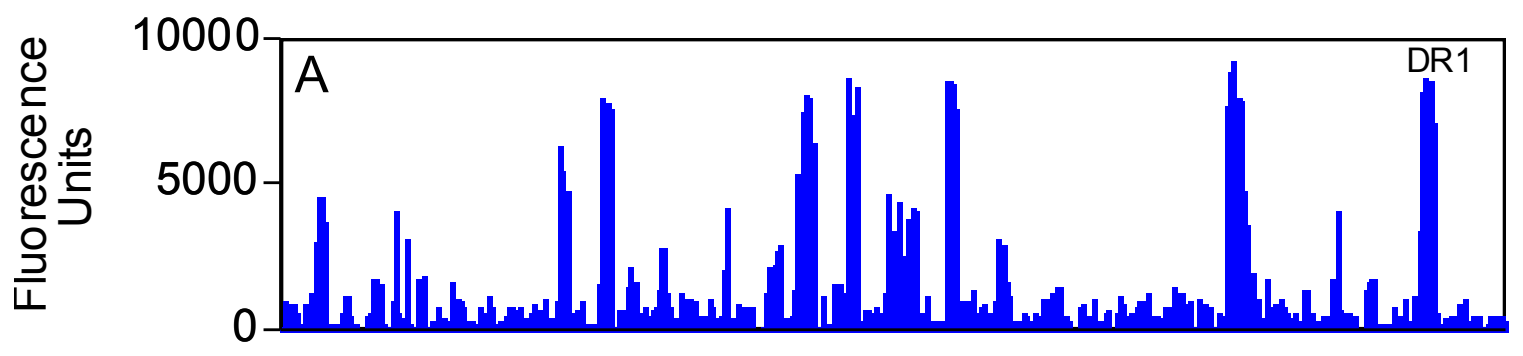

hCll Peptide \# 1-344

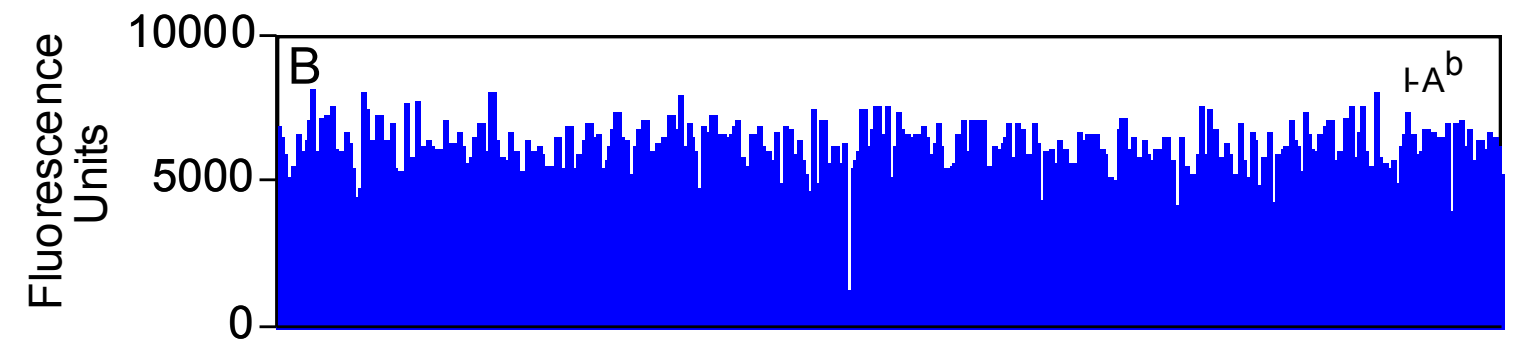

hCII Peptide \# 1-344

Figure A.5 Binding of CII Determinants to DR1 or I-A ${ }^{b}$ MHC Class II Molecules. 15 mer peptides derived from the human sequence of CII were used in competitive binding assays with soluble DR1 or soluble I-A ${ }^{b}$. A. Competition of library peptides with labeled CII(257-274) resulted in the identification of 12 regions that bind DR1 with elevated affinity. B. Competition of library peptides with soluble I-A ${ }^{\mathrm{b}}$ did not exhibit increased binding affinity at any region. 


\section{Vita}

Timothy D. Kayes was born on January 15, 1977 in Long Beach, MS. He received his Bachelor of Science degree with a major in Biology and a minor in Chemistry from Mississippi State University in Mississippi State, MS in May 2000. He joined the Interdisciplinary Sciences Program at the University of Tennessee Health Science Center in August 2001 and began his research project in the laboratory of Dr. Edward Rosloniec in 2003. Timothy plans to graduate from the Interdisciplinary Sciences Program in May 2009. 